Innovating HRM for Employee-Driven Innovation A Multilevel Perspective
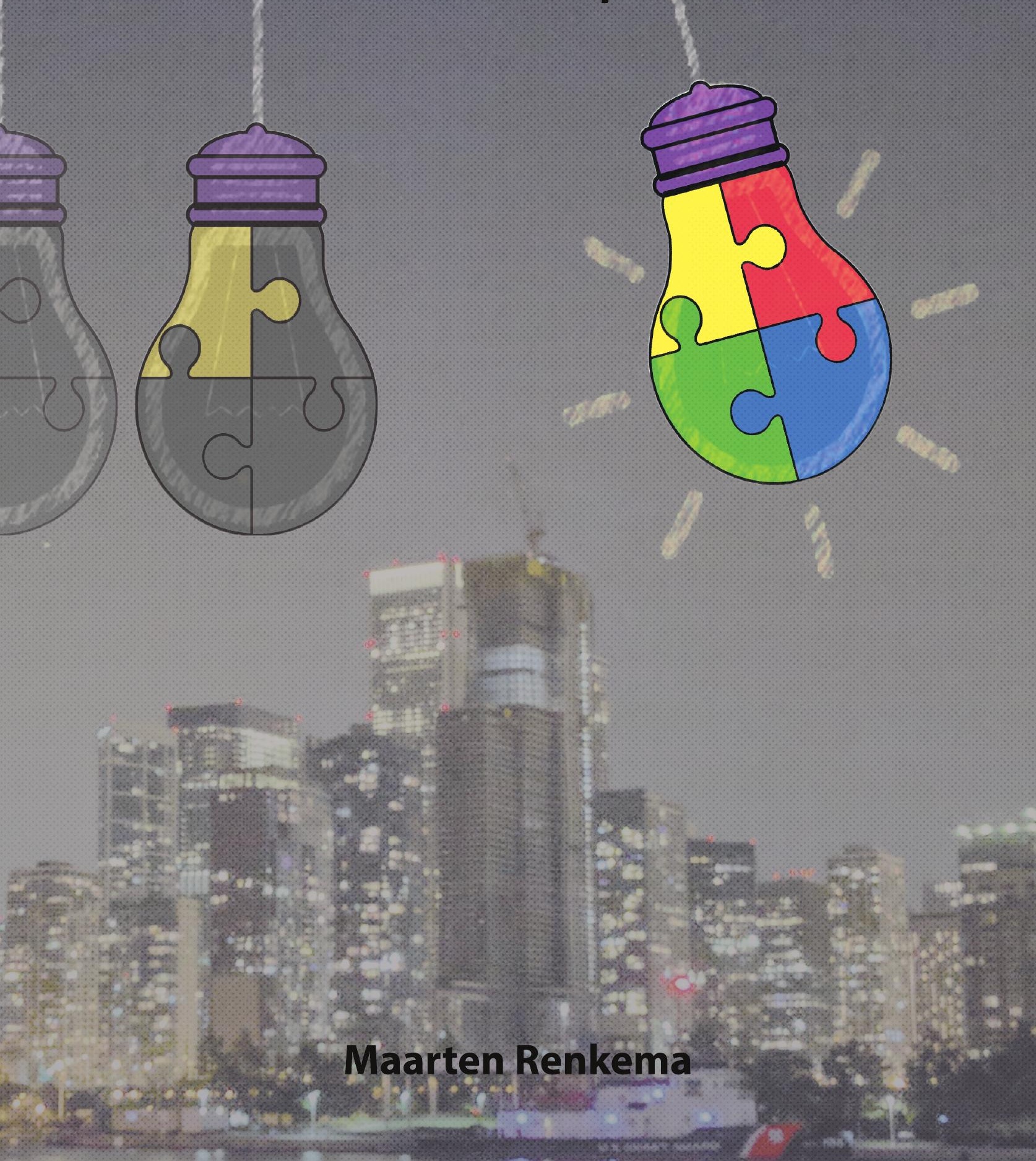

INNOVATING HRM FOR EMPLOYEE-DRIVEN INNOVATION A MULTILEVEL PERSPECTIVE

Maarten Renkema 


\section{Graduation Committee:}

Chairman: prof. dr. Th.A.J. Toonen

Secretary: $\quad$ prof. dr. Th.A.J. Toonen

Supervisor: prof. dr. T.A. Bondarouk

Co-supervisor: dr. J.G. Meijerink

Members: $\quad$ prof. dr. H. Shipton

prof. dr. P.R. Sparrow

prof. dr. E. Giebels

dr. M.L. Ehrenhard
University of Twente

University of Twente

University of Twente

University of Twente

Nottingham Trent University

Lancaster University

University of Twente

University of Twente

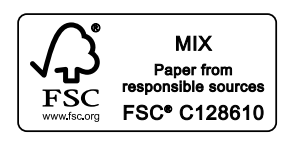

Printed by Ipskamp Printing, Enschede, The Netherlands

Cover design: Maarten Renkema

ISBN: 978-90-365-4647-8

DOI: https://doi.org/10.3990/1.9789036546478

Renkema, M. (2018). Innovating HRM for Employee-Driven Innovation: A Multilevel Perspective. Enschede, The Netherlands: University of Twente.

(C) 2018 M. Renkema, The Netherlands

All rights reserved. No part of this publication may be reproduced, stored in a database or retrieval system, or published in any form or in any way, electronically, mechanically, by print, photo print, microfilm, or any other means without prior written permission from the author. 


\title{
INNOVATING HRM FOR EMPLOYEE-DRIVEN INNOVATION A MULTILEVEL PERSPECTIVE
}

\author{
DISSERTATION
}

to obtain

the degree of doctor at the University of Twente, on the authority of the rector magnificus, prof.dr. T.T.M. Palstra,

on account of the decision of the graduation committee, to be publicly defended

on Thursday the $1^{\text {st }}$ of November 2018 at 16.45 hours

by

\section{Maarten Renkema}

born on the $4^{\text {th }}$ of February 1990

in Nijverdal, The Netherlands 
This dissertation has been approved by:

Supervisor:

Prof. Dr. T.A. Bondarouk

Co-supervisor:

Dr. J.G. Meijerink 
This work is part of the Innovating Human Resource Management research program for Employee-Driven Innovation, which is partly financed by The Netherlands Organization for Scientific Research (NWO) under project number 409-13-204. 

Dedicated to my grandparents. 


\section{Table of contents}

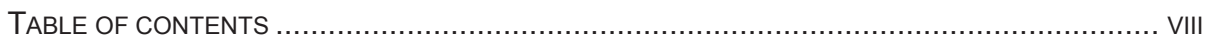

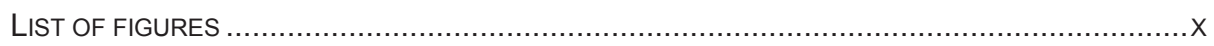

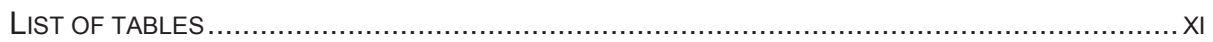

LIST OF ABBREVIATIONS ..................................................................................... XII

ACKNOWLEDGEMENTS (DANKWOORD) ................................................................ XIII

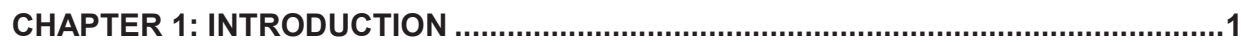

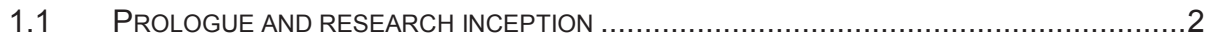

1.2 RESEARCH MOTIVATION AND BACKGROUND .................................................

1.3 RESEARCH CHALLENGES AND FRAMEWORK ................................................ 12

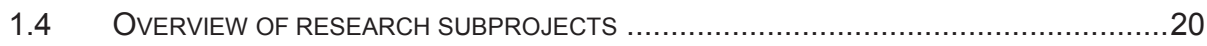

1.5 RESEARCH APPROACH AND PHILOSOPHICAL POSITIONING ..................................25

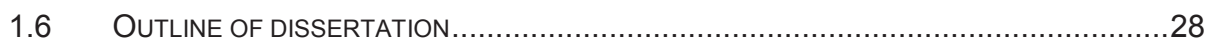

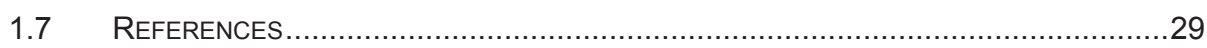

CHAPTER 2: MULTILEVEL THINKING IN HRM RESEARCH ...................................31

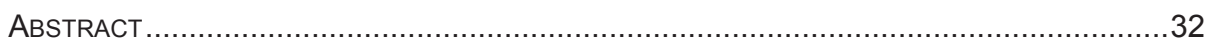

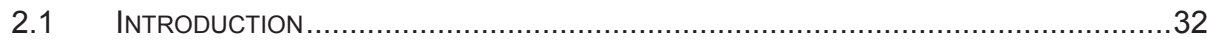

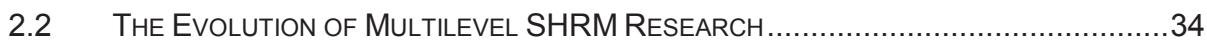

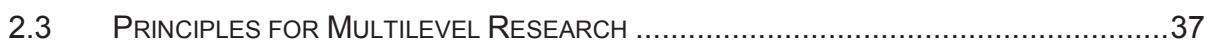

2.4 SELECTION AND REVIEW OF MULTILEVEL HRM STUDIES ......................................

2.5 The MultileVelity Cube of HRM in PRACTICE ................................................ 39

2.6 APPLICATION OF PRINCIPLES IN MULTILEVEL HRM RESEARCH ..............................40

2.7 IMPLICATIONS AND INTERPLAY BETWEEN PRINCIPLES AND GUIDELINES .....................59

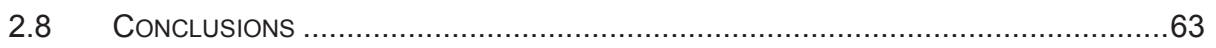

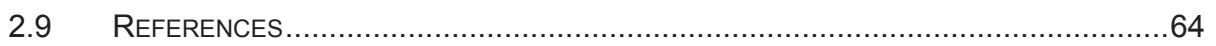

CHAPTER 3: EXPLORING THE IMPLICATIONS FOR THE HRM FUNCTION OF IMPLEMENTING SELF-MANAGING TEAMS ........................................................71

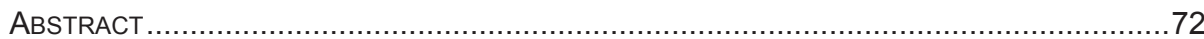

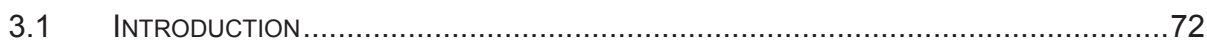

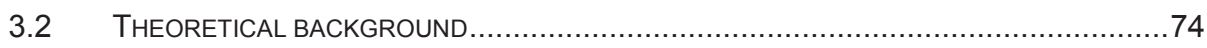

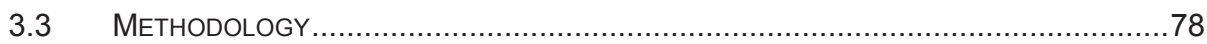

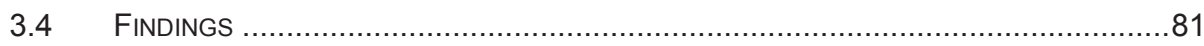

3.5 IMPLICATIONS FOR THE HRM FUNCTION: A MULTILEVEL PERSPECTIVE ......................89

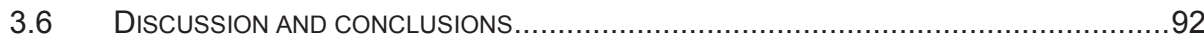

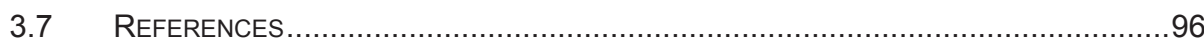

CHAPTER 4: HIGH-INVOLVEMENT HRM AND INNOVATIVE WORK BEHAVIOR .....97

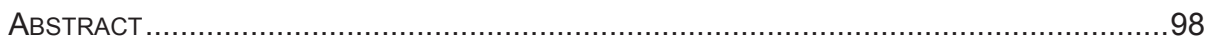

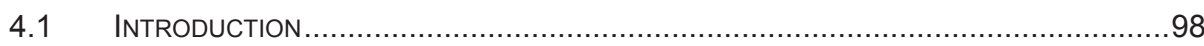

4.2 THEORETICAL BACKGROUND AND HYPOTHESES........................................... 101

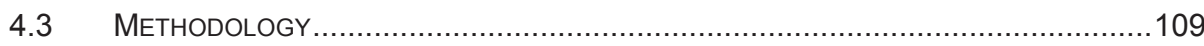




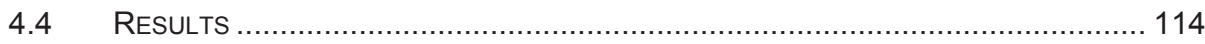

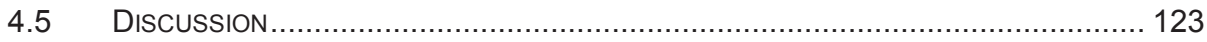

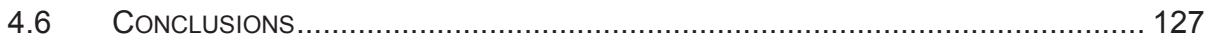

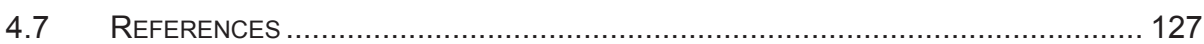

CHAPTER 5: ROUTES FOR EMPLOYEE-DRIVEN INNOVATION............................. 129

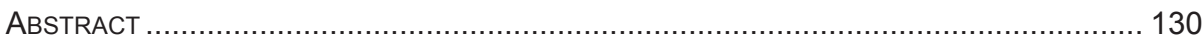

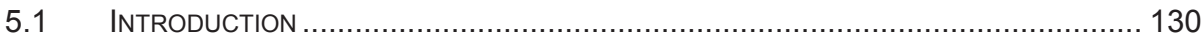

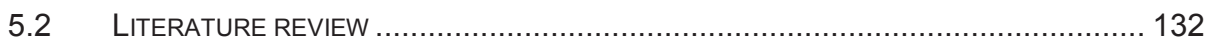

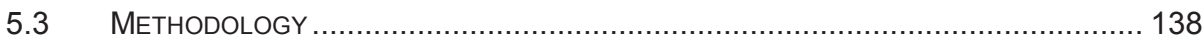

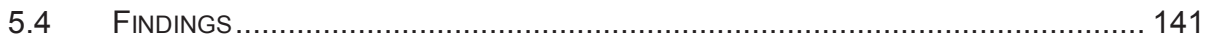

5.5 TOWARDS A MODEL OF ENABLING EDI EMERGENCE ..................................... 151

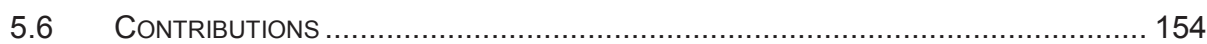

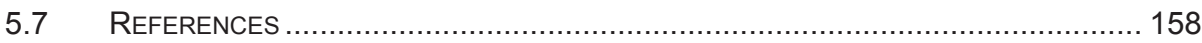

CHAPTER 6: ADVANCING MULTILEVEL THINKING AND METHODS IN HRM

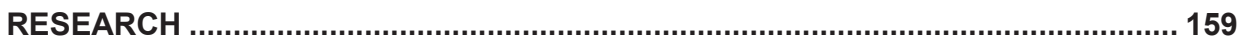

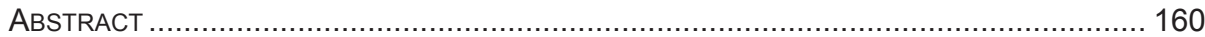

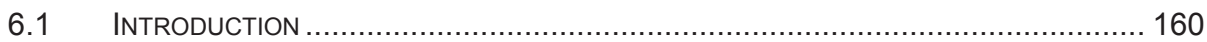

6.2 A MULTILEVEL HRM RESEARCH LANDSCAPE................................................ 162

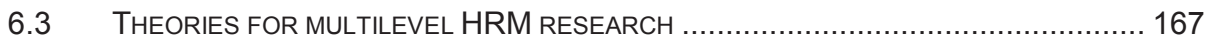

6.4 METHODS FOR MULTILEVEL HRM RESEARCH ............................................. 170

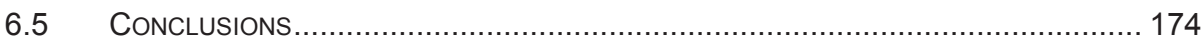

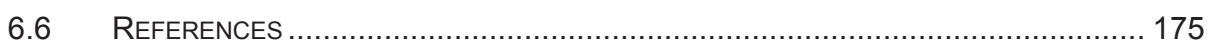

CHAPTER 7: DISCUSSION AND CONCLUSIONS .................................................. 177

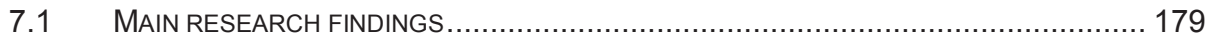

7.2 EDI APPROACHES IN TWO CASE ORGANIZATIONS: CROSS-CASE ANALYSIS ............... 184

7.3 SYNTHESIS: THREE MECHANISMS UNDERLYING THE HRM - EDI RELATIONSHIP....... 189

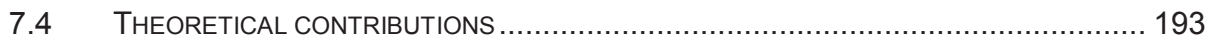

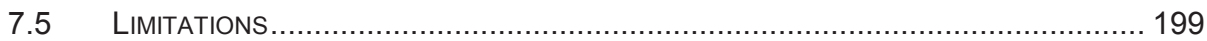

7.6 SUGGESTIONS FOR FUTURE RESEARCH ..................................................... 202

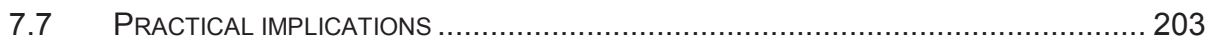

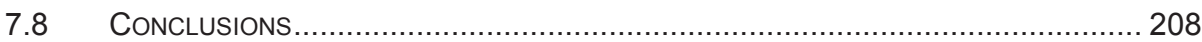

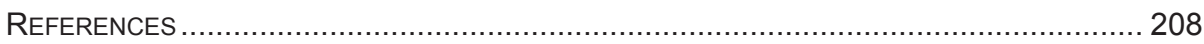

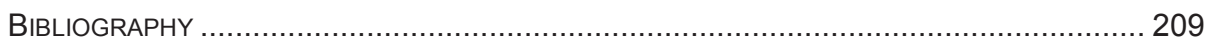

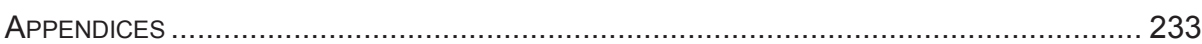

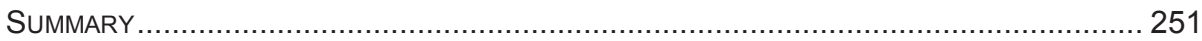

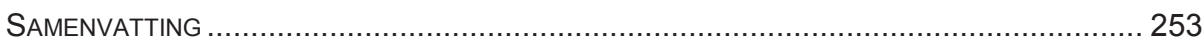

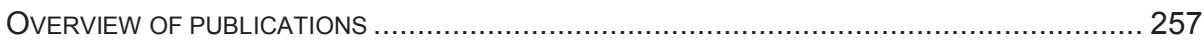

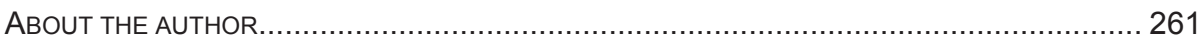




\section{List of figures}

\section{Chapter 1}

Figure 1.1. Research framework "Innovating HRM for Employee-Driven Innovation”.....19

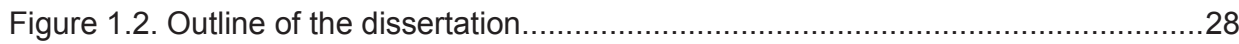

\section{Chapter 2}

Figure 2.1. The multidimensional "Multilevelity Cube" of SHRM research.......................37

Figure 2.2. Venn Diagram of The Studies that Incorporate Multilevelity Dimensions ......39

\section{Chapter 3}

Figure 3.1. Organisational model of self-managing teams (SMTs) ............................. 82

Figure 3.2. Overview of intended HRM policy-distribution....................................... 85

Figure 3.3. Overview of actual HRM policy-distribution ............................................... 87

Figure 3.4. The cyclical relationship model between HRM function and SMTs ...............91

\section{Chapter 4}

Figure 4.1. Conceptual model of HRM and IWB 109

Figure 4.2. Results of SEM: mediation effect of autonomy and affective commitment in the relationship between high-involvement HRM and IWB.

\section{Chapter 5}

Figure 5.1. Initial conceptual framework: EDI emergence model 138

Figure 5.2. Inductive model of HRM and Employee-Driven Innovation emergence. .....152

\section{Chapter 6}

Figure 6.1. Cascading Multilevel Approach to HRM Research. 162

Figure 6.2. The Landscape of Unanswered Multilevel HRM Research Questions

\section{Chapter 7}

Figure 7.1. Adapted research framework: "Innovating HRM for Employee-Driven Innovation" 


\section{List of tables}

\section{Chapter 1}

Table 1.1. Overview of research questions and approaches included in this dissertation.

\section{Chapter 2}

Table 2.1. Multilevelity Dimensions of Multilevel HRM studies 40

\section{Chapter 3}

Table 3.1. Overview of interviews at HealthServ

\section{Chapter 4}

Table 4.1. Demographic and biographical characteristics

Table 4.2. Descriptive statistics, alpha coefficients, composite reliabilities and correlations

Table 4.3. Fit statistics for competing measurement models 117

Table 4.4. Fit statistics for structural models......

Table 4.5. Indirect effects of autonomy and affective commitment on the relationship between high-involvement HRM and IWB 120

Table 4.6. Fit statistics for alternative models. 120

Table 4.7. Fit statistics for alternative models of IWB. 122

\section{Chapter 5}

Table 5.1. Overview of interviews at MedLab 140

Table 5.2. Examples of different types of employee-driven innovation routes at MedLab.

\section{Chapter 6}

Table 6.1. Multilevel HRM Research Domains with Sample Research Questions 166

\section{Chapter 7}

Table 7.1. Cross-case analysis. 


\section{List of abbreviations}

CR

EDI

FLM(s)

HIHRM

HRM

IWB

SEM

SMT(s)
Composite reliability

Employee-driven innovation

First-line manager(s)

High-involvement HRM

Human Resource Management

Innovative work behaviour

Structural equation modeling

Self-managing team(s) 


\section{Acknowledgements (dankwoord)}

"Waarom?" I know that as a child I always wanted to know more about why and how things happened. However, in those days I would not have imagined that one day I would earn my money with answering those types of questions. To some it may have come as a surprise that I became a university employee. However, to me it became clear during my studies that I liked to dive deep into difficult questions and to find evidence-based answers. So, four years ago my adventure as $\mathrm{PhD}$ researcher started. Now I am happy to present the result of 34.320 hours of hard work, with ups and downs, despair and celebration, laughter and sadness. It is the product of exactly 1.430 days of thinking and writing, discussing and editing, of transcribing interviews and coding data, of drawing models and writing results. In fact, it was the most challenging project of my life. I am certain that I would not have been able to make it without the incredible support of many people, whom I want to thank here.

I am very grateful for the role that Tanya played throughout the process. I always felt you trusted and supported me. You challenged me and pushed me forward to develop myself, and this been an irreplaceable help to write this book and to grow as a person. You really inspired me with your passion and dedication to your work and the work of others. Next to that, you never forgot to stress the importance of taking time off. Every now and then you even told me it was time to go home. And there were plenty of opportunities for humour and laughter. I also very much appreciate the interest you showed in things other than work. Many thanks for your support! Trust me, it was great!

I am also very thankful for the big role that Jeroen and Anna played. Jeroen as my daily supervisor, you were always available for questions. And there were a lot of questions. I learned a lot from you, both in terms of research as well as professional skills. You were always willing to help, and your dedication was a great example to me. Anna, thank you for the great time working together. Teaching the master course HRM \& Innovation together was very instructive for me. I have learned a lot about the educational side of the university during this course and the during our supervision of students. And I always liked your interest in discussing our family lives and weekends. I am also very proud that I wrote a book together with Tanya, Anna, Jeroen and Jan about self-managing teams, next to my regular $\mathrm{PhD}$ work.

A big thanks to Jan as well. It was wonderful to work together with you on a project called De Kanteling. I really enjoyed collaborating with you on such a big project, 
in which research and consulting were combined. I have learned a lot from you about translating research to practice. I am happy we have been able to write papers together. One of those papers we wrote together with Lew. I am thankful for the opportunity to work together with both of you. Lew, it was great that you became part of my PhD journey, and I really valued your help with the methodology and statistics. I enjoyed your double coffee breaks and enthusiasm!

I also like to thank the members of the graduation committee: prof. dr. Helen Shipton, prof. dr. Paul Sparrow, prof. dr. Ellen Giebels and dr. Michel Ehrenhard. Thank you for your willingness to be a member of the committee. It is an honour you are part of my promotion. Some of you I already met on multiple occasions, during which we could always discuss my research in a very nice and constructive way. Thanks to prof. dr. Petra de Weerd-Nederhof for chairing the defence.

I like to thank my fellow PhDs from the HRM department. First of all, my colleagues from the employee-driven innovation project Jorrit and Milana. It was great to start the PhD project with the three of us, we could always help and support each other. Besides that, I had a great time with you, sharing the office and going to conferences and workshops together. For a great part, thanks to you I enjoyed going to work every day. Your support was very important to me.

Many thanks to the other PhDs of the HRM group: Dustin, Luuk, Henk-Jan, Sri, Ewold and Milou. Milou, thank you for sharing the office with me for the last two years. You were always willing to help, and thanks to you I always knew when the sandwiches were ready downstairs! A big thanks to the other colleagues of the HRM group: Jan Kees, Huub, André, Sjoerd, Dennis, Gregory, Ida, Irene, and Jeanette. Together you created a very nice working environment, in which hard work and having fun were easily combined. I think I am very lucky to have been doing my $\mathrm{PhD}$ in such an amazing department. You helped me to improve my research, for example by asking the right questions during department meetings. And our HRM 'outjes' were terrific: we went for cooking workshops, sailing, ballooning, and barbecuing, among other things. Special thanks to MarieChristine for all your help!

Some big thanks is appropriate for the Netherlands Organisations for Scientific Research (NWO) who, together with the consortium partners, funded the research program Innovating Human Resource Management for Employee Driven Innovation. The consortium partners are: The Ministry of Interior and Kingdom Relations (BZK), Medisch Spectrum Twente (MST), WGV Zorg en 
Welzijn, and TSN Thuiszorg. Thanks for making our PhD projects possible and providing input during the progress meetings.

Further, I would also like to thank my fellow and former PhD colleagues: Frederik, Tamara, Jacco, Sunu, Haider, Koen, Igors, Ymke, Anna, Lisa, Kathy, Remco, Vincent, Afsheen, Siraz, Timo, Marlies, Andrès, Ari, Yasin, Arjan, Sílvia, Raja, André, Imke, Niels, Letizia, Björn, Martin, Tijs, Shuijing. Thank you for sharing $\mathrm{PhD}$ experiences and having fun during lunch and coffee breaks and parties. I always enjoyed our PhD dinners together, Tamara thank you for co-organizing them. And thanks to other colleagues of BMS: Erwin, Matthias, Ariane, Raymond, Sandor, Desiree, Celeste, Rez, Petra, and Efthymios.

Monday Funday! Because playing football every Monday evening (in Heracles outfit) with UT colleagues was amazing. The UT Futsal group has been very important throughout my PhD project. My special thanks to Michel for introducing me to the football and making me part of the board, and to the other fellow board members during those years: Anne, Sebastiaan, Jorrit, Djoerd, and Paul. The UT Futsal was one of the reasons why starting the week was never tough.

This dissertation would not have been possible without the help of the organizations that allowed me to conduct research. For that reason, I am very grateful for the opportunity to collect data at Medlon and Livio. Especially, I would like to thank Tamara of Medlon and Heinz and Henk of Livio for their willingness to collaborate and openness to collect all the data we needed. I would also like to thank all the interviewees, thanks to you we could find answers to our research questions. I am also thankful for the opportunity to collect survey data in the Kanteling project. Many thanks to the organizations of the co-called 'tweede spoor', and especially to Jan and Ben who allowed me to do my research in this project. Over the years, I worked together with a number of students, supervising their theses and conducting research together. I want to thank you for your role in this PhD project: Anneke, Anastasia, André, Cindy, Daphne, Giulia, Laurens, Marijn, Mark, Nadine, Patty, Rohid, Roos, Stefan, Ufuk, Wouter, and Yosri.

Finally I want to thank my friends and family, to whom I am tremendously grateful. I am very happy that Jorrit and my sister Henrike will be my paranimfs. Jorrit, you are not only a colleague but also a great friend. We can talk about anything, from printing our theses to discussing football. It has been great to have you by my side as a colleague and friend, during conferences, courses, networking events, Mexican and wedding parties, lunches, coffee breaks, and our creative endeavors. Also, a special thanks to Samara, I am grateful for your kindness and 
hospitality. Henrike, many thanks for your support throughout the years and all our trips together.

I also want to express my gratitude to my family-in-law for the fun we had during the years. The roadtrip, the time in Berlin, the many places we visited together. Thanks Marianne, Jeroen en Jorn for having me as a regular visitor.

Marc, Hugo, and Geert-Jan, also many thanks to you, for all those times we got together during the years, when it felt back like in those days of our Bedrijfskunde studies. I am also very grateful for having Tamara as a great friend. We could always discuss the difficulties of doing a $\mathrm{PhD}$ and share our successes. I really liked our dinners and coffee breaks, and there has not been one occasion we did not discuss our great time together in Berlin. Thank you for your support!

I could not have done this without the unconditional love, support, and encouragement of my parents Jakob and Ria. You have given me the opportunity to develop myself and I always feel welcome at home in Nijverdal. Whether it was in Berlin, Delft, or Hengelo, you are always there for me to help. Your care and trust have made me who I. You inspired me to work hard, but also to take a break now and then. Also big thanks to the rest of the family, the Renkema's and the Keizers (some of whom also studied and worked at the UT), for their interest in my work. Speciaal woord van dank aan mijn grootouders, Herman en Henny, ik ben heel blij dat jullie erbij kunnen zijn op dit speciale moment.

Lastly, I want to thank Martijn. For your great support and love. You were always there to listen to my stories and when I needed to talk about my frustrations, and you helped to find solutions to every problem. You asked the right questions and put me on the right track again. You were also willing to read and comment on my texts and were genuinely interested in my research. We could share our experiences about being a PhD, although we also frequently saw that this meant something different in the US than in The Netherlands. Most importantly, we celebrated and laughed together a lot, and you cheered me up when I needed it.

Maarten - September 2018 


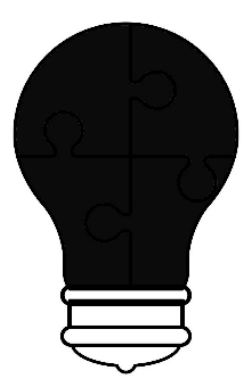

\section{CHAPTER 1}

\section{Introduction}

"How inscrutable and incomprehensible are the hidden works of nature!"

(Antoni van Leeuwenhoek) 


\title{
1.1 Prologue and research inception
}

\begin{abstract}
"Those teams have the best ideas. Yes, I really think that! Go and ask a question in those teams and you will get great solutions. They can be very simple, really very simple. However, because you now call much more on their own abilities, you can see that they make a great development and propose nice ideas." (interview first-line manager of 'HealthServ')
\end{abstract}

"When we see a problem, we immediately look into it and really get our teeth into it until we have an answer from someone how to deal with it. Most of our colleagues do posit their ideas, but when there is no or an unclear reaction they will think 'never mind'." (interview work-floor employee 'MedLab')

As the above examples from two of the case studies in this dissertation show, employees need to be empowered and involved if they are to be a source of innovation. Organizations can make use of the innovative potential of their workforce if they involve and empower employees. In this dissertation, I argue that organizations miss opportunities to innovate when they do not draw on the multitude of ideas from their own workforce. Employees on the work floor often have a good understanding of the problems and opportunities in the organization's processes and, because they are in close contact with customers, they also understand how to meet their demands. Organizations that utilize the creativity of their own workforce are therefore expected to be able to be more innovative. Since it is eventually employees who develop and utilize new ideas, organizations need innovative personnel management and Human Resource Management (HRM) can play an important role in stimulating and facilitating innovation.

Therefore, this dissertation studies how organizations can enhance innovation performance through stimulating the innovativeness of 'regular' employees, a process referred to as employee-driven innovation. In particular, this research is focused on the role of HRM in encouraging and facilitating innovation on multiple organizational levels since the HRM - innovation relationship inherently represents a multilevel problem. The scope of this dissertation includes both the activities and management of organizations and the role and actions of work-floor employees in innovation processes. 
The goal of this dissertation is to uncover the role of HRM in generating innovative outcomes across different levels of analysis. More specifically, I want to understand in what ways innovations in HRM enhance the innovation performance of organizations through enhancing employee-level innovative behaviour. The underlying premise is that Human Resource Management needs to innovate itself in order to stimulate the innovativeness of the human resources it manages.

I have always been interested in the management of innovation, especially given that some organizations succeed in renewing themselves through innovation whereas others fail and go bust. Through studying Business Administration and Innovation Management \& Entrepreneurship, I learnt that organizations can manage and influence their innovation performance. Nevertheless, at that time, most of the research seemed to focus on innovation in a high-technology context, where companies were forced to innovate and where innovation was mainly the domain of R\&D centres and new-project development teams. However, what about all the other employees, and what about employees in jobs and/or firms where innovation is neither necessarily required nor expected?

For that reason, I was happy when I got the opportunity to do research in this area. In May 2014, I saw that the Human Resource Management group of the University of Twente started a large NWO-funded project about HRM and Employee-Driven Innovation (EDI). The main question was focused on what is needed in terms of human resources and the management of those resources to stimulate the innovativeness of 'regular' employees, which fitted neatly with my own research interests as described above. My attention was immediately drawn to one of the subprojects, one that was focused on exploring how individual innovative behaviours aggregate to the organizational level to explain the innovation performance of the organization.

As you might deduce, I was selected to study this topic and this has led to the dissertation you are now reading. Earlier doctoral research within the HRM group has shown that HRM can indeed enhance innovation. However, it was also clear that many questions remained unanswered. Particularly, the multilevel nature of the HRM - innovation relationship needed to be addressed to gain a better understanding of this relationship. The connection is inherently multilevel given that employees' innovative behaviours are related to the individual level, whereas the HRM - innovation performance relationship is usually seen as an organizational-level attribute. For this reason, I decided to study HRM and innovation from a multilevel perspective. When I set out, scholars had paid little attention to multilevel issues in HRM - innovation research. 
The first two tasks on my list were to learn more about multilevel research and to understand better how work-floor employees could be engaged in innovative activities. Regarding the first task, it became clear that the theoretical multilevel perspective would fit well with the more practical research question about HRM and innovation. For that reason, I needed to map what we can learn from multilevel theory in better understanding the multilevel relationship between HRM and innovation. However, after reading many articles and the book of Klein and Kozlowski (2000), I concluded that the multilevel approach was not very welldeveloped in the HRM literature. For that reason, we decided to first carry out a systematic literature review of the application of multilevel theory in HRM research (see Chapter 2), and then to write a paper with guidelines to advance multilevel thinking and research in HRM (Chapter 6).

Furthermore, early in my PhD project, I came in contact with the medical laboratory 'MedLab'1 and its HRM manager to discuss employee-driven innovation. The HRM manager at MedLab had almost the same question as we had in our project: how can we empower and enable employees to ensure that employees take responsibility and initiatives to make changes to their work? She explained that the organization was planning to change its structure, and that this also involved empowering employees and providing ownership and responsibility. Existing research provided some indications of how innovation can be stimulated, but HRM scholars had paid little attention to employee-driven innovation, that is innovation made possible by work-floor employees, especially in a context were this was not overtly required nor expected. I therefore decided to study employee-driven innovation in this formalized context and how an organization can use HRM to stimulate it (Chapter 5).

At the same time, I joined a project on the long-term and elderly care sector that concerned empowering employees, particularly in terms of worktime control, self-scheduling and self-management. Within this project, several studies were conducted, some of which are still work-in-progress. In one of these studies, we focused on the innovative behaviours of employees and tried to uncover how a bundle of high-involvement HRM practices influences these behaviours (Chapter 4). Furthermore, we have written a paper about the effects of job control on work-life balance and commitment, and looked into the role of autonomous teamwork. Based on our research and experiences with organizations that adopted self-scheduling and/or self-managing teams, I started another project with 'HealthServ' - a large healthcare organization - to study the changes to the HRM function that result from introducing self-managing teams (Chapter 3 ), and

\footnotetext{
${ }^{1}$ Fictional names are used for the participating case study companies ('MedLab' and 'HealthServ') to preserve their anonymity.
} 
to explore the HRM support that teams need in their transformation towards selfmanagement (Bondarouk, Bos-Nehles, Renkema, Meijerink, \& De Leede, 2018). Furthermore, this case study allowed me to compare different EDI approaches taken by organizations and the ways in which HRM can contribute to EDI. In combination, these different studies have helped me to explore and explain the HRM - innovation relationship.

This study is part of the "Innovating Human Resource Management for Employee-Driven Innovation" research project, which takes a holistic approach towards understanding the ways in which innovations in HRM can stimulate the innovation performance of both employees and organizations, and how these HRM innovations are implemented. The first pillar of the research project explores the implementation of innovations in HRM, the second pillar is about uncovering the relationship between HRM and innovation from a configurational perspective, and the third pillar aims to increase our knowledge about how these HRM innovations lead to innovation outcomes on different organizational levels.

Pillar 1 provides insights into the dynamic implementation processes of HRM (Van Mierlo, 2018). This pillar builds on a developing research tradition that has focused on "HRM-as-a-process" (Bowen \& Ostroff, 2004; Wright \& Nishii, 2013), with the aim of understanding how HRM can be successfully implemented. In this, Van Mierlo (2018) studied the dynamic process of HRM implementation, focusing on interactions between organizational actors and HRM, to uncover what happens during the process of implementation. However, here, by building on structuration theory (Giddens, 1984), HRM implementation is reconceptualized with a focus on outlining how the interplay between structure and action continuously affects the implementation process (Van Mierlo, Bondarouk, \& Sanders, 2018). In this reasoning, for HRM innovations to be successfully implemented, they need to become part of actors' interpretive schemes, resources need to be distributed and the innovations need to acquire legitimacy (Van Mierlo et al., 2018). Empirical research by Van Mierlo and Bondarouk (2018) show how HRM innovations develop throughout the implementation process. The process of HRM practice maturation should therefore be seen as a dynamic development in which actors shape HRM innovations, while HRM innovations shape the organizational actors (Van Mierlo \& Bondarouk, 2018). Summarizing, from this pillar of the project, we know that HRM innovations that organizations adopt in order to enhance innovation outcomes need to be carefully implemented if they are to achieve their goals. To stimulate innovation it is therefore crucial to not only look at what practices to adopt but specifically also about how to implement them to achieve the original intentions.

Pillar 2 revisits the role of configuration theory in HRM and performance research, and identifies existing ideal HRM configuration types for achieving 
desired performance outcomes, such as innovation. For example, based on a systematic literature search of HRM configurations, a set of configuration principles was developed to illustrate the use of configuration theory in HRM studies (Korotka \& Bos-Nehles, 2016). In this pillar, research is conducted into the HRM configurations that are needed to stimulate the performance of medical specialists. Based on data gathered in two Dutch hospitals, cultural differences were identified between so-called 'contract specialists' and specialists in their own partnerships. Based on these findings, an Abilities-Motivation-Opportunitiesbased HRM framework was developed that proposes differences in the HRM policies for these two types of specialists (Felius, Bondarouk, \& Bos-Nehles, 2018). This pillar also explores the role of professional cultures within medical specialisms and their impact on HRM design.

This dissertation presents results of a study from Pillar 3 of the research project. It is focused on how HRM can enhance innovation performance of both employees and organizations. In this, this dissertation builds on existing knowledge found in both HRM and innovation management literature streams and addresses several mechanisms and aspects of how HRM can enhance innovation and how innovations in HRM can contribute to this. The third pillar starts with the assumption that individuals are the source of innovative ideas, and that to understand how HRM can stimulate employees' innovative behaviours requires an analysis that integrates multiple organizational levels. For that reason, this research draws on ideas from multilevel theory building (Kozlowski \& Klein, 2000) and advances multilevel thinking in the HRM literature.

I explore and explain the multilevel relationship, and the underlying mechanisms, between innovative HRM and innovation performance, by studying both the ways in which HRM affects innovative behaviours and how HRM contributes to bottom-up emergence. This introductory chapter continues with the research motivation and background (1.2), the research challenges and framework (1.3), an outline of the five research projects that answer the research questions (1.4), and a brief reflection on the scientific and methodological approach (1.5). 


\subsection{Research motivation and background}

The importance of innovation capabilities for modern firms has been widely researched and acknowledged (Agars, Kaufman, \& Locke, 2008; Cohen \& Levinthal, 1990; Crossan \& Apaydin, 2010). The capacity of organizations to manage their employees such that they are creative and innovative has been suggested as an important source of competitive advantage (Barney, 1991; Mumford, 2000). For this reason, scholarly attention to the topics of innovation and creativity has grown immensely during the past decade or so (Anderson, Potočnik, \& Zhou, 2014). In its original definition, coined by Schumpeter in 1934, innovation is seen as novelty that creates economic value, based on new combinations (Schumpeter, 1934). Nowadays, definitions of innovation are lengthier and more specific in terms of level of analysis and innovation types. For example, one generally accepted definition of innovation is "the intentional introduction and application within a role, group or organization of ideas, processes, products or procedures, new to the relevant unit of adoption, designed to significantly benefit role performance, the group, the organization or the wider society" (West \& Farr, 1989, p. 16). In this dissertation, I see innovations as ideas that are perceived as new in the context of interest, to the people involved, meaning that ideas may not be new to other individuals outside that context (Van de Ven, Polley, Garud, \& Venkataraman, 2008).

Different approaches and sub-streams of innovation research have developed over the years. One stream has focused on conceptualizing innovation, and gathering knowledge about dimensions of innovation (Crossan \& Apaydin, 2010), types of innovation (Garcia \& Calantone, 2002), degrees of innovation (Gopalakrishnan \& Damanpour, 1997), and determinants of firm-level innovation (Damanpour, 1991). Other streams have examined open innovation (Chesbrough, 2006), user-driven innovation (Von Hippel, 1986), highinvolvement innovation (Bessant, 2003), employee-driven innovation (Kesting \& Ulhøi, 2010) and, most recently, workplace innovation (Oeij, Rus, \& Pot, 2017; Pot, 2011). These all have in common that different actors have roles in the innovation processes of organizations.

An important perspective in the latter innovation research addresses the innovativeness of workplace employees (Scott \& Bruce, 1994; West \& Farr, 1989). In this literature, scholars try to discover what stimulates innovative behaviour by individual employees (Janssen, 2000; Yuan \& Woodman, 2010). That is, it is not organizations that innovate, it is employees. Individuals play a vital role in innovation because they are the ones who hold and process new ideas (Van de Ven, 1986). An individual's ideas and creativity form the basis of most innovations (Amabile, Conti, Coon, Lazenby, \& Herron, 1996). Almost three 
decades ago, Kanter (1988) and West and Farr (1989) developed the idea of innovative behaviour by employees. This was seen as consisting of four distinct tasks: idea generation, coalition building, idea realization and transfer. In the following decade, researchers started to study factors that could stimulate individuals to show innovative behaviours (Scott \& Bruce, 1994). A further decade later, Janssen (2000) introduced the concept of Innovative Work Behaviour (IWB), which he defined as "[...] the intentional creation, introduction, and application of new ideas within a work role, group, or organization, in order to benefit role performance, the group, or the organization" (p. 288). This definition was based on the work of Scott and Bruce (1994) that had described innovative behaviour in the workplace.

Given that employees are an important source of innovation, researchers have increasingly studied the contribution of HRM to innovation outcomes (BosNehles, Renkema, \& Janssen, 2017; Seeck \& Diehl, 2017). Research into HRM has provided insights into the antecedents of innovative behaviour and the innovation performance of organizations. Since HRM is concerned with managing and developing employees, researchers started to examine which HRM activities should be implemented to increase the innovativeness of organizations. The first conceptualizations of the HRM - innovation relationship were presented more than a decade ago (De Leede \& Looise, 2005; Laursen \& Foss, 2003). Since the launch of this field of research, there have been an increasing number of empirical studies into this relationship (e.g. Beugelsdijk, 2008; Cabello-Medina, López-Cabrales, \& Valle-Cabrera, 2011; Fu, Flood, Bosak, Morris, \& O'Regan, 2015; Lopez-Cabrales, Pérez-Luño, \& Cabrera, 2009; Shipton, Fay, West, Patterson, \& Birdi, 2005; Shipton, West, Dawson, Birdi, \& Patterson, 2006; Veenendaal, Van Velzen, \& Looise, 2014), and books dedicated to the HRM - innovation relationship (Shipton, Budhwar, Sparrow, \& Brown, 2016a). Moreover, we have seen recent literature reviews (Bos-Nehles, Renkema, et al., 2017; Lin, 2015; Seeck \& Diehl, 2017). Some scholars have focused on the relationship between HRM practices and systems and different types of innovation (Seeck \& Diehl, 2017), while others have sought 'the best HRM practices' for enhancing IWB (Bos-Nehles, Renkema, et al., 2017). Evidence suggests that HRM can positively contribute to an organization's innovativeness by creating an innovative organizational climate (Bos-Nehles \& Veenendaal, 2017; Shipton et al., 2006), enhancing organizational learning (Shipton et al., 2005), increasing innovative human capital (De Winne \& Sels, 2010; Jiang, Lepak, Hu, \& Baer, 2012) and supporting employees' innovative behaviour (Dorenbosch, van Engen, \& Verhagen, 2005; Veenendaal \& Bondarouk, 2015). Despite these findings, innovation remains challenging for organizations, in part because employees are often wedded to doing things as 
they always have, because they have worked well in the past (Unsworth \& Clegg, 2010).

This dissertation applies the concept of employee-driven innovation (EDI) to the HRM literature with the goal of improving our understanding of the HRM innovation relationship at different organizational levels of analysis. EDI is an umbrella term which is useful to describe the different forms of employee participation in innovation processes (Høyrup, 2012). In management science, considerable attention has been given to the top-down approach to innovation in which new products, services and processes are developed by selected employees in R\&D departments or project teams. In contrast, EDI research starts with the assumption that every employee can be a source of creativity and innovation when organizations provide the right support (Evans \& Waite, 2010). EDI is a relatively new and understudied concept, and shifts the attention towards innovations that arise beyond the R\&D departments and are initiated, developed and implemented by employees who are not tasked with innovation creation (Høyrup, 2010). EDI is important because, in today's world, workplaces have to be innovative, and organizations have to build resources for innovation (Høyrup, 2012). Although the potential level of creativity and innovation will depend on task design and the type of organization, there is room for creativity in almost every job (Shalley \& Gilson, 2004).

Employee-driven innovation covers multiple activities that involve workfloor employees contributing to innovation. In general, the various EDI modes can be placed on a continuum from management-directed to self-initiated employee innovation activities. The former involves a top-down deliberately planned process, in which innovation is directed by management, whereas the latter entails a practice-based bottom-up process that is fully self-initiated (Sørensen, Sundbo, \& Mattsson, 2013). Other EDI models are based on there being several orders of EDI. For example, Høyrup (2012) distinguishes three orders of EDI: first-order EDI (truly bottom-up, self-initiated), second-order EDI (mixture of topdown and bottom-up processes in which managers have an important role), and third-order EDI (top-down process in which managers invite employees to innovate). This is similar to the 'management-initiated', 'management-mediated' and 'employee-bricolage' model (Fuglsang \& Sørensen, 2011). Nevertheless, rather than seeing these EDI forms as top-down versus bottom-up approaches (dualism), EDI can also be seen as a combination of top-down and bottom-up innovation initiatives by employees (duality). As such, EDI is an integration of management and employee actions to stimulate innovation, a so-called balanced approach (e.g. Engen, 2016; Fuglsang, 2008). This approach recognizes that individual employees cannot singlehandedly generate innovation in modern organizations (Sundbo, 2003): although an innovation process may start on the 
work floor, it eventually becomes a process in which interaction takes place between employees and managers (Høyrup, 2012).

In line with the definitions coined by Høyrup (2010) and Kesting and Ulhøi (2010), I view employee-driven innovation as: "the generation and implementation across organizational levels of new ideas, products, services, and/or processes originating from one or more work-floor employees who are not overtly required to be active in these activities" (Renkema, Meijerink, \& Bondarouk, 2018, p. 7). The last part of this definition warrants emphasis because it highlights the novel aspect of this term: employees who are not considered innovative come up with new ideas that, once implemented, are called EDIs. That is, these innovations are conceptualized as emerging from "regular" employees, such as shop-floor workers, professionals and middle managers (Kesting \& Ulhøi, 2010). As such, EDI is about activities that go beyond the job description (extrarole or discretionary behaviour), highlighting that such innovations are not necessarily required from employees (Montag, Maertz, \& Baer, 2012). This means that every employee, from top managers to front-line employees, has the potential to contribute to innovation, which underscores the underlying premise in this thesis. Consequently, I have chosen work-floor employees as the focal actors in this dissertation, and I primarily focus on their actions and activities in the organizational context. These are ordinary employees, who have not been hired for nor assigned to an innovation task.

In their daily work, work-floor employees regularly face challenges and complex issues, ideally positioning them to gain insights into what their organization could improve, and to turn these insights into innovative solutions (Wihlman, Hoppe, Wihlman, \& Sandmark, 2014). By being in close contact with customers, they also acquire an understanding of market demands (Skaggs \& Youndt, 2004). Moreover, employees typically possess in-depth and contextdependent knowledge that managers lack, thereby highlighting the importance of EDI for modern organizations (Høyrup, 2012; Kesting \& Ulhøi, 2010). Recognizing and following up on the insights acquired, requires specific characteristics from employees (Cadwallader, Jarvis, Bitner, \& Ostrom, 2010). EDI entails a change in management philosophy, from top-down to bottom-up, whereby innovation is initiated and led by operational employees (Birkinshaw \& Duke, 2013). The underlying assumption is that provided employees have the necessary abilities, motivations and opportunities to engage in innovative behaviour, every employee can be a source of creativity and innovation. Consequently, employees are seen as the driving forces behind EDI. However, to benefit from this innovative potential of employees requires careful consideration because the organizational context has to be facilitating while preventing the participation of employees in the innovation process becoming 
counterproductive (Kesting \& Ulhøi, 2010). Although we know that frontline employees are in a good position to generate and implement innovative ideas, there is a need for a better understanding of the underlying processes and the outcomes.

Therefore, in this dissertation, I use the concept of EDI to study the link between HRM and innovation from a multilevel perspective. I view innovation as the 'outcome' of the EDI process, whereas employees' innovative behaviour is its input. As such, EDI essentially combines both individual innovative behaviours and the collective innovation outcomes. On this basis, I view EDI as a concept that can aid understanding of how all employees can be involved in innovation processes and how innovation unfolds across organizational levels. As such, the EDI approach is helpful in tackling the mono-level approach that HRM research has been criticized for (e.g. Paauwe, 2009). Further, applying the EDI concept helps to gain insights into how the innovative behaviours of employees are configured and aggregated to explain innovation performance at the organizational level, thereby uncovering the micro-foundations of HRM and innovation (Coff \& Kryscynski, 2011), which are not well understood. The relationship between HRM and innovation is multilevel in nature (Kozlowski \& Klein, 2000; Ostroff \& Bowen, 2000) because organization-level HRM policies and practices affect individual employees' attitudes and innovative behaviours that, in turn, affect innovation performance (Schuler \& Jackson, 1987; Wright \& Boswell, 2002). This shows that the relationship between HRM and EDI spans multiple organizational levels and, therefore, that applying a multilevel perspective could aid understanding of how HRM and EDI are connected. Although this has been recognized, there is a lack of multilevel theory and research to explain how HRM stimulates employees to contribute to EDI, an aspect that is addressed in this dissertation.

Summarizing, the increasing scholarly attention to and interest in the relationship between HRM and innovation has provided us with important insights. We now know a lot more about which HRM policies and practices eventually lead, and to what extent, to innovation outcomes. This progress allows us to go another step and gain a better understanding of the underlying mechanisms of the HRM - innovation relationship: to learn more about the ways in which HRM influences innovation. Indeed, to stimulate and facilitate innovation through HRM, it is important to understand how HRM policies and practices lead to innovation. What happens when organizations implement innovative HRM policies in order to encourage employees to be more innovative? What are the drivers of employee-driven innovation and how do HRM processes work on different levels? Further, in what ways do the innovative ideas of employees lead to more innovations? Answering these questions will enable us to understand 
and further advance the theoretical foundations of the HRM - innovation relationship. More specifically, we will be able to refine the theoretical understanding of how innovations develop in the multilevel context in which they occur. That is, we aim to find theoretical and empirical answers so that we can explain the multilevel relationship between HRM and innovation. For these reasons, this dissertation research aims to explore and explain the mechanisms underlying the relationship between innovative HRM and EDI. In this, I integrate both the individual and organizational levels to explain the ways in which HRM leads to employee-driven innovation.

The overall research question is: "In what ways does innovative HRM contribute to employee-driven innovation?

\subsection{Research challenges and framework}

My central thesis in this dissertation is that employees' innovative behaviour constitutes an important mechanism through which HRM can stimulate employee-driven innovation. In other words, the innovative behaviour of regular employees forms a bridge that links innovative HRM policies and practices with organization-level innovation performance outcomes. In recent years, I have observed significant progress in understanding to what extent HRM leads to organizational innovation outcomes (for a review, see Seeck \& Diehl, 2017) and which HRM policies and practices stimulate innovative work behaviours (BosNehles, Renkema, et al., 2017). Nevertheless, there are many opportunities to further enhance our knowledge about the HRM - innovation relationship. In the next section, I will focus on those aspects of this relationship that are, from my point of view, most important in advancing this field of research. Addressing these challenges will help make sense of the bigger picture as outlined in the section above, which we will address by developing a research framework that forms the basis of this dissertation.

\subsubsection{Challenge 1: The underdeveloped multilevel relationship between HRM and innovation}

Given that the focal relationships in this dissertation framework exist on different organizational levels, I adopt the principles of multilevel theory building and thereby empirically and theoretically advance the multilevel perspective in HRM research. The role of HRM in achieving firm-level innovation performance outcomes is thought to be through its mediating effects on desirable employee behaviours. HRM policies and practices are targeted at directing employees towards desirable behaviour (Jiang et al., 2012), which in turn contribute to 
innovation performance outcomes. The relationship between HRM and innovation performance is therefore inherently multilevel (Kozlowski \& Klein, 2000; Ostroff \& Bowen, 2000). HRM affects performance through its effect on employee's attitudes and behaviours (Schuler \& Jackson, 1987; Wright \& Boswell, 2002), and therefore this relationship resides on multiple levels of the organization. In this thesis, this relationship is reflected in the role that innovative HRM policies play in producing innovation performance outcomes through stimulating individual-level employees' perceptions, attitudes, motivations and behaviours. Nevertheless, to date, there is no well-developed multilevel theory that explains how human resources can be managed to promote innovative behaviour across organizational levels. Although we know that individuals are the basis for organizational innovation performance, the micro-foundations of innovation and the role of HRM in shaping these foundations have not been studied (Coff \& Kryscynski, 2011). Despite the advances in HRM research, the majority of existing studies have adopted a single-level perspective (Lin, 2015; Paauwe, 2009). Some studies have adopted an organizational-level approach by examining the effect of HRM on the innovation performance of organizations (Beugelsdijk, 2008; De Winne \& Sels, 2010), while other studies applied an employee-level approach in examining the effect of perceived HRM practices on employees' innovative behaviour (Dorenbosch et al., 2005; Veenendaal \& Bondarouk, 2015). However, these studies ignored the embeddedness of employees in teams and organizations (Hitt, Beamish, Jackson, \& Mathieu, 2007) and therefore it remains unclear how an organization's innovation performance emerges from individual employees, and how HRM can contribute to this.

Given that existing studies have built a theoretical and empirical understanding of the effects of HRM and of the innovative behaviours of employees, and that both concepts are multilevel phenomena, enables us to advance the different perspectives and integration levels seen in the literature on HRM and innovation. The innovation concept itself is also a multilevel construct because it occurs on individual, team and organizational levels, and even on higher industry-wide and geographic regional levels (e.g. Gupta, Tesluk, \& Taylor, 2007). Previous research on multilevel HRM has been on the level of HRM abstraction, which is pertinent for addressing the internal vertical fit between HRM philosophies, policies and practices (Arthur \& Boyles, 2007; Kepes \& Delery, 2007). Here, scholars note that HRM practices (including single practices or systems of HRM practices) could target individual actors or groups of actors and affect outcomes on different levels (Kepes \& Delery, 2007). Several authors have more recently examined HRM practices on different levels of analysis (e.g. Jiang, Takeuchi, \& Lepak, 2013; Wright \& Nishii, 2013). As part of this, scholars have been developing conceptual frameworks focused on the cross-level 
linkages between HRM and innovation (Lin \& Sanders, 2017; Shipton, Budhwar, Sparrow, \& Brown, 2016b; Shipton, Sparrow, Budhwar, \& Brown, 2017). For those reasons, this dissertation aims to extend multilevel thinking in HRM innovation research by applying systems thinking and the principles of multilevel theory building (Kozlowski \& Klein, 2000). Given the extensive knowledge in the HRM - innovation literature, we can go a step further and enrich our understanding of how innovations in HRM can stimulate employee-driven innovation to gain insights into the dynamics underlying this relationship. By adopting a multilevel perspective, we will gain an understanding of the ways in which employees respond to innovative HRM policies, and how they in turn contribute to innovation. Therefore, in this research, I focus on the multilevel relationship between HRM and employee-driven innovation. In my view, it is important to gain greater insight into the ways in which innovative HRM can successfully lead to innovative ideas being developed and implemented by workfloor employees.

\subsubsection{Challenge 2: The implications of introducing innovative HRM policies are unclear}

It is claimed that innovative HRM will only affect attitudes and behaviours as intended if they are perceived and experienced as such by employees (Nishii \& Wright, 2007). Moreover, several recent studies have revealed that actual and experienced HRM practices are not always similar, and indeed that experienced, or perceived, HRM practices have the greater impact on employee outcomes (Aryee, Walumbwa, Seidu, \& Otaye, 2012; Liao, Toya, Lepak, \& Hong, 2009). Therefore, in addition to designing innovative HRM practices to enhance innovation, these practices need to be implemented, meaning that they have to be put into practice and institutionalized by the employees. Research shows that employees often report receiving few or none of the intended practices (Bondarouk, Looise, \& Lempsink, 2009). Despite such links and failings being widely acknowledged, there are few studies that take the experience of individual employees into account when studying HRM - performance relationships (Jiang, $\mathrm{Hu}$, Liu, \& Lepak, 2017). As such, existing research underlines the need to include the HRM perceptions of employees when examining HRM - innovation performance relationships, and to examine the relationship between intended HRM and perceived HRM innovations.

HRM implementation has been seen as a process, through which HRM policies are transformed from an abstract plan into an institutionalized use of instruments (Bowen \& Ostroff, 2004; Nishii, Lepak, \& Schneider, 2008). As such, implementing HRM innovations to enhance innovation performance involves 
more than HR professionals. The term HRM refers to all the activities that organizations use to manage human resources effectively (Wright \& McMahan, 1992), and so success in implementing HRM innovations is dependent on how a range of organizational actors implement and use them. The implementation is therefore affected by the actions of various HRM actors such as line managers, HR specialists and work-floor employees (Farndale, Paauwe, \& Boselie, 2010; Valverde, Ryan, \& Soler, 2006). Given this recognition, a relatively new line of research is focused on studying the gaps between intended, actual and perceived HRM (Bondarouk, Bos-Nehles, \& Hesselink, 2016; Bos-Nehles, Bondarouk, \& Labrenz, 2017; Khilji \& Wang, 2006; Makhecha, Srinivasan, Prabhu, \& Mukherji, 2018; Piening, Baluch, \& Ridder, 2014a). From this perspective, HRM practices are seen as designed by the HRM department and then applied in a top-down manner through the organization. The implementation of innovative HRM policies should therefore be seen as a process in which these policies and practices evolve until they are used by all HRM actors on a regular basis (Bondarouk, Trullen, \& Valverde, 2016; Trullen, Bos-Nehles, \& Valverde, 2018). Recently, HRM implementation has been re-conceptualized by outlining how the interplay between structure and action continuously affects the implementation process (Van Mierlo et al., 2018), thereby offering an alternative to the static and onesided approach of earlier studies. Hence, the implementation of innovative HRM is now seen as a multilevel and multi-actor process in which HRM practices are present on various levels and are implemented by various HRM actors (BosNehles \& Bondarouk, 2017).

The implementation of HRM innovations does not only involve several organizational levels and various HRM actors, it might also change the responsibilities and daily activities of those actors. One HRM innovation that organizations increasingly adopt to enhance the innovativeness, adaptability and involvement of employees is self-managing teams (Kirkman \& Rosen, 1999; Maynard, Gilson, \& Mathieu, 2012). There is a growing literature on the antecedents and effects of self-managing and empowered teams, including several literature reviews (e.g. Magpili \& Pazos, 2018; Seibert, Wang, \& Courtright, 2011). Nevertheless, there is still a need to enhance our understanding of the implications for the HRM function, and thereby the processes of HRM implementation, when implementing innovations such as selfmanaging teams. In order to study the link between HRM and innovation, it is therefore necessary to increase knowledge on how innovative HRM policies transform the ways in which HRM itself functions within organizations. In other words, the HRM function changes as a consequence of implementing new HRM policies to enhance innovation performance. Studying this link should also help clarify the reasons why and how intended HRM policies lead to different HRM 
perceptions in employees. For these reasons, it is important to gain greater insight into how HRM innovations change the HRM function in terms of the focal actors and their activities.

\subsubsection{Challenge 3: Lack of theoretical mechanisms underlying the HRM - IWB relationship}

Intended HRM policies will only affect innovation outcomes if they are perceived by employees. It is when HRM policy innovations are implemented and become institutionalized that they will change employees' perceptions of HRM. Furthermore, individual employees respond differently to HRM policies and will perceive them differently from how they were originally intended (Aryee et al., 2012; Liao et al., 2009; Nishii et al., 2008). For these reasons, it is important to understand what makes employees reciprocate the investments in HRM policies by generating and implementing new ideas. Adopting a behavioural perspective can help to explain the effect of HRM innovations on innovative work behaviour, a concept that consists of both idea generation and idea implementation by employees (De Jong \& Den Hartog, 2010). For employees to become innovative, they need to have the abilities, motivation and opportunities to perform innovative activities (Appelbaum, Bailey, Berg, \& Kallenberg, 2000; Jiang et al., 2012). Therefore, in our research model, we assume that innovations in HRM policies, once they are implemented and perceived by employees, positively influence employees' innovative work behaviours by affecting their attitudes and resources.

In particular, HRM innovations related to empowerment seem to be related to IWB (Bos-Nehles, Renkema, et al., 2017). In our systematic literature review, we saw that HRM practices related to employees' opportunities are particularly effective in stimulating IWB. This is in line with the shift from controloriented HRM systems to a more commitment- and involvement-oriented HRM approach (Lawler, 1986). High-involvement HRM increases employee empowerment by providing employees with, among other things, decisionmaking authority and information. High-involvement implies that organizations use employees' capabilities for self-management, personal development and problem solving (Boxall \& Macky, 2009). Therefore, one HRM innovation that organizations can introduce to enhance IWB is high-involvement HRM practices.

Contemporary literature reviews show that there is little theoretical foundation for the underlying causal mechanisms that link HRM and innovation (Bos-Nehles, Renkema, et al., 2017; Seeck \& Diehl, 2017). Employees are assumed to reciprocate the high-involvement HRM investment in them by showing valuable behaviours (Gouldner, 1960), which is in line with social exchange theory (Blau, 1964). To further explain the link between employees' 
perceptions of innovative HRM and their behaviours, two perspectives from the HRM literature can be combined. First, HRM is expected to affect employee outcomes by providing job resources (Boon \& Kalshoven, 2014; Peccei, van de Voorde, \& Van Veldhoven, 2013) such as autonomy and competences. Second, there is a literature stream that has focused on desirable job attitudes, such as affective commitment and job satisfaction, to explain the link between HRM and employee outcomes (Jiang et al., 2013; Paauwe \& Blok, 2015). Based on a recent meta-analysis that has shown that the combination of job attitudes and resources provides a fuller understanding of how employees' perceptions of HRM are related to employee outcomes (Meijerink, Beijer, \& Bos-Nehles, 2017), one can anticipate that employees' attitudes and resources will also play an important role in the link between HRM innovations and IWB. Nevertheless, the underlying relationships between HRM and IWB remain uncertain. Thus, in my view, it is important to gain further insights and empirically explore the ways in which innovative HRM leads to IWB. Uncovering the process through which innovative HRM influences the generation and implementation of employees' ideas will help both researchers and practitioners understand better the nature of the relationship between the relatively distant HRM and innovation. Therefore, the research model used in this dissertation includes both job resources and employee attitudes to gain a better understanding of how high-involvement HRM is related to employees' IWB. We hypothesize that high-involvement HRM affects the more proximal outcomes of employees' commitment and autonomy, which in turn influence the more distant outcome of IWB.

\subsubsection{Challenge 4: The bottom-up emergence perspective of the HRM - innovation link is incomplete}

As we have seen, HRM innovations can stimulate innovative behaviour of employees. However, that does not automatically mean that the innovation performance of the organization will increase. In our research framework, innovation performance is the organization-level outcome, which we are attempting to explain by the individual-level innovative behaviours of employees. Researchers have already shown that HRM can contribute to innovation performance (Seeck \& Diehl, 2017), and therefore the next step is to turn attention towards the bottom-up emergence of innovation as a result of innovative behaviours. Recently, research has started to conceptualize and explore the emergence of innovation at the organizational-level based on employees' IWBs (Lin \& Sanders, 2017; Shipton, Sparrow, et al., 2017). The emergence of innovation depends on employees generating and sharing their ideas within organizations (Gong, Zhou, \& Chang, 2013). However, that ideas of creative 
employees are not necessarily implemented within the organization (Baer, 2012). This is in part because different phases of the innovation process reside on different organizational levels (Axtell, Holman, \& Wall, 2006). Whereas the first phases of innovation (i.e. creativity) are more related to the individual employee, the later phases of innovation (i.e. implementation) involve the unit and organizational levels (Shipton, Lin, Sanders, \& Yang, 2017). Consequently, it is logical to expect individual-level variables to be more strongly related to idea generation, while group- and organization-level variables are more related to idea implementation (Axtell et al., 2000). HRM policies and practices can play a role in establishing an organizational-level emergence-enabling structure (Fulmer \& Ostroff, 2016; Ployhart \& Moliterno, 2011). Thus, the research framework presupposes that employees' IWB leads to their organization's innovation performance and that HRM innovations can stimulate this bottom-up process. Unfortunately, the literature on HRM and innovation does not yet explain how individual-level innovative ideas develop into innovation at the organizational level. This offers valuable opportunities to expand our knowledge of how employees' innovative behaviours turn into innovation outcomes, and to explore the role of HRM in this process. 
Based on these challenges, I have developed a holistic framework that ties them together and can help in tackling the challenges in moving the HRM - innovation field forward. As such, the research framework in Figure 1.1 forms the conceptual basis for addressing the overall research question and the corresponding subquestions. This research framework is built on the model developed by Coleman (1990). The framework is used to explain our approach and integrate the four different challenges of this dissertation.

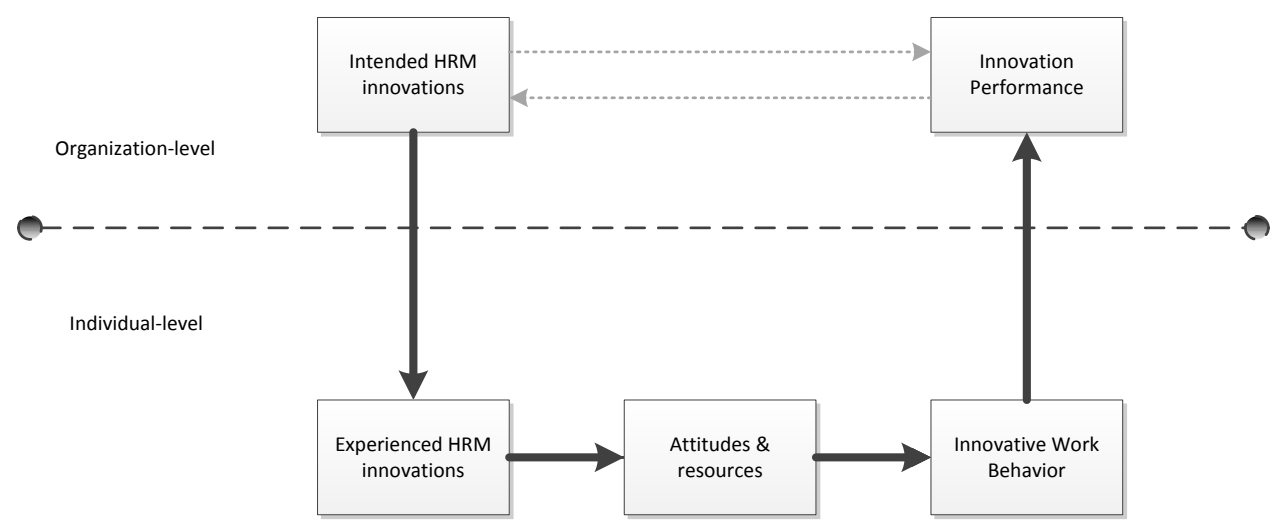

Figure 1.1. Research framework "Innovating HRM for Employee-Driven Innovation"

The figure shows two different organizational levels of analysis, which will be used to characterize the ways in which innovations in HRM lead to innovation performance outcomes. The macro-level in this research framework is the organizational level, while the micro-level refers to the individual employee level. The model illustrates the causal mechanism that link HRM and innovation performance outcomes. Innovation performance is the outcome variable, which I argue can be explained by the innovative work behaviours of individual-level employees. These innovative behaviours are a result of individual-level attitudes and resources, which are affected by employees' perceptions of HRM practices. How employees perceive and respond to HRM practices is influenced by the intended and implemented HRM innovations at the organizational level. Completing this relationship, we see that organizational innovation performance is affected by the HRM practices that they adopt, through their effect on individual employees. Hence, in line with Coleman's (1990) reasoning: the organization reflects the system-level that produces innovation outcomes, which should be explained by the behaviour of parts of the system - the employees within the organization. 


\subsection{Overview of research subprojects}

In this dissertation, I study how innovations in HRM affect employee-driven innovation from a multilevel perspective. Based on the research framework and the challenges identified in the previous section, this dissertation is focused on four main areas: (1) multilevel HRM research, (2) the organization of innovative HRM, (3) the effect of innovative HRM on employees' innovative behaviours and (4) the innovation emergence process (Table 1.1). In addressing these research themes, lessons from multilevel theory are adopted and applied. Through the following five studies, I address five specific research questions which, when integrated, answer the overall research question of this dissertation.

First, I consider what HRM research can learn from the principles of multilevel theory building to better understand the multilevel HRM - innovation relationship. Consequently, Study 1 draws on the principles of multilevel theory building developed by Kozlowski and Klein (2000) to investigate the application of the multilevel perspective in HRM research. In the past, HRM scholars have been more focused on single-level relationships. Recently, after several calls for more multilevel HRM research (Boselie, Dietz, \& Boon, 2005), there have been moves to develop HRM into a fully-fledged multilevel field (Jiang et al., 2013). In this study, we develop a multilevel framework that integrates three streams of strategic HRM research, which we label the 'multilevelity cube' of HRM. Further, since much of HRM research is built on cross-level relationships that examine how organization-level variables such as HRM policies affect individual-level outcomes such as employee attitudes and behaviours (Ostroff \& Bowen, 2000; Wright \& Boswell, 2002), we take stock of how the principles of multilevel theory building have been applied (Kozlowski \& Klein, 2000). Through a systematic literature review, we assess possibilities for future research and offer guidelines to further integrate multilevel thinking in HRM research. As such, this chapter provides a conceptual and theoretical underpinning of the four research problems addressed in this dissertation, and particularly supports the understanding of the multilevel HRM - innovation relationship (Challenge 1). This study addresses the following research question:

What can Human Resource Management research learn from the principles of multilevel theory building? 


\begin{tabular}{|c|c|c|c|c|}
\hline Study & Challenges & $\begin{array}{l}\text { Specific } \\
\text { research } \\
\text { question }\end{array}$ & $\begin{array}{l}\text { Key concepts \& } \\
\text { theory }\end{array}$ & Methods \\
\hline Chapter 2 & $\begin{array}{l}\text { The field of HRM } \\
\text { is lacking the } \\
\text { application of } \\
\text { multilevel thinking. }\end{array}$ & $\begin{array}{l}\text { What can HRM } \\
\text { research learn } \\
\text { from the } \\
\text { principles of } \\
\text { multilevel } \\
\text { theory building? }\end{array}$ & $\begin{array}{l}\text { Multilevelity Cube; } \\
\text { Principles of } \\
\text { multilevel theory } \\
\text { building }\end{array}$ & $\begin{array}{l}\text { Systematic } \\
\text { literature } \\
\text { review }\end{array}$ \\
\hline Chapter 3 & $\begin{array}{l}\text { How the HRM } \\
\text { function itself } \\
\text { changes when } \\
\text { implementing } \\
\text { HRM innovations } \\
\text { has not yet been } \\
\text { explored. }\end{array}$ & $\begin{array}{l}\text { What are the } \\
\text { most important } \\
\text { changes to the } \\
\text { HRM function } \\
\text { regarding its } \\
\text { actors and } \\
\text { activities when } \\
\text { implementing } \\
\text { self-managing } \\
\text { teams? }\end{array}$ & $\begin{array}{l}\text { HRM function; } \\
\text { Self-managing } \\
\text { teams; } \\
\text { Multilevelity cube; } \\
\text { HRM } \\
\text { implementation; } \\
\text { HRM process } \\
\text { model }\end{array}$ & $\begin{array}{l}\text { In-depth } \\
\text { single case } \\
\text { study of } \\
\text { self- } \\
\text { managing } \\
\text { teams in a } \\
\text { long-term } \\
\text { and elderly } \\
\text { care } \\
\text { organization }\end{array}$ \\
\hline Chapter 4 & $\begin{array}{l}\text { It is unclear how a } \\
\text { bundle of HRM } \\
\text { practices affect } \\
\text { IWB. To date, } \\
\text { research has not } \\
\text { addressed the } \\
\text { mediating } \\
\text { mechanisms of } \\
\text { autonomy and } \\
\text { affective } \\
\text { commitment. }\end{array}$ & $\begin{array}{l}\text { To what extent } \\
\text { do autonomy } \\
\text { and affective } \\
\text { commitment } \\
\text { mediate the } \\
\text { relationship } \\
\text { between high- } \\
\text { involvement } \\
\text { HRM and IWB? }\end{array}$ & $\begin{array}{l}\text { High-involvement } \\
\text { HRM; Innovative } \\
\text { work behaviour; } \\
\text { Autonomy; } \\
\text { Affective } \\
\text { commitment; } \\
\text { social exchange } \\
\text { theory; job } \\
\text { resources and } \\
\text { attitudes } \\
\text { perspectives }\end{array}$ & $\begin{array}{l}\text { Survey } \\
\text { study using } \\
\text { Structural } \\
\text { Equation } \\
\text { Modelling }\end{array}$ \\
\hline Chapter 5 & $\begin{array}{l}\text { Current research } \\
\text { lacks in-depth } \\
\text { knowledge of how } \\
\text { bottom-up } \\
\text { innovation works } \\
\text { and how it can be } \\
\text { facilitated by } \\
\text { HRM. }\end{array}$ & $\begin{array}{l}\text { How can HRM } \\
\text { contribute to the } \\
\text { bottom-up } \\
\text { emergence of } \\
\text { innovation in a } \\
\text { formalized } \\
\text { business } \\
\text { context? }\end{array}$ & $\begin{array}{l}\text { Bottom-up } \\
\text { emergence; } \\
\text { employee-driven } \\
\text { innovation; } \\
\text { formalization and } \\
\text { HRM; multilevel } \\
\text { theory building }\end{array}$ & $\begin{array}{l}\text { In-depth } \\
\text { single case } \\
\text { study: } \\
\text { employee- } \\
\text { driven } \\
\text { innovation } \\
\text { in a medical } \\
\text { laboratory }\end{array}$ \\
\hline$\underline{\text { Chapter } 6}$ & $\begin{array}{l}\text { Multilevel HRM } \\
\text { research is } \\
\text { underdeveloped in } \\
\text { terms of theory } \\
\text { development and } \\
\text { methodological } \\
\text { advances. }\end{array}$ & $\begin{array}{l}\text { What are the } \\
\text { most valuable } \\
\text { multilevel } \\
\text { research } \\
\text { directions, } \\
\text { theories and } \\
\text { methods for } \\
\text { advancing } \\
\text { multilevel } \\
\text { thinking in } \\
\text { HRM? }\end{array}$ & $\begin{array}{l}\text { Institutional } \\
\text { theory; } \\
\text { configuration } \\
\text { theory; } \\
\text { structuration } \\
\text { theory; process } \\
\text { methodology; } \\
\text { fsQCA; case } \\
\text { studies. }\end{array}$ & $\begin{array}{l}\text { Developing } \\
\text { a research } \\
\text { agenda }\end{array}$ \\
\hline
\end{tabular}

Table 1.1. Overview of research questions and approaches included in this dissertation. 
Second, one needs to understand how innovations change the HRM function to understand how implementing HRM innovations can affect employees' perceptions of HRM. For that reason, Study 2 investigates how the HRM function changes as a consequence of implementing an HRM innovation, in this case employee empowerment. More specifically, we examine how the HRM actors and activities change as a consequence of implementing self-managing teams. Organizations increasingly adopt empowered or self-managing teams (Maynard et al., 2012) in order to boost the innovativeness, adaptability and involvement of employees (Kirkman \& Rosen, 1999). Despite the considerable literature on the antecedents and effects of self-managing teams (e.g. Magpili \& Pazos, 2018; Seibert et al., 2011), there is a lack of understanding of what the implications are for the HRM function in organizations with self-managing teams. In this study, we seek to uncover how HRM activities change when organizations implement selfmanaging teams (Challenge 2). By applying the multilevelity cube of HRM developed in Chapter 2, we want to uncover how the HRM function changes. We also extend the HRM implementation literature (Bowen \& Ostroff, 2004; Wright \& Nishii, 2013) based on the idea that implementing HRM involves multiple HRM actors (Van Mierlo et al., 2018). The research question that I will answer in this study is the following:

What are the most important changes to the HRM function regarding its actors and activities when implementing self-managing teams?

Third, I aim to gain a better understanding of how HRM innovations lead to innovative work behaviour. Therefore, in Study 3, we examine how perceptions of a bundle of high-involvement HRM practices lead to IWB. Although existing studies have shown that HRM practices and systems can enhance innovation (Bos-Nehles, Renkema, et al., 2017; Seeck \& Diehl, 2017), we know little about the underlying mechanisms that explain these relationships. Here, we adopt an employee-centred approach (Wright \& Boswell, 2002) by focusing on the effect of employees' perceptions of HRM on their IWBs (Bowen \& Ostroff, 2004; Nishii et al., 2008). On the basis that it is crucial to understand how employees' perceptions lead to employee outcomes (Den Hartog, Boon, Verburg, \& Croon, 2013; Kehoe \& Wright, 2013; Takeuchi, Chen, \& Lepak, 2009), this study addresses two potential mediators, namely affective commitment and experienced autonomy, to uncover ways in which HRM can stimulate innovation. In doing so, we combine the attitudes perspective (e.g. Jiang et al., 2013; Paauwe \& Blok, 2015) with the job resources perspective (e.g. Boon \& Kalshoven, 2014; Peccei et al., 2013) to explain how HRM is translated into employee outcomes or in this case how an HRM innovation such as high-involvement HRM leads to 
innovative work behaviour. As such, Chapter 4 is concerned with the theoretical mechanisms underlying the HRM - IWB relationship and thereby primarily addresses Challenge 3. Hence, this study addresses the following research question:

To what extent do autonomy and affective commitment mediate the relationship between high-involvement HRM and IWB?

Fourth, I want to understand how innovative ideas eventually lead to innovation outcomes. To that end, Study 4 explores how innovative initiatives of work-floor employees are developed and implemented in the organization. We adopt the concept of employee-driven innovation (Høyrup, 2010; Kesting \& Ulhøi, 2010) to uncover and describe the ways in which employees' ideas lead to innovation outcomes. In this study, I research how employees who are not overtly required to be innovative (Montag et al., 2012) were engaged in innovative activities. This is an interesting avenue since HRM and innovation research has largely focused on innovation where it is to be expected, for example in an R\&D setting. However, in many contexts, innovative behaviours are not overtly required (Montag et al., 2012), which necessitates a different set of HRM practices (Shipton, Lin, et al., 2017). Therefore, this study is conducted in a formalized context, one where innovation is particularly difficult for work-floor employees to achieve.

This study conceptualizes employee-driven innovation as a multilevel bottom-up process and adopts ideas from multilevel thinking (Kozlowski \& Klein, 2000). Previous research has already conceptualized and shown that idea generation and idea implementation occur on different organizational levels (Shipton, Lin, et al., 2017), each with different antecedents (Axtell et al., 2000). While organizational practices and structure have been shown to be able to contribute to the bottom-up emergence of innovation (Fulmer \& Ostroff, 2016; Ployhart \& Moliterno, 2011), there has been no attention to the role of HRM as a potential emergence-enabling factor. In this study, we therefore seek to reveal EDI emergence, and the role that HRM plays in it (Challenge 4). This study thus aims to answer the following question:

How can Human Resource Management contribute to the bottom-up emergence of innovation in a formalized business context?

Fifth, I think the development of multilevel thinking would benefit from discussing avenues for future research and discussing theories and methods that are valuable for scholars wanting to adopt a multilevel perspective. Multilevel HRM research involves integrating constructs from different organizational levels, and 
is based on the idea that organization-level HRM practices influence performance through individual-level attitudes and behaviours (Ostroff \& Bowen, 2000; Wright \& Boswell, 2002). This means that HRM research is inherently multilevel and should therefore draw its core assumptions from multilevel theory (Kozlowski \& Klein, 2000). Despite this, the HRM field has been a late adopter of the multilevel perspective compared to other fields (Molloy, Ployhart, \& Wright, 2011). Furthermore, existing studies have mainly focused on top-down effects. The few exceptions that have examined bottom-up relationships have been limited by only using composition models which assume that phenomena are unchanged on higher organizational levels (Aryee et al., 2012; Nishii et al., 2008). Therefore, Study 5 discusses current challenges to the multilevel perspective in HRM research: namely, the failure to apply the principles of multilevel theory building, appropriate statistical methods and techniques, and theories that could help to explain cross-level relationships. As such, Chapter 6 integrates the previous four challenges by offering theoretical and practical guidance for conducting multilevel HRM research. As such, the following question is addressed:

What are the most valuable multilevel research directions, theories and methods for advancing multilevel thinking in HRM? 


\subsection{Research approach and philosophical positioning}

In terms of the philosophy of science, the research design of this dissertation can be positioned in the stream of critical realism. In line with the goal of critical realism, the goal of this study is to develop deeper levels of explanation and understanding, not to identify the experiences and beliefs of social actors (as in interpretivism) or to identify generalizable laws (as in positivism) (McEvoy \& Richards, 2006). Thereby, this doctoral work starts from the assumption that an entity can exist independent of our knowledge of it (Fleetwood, 2005). There is a real world, including a social world that exists independently of our knowledge (Bhaskar, 2009; Sayer, 2000). Critical realists differentiate between multiple ontological modes of reality. An entity is said to be real if it has an effect on behaviour (Fleetwood, 2005). Reality has three domains: the empirical, the actual and the real (Bhaskar, 2013; McEvoy \& Richards, 2006). The empirical refers to those aspects of reality that can be experienced, the actual involves those aspects that exist but are not necessarily experienced, and the real refers to structures and enduring mechanisms that generate phenomena (McEvoy \& Richards, 2006). In the context of this study, organizational phenomena, such as innovative employees, can be empirically observed, and this helps in capturing the underlying structures and mechanisms that generate these organizational phenomena.

Furthermore, based on the idea that employees develop perceptions of HRM and experience HRM policies and practices that influence their innovativeness, I study the influence of HRM policies and practices on employees. According to critical realism, employees' perceptions of HRM are 'real' because they have the power to cause events or, in this case, to affect employees' attitudes and behaviours. The critical realist perspective can help to uncover underlying mechanisms in the relationship between HRM and innovation because explaining this relationship depends on identifying causal mechanisms and describing how they work, and under what conditions (Sayer, 2000). Further, the critical realist perspective fits very well with a multilevel perspective because, according to critical realists, the social world consists of human agents and social structures in which human agents are embedded (Hesketh \& Fleetwood, 2006). Explaining why a certain mechanism exists involves discovering the nature of the structure or object that influences the mechanism (Sayer, 2000). Consequently, the innovative behaviours of employees depend on the HRM policies that here function as a structure.

As a researcher, you can only capture parts of the real, mind-independent world - and prior experiences and theoretical knowledge influence the ways in which you see this world. Thus, critical realism involves a subjective view on 
epistemology: there is no single best way to study certain phenomena. Given that this approach involves the creation of knowledge that best approximates the mind-independent or 'real' world (abductive reasoning), I adopt various qualitative and quantitative methodologies and techniques to study EDIs and increase understanding of the mechanisms that generate EDIs. The adopted mixedmethodology is appropriate given the challenges addressed in this dissertation. The qualitative methods that I apply (i.e. case studies) are appropriate for exploring understudied cross-level HRM relationships and for identifying and conceptualizing EDI, while the quantitative methods (i.e. surveys) fit better when studying underlying causal mechanisms in the HRM - EDI relationship.

\subsubsection{Methodologies}

The critical realism philosophy of science argues that the choice of methods should follow from the nature of a research problem, allowing both qualitative and quantitative methods (McEvoy \& Richards, 2006). These methods can be broadly divided into so-called intensive and extensive research designs (Sayer, 2000). An intensive design involves searching for what makes things happen, whereas the extensive design aims to uncover certain patterns in a population (Sayer, 2000). As such, an intensive design is more suitable for studying questions as to how a process works in a few cases, while an extensive approach can answer questions dealing with finding regularities and common patterns on a wider scale.

In two of the studies (Chapter 3 and Chapter 5), I conducted case studies of different employee groups embedded in the organizational context, an intensive approach suited to better understanding how innovation processes work. The case study approach fits the research goal of this dissertation because it enables one to observe the processes of HRM and EDI in their natural organizational context (Yin, 2014). These case studies helped to identify and uncover in-depth processes within organizations that help in advancing explanatory knowledge about HRM and innovation. These two case studies provide a rich empirical description of innovative HRM policies and EDI in the organizational context. Further, they are particularly useful for identifying underexplored research domains, an aim of this dissertation.

In one study (Chapter 4), I statistically analysed the relationship between high-involvement HRM and employees' innovative work behaviour based on a survey research approach with 567 respondents. Although statistics are not a natural part of the critical realist approach to establishing causal explanations, the use of statistics is helpful in uncovering new causal mechanisms (McEvoy \& Richards, 2006). 


\subsubsection{Multilevel research}

The relationships in this dissertation's research framework (Figure 1.1) manifest themselves on different organizational levels. Therefore, I adopt a multilevel perspective and apply the principles of multilevel theory building to the field of HRM research. First, in a qualitative way, by studying how the multilevelity cube developed in Chapter 2 can help understand changes to the HRM function and the implications for multilevel HRM implementation. Second, addressing the bottom-up emergence of innovation through a qualitative case study allows me to explore the process of EDI in its natural context, thereby identifying and combining drivers on multiple organizational levels. The initial intention was to include another chapter testing multilevel relationships but it has proved impossible to collect sufficient data to perform a multilevel analysis in this research. Multilevel analyses are used to avoid incorrect estimates and incorrect standard errors when data have a hierarchical structure (Snijders \& Bosker, 1999). For multilevel research, the rule of thumb is to have at least 30 level-2 units (i.e. working-units) and 30 level-1 units (i.e. individual employees that show innovative behaviour) (Kreft, 1996). Others suggest having even more level-2 units to test cross-level effects: simulation models show that at least 50 level-2 units are needed to provide accurate standard errors and to test cross-level interactions (Hox, 1998; Maas \& Hox, 2005). Unfortunately, our sample contained insufficient organizations, and there were not enough respondents per team or business unit. For this reason, we could not statistically uncover the dynamics and underlying processes of the multilevel relationships in our research framework. Although multilevel relationships are not tested using quantitative analysis, one of the studies in this thesis (Chapter 4) includes a statistical analysis of the HRM - IWB relationship. Fortunately, this individual-level quantitative analysis provides sufficient insights into how HRM leads to IWB, and the underlying mechanisms that link these two concepts, thereby achieving the goal of this research. 


\subsection{Outline of dissertation}

This dissertation is paper-based and includes five scientific papers, published in either a peer-reviewed international journal, the proceedings of an international conference or representing work-in-progress as submitted to an international journal. The five papers are presented as five chapters and are followed by a final chapter that includes a general discussion pulling the findings together. The papers are presented in their original form, with some minor alterations in layout and numbering. Figure 1.2 presents a visual outline of the seven chapters and how they interrelate.

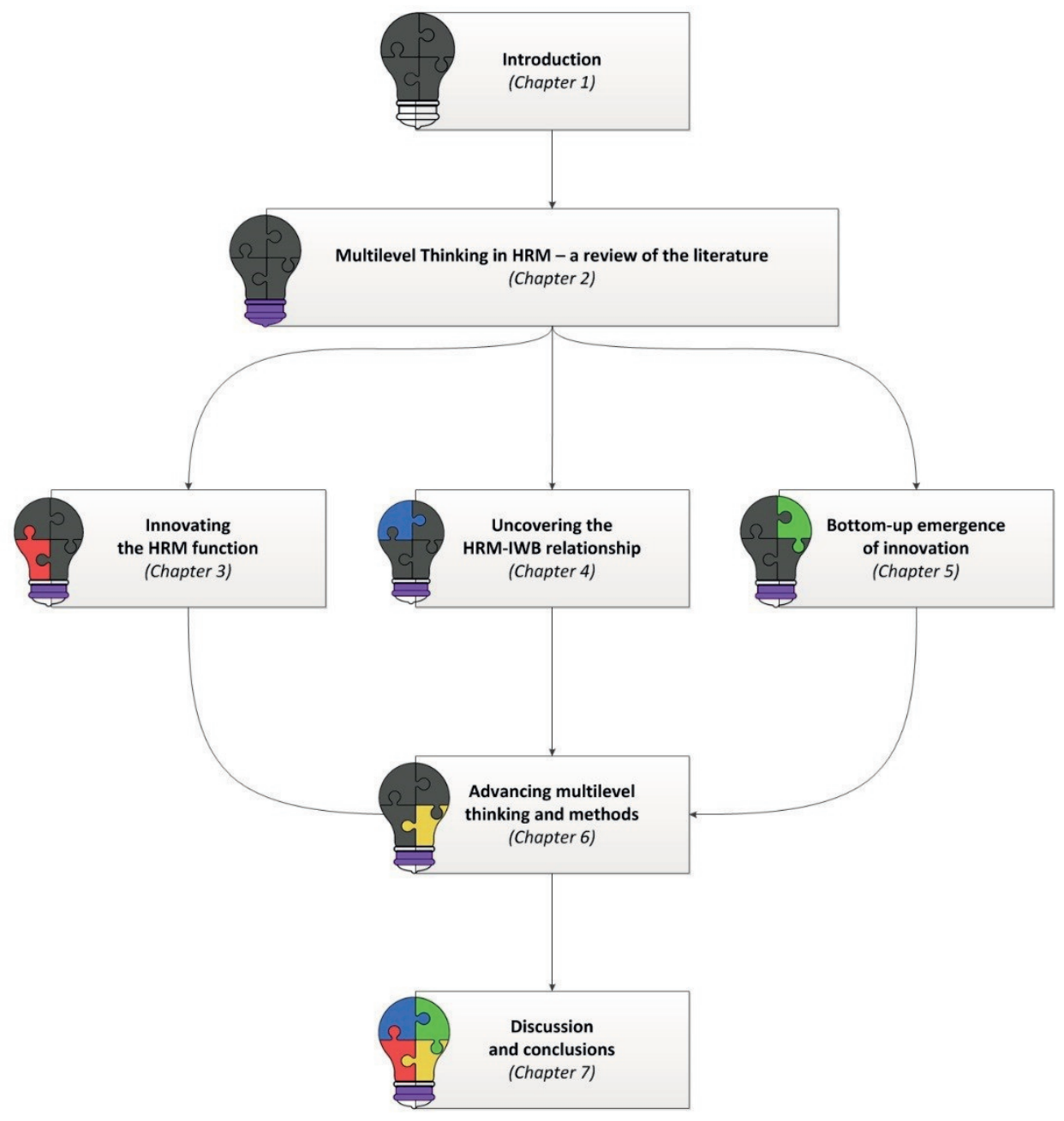

Figure 1.2. Outline of the dissertation 
In this chapter, Chapter 1, I have explained my motivation, the challenges that have been addressed and the research design. In Chapter 2, I present the systematic literature review of multilevel thinking in HRM research. Following this, Chapters 3 to 5 present the three empirical studies. In line with the challenges outlined in this introduction, I report respectively on research into how HRM innovations change the HRM function, the underlying mechanisms in the HRM IWB relationship, and the bottom-up process of EDI and the role of HRM as facilitator. In Chapter 6, I present directions for further development of multilevel thinking in HRM research, by discussing novel research avenues, theories and methods. Chapter 7, the final chapter, answers the overall research question, discusses the contributions of this dissertation to theory and practice, discusses the most important limitations and offers directions for future research.

\subsection{References}

References can be found on page 209 . 



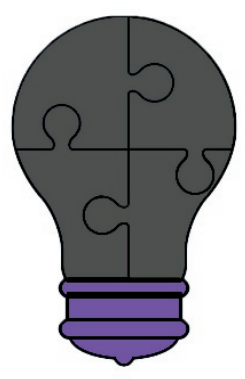

\title{
CHAPTER 2
}

\section{Advancing Multilevel Thinking in Human Resource Management Research: Applications and Guidelines}

\author{
"If I wanted you to understand, I would have \\ explained it better"
}

(Johan Cruijff)

This chapter is published as Renkema, M., Meijerink, J., \& Bondarouk, T. (2017). Advancing Multilevel Thinking in Human Resource Management: Applications and Guidelines. Human Resource Management Review, 27(3): 397-415. DOI: http://dx.doi.org/10.1016/j.hrmr.2017.03.001

A preliminary version of this paper was presented at the Presented at the 76th Annual Meeting of the Academy of Management, 5-9 August 2016, Anaheim (CA), United States, and at the $9^{\text {th }}$ Biannual International Conference of the Dutch HRM Network, Utrecht, Netherlands. 


\section{Abstract}

Strategic Human Resource Management (SHRM) researchers have recently turned their attention to using various levels of analysis in examining the relationship between HRM and performance. Despite several calls for research that integrates multiple levels of analysis, HRM research has yet to apply a multilevel approach to its full advantage. In our view, the paucity of multilevel research is rooted in the lack of what we label multilevel thinking: the application of multilevel principles. In this conceptual paper, we develop 9 guidelines based on tailored multilevel HRM principles that offer a course of action for scholars who are interested in conducting multilevel HRM research. Following Kozlowski and Klein (2000), we build these principles around the what, how, where, when, and why questions in multilevel HRM research. Based on an analysis of 88 empirical multilevel HRM studies, we identify the approaches commonly applied when using multilevel principles, explain the weaknesses in current multilevel HRM studies, and offer what we consider good examples of a rigorous approach.

\subsection{Introduction}

Motivated by the evidence that human resource management (HRM) can have a positive effect on firm performance (Combs, Liu, Hall, \& Ketchen, 2006; Jiang et al., 2012), strategic HRM researchers have recently turned their attention to the various levels at which this interaction occurs. In the past, HRM scholars tended to focus on single-level effects, among others, on the effect of organizational HRM policies on organizational-level performance. There have been regular calls for multilevel HRM research (e.g. Boselie et al., 2005; Kepes \& Delery, 2007; Wright \& Boswell, 2002), and an increasing number of studies have examined HRM-performance relationships across various levels of analysis (Jiang et al., 2013). Integrating levels of analysis, so-called multilevel research, grew out of two ideas. First, organizational HRM policies influence organization-level performance by affecting lower-level variables such as individual-level attitudes and behaviors (Ostroff \& Bowen, 2000; Paauwe, 2009; Wright \& Boswell, 2002). Second, these cross-level relationships reflect the reality that Strategic HRM (SHRM) is inherently multilevel and, consequently, that its assumptions are built upon multilevel theory (Kozlowski \& Klein, 2000; Ostroff \& Bowen, 2000).

Examining cross-level effects is important for at least two reasons. First, models that integrate multiple levels of analysis are able to explain how lowerlevel entities, such as employees, become aligned with higher-level entities such as organizational goals (Wright \& Boswell, 2002). Second, due to the hierarchical nature of organizations, the majority of problems encountered by managers are anything but single level in nature. Since managerial problems are rooted in 
causes that reside on various levels, a multilevel perspective can offer a nuanced view that is closer to the organizational HRM reality. By building on a multilevel perspective, HRM studies have shown that organization-level HRM practices have a positive, top-down effect on individual-level outcomes (Aryee et al., 2012; Bal, Kooij, \& De Jong, 2013; Liao et al., 2009; Takeuchi et al., 2009), and that individual employees' traits, attitudes, and behaviors can be aggregated to higher hierarchical organizational levels thereby having a bottom-up effect on organizational-level outcomes such as organizational innovation, service quality, and financial performance (Aryee et al., 2012; Den Hartog et al., 2013; Nishii et al., 2008). Notwithstanding the attention given to both these top-down and bottom-up effects, multilevel HRM research has yet to achieve conceptual and empirical maturity (Molloy et al., 2011; Shen, 2016). More specifically, this paper argues that the majority of multilevel HRM studies have only limitedly applied conceptual insights from multilevel theory. This caveat regarding multilevel HRM research is rooted in the deficiency in what we term multilevel thinking, or the application of multilevel principles (Costa et al., 2013). These principles were introduced by Kozlowski and Klein (2000) and represent the fundamental processes to be addressed in developing multilevel theory. These principles can aid researchers in specifying the what, how, where, when, and why constructs and relationships that occur across various levels. So far, as we will show in this paper, multilevel HRM studies have either overlooked some of these principles or applied them in a somewhat implicit or arbitrary manner.

Further attention to multilevel thinking in HRM research is necessary because, ultimately, applying multilevel principles will enable the development of better, contextualized, and nuanced explanations of how HRM and performance are related across various levels of analysis. To advance multilevel thinking in strategic HRM research, we have developed a set of guidelines based on multilevel principles that explain the what, how, where, when, and why of multilevel relationships between HRM and performance. In so doing, we contribute to the field by outlining a research agenda to inform future multilevel HRM research and which, once addressed, will improve our understanding of the multilevel nature of HRM-outcome relationships. Furthermore, we contribute to multilevel research, which has traditionally applied the multilevel principles for examining relationships across hierarchically ordered entities (e.g. industries, organizations, units, and employees), by showing that principles of multilevel theory building can be applied to types of nested structures that traditional multilevel research has overlooked.

The paper is structured as follows: we begin with an introduction to multilevel theory and its evolution in HRM research. This is followed by a structured literature review of the application of multilevel principles in existing 
HRM research. Based on the analysis of 88 empirical multilevel HRM studies, we identify approaches commonly applied when using multilevel principles in HRM research, explain the weaknesses in current studies, offer what we consider good examples of a vigorous approach, and propose guidelines for advancing multilevel HRM research.

\subsection{The Evolution of Multilevel SHRM Research}

Central to multilevel thinking is the proposition that organizational entities exist in so-called nested arrangements (Hitt et al., 2007). Although such entities generally refer to units that consist of hierarchically ordered individuals - such as employees nested in a team, teams nested in an organization, and organizations nested in an industry - they can also refer to components of systems that are hierarchically arranged. Although not using the term 'multilevel', one of the earliest streams of strategic HRM research that examined such nested entities addressed HRM systems (Becker \& Gerhart, 1996; Schuler, 1992). We elaborate on three crucial directions that have been taken in the past two decades and that, in our view, have assembled building blocks for multilevel research in HRM.

Back in the early 1990s, Schuler (1992) was one of the first to argue that HRM systems consist of at least three hierarchically ordered components: HR philosophies, policies, and practices. An HR philosophy amounts to "a statement of how the organization regards its human resources, what role the resources play in the overall success of the business, and how they are to be treated and managed" (Schuler, 1992, p. 21). They can be seen as guiding principles that are fundamental to the choice of HR policies and practices, and indicate how workers contribute to organizational goals (Arthur \& Boyles, 2007; Becker \& Gerhart, 1996). The HR philosophy provides guidelines for the development of HR policies that should help realize the HR philosophy (Kepes \& Delery, 2007). HR policies describe objectives for managing human resources and outline the relative emphasis that an organization places on HR choices. As such, HR policies reflect what organizations want to achieve rather than how to achieve people-related business objectives (Kepes \& Delery, 2007; Schuler, 1992). While HR philosophies represent the values, beliefs, and norms about how success can be achieved through employees (Arthur \& Boyles, 2007), HR policies are specific objectives for realizing employee performance. For example, Schuler (1992) referred to the need to hire skilled workers or to appraise workers as examples of HR policies. Ultimately, the HR policies should be translated into HR practices, which are the specific instruments that are used to manage employees' abilities, motivations, and opportunities to perform (Jiang et al., 2012). As such, 
researchers have already recognized that the HRM system, as a construct, is multilevel in nature, consisting of different levels of abstraction with HRM practices being nested in HRM policies which are nested in HRM philosophies (Arthur \& Boyles, 2007).

A decade later, the seminal book chapter by Ostroff and Bowen (2000) integrated different levels of analysis in conceptualizing the multilevel relationships between HRM systems and performance. They argued that organization-level HRM systems affect organizational performance by creating organizational and psychological climates. Since these climates reside at (i.e. are a feature of) the organization and individual levels respectively, Ostroff and Bowen (2000) showed that, conceptually, HRM systems, company performance, and the relationships between them can manifest themselves at least at two organizational levels of analysis. That is, organization-level HRM practices create a psychological climate at the employee level in terms of the employee's perceptions of what behavior is expected, which in turn can also manifest itself as an organizational climate at the organization-level once all employees in the organization share the expected behaviors. Hence, to investigate the relationship between HRM and performance, Ostroff and Bowen (2000) argued that research should include constructs that exist at both the organization and employee levels. Later, other researchers added further levels at which the HRM - performance relationship manifests itself, such as the team level (Jiang et al., 2013) and the department level (Liao et al., 2009). Thus, the second crucial step in multilevel HRM research highlighted that the relationships between HRM and performance exist at various levels that can be coarsely classified as the individual, the unit, and the organization (Banks \& Kepes, 2015; Jiang et al., 2013).

The third key step we identify was the proposal of a multilevel model consisting of "a rudimentary process that must take place in order for HRM practices to impact organizational performance" (p. 8). (Wright and Nishii (2007). This so-called HRM process model consists of intended, actual, and perceived HRM practices, and focuses on how HRM systems lead to performance. Intended HRM practices are seen as being rationally designed during HR strategy development in order to realize desired employee behaviors. However, HRM practices are not always fully implemented in line with the original intentions. This leads to the second level of HRM implementation: the realization of the intended HRM practices, termed the actual HRM practices (Wright \& Nishii, 2007). Variations may occur at the level of the actual HRM practices because the intended practices are usually implemented by many people within an organization, including front-line managers (e.g. Nehles, van Riemsdijk, Kok, \& Looise, 2006) and employees themselves (Meijerink, Bondarouk, \& Lepak, 2016). Ultimately, the HRM practices exist objectively, but some have to be 
experienced and understood by the employees if they are to affect employee behaviors, highlighting the relevance of the variation in individual experiences (Wright \& Nishii, 2007). At the same time, some HR activities need not be experienced by employees to achieve the intended results. For example, employee selection tests or procedures affect the human capital of an organization and thereby influence employee-related outcomes (e.g. customer satisfaction), without having to work through employees' perceptions (Liao et al., 2009) ${ }^{2}$. Nevertheless, the third crucial direction in multilevel HRM research has been the recognition that the process of HRM implementation does not always achieve the intended results because of variations at various levels in the internalization process (i.e. the intended, introduced, and experienced HRM activity levels).

On the basis of these developments in strategic HRM research, we argue that the multilevel nature of HRM research reflects an amalgam of complex relationships among three multilevel HRM dimensions: system abstraction levels, hierarchical organizational levels, and HRM internalization levels. Figure 2.1 integrates these three dimensions into a concept that we call the Multilevelity Cube of Strategic HRM research. First, the system abstraction dimension involves the multilevelity of the HRM construct itself, covering the various levels of the HRM system components. Second, the hierarchical levels dimension concerns the integration of multiple organizational levels in the analysis of HRM relationships, and addresses the influence of HRM system components on outcomes across different levels of analysis in the organizational hierarchy. Third, the internalization dimension addresses the multilevelity associated with the implementation of HRM activities, and distinguishes between how HRM practices are intended, how they are actually applied, and how they are perceived and routinized by targeted employees.

In combination, these three dimensions reflect the various aspects and complexity of contemporary multilevel HRM research and highlight the importance of covering these dimensions when adopting a multilevel perspective. Current multilevel HRM studies illustrate how these intersections are studied. For example, Nishii et al. (2008) studied HRM attributions in the form of employeelevel HRM constructs that describe experienced HRM philosophies. Further, Liao et al. (2009) examined the intersections of introduced and experienced HRM practices on the unit and employee levels respectively, while Whitener (2001) focused on introduced HRM practices at the organizational level. Notwithstanding these examples, the Multilevelity Cube highlights that there are a large number of possible combinations and research scenarios, such that it is not feasible to

\footnotetext{
${ }^{2}$ We would like to thank the anonymous reviewer for this remark.
} 
integrate them all in a single study. Therefore, in this paper, we elaborate on specific guidelines, derived from the multilevel principles, that could form the basis for individual studies to further advance multilevel HRM research.

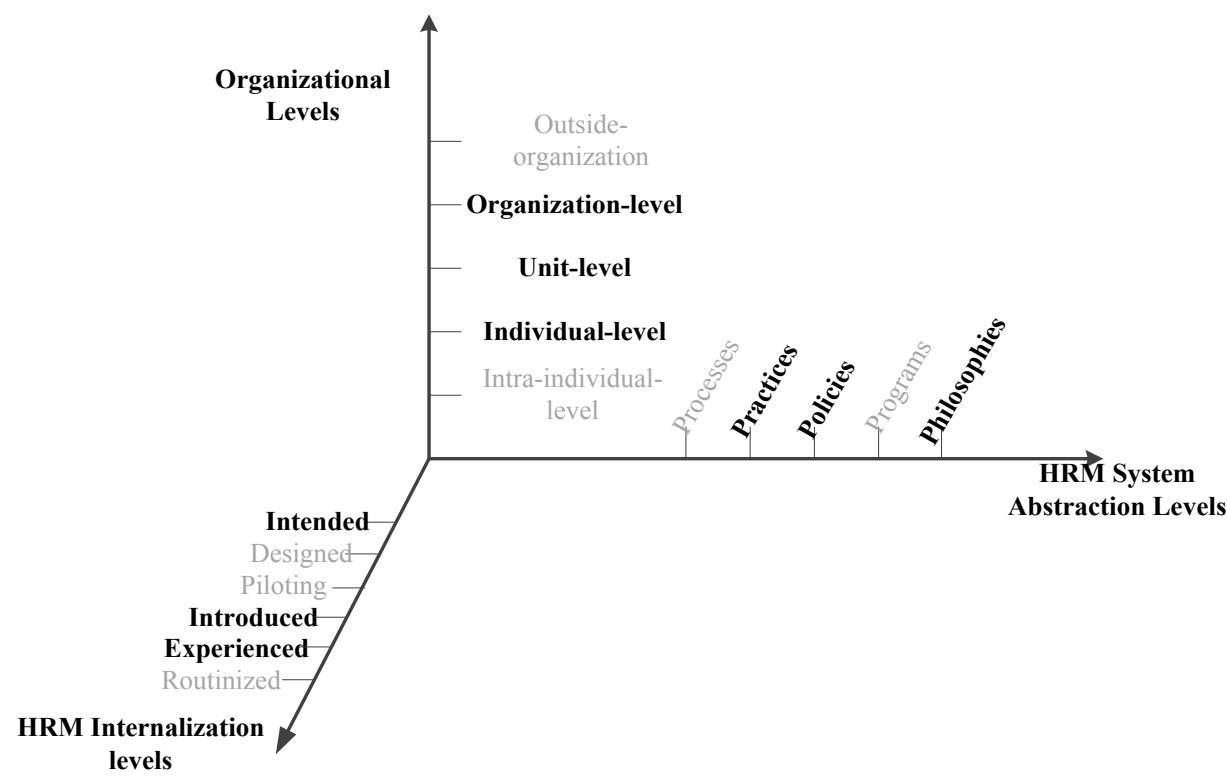

Figure 2.1. The multidimensional "Multilevelity Cube" of SHRM research

\subsection{Principles for Multilevel Research}

The principles of multilevel theory building constitute the fundamental theoretical building blocks that underpin the development of multilevel theory (Kozlowski \& Klein, 2000). Some claim that, compared to others, the approach of Kozlowski and Klein (2000) is thorough in that it includes an overarching theory-building process that integrates existing work (Upton \& Egan, 2010). Therefore, in this paper, their principles are discussed in relation to existing multilevel HRM research. The primary goal of multilevel thinking is to "... identify principles that enable a more integrated understanding of phenomena that unfold across levels in organizations" (Kozlowski \& Klein, 2000, p. 7). One of the fundamental underpinnings of multilevel theory is that phenomena at the micro-level of the organization are embedded in macro-contexts, and that macro-phenomena will emerge through the interaction and dynamics of micro-level features. The argument for embeddedness is based on the view that an individual's behavior is constrained by social relationships and, for that reason, should not be seen as independent from its social context (Granovetter, 1985). The key assumption of 
the multilevel approach is that various phenomena can only be explained by combining factors at different levels of analysis (House, Rousseau, \& ThomasHunt, 1995; Rousseau, 1985). On this basis, macro- and micro-level research need to be integrated to understand how organizations function.

We borrow five sets of principles from Kozlowski and Klein (2000) that can assist researchers in developing multilevel theoretical models. These principles address the what, how, where, when, and why of multilevel effects, but are not simple rules that researchers can follow because they require elaboration regarding the content of multilevel models. Rather, they should be seen as fundamental building blocks for developing multilevel models. Based on these principles, we have developed a non-exhaustive set of guidelines for multilevel HRM research. As such, these multilevel principles can steer researchers when conducting multilevel HRM research. To identify future research avenues that would advance multilevel HRM research, we conducted a review of the multilevel HRM literature to assess which multilevel principles have (or not yet) been applied, and how, in existing multilevel HRM studies.

\subsection{Selection and review of multilevel HRM studies}

To analyze key trends in multilevel HRM research and thereby uncover the current application of multilevel principles in HRM we followed a systematic literature review approach (Cropanzano, 2009; Short, 2009). We searched for relevant multilevel HRM studies in the Scopus and ISI Web of Knowledge databases. These two databases were selected for two reasons: they are among the most comprehensive databases of peer-reviewed journals in social sciences and, at the same time, neither includes all the potentially relevant academic journals (Falagas, Pitsouni, Malietzis, \& Pappas, 2008).

In line with the three dimensions of our Multilevelity Cube, we adopted three sets of search terms and thus conducted three rounds of literature searching to avoid excluding HRM studies that did not explicitly state they were multilevel. During each round, studies were identified for further analysis when they were published in a peer-reviewed journal, published in English, were empirical, and were multilevel along at least one of our three multilevelity cube dimensions. More specifically, a study was included when it empirically examined a multilevel model or tested hypotheses with HRM and its outcomes conceptualized at different organizational levels, and/or studied at least two HRM abstraction levels, and/or examined at least two HRM internalization levels. To minimize the risk of excluding relevant articles and boost the reliability of the results, two authors independently assessed whether each study should be included. The intercoder reliability was $92 \%$ and, after discussion, there was full 
agreement over which articles to include. In Appendix A we discuss the search process in each of the three rounds and the number of studies included in our review. In the end, our literature search yielded 88 original multilevel HRM articles.

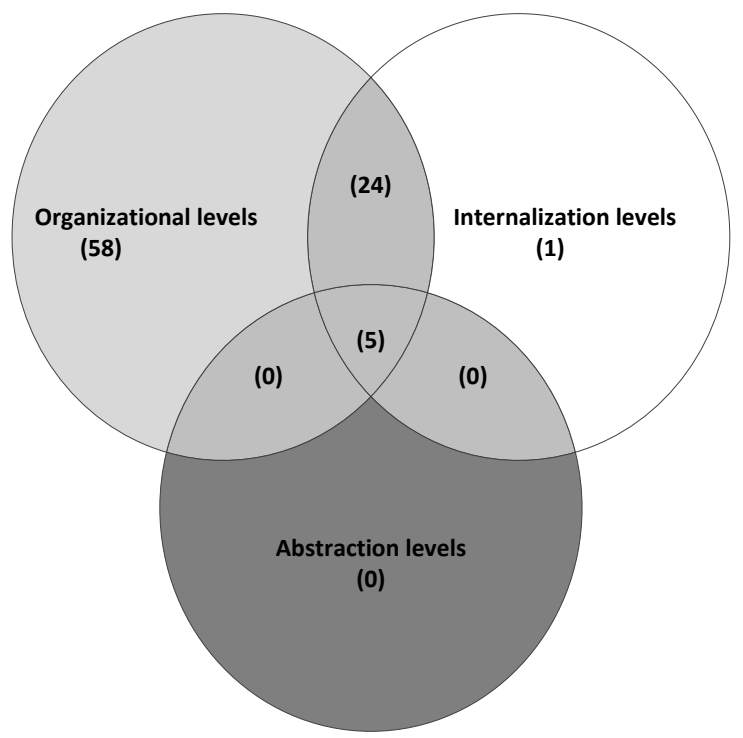

Figure 2.2. Venn Diagram of The Studies that Incorporate Multilevelity Dimensions

\subsection{The Multilevelity Cube of HRM in Practice}

Reflecting the ideas behind the multilevelity cube, a single HRM study could incorporate multiple levels of analysis along two or even three multilevel dimensions. To see whether that was happening, we identified those studies in our sample that studied cross-level relationships along multiple multilevel dimensions (see Figure 2.2). As can be seen in Figure 2.2, we identified 30 such studies, of which 29 examined multiple internalization levels alongside multiple hierarchical levels. A reason for this overlap predominating can be identified in Table 2.1: most of the publications studied experienced/perceived HRM perceptions on the employee level while introduced/actual HRM was conceptualized at the unit level. This suggests that the internalization dimension is often equated to the organizational-hierarchical dimension. As a consequence, there are, for example, no studies that have examined the degree to which HRM is intended or introduced to individual employees. This is remarkable given that other streams of research into idiosyncratic deals and job crafting argue that 
individual employees differ in the degree to which they actually receive HRM policies/practices (e.g. Rousseau, Ho, \& Greenberg, 2006). Furthermore, Figure 2.2 indicates that all the studies into multilevel relationships among HRM philosophies, policies, and practices (i.e. abstraction dimensions) also incorporate multiple hierarchical and internalization levels of analysis. As can be seen in Table 2.1, the majority of these studies examined HRM practices (or bundles thereof) in relation to HRM policies, and that HRM philosophies are largely overlooked. HRM practices are studied at all levels (organization, unit, and individual employee) of analysis, indicating that the abstraction and hierarchical levels are not equated and thus treated as conceptually different in existing HRM studies.

\begin{tabular}{|c|c|c|c|c|c|c|c|c|c|c|}
\hline & & \multicolumn{9}{|c|}{ Internalization levels } \\
\hline & & \multicolumn{3}{|c|}{ Intended HRM } & \multicolumn{3}{|c|}{ Introduced HRM } & \multicolumn{3}{|c|}{ Experienced HRM } \\
\hline & $\frac{\text { Abstraction }}{\text { levels }}$ & $\begin{array}{c}\text { Philos } \\
\text { ophie } \\
\text { s } \\
\end{array}$ & $\begin{array}{l}\text { Polici } \\
\text { es }\end{array}$ & $\begin{array}{l}\text { Practi } \\
\text { ces }\end{array}$ & $\begin{array}{c}\text { Philos } \\
\text { ophie } \\
\text { s } \\
\end{array}$ & $\begin{array}{l}\text { Polici } \\
\text { es }\end{array}$ & $\begin{array}{l}\text { Practi } \\
\text { ces }\end{array}$ & $\begin{array}{c}\text { Philos } \\
\text { ophie } \\
\mathrm{s} \\
\end{array}$ & $\begin{array}{l}\text { Polici } \\
\text { es }\end{array}$ & $\begin{array}{l}\text { Practi } \\
\text { ces }\end{array}$ \\
\hline \multirow{3}{*}{ 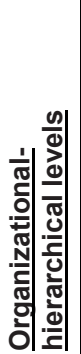 } & $\begin{array}{l}\text { Organization- } \\
\text { level }\end{array}$ & 2 & 3 & 12 & 1 & 2 & 20 & 1 & 1 & 11 \\
\hline & Unit-level & 0 & 0 & 0 & 0 & 1 & 33 & 0 & 0 & 6 \\
\hline & $\begin{array}{l}\text { Individual- } \\
\text { level }\end{array}$ & 0 & 0 & 0 & 0 & 0 & 0 & 1 & 0 & 28 \\
\hline
\end{tabular}

Table 2.1. Multilevelity Dimensions of Multilevel HRM studies ${ }^{3}$

\subsection{Application of Principles in Multilevel HRM Research}

We first briefly discuss each principle before presenting findings related to the application of the principles in the studies included in our sample. Finally, based on these findings, and examples from both within and beyond the sample, we offer guidelines for future multilevel HRM research. We have analyzed studies that explicitly included at least two organizational levels since the principles were developed for research that included relationships across different hierarchicalorganizational levels. Where possible, we also reflect upon the application of the principles on the internalization and abstraction levels.

3 The number of studies reported exceeds our sample size of 88 since some studies include multiple levels of analysis. 


\subsubsection{The WHAT of Multilevel HRM Research}

The WHAT principle concerns the level at which the focal phenomenon manifests itself (Kozlowski \& Klein, 2000). Researchers who use multilevel thinking should start by defining and justifying the level at which the main constructs are placed in their theoretical model (Kozlowski \& Klein, 2000). In general, a dependent construct is both embedded in higher-level contextual settings as well as emerging from lower-level constructs because of the nested arrangements in which most organizational entities exist (Hitt et al., 2007). As discussed by Reynolds Fisher (2000), a multilevel theory need not include every level of a hierarchical system, but it should at least take into account the effects on the dependent variable of independent variables that are a level higher or a level lower.

\subsubsection{Current Application and Key Findings related to the WHAT Principle in HRM Research}

In the HRM studies in our review, dependent constructs were positioned at the individual, team, work-unit, department, and organization levels. The most frequent level at which the dependent constructs were analyzed is the individual employee level (78\%), followed by the unit level (18\%), and the organization level $(15 \%)^{4}$. In $48 \%$ of the articles, HRM was studied at the organization level, followed by $45 \%$ and $29 \%$ at the unit and individual levels respectively. Fifteen papers studied HRM at both the unit and the individual levels, with the explicit goal of determining whether employees' perceptions of HRM differ from the HRM introduced at the unit level. Most of the multilevel HRM-outcome relationships studied are at the lower hierarchical levels. All but four of the papers included in our review studied no more than two nested hierarchical levels and therefore only looked up or down, not both. Although some conceptual models have integrated multiple levels of analysis (Farr \& Tran, 2008; Jiang et al., 2013), the majority of the empirical papers adopted a perspective that included only the individual level and one higher level (predominantly the unit level). A notable exception is the article by Chang, Jia, Takeuchi, and Cai (2014) who examined a three-level topdown model in which team-level constructs moderate the effect of an organization-level HR system on individual-level creativity. Hong, Liao, Raub, and Han (2016) also examined a three-level model, including the establishment, department, and individual levels, to explain personal initiative. In the sample identified through the internalization dimension, there are more studies that examine the multilevel links between intended, actual, and perceived HRM (e.g.

\footnotetext{
${ }^{4}$ The sum of these percentages exceeds $100 \%$ because some studies included multiple levels.
} 
Piening, Baluch, \& Ridder, 2014b). In the abstraction-level dimension papers, the study of Monks et al. (2013) provides a good example of multilevel research by exemplifying how nested HRM systems work. They found that HRM processes are used to uphold a particular HRM philosophy, and that a configuration of HRM practices is used to execute this philosophy. As such, they exposed the embeddedness of HRM practices and processes in HRM philosophies.

Although incorporating multiple levels of analysis, none of the studies discussed above looked up and down simultaneously. Of our total sample, $96 \%$ examined higher-level antecedents, and thus 'looked up', and around 16\% investigated whether lower-level antecedents affected higher-level outcomes. We identified 12 studies that examined mixed multilevel models, including both topdown and bottom-up relationships (e.g. Aryee et al., 2012; Den Hartog et al., 2013), although none of these examined three levels. As such, the main impression gained from our review is that the WHAT principle (i.e. looking up and down to identify the levels of independent constructs) seems to be hardly applied in existing multilevel HRM research. This is a concern since, to account for the embeddedness of HRM outcomes, it is important to consider three levels of analysis since, ultimately, an identified top-down effect of HRM on performance will be biased if lower-level variables that also affect the performance outcome of interest are excluded.

\subsubsection{Directions and Guidelines related to the WHAT Principle}

We would encourage using three levels of analysis, looking both up at contextual factors and looking down at emergent processes. Many combinations are possible: studies examining HRM-performance relationships at the organizationlevel could include both industry-level factors that influence these relationships, and business unit-level factors that affect the performance of firms as a whole. Here, future research needs to incorporate the extra-organizational level. Alternatively, if researchers want to explain team-level innovativeness, they could look at how individuals contribute to innovation within a team (lower level) and, at the same time, consider how strategic processes affect the possibilities for team innovation (higher level).

Given that the majority of the multilevel HRM studies have examined individual-level outcomes, it is striking that there has been little attention given to 'looking down' to see whether intra-individual constructs can explain individuallevel outcomes. Intra-individual constructs refer to personal characteristics, such as affective attitudes and satisfaction, that can fluctuate over situations and occasions (Ilies, Scott, \& Judge, 2006). Recently, management researchers have started to draw attention to intra-individual differences (e.g. Fisher \& To, 2012; Laureiro-Martínez, Brusoni, Canessa, \& Zollo, 2015). One way to include the 
intra-individual level is to model the sequential changes in individual characteristics over time (Ten Brummelhuis, Bakker, Hetland, \& Keulemans, 2012). For example, Bakker and Bal (2010) showed that intra-individual variability in employees' work engagement can explain their weekly job performance. By incorporating variables at the intra-individual level, multilevel HRM research can address the intra-individual differences that partly explain individual-level outcomes. Integrating intra-individual level variables could, for example, help to uncover the effect of variations in introduced HRM activities over time on individual performance outcomes; or the effect of perceptions of HRM changing over time on individual performance outcomes. Some HRM activities (e.g. feedback or information sharing) could affect employees more strongly when more recently applied and thereby might influence intra-individual antecedents of performance. Including these intra-individual differences, for example by examining the effect of HRM practices such as information sharing or feedback on affect, mood, fatigue, or the perception of HRM over time, would improve the understanding of HRM-performance relationships. Given that HRM activities can vary over time on an individual basis, and can be expected to influence intraindividual constructs, we would encourage scholars to include within-individual differences in multilevel HRM models. One particularly suitable method for including the intra-individual level is the "experience sampling methodology (ESM)"5. Here, intra-individual-level variables, such as engagement or affect, are measured repeatedly over time for each person; while the more-stable individuallevel variables, such as demographics, stable attitudes, or traits, are usually measured once (Fisher \& To, 2012). In essence, ESM entails repeated measurements over time of the same participants, for example using methods such as daily diaries. Multilevel HRM research could adopt this approach to examine the relationship between HRM activities and both individual and intraindividual variables. Thus, both the intra-individual and the extra-organizational levels could be incorporated to further advance multilevel HRM research:

Guideline 1: Future multilevel HRM research should stretch the nominal boundaries and include constructs at the intra-individual and extraorganizational levels when examining HRM-performance relationships since HRM activities influence both intra-individual and extraorganizational variables over time and these, in turn, influence HRMperformance relationships.

\footnotetext{
${ }^{5}$ We like to thank the anonymous reviewer for this remark.
} 


\subsubsection{The HOW of Multilevel HRM Research}

Following Kozlowski and Klein (2000), we describe two ways in which levels are linked: through top-down and bottom-up processes. Top-down processes describe the influence of higher-level contextual factors on lower-level phenomena. Higher-level units may have a direct effect on lower-level units, and higher-level constructs may also shape relationships in lower-level units, referred to as cross-level moderator effects. Bottom-up processes describe the manner in which lower-level constructs result in, or aggregate to, higher-level constructs. This so-called emergence is defined as a phenomenon that originates in the affective, behavioral, and cognitive components of individuals, and is then amplified through interactions to manifest itself as a collective phenomenon (Allport, 1954; Katz \& Kahn, 1978; Kozlowski \& Klein, 2000). Many collective phenomena in organizations, such as human capital, organizational capabilities, and climates, have their theoretical foundations in the characteristics of individuals. These characteristics have emergent properties in that they manifest themselves as collective phenomena at levels that transcend the individual when individuals interact and exchange ideas, knowledge, or attitudes (Kozlowski \& Klein, 2000).

Emergence has three features: content, process, and structure (Fulmer \& Ostroff, 2016). The content of emergence refers to its elemental content, that is, the 'raw element of emergence' that is provided by the individuals and aggregated at a higher level. As such, elemental content can consist of concepts such as the cognitions or behaviors of individuals (Ostroff, Kinicki, \& Muhammad, 2012). As an example, Ployhart and Moliterno (2011) argue that the cognitive and the non-cognitive attributes of individuals are the elemental contents of collective human capital resources. Another example is the organizational climate, a concept that resides at the organization-level but is based on the psychological meanings that individuals attach to a situation (Rentsch, 1990) that form the elemental content of emergence. Therefore, the content of emergence can be seen as the individual parts of a system that together create the higher-level whole (Fulmer \& Ostroff, 2016). Second, the process of emergence refers to the interactions among individuals that provide the means for lower-level elemental content to become higher-level content (Kozlowski \& Klein, 2000; Ployhart \& Moliterno, 2011). This process involves acts where individuals share ideas, communicate feelings, and jointly perform tasks, through which affections, cognitions, and behaviors become shared and form a collective phenomenon. Finally, emergence has a structure formed by higher-level contextual factors that shape the process of emergence. These higher-level factors can be both formal (e.g. organizational structure) and informal (e.g. cross-department networks) structures that enable or constrain individual interaction. Following Kozlowski and 
Klein (2000), we distinguish two opposing types of emergence models based on their elements, processes, and structures: composition and compilation. Composition models assume isomorphism, and describe phenomena that essentially remain the same as they emerge upwards to higher levels, such as an organizational climate that reflects the common perceptions shared among employees. In contrast, compilation is based on assumptions of discontinuity (i.e. the lack of a logical sequence), and describes phenomena that share a common domain but are distinctively different across levels. Compilation occurs, for example, in teams where highly-interdependent employees perform different tasks that enable the team to collectively succeed.

\subsubsection{Current Application and Key Findings related to the HOW Principle}

Our sample was heavily dominated by top-down relationships (discussed in 71 studies), and 62 of these examined the top-down effect of HRM on lower-level outcomes such as affective commitment (Ang, Bartram, McNeil, Leggat, \& Stanton, 2013) or employee job performance (Chang \& Chen, 2011). Further, 27 studies examined a cross-level moderator model of which 20 investigated whether HRM-outcome relationships are moderated by constructs such as team cohesion and task complexity (Chang et al., 2014) and 7 that conceptualized HRM as a moderator of lower-level relationships such as between perceived organizational support and commitment (Whitener, 2001). Bottom-up relationships have not been studied frequently, with only 12 studies examining a model with a bottom-up relationship between HRM and a higher-level outcome. This could be a consequence of the limited amount of longitudinal multilevel research, which is necessary to analyze bottom-up effects as they generally take a significant period to appear (Kozlowski \& Klein, 2000). Nevertheless, the scarcity of bottom-up multilevel HRM research is surprising given that strategic HRM may 'loose its raison d'être if individual employees' outcomes influenced by HR systems cannot be related to firm-level outcomes" (Jiang, et al., 2013, p. 1468).

Further, all the studies that had examined bottom-up relationships used composition models, where individual scores are aggregated to establish a collective construct. Typically, these studies measured individual-level concepts and aggregated them at a higher organizational level using mean scores based on a combination of theory, measurement method (e.g. a referent-shift model), and statistics to justify aggregation. An archetypical multilevel HRM study that applied a composition model is the one by Liao and Chuang (2004) who argued that store-level performance will emerge through bottom-up processes from 
individual performances and exists as a collective phenomenon. Based on attraction-selection-attrition, socialization, and social information processes, they proposed that the behaviors and performance of employees within the same unit will be homogeneous. Furthermore, this study, like most of the studies in our sample, used intraclass correlation scores to justify aggregating variables.

We observed that the bottom-up studies in our sample mainly draw on two theories to justify using a composition model: the attraction-selection-attrition model (Schneider, Goldstein, \& Smith, 1995) and social-information processing (Salancik \& Pfeffer, 1978). The former argues that employees are similar because individuals with certain characteristics are attracted to, selected by, and retained by a particular organization. Over time, these processes lead to employees demonstrating similar behaviors and attitudes (e.g. Nishii et al., 2008). Socialinformation processing theory argues that employees' work-related perceptions are filtered through contextual influences and collective sensemaking. Employees are therefore likely to develop similar perceptions because they are working under similar contextual influences and thus collectively make sense of the available HR practices (Kehoe \& Wright, 2013).

Although these theories help explain why composition effects can lead to individual-level phenomena aggregating on higher levels, HRM researchers have yet to examine how individual-level phenomena emerge, through compilation, on a higher level. This is surprising given that many of the outcomes of interest to this stream of research have their origins in heterogeneous elemental contents.

\subsubsection{Directions and Guidelines related to the HOW Principle}

Given the scarcity of studies that use compilation models to examine how heterogeneous content leads to collective outcomes, we address the possibilities for applying such models in HRM research. HRM outcomes that could be studied using a compilation model include innovation performance, human capital resources, and team configuration. For example, as noted by Veenendaal et al. (2014), organizations realize explorative innovations by drawing on heterogeneous human capital. Given this requirement for heterogeneous elemental content, a compilation model would be appropriate for studying innovation performance. Human capital resources are also considered to emerge from compilation processes. Ployhart and Moliterno (2011) argue that the emergence of human capital resources reflects a compilation model in that, as task complexity increases, team members require specialized knowledge that allows the collective to adapt to the heightened complexity. When it comes to managing heterogeneity, some individuals may be more important than others. For example, in a sports team, performance is not a linear sum of individual performances but is formed through irregularity, non-uniformity, and configuration 
(Kozlowski \& Klein, 2000). One player can have exceptional talent and contribute disproportionately to the performance. Likewise, in organizations, there might be star individuals who contribute more than others to performance. For example, research has shown that star scientists and non-star scientists contribute differently to innovation performance (Rothaermel \& Hess, 2007). In such cases, emergence models need to reflect the variability in the individual inputs that eventually determine the collective outcome.

Compilation can be empirically examined either using minimum/maximum models that distinguish between the qualitatively different contributions of individuals, or by using a variance form of emergence that focuses on variability in the elemental content (Kozlowski \& Klein, 2000). All these models analyze the composition of units or teams based on the characteristics of individual members (Mathieu, Tannenbaum, Donsbach, \& Alliger, 2014). Team performance can then be related to the minimum and maximum general mental abilities of team members (Bell, 2007). A good example of such a study, albeit from outside our sample (as it did not address HRM activities), is the work of Stewart, Fulmer, and Barrick (2005). They examined the link between individual roles and role structure across organizational levels and examined emergence as a complex process in which the individual-level elements (roles) combine into a higher-level phenomenon of the team (role structure) through composition and compilation.

In a similar way, future multilevel HRM research could examine bottomup effects across different levels of abstraction. For example, researchers could study how HRM philosophies are realized in a top-down manner through the implementation of HRM practices, or how HRM systems are built from different HRM policies and practices. That is, different HRM practices might substitute for each other in realizing a selected policy (Jiang et al., 2012) such that achieving HRM policies could follow from heterogeneous lower-level elemental content (i.e. HRM practices). Lastly, strategy-as-practice research shows that strategies can emerge from actual managerial behavior (e.g. Jarzabkowski, 2004). For multilevel HRM research, this implies that actual HRM, i.e. as introduced by managers, might play an important role in the (re)formulation of intended HRM, rather than the other way around as is currently often assumed. Following these examples, HRM researchers investigating higher-level outcomes (e.g. collective human capital, creativity, innovation, and intended HRM philosophies and policies) could examine the diversity in lower-level inputs (e.g. human capital, creativity, or actual HRM practices), and how this influences the collective outcomes. 
Guideline 2: Future multilevel HRM research should analyze the variability in lower-level phenomena to explain the emergence of higherlevel phenomena.

A second insight gained from the review is that all of the multilevel bottom-up HRM studies only examined the elemental content component of emergence, and overlooked its other two dimensions. More specifically, these studies examined the extent to which HRM practices affect employee-level outcomes, such as job satisfaction, commitment, or human capital, but overlooked the extent to which HRM practices support the processes through which these outcomes aggregate at higher levels. This is remarkable given that HRM practices can represent the structural dimension of emergence in that they are contextual factors that regulate how individuals interact and, thus, facilitate the process of emergence. A rare example of a study that examined emergence processes is the paper by Wang and Zatzick (2015) who examined how emergence-enabling strategies - such as participation in decision-making - support emergence processes. They found support for their hypothesis that these strategies enhance the relationship between the knowledge, skills, and abilities of new employees at the individual level and innovation at the organization level.

Following these results, we argue that it is possible to distinguish between the effects of HRM practices on the process and on the elemental contents of emergence. Actual HRM practices such as staffing, training, and development appraisal can shape elemental content such as an individual's knowledge, skills, and abilities (KSAs) that aggregate into collective unit-level human capital resources (Nyberg, Moliterno, Hale, \& Lepak, 2014). However, the process of emergence is likely to require HRM practices such as teamwork and group incentives since these allow and motivate employees to exchange and interact (Collins \& Smith, 2006; Kozlowski \& Klein, 2000). These practices form a structure that enables individual-level elemental content to emerge as collective phenomena. For example, through enabling states - such as behavioral processes, cognitive mechanisms, and affective states - individual-level human capital can be transformed into unit-level human capital resources (Kozlowski \& Ilgen, 2006; Ployhart \& Moliterno, 2011). These concepts can be viewed as the process of emergence, and they can be influenced by HRM. In this role, HRM focuses on the creation of a workforce with high abilities, motivation, and opportunities to interact effectively with each other. As such, ability-enhancing HRM can be expected to be most strongly related to the content of emergence, whereas motivation-enhancing and opportunity-enhancing HRM are expected to be more strongly related to the process of emergence. Therefore, we propose the following: 
Guideline 3: Future multilevel HRM research should examine whether HRM has differential effects on the process and on the content of emergence.

\subsubsection{The WHERE of Multilevel HRM Research}

This principle considers where top-down and bottom-up processes originate and culminate. It addresses the so-called unit specification (i.e. the organizational units where cross-level effects occur) and bond strength (i.e. the strength of cross-level relationships). Unit specification recognizes that multilevel effects can become manifest in formal and in informal organizational entities. Formal organizational entities are those collectives of individuals whose boundaries are formalized on the basis of the organizational structure, whereas informal entities are collectives of individuals that transcend organizational structures, such as informal networks or friendships. In multilevel research, it is important to determine whether multilevel effects appear in formal or informal organizational entities because individuals interact with others from both formal entities (e.g. coworkers) and informal entities (e.g. friends), and this affects the sensemaking processes (Rentsch, 1990). Basing unit specification on formally designated units and levels can lead to an overestimation of their influence when phenomena are also affected by informal networks. Bond strength - also referred to as embeddedness - refers to the extent to which characteristics, behaviors, dynamics, and processes at one level affect these elements at another level or in a unit (Simon, 1973). The idea behind bond strength is that links between levels are stronger when the levels are more proximate, and that this explains the extent to which constructs at different organizational levels are expected to be related (Kozlowski \& Klein, 2000). For example, when considering the effect of climate, the team climate is likely to be more strongly related to individual behavior than the organizational climate. Summarizing, bond strength determines the interconnectedness of phenomena at different levels and influences the effect sizes that can be found in cross-level relationships. The more a unit is involved in a higher level unit, the more impact the cross-level relationships will have (House et al., 1995).

\subsubsection{Current Application and Key Findings related to the WHERE Principle}

All the studies in our review looked at effects in formal organizational entities, such as branches of a bank (Aryee, et al., 2012), hairdressing shops (P. C. Chang \& Chen, 2011), and teams in a hospital (Ang, et al., 2013). Some studies have 
used very precise unit specifications by including all the hierarchical levels in their hypotheses. For example Hong et al. (2016) were explicit as to the organizational levels at which they expect and examine multilevel effects. The fact that multilevel HRM research on multilevel effects focuses on formal entities is further demonstrated by the aggregation procedures adopted in which lower-level phenomena are aggregated to a formal organizational entity. As such, it seems that informal unit specifications have largely been overlooked in multilevel HRM research.

Although all the multilevel HRM studies in our sample investigated crosslevel relationships between HRM and selected outcomes, none of them explicitly conceptualized the strength of these relationships. This is evidenced by the formulation of hypotheses that question whether HRM has a positive or a negative effect on an outcome, without addressing whether the effects are weak or strong. Although some studies have hypothesized moderator effects that strengthen or weaken cross-level HRM-outcome relationships, these studies do not conceptualize how the proximity of the different levels in the analysis affects these relationships. However, there are some studies that do examine how the similarity of constructs at two organizational levels affects cross-level relationships. For instance, Li and Frenkel (2017) studied how the "status similarity" of supervisors and employees affects the cross-level link between the HR perceptions of both parties. Nevertheless, studies explicitly examining bond strength remain rare and multilevel HRM research has not yet explicitly examined how bond strength affects HRM-outcome relationships across different levels of analysis.

\subsubsection{Directions and Guidelines related to the WHERE Principle}

To date, multilevel HRM researchers have focused on cross-level HRM-outcome relationships in formal organizational entities, and we see a need for further research into HRM-outcome relationships in both formal and informal organizational entities. Although the formal structures and hierarchies in organizations influence organizational members by determining with whom they will most likely interact (Kozlowski \& Chao, 2012), informal structures and horizontal linkages between organizational members also exist and influence their behavior and interactions. As an illustration of this, Liao et al. (2009) examined the perceptions of HRM held by employees in certain employment groups, but did not address the possibility that employees in these groups might also interact with employees outside their own employment group. By not taking these informal structures into account, difficulties in isolating the effects of HRM can arise. Social information processing theory (Salancik \& Pfeffer, 1978) suggests that employees' perceptions of organization-level HRM philosophies 
can be informally shared since almost all employees are exposed to them and can then share their perceptions in informal entities with those outside their own organizational unit. For example, the climate in a friendship network can influence, both positively and negatively, the effect of HRM on performance because these informal networks can change the perceptions of employees regarding the quality and quantity of the HRM activities in their formal unit. Further, Jiang et al. (2017) show that employees' perceptions of HRM are affected by their co-workers' perceptions. As such, employees' attitudes and behaviors can be affected by HRM in both formal and informal organizational entities. Taking both these potential influences into account would prevent an overestimation of the effects stemming from a formal unit and potentially expose how HRM outcomes are affected by mechanisms within informal units.

Furthermore, unit specification is also relevant for research that includes constructs at levels outside the organization. For example, organizational membership of informal business networks could influence the adoption of HRM practices. Being part of an informal inter-organizational network could affect the decision to adopt certain HRM practices, for example because of institutional pressures (Paauwe \& Boselie, 2003), which will potentially affect multilevel HRM relationships and therefore should be incorporated in multilevel HRM research (Renkema, Meijerink, \& Bondarouk, 2016). Although some of the studies included in our review examined extra-organizational level constructs, none of them incorporated the unit-specification principle by investigating informal extraorganizational entities, such as business networks, and their multilevel effect on HRM phenomena. Therefore, we propose the following:

Guideline 4: Future multilevel HRM research should examine the effect of antecedents at both formal and informal levels on intended, actual, and perceived HRM and on selected HRM performance outcomes.

As already noted, current HRM research pays insufficient attention to the influence of the organizational level on relationship strengths (i.e. bond strength). Current multilevel HRM research is mostly concerned with cross-level relationships and, as we have argued, these are likely to have high bond strengths because these relationships connect proximal organizational entities on the unit and individual levels. As an example, Ang et al. (2013) studied the relationship between unit-level HRM and individual-level affective commitment. In contrast, $\mathrm{Wu}$ and Chaturvedi (2009) examined whether individual-level affective commitment is influenced by HRM while conceptualizing HRM at the organization-level. Such differences make it difficult to compare findings across levels and, therefore, it is dangerous to draw conclusions about the impact of 
bond strength and the extent to which cross-level HRM-outcome relationships can be generalized across levels. However, it would be valuable to know the scale of the differences in effect sizes between organization-level HRM and unitlevel HRM because this could have implications when it comes to deciding which HRM activities to introduce and implement at which levels of the organization. Bond strength principles argue that HRM-outcome relationships will be stronger when the unit in which an HRM outcome is conceptualized is more strongly coupled to, or embedded in, the unit where the HRM predictor is conceptualized.

For example, teams that are more autonomous when it comes to introducing HRM policies and practices will be less embedded in the contextual processes on higher levels of the organization. In other words, when work-units have more autonomy, the bond strength between the organization and team levels is weaker, and HR-related phenomena on the unit level are less likely to be influenced by the organizational-level phenomena. Further, and in terms of abstraction levels, it is likely that HRM philosophies are more strongly related to HRM policies than to HRM processes because, conceptually, HRM philosophies influence HRM processes through HRM policies and practices. Finally, House et al. (1995) argue that the bond strength is greatest when a unit is embedded within a single higher-level unit. As illustrations, they mention a team whose activities are only linked with one higher-level division, and an employee who only services one customer. The more an employee interacts with only one team or one supervisor, the more influence that higher-level entity is expected to have. As such, employees who only work for one team, or with one supervisor, will be more strongly affected by the HRM practices on the team-level than employees who work in multiple teams or a team with multiple supervisors. As these examples show, the strength of the effect of HRM on performance, and the strength of the interrelationships among HRM system components, are likely to depend on the level of analysis. Therefore, we propose the following:

Guideline 5: Future multilevel HRM research should develop theory and conduct research into how and why the cross-level effects of HRM on an outcome are stronger when the level at which HRM is conceptualized is closer to the level of the selected outcome.

\subsubsection{The WHEN of Multilevel HRM Research}

Although time influences many organizational phenomena, it rarely features in multilevel organizational models. Following Kozlowski and Klein (2000), we discuss three ways in which time could be incorporated in a multilevel model. First, time as a boundary condition could reflect the reality that the direction of 
multilevel relationships can vary depending on the point in time and the position in the relevant work cycle. For example, organizational climate is defined as the shared perception of employees (Schneider, 1990), and this implies that changes in organizations will first lead to changes in perceptions (i.e. top-down) and then to a changed shared perception (i.e. bottom-up). Given this reality, a multilevel theory needs to explicitly specify the point in time in order to capture the direction of the relationships of interest (Kozlowski \& Klein, 2000). Therefore, depending on the time, or position in the cycle of events, a phenomenon can be modeled at different levels and the direction of a relationship can change from top-down to bottom-up, or vice- versa. Second, time-scale variation across levels addresses differences in the nature of links between lower-level and higher-level phenomena, that is, the time that is required before an effect occurs on other levels (Kozlowski \& Klein, 2000). In general, lower-level phenomena tend to change faster than higher-level and emergent phenomena because they can adapt easier and require less coordination. For example, training programs can immediately increase the abilities of individual employees, but the effect of training on organizational outcomes is an emergent phenomenon and, therefore, requires more time. Finally, entrainment refers to changes in multilevel linkages over time due to variations in the coupling between levels. The degree of entrainment is higher when units at different levels are more tightly coupled. Since the coupling between levels and units can vary over time, this can change the effect of multilevel phenomena (Kozlowski \& Klein, 2000). For example, at some point in time, an employee may be influenced by attitudes and behaviors of colleagues and supervisors because they are actively collaborating with them while, at another point in time, the employee may be working independently and be less influenced by the context. In the latter situation, multilevel effects may well be weaker because embeddedness and interaction are less influential.

\subsubsection{Current Application and Key Findings related to the WHEN principle}

Since the early days of HRM research, it has been argued that there might be a time lag between the adoption of HR practices and the effect on firm performance (Huselid \& Becker, 1996). However, in current multilevel HRM research, the time dimension is largely implicit. This is primarily because longitudinal research using multilevel models in HRM is still the exception, with only $8 \%$ of studies adopting a longitudinal design (10\% if time-lagged studies are included). Further, applying multilevel models in cross-sectional research is problematic because cross-level effects take longer to appear than single-level effects (Kozlowski \& Klein, 2000). In particular, bottom-up effects require a significant amount of time to appear. As 
such, we would add to the methodological criticisms of cross-sectional research that these models are unable to analyze the emergence of cross-level effects. If time is not included in a model, one cannot gain knowledge about the kinds of cross-level influence present, where these effects originate and appear, and when these effects can be expected. Further, time was not an explicit boundary condition in many of the studies included in this review. Although almost all the studies referred to the problems of using cross-sectional approaches, virtually none referred to the position, or time, in the cycle of events of a phenomenon and as such did not designate a time boundary or specify the generalizability across event-cycles. An exception is the study by Chang (2005) that argued that the mediating effect of procedural justice may vary over time, and could be stronger immediately after a performance appraisal. Similarly, we found no evidence of the explicit use of the concept of entrainment in our sample: no study referred to the pace or the cycle of events across units of analysis, or how these might influence multilevel relationships.

\subsubsection{Directions and Guidelines related to the WHEN Principle}

In multilevel HRM research, time as a boundary condition is an important concept because cross-level relationships can have bidirectional effects. For example, Takeuchi et al. (2009) studied the link between establishment-level HRM and employee climate, and viewed climate as a unit-level construct. They argued that climate is a shared construct in that employees will have similar perceptions of the climate because they are exposed to similar stimuli. As such, climate is conceptualized as a reciprocal variable: it is based on individual perceptions and influences individual attitudes. This relationship illustrates the influence of time as a boundary condition: the relationship between individual-level and unit-level constructs differs depending on the stage in the development cycle of a phenomenon. Takeuchi et al. (2009) assumed the climate was shared, and therefore identified only a top-down effect. If we followed this, and applied the time as a boundary condition principle, the model would not be able to draw conclusions about the process of creating a shared climate because this part of the cycle of events would be outside the boundary condition. To find out more about the relationship between HRM and climate, it would be worth studying simultaneously the bottom-up process of creating a shared climate and the topdown process of influencing individual attitudes, and testing whether HR systems are related to both the individual-level psychological climate and the organizational climate, as suggested by Ostroff and Bowen (2000). To achieve this, a longitudinal research design would be required to shed light on both the top-down and bottom-up cross-level effects throughout the cycle of an organization's events. The organizational lifecycle could be such a cycle, and this 
generally consists of the following phases: birth (start-up), growth, maturity, and decline (Milliman, Von Glinow, \& Nathan, 1991). In the start-up phase, the organizational climate is developing and HRM has a bottom-up effect on climate, whereas, in the mature phase, the organizational climate has been developed and now affects the attitudes and behaviors of employees in a top-down fashion. To conclude, multilevel HRM research should take temporal requirements and boundary conditions into account.

Guideline 6: Future multilevel HRM research should study whether multilevel HRM-performance relationships vary (between top-down or bottom-up) across the lifecycle of organizational phenomena.

Further, Ostroff and Bowen (2000) highlighted the importance of organizational context in determining the direction of cross-level relationships: in stable organizations, HRM systems and climates tend to have a stronger top-down influence whereas, in changing organizations, the influence of HRM systems and climates is more bottom-up. This is explained by the greater influence of individuals on the HRM systems, climate, and normative contracts in changing organizations. In stable organizations, employees are influenced by the existing organizational climate, which has been established over time and produced by the shared perceptions of employees about practices, procedures, and behaviors that are rewarded and supported in a particular setting (Schneider, 1990). In essence, organizational stability means that perceptions are more alike and that the climate determines how individuals behave. However, in changing organizations, for example during restructuring, perceptions about desirable behaviors change, and individuals influence the new climate. Further, employees can have a bottom-up influence on the HRM systems that are being introduced, since these might require, or the unstable situation might necessitate, a change in the HRM system(s). Furthermore, bottom-up changes to collective structures are more prevalent when the institutional environment is unstable (Bitektine \& Haack, 2015). To analyze these processes, researchers need to study the influence of HRM systems and climates on individual attitudes and behaviors over longer cycles.

Further, not only does the direction of these cross-level relationships change, but also the speed of change. In general, bottom-up processes tend to take longer than top-down processes (Kozlowski \& Klein, 2000). For example, some HR practices, such as information sharing and feedback, can immediately affect individual employees and their performance (a top-down process), while it may require much longer before the performance of a unit is affected by the increased performance of its individual members (bottom-up). This relates to the 
concept of time-scale differences: some relationships manifest themselves fairly quickly, while others require longer (Kozlowski \& Klein, 2000). It is also possible that the time it takes for a given process to manifest itself might vary. For instance, one could expect collective constructs to emerge faster when there are strong emergence-enabling strategies in place (Ployhart \& Moliterno, 2011; Wang \& Zatzick, 2015). Given the more nuanced approach that the inclusion of time-scale variation across levels allows, we propose the following guideline:

Guideline 7: Future multilevel HRM research should examine differences in the time it takes for bottom-up and top-down effects to manifest themselves, and the factors that determine the time required for these effects to appear.

The last aspect of time to be considered is entrainment - defined as "the adjustment of the pace or cycle of an activity to match or synchronize with that of another activity" (Ancona \& Chong, 1996, p. 253). In multilevel research, entrainment reflects a situation where the rhythm, or the pace and cycle, of activities is aligned across levels. In our view, organizational rhythm in this sense refers to factors related to when, how fast, and in what sequence organizational processes take place. For example, Orlikowski and Yates (2002) argued that organizational rhythm can be shaped by larger economic or institutional pressures such as the fiscal year, the academic cycle, or quarterly sales cycles. In these examples, the timing of organizational processes is adapted based on when organizations need to report financial figures or audits. Following this argument, multilevel HRM research could examine how higher-level constructs, at the unit, organization or institutional level, affect the rhythm of lower-level constructs such as employee behavior. A stronger entrainment means that two or more organizational levels are more tightly coupled or aligned and, therefore, the overall rhythm is more synchronic. We refer to the alignment of organizational levels over time as a temporal fit. A higher temporal fit means that the cycles of events are more congruent across organizational levels and, therefore, that cross-level effects are stronger. For example, the timing of processes in business units may be similar to the sequence and timing of those in the firm's headquarters; or the timing of an individual's work - when and in what order certain tasks are conducted - may be adapted to the work at the business unit level. With a high temporal fit, the cycle and pace of employee tasks are aligned with the pace of the higher-level unit. HRM practices such as feedback or annual appraisals will affect individual attitudes and behavior more strongly when they are contemporaneous with the work cycle. HRM practices such as recruitment or training may be better aligned with organizational processes if they fit within the 
normal work processes. Furthermore, one could expect that introducing HRM practices at the appropriate time in the sequence of work could lead to better results because they will fit better with other processes and/or are perceived as more useful.

Consequently, implementing HRM at different organizational levels might not be straightforward. Moreover, changes in HRM activities that have positive effects at one organizational level might have other effects on another organizational level due to differences in entrainment. A good example of an article that addressed this issue is that of Elorza, Harris, Aritzeta, and Balluerka (2016). These authors showed that there is a gap between management-HRM and employee-HRM, and argued "this might suggest that managers are trying to "move along" their employees perceptions of the system, which would imply a time gap between managers' implementation and employees' perceptions" ( $p$. 135). One way to take these entrainment issues into account would be to conceptualize the influence of time lags and entrainment, and to be more explicit about when changes at one level will lead to changes at another (Ancona, Goodman, Lawrence, \& Tushman, 2001).

Guideline 8: Future multilevel HRM research should theorize on the time lags between causes and their effects that result from entrainment, on the basis that the effect of HRM on an outcome of interest is faster when the temporal fit is better.

\subsubsection{The WHY of Multilevel HRM Research}

The WHY principle demands the provision of theoretical explanations and justifications for the assumptions underlying multilevel models. Selecting a composition model rather than a compilation model for describing a bottom-up relationship requires an explanation: why, for example, is a composition model, as in Liao and Chuang (2004), justified for the relationship between individual service performance and unit-level service performance? Here, the underlying assumption could be that employees will demonstrate homogeneous behaviors because they are influenced by similar processes. Following Kozlowski and Klein (2000), theorists should explicitly provide such theoretical justifications for such underlying assumptions in support of their multilevel models.

\subsubsection{Current Application and Key Findings related to the WHY Principle}

In our review, we have considered the three dimensions of the Multilevelity Cube, whose contents could function as underlying assumptions to justify the need for 
multilevel research. Most of the studies in our review referred to Ostroff and Bowen (2000) and, as such, to the organizational levels dimension of the multilevelity cube in explaining the need for multilevel research. These studies refer to the view, as discussed by Wright and Boswell (2002) and by Nishii et al. (2008), that HRM influences organizational performance through the attitudes and behaviors of individual employees. The least frequently referred to dimension of the cube in attempting to underpin multilevel models has been the abstraction level as discussed by Arthur and Boyles (2007) and Schuler (1992).

The most frequently used theoretical basis for cross-level models in our sample of multilevel HRM studies was the Social-Exchange Theory of Blau (1964), which argues that HRM activities elicit certain employee attitudes and behaviors because employees want to reciprocate the support received from their organization. Of the studies included in our review, 29 used SET to underpin their theoretical arguments. The Resource-Based View (Barney (1991) that explains the competitive advantages of organizations as stemming from human resources that are valuable, rare, and difficult to imitate was referred to in seven studies in the review. Signaling theory, HRM system strength, HRM process theory, and the AMO framework are other theoretical concepts that have been used on occasions.

\subsubsection{Directions and Guidelines related to the WHY Principle}

Following Kozlowski and Klein (2000), we argue that it is relevant, in order to test the underlying assumptions of theoretical models, to examine why, and in what circumstances, cross-level relationships do not always lead to shared outcomes or to constrained behavior. For example, Liao, et al. (2009) found that the crosslevel relationship between management-rated HRM and employee-rated HRM was insignificant. One possible explanation is a disconnect between different HRM levels (see Figure 2.1), for example because employees experience different practices (Bowen \& Ostroff, 2004; Lepak \& Snell, 2002). Testing the underlying assumptions could lead to an understanding of why HRM is unrelated across levels, or why HRM on a higher organizational level does not influence employees' attitudes and behaviors. In this way, existing theories and assumptions that underlie multilevel models could be tested and further developed.

In general, research is needed to clarify why HRM contributes to better performance: to open the so-called black box (Paauwe \& Blok, 2014). In particular, bottom-up theories and processes that link individual employees to organizational performance have received scant attention by HRM researchers. Our review found that the ASA framework and social information processing theories have been used to explain why employees have similar perceptions, and 
then to aggregate individual scores to explain higher-level outcome variables. Future research could investigate if the explanatory power of the various theories used to explain emergence differ, and if different theories need to be applied for various types of elemental content and processes of emergence. For example, differences in explanatory and predictive powers could depend on the fit between the theory and the model of emergence (e.g. composition or compilation). Further, theories that address dissimilar contributions are necessary in order to explain the complex processes of integrating and coordinating individual performances. There remains a lack of theory to explain the mechanism that links individual outcomes with organizational performance. Paauwe and Blok (2014) have proposed using relational coordination theory (Gittell, 2000) because this is concerned with the management of interdependence between people and tasks, and thereby focuses on increasing organizational performance. To investigate these types of relationships further, we propose adopting a configurational approach as this will enable theorizing on, and examination of, different combinations, and the alignment of individual contributions, that lead to organizational outcomes. In this sense, compilation means combining different dimensions, and thus establishing a configuration of employee characteristics that lead to higher-level performance. Furthermore, a theoretical process approach could advance understanding of how HRM-performance relationships emerge and change over time by analyzing how key events and time shape change processes (Langley, 1999).

Guideline 9: Future multilevel HRM research should explore mechanisms that underlie multilevel HRM-performance relationships and develop theories that connect individual-level constructs with organization-level constructs.

\subsection{Implications and Interplay between Principles and guidelines}

Our review of multilevel thinking in HRM research suggests that progress has been made in developing and examining multilevel models. However, our review also revealed that multilevel thinking is only partly applied, and that further progress needs to be made. We now discuss two main contributions from this review of applications of multilevel thinking: implications for HRM research, and contributions to multilevel research beyond the boundaries of HRM research. 


\subsubsection{Implications for HRM Research}

The proposed conceptualization of HRM with three multilevel dimensions has important implications for HRM research. First, we are convinced that multilevel HRM research starts from the acceptance of the notion that HRM is an inherently multilevel construct with multiple dimensions. Building on diverse HRM research streams, we explored and integrated three dimensions (multilevelity cube of HRM; see Figure 2.1). These dimensions are helpful in distinguishing HRM constructs in multilevel models because they highlight that HRM at various levels is conceptually different, leads to different outcomes, and needs to be measured in different ways. To cope with these complexities, we analytically separated the principles of multilevel theory building to uncover ways in which HRM scholars could learn from them. The systematic review showed that neither the fullyfledged application of the dimensions of multilevel HRM nor the use of multilevel thinking have yet been institutionalized in multilevel HRM research. Based on this evaluation, we have proposed future research directions in the form of guidelines. In particular, we observed that there has been only limited attention to the WHERE and WHEN principles of multilevel research. Given that theoretical arguments and findings from other fields have shown the importance of these principles, a more profound approach to multilevel HRM research is needed to understand where multilevel effects originate and emerge, and when these effects will occur. Future research will benefit from going beyond the conventional examination of how HRM influences individual outcomes in a top-down fashion. This requires conceptualizing different ways to aggregate individual characteristics into collective outcomes.

Although we divided the principles into separate categories to clarify the current state of multilevel thinking in HRM, in reality they are interrelated and, therefore, we propose applying a combination of these principles to increase understanding of multilevel HRM-outcome relationships. This approach will provide a more nuanced explanation of multilevel phenomena than selecting only one or a few principles by taking several interconnected aspects of multilevel theory building into account. When adopting a multilevel approach, we would suggest starting from the phenomenon of interest and then, apply the principles of multilevel HRM theory building provided in this paper. However, we suspect that it is impractical to examine every aspect of multilevel HRM in every study. Nevertheless, we would encourage researchers, when following the guidelines, to adopt the principles of multilevel theory building in multilevel HRM research. The principles and guidelines are interdependent in that the choice for a specific theoretical model and the methodological choices made should be closely related to the application of the principles. Whereas the guidelines reflect research areas that deserve more attention, the principles can be applied in any multilevel 
research design. Studies should start by identifying the relevant levels of the phenomena of interest, and then look up and down to analyze whether these phenomena are influenced by concepts at other levels (WHAT). This cannot be separated from the questions of how these phenomena are related across levels, whether there is a top-down or a bottom-up relationship, and the form of these relationships (HOW). At the same time, researchers should evaluate where these relationships originate and culminate, whether they are established in formal or informal units (WHERE), and they need to address the time required for crosslevel effects to occur (WHEN). Finally, multilevel models need theories that can explain cross-level relationships (WHY), which is related to the direction and form of cross-level relationships.

\subsubsection{Implications for Multilevel Research}

The second contribution is that the review of multilevel thinking in HRM research is also valuable for multilevel theory building and research beyond the boundaries of HRM. Despite our prime aim being to assist the development of multilevel thinking in HRM research, we hope that the discussion on principles and guidelines will also inspire multilevel research in other management fields. Below we discuss two ways in which HRM research can contribute to multilevel thinking.

First, our research shows that multilevel principles can also be applied to dimensions other than hierarchical levels. We have seen that the principles of multilevel theory building can be applied not only to organizational levels but also to internalization and abstraction levels. As such, we have argued that multilevel research amounts to more than including nested data in hierarchical structures. Other management research domains could learn from this approach and similarly conceptualize their main phenomena of interest in a multilevel framework. Furthermore, HRM research shows that constructs can be conceptualized at many different hierarchical levels, levels of internalization, and abstraction levels, and that these conceptualizations do not necessarily refer to the same construct (see Table 2.1). Rather, conceptualizing HRM at different levels of these three dimensions could potentially lead to different HRM-outcome relationships being identified.

Second, we identified research areas in which we think multilevel research could particularly provide new insights. However, the analysis of multilevel principles could also be thought provoking for other management domains such as entrepreneurship, innovation management, and service management. Molloy et al. (2011) compared six subdomains of management research and found that some of these domains were more advanced in bridging micro- and macro- level research than others. Our research could inspire those 
fields lagging behind to apply the basic principles of multilevel theory building to advance the application of multilevel thinking. Some of the guidelines could be used in other fields of management research. For example, researchers could examine whether entrepreneurs' intra-individual variability affects their business success. In this way, this paper contributes to multilevel research by showing how the somewhat abstract principles of multilevel theory building described by Kozlowski and Klein (2000) can be applied in a specific research domain.

\subsubsection{Methodological Challenges and Limitations}

In this paper, we have focused on multilevel theory building, but conceptualizing HRM as a multilevel construct also has important implications for empirical research. The resulting methodological choices are beyond the scope of this paper, but should be closely related to the development of multilevel theoretical models. Various conceptual studies have focused on how to measure the multilevel HRM construct at different levels. The predominant approach is to measure HR principles, or intentions, on the organization level, HR practices at the unit level, and HR perceptions at the individual level (Arthur \& Boyles, 2007; Minbaeva, 2013). We beg to differ in that we argue that the multilevelity cube of HRM reflects a more inclusive approach. That is, the many intersections of the three dimensions provide many opportunities to measure the HRM construct. Theoretically, all these intersections are valid, but measuring the concepts sets various challenges. First, there are practical challenges because of the timeconsuming process of conducting multilevel research and the methodological and analytical requirements. An explanation for the lack of multilevel research might be the statistical specificity required and the pressure on academics to publish, which conflicts with the time required to conduct multilevel research. Further, there are design challenges. For example, HR philosophies can be measured at the organization level, by asking senior management about the philosophy of the whole organization, at the unit level, by asking a unit-manager about the philosophy of a specific unit or sub-unit, or at the individual level, by asking employees about their perceptions of the HR philosophy. Scholars could advance the HRM field by, when theorizing, more clearly specifying the dimension of the HRM construct addressed, and then operationalizing the HRM measurement at the appropriate level. Given the goal of this paper, to advance multilevel thinking in HRM, these methodological aspects have not been discussed in detail. This is a limitation, and the next step in advancing multilevel HRM research could be to focus on the methodological and statistical challenges. Another limitation of the current study is that our sample is an incomplete subset of multilevel HRM studies. We did not include studies that used data from different levels but 
conceptualized variables at only one level - for example the collective level (e.g. Gardner, Wright, \& Moynihan, 2011), as we centered our analysis around the principles of multilevel theory building. Further, although we also drew on some examples from outside the HRM field, there is no doubt that more lessons can be learnt from other fields. Here, the HRM field might benefit from the management and organizational science fields that are more advanced in terms of multilevel thinking. Despite these limitations, we are confident that the growing number of researchers conducting multilevel studies will be able to develop new insights based on the multilevel HRM principles and guidelines that we have discussed.

\subsection{Conclusions}

During the past decade, an increasing number of scholars have been investigating various aspects of the multilevel HRM construct. Nevertheless, our in-depth analysis has shown that HRM research has still to reap the full benefits of multilevel thinking. Although many studies have conducted HRM-performance research at more than one level, few have gone beyond top-down empirical considerations, composition-based emergence, and two levels of analysis. We argue that the relationship between HRM and performance is far more complicated, and that future research would greatly benefit from a systematic application of multilevel theory. Based on the multilevel theory building principles of Kozlowski and Klein (2000), we reviewed a sample of the current literature and found that many aspects of these principles were implicitly, arbitrarily, or not at all applied. We have argued that using these principles would contribute to a more integrated understanding of HRM-performance relationships. The paper reveals the inherently multilevel nature of HRM, and shows that multilevel research has only recently gained attention in the HRM field. In adopting a multilevel theoretical approach, we have highlighted three multilevel dimensions of HRM: internalization levels, organizational levels, and levels of abstraction. These dimensions formed the basis of the proposed research framework - the multilevelity cube - that integrates the principles of multilevel theory building. By drawing on these principles, we were able to illustrate the what, how, where, when, and why of HRM-performance relationships across levels. In so doing, we highlighted some areas in which the HRM field could learn from multilevel theory. We attempted to reveal multilevel thinking - the application of the principles of multilevel theory building - in the HRM literature, and provide guidelines based on multilevel theory to improve our understanding of how this could be utilized. This paper should not be seen as a criticism of current developments in HRM research, rather our aim has been to provide guidelines that can help future research use multilevel HRM models to define and then populate a research 
landscape. We would urge researchers to adopt multilevel principles to gain a more integrated understanding of HRM as a multilevel reality and hope that our guidelines can serve as a basis for generating relevant research directions.

\subsection{References}

References can be found on page 209.

Multilevel studies included in our sample are presented in the list below:

Ang, S. H., Bartram, T., McNeil, N., Leggat, S. G., \& Stanton, P. (2013). The effects of high-performance work systems on hospital employees' work attitudes and intention to leave: a multi-level and occupational group analysis. The International Journal of Human Resource Management, 24, 3086-3114.

Aryee, S., Walumbwa, F. O., Seidu, E. Y., \& Otaye, L. E. (2012). Impact of highperformance work systems on individual-and branch-level performance: test of a multilevel model of intermediate linkages. Journal of Applied Psychology, 97, 287-300.

Bal, P. M., Kooij, D. T. A. M., \& De Jong, S. B. (2013). How Do Developmental and Accommodative HRM Enhance Employee Engagement and Commitment? The Role of Psychological Contract and SOC Strategies. Journal of Management Studies, 50, 545-572.

Baluch, A. M. (2016). Employee perceptions of HRM and well-being in nonprofit organizations: unpacking the unintended. The International Journal of Human Resource Management, 1-26.

Bondarouk, T., \& Ruël, H. (2013). The strategic value of e-HRM: results from an exploratory study in a governmental organization. The International Journal of Human Resource Management, 24, 391-414.

Chang, E. (2005). Employees' overall perception of HRM effectiveness. Human Relations, 58, 523-544.

Chang, P. C., \& Chen, S. J. (2011). Crossing the level of employee's performance: HPWS, affective commitment, human capital, and employee job performance in professional service organizations. International Journal of Human Resource Management, 22, 883-901.

Chang, S., Jia, L., Takeuchi, R., \& Cai, Y. (2014). Do high-commitment work systems affect creativity? A multilevel combinational approach to employee creativity. Journal of Applied Psychology, 99, 665-680.

Chang, W.-J. A., Wang, Y.-S., \& Huang, T.-C. (2013). Work Design-Related Antecedents of Turnover Intention: A Multilevel Approach. Human Resource Management, 52, 1-26.

Chang, Y.-Y. (2015). A multilevel examination of high-performance work systems and unit-level organisational ambidexterity. Human Resource Management Journal, 25, 79-101.

Chang, Y. Y. (2016). High-performance work systems, joint impact of transformational leadership, an empowerment climate and organizational ambidexterity Cross level evidence. Journal of Organizational Change Management, 29, 424-444. 
Chiang, H. H., Chang, A., \& Han, T. S. (2012). A multilevel investigation of relationships among brand-centered HRM, brand psychological ownership, brand citizenship behaviors, and customer satisfaction. European Journal of Marketing, 46, 626-662.

Choi, J. H., \& Lee, K. P. (2013). Effects of employees' perceptions on the relationship between HR practices and firm performance for Korean firms. Personnel Review, 42, 573-594.

Chuang, C.-H., Jackson, S. E., \& Jiang, Y. (2016). Can Knowledge-Intensive Teamwork Be Managed? Examining the Roles of HRM Systems, Leadership, and Tacit Knowledge. Journal of Management, 42, 524-554.

Colakoglu, S., Allen, M., Miah, K., \& Bird, A. (2016). High-investment HR values and firm performance among local firms and US MNCs' subsidiaries in South Asia: a comparative study. The International Journal of Human Resource Management, 27, 1426-1447.

De Menezes, L. M., Wood, S., \& Gelade, G. (2010). The integration of human resource and operation management practices and its link with performance: A longitudinal latent class study. Journal of Operations Management, 28, 455-471.

Dello Russo, S., Mascia, D., \& Morandi, F. (2016). Individual perceptions of HR practices, HRM strength and appropriateness of care: a meso, multilevel approach. International Journal of Human Resource Management, 1-25.

Den Hartog, D. N., Boon, C., Verburg, R. M., \& Croon, M. A. (2013). HRM, Communication, Satisfaction, and Perceived Performance A Cross-Level Test. Journal of Management, 39, 1637-1665.

Du, J., \& Choi, J. N. (2010). Pay for performance in emerging markets: Insights from China. Journal of International Business Studies, 41, 671-689.

Edgar, F., \& Geare, A. (2005). HRM practice and employee attitudes: different measures-different results. Personnel Review, 34, 534-549.

Elorza, U., Aritzeta, A., \& Ayestaran, S. (2011). Exploring the black box in Spanish firms: the effect of the actual and perceived system on employees' commitment and organizational performance. International Journal of Human Resource Management, 22, 1401-1422.

Elorza, U., Harris, C., Aritzeta, A., \& Balluerka, N. (2016). The effect of management and employee perspectives of high-performance work systems on employees' discretionary behaviour. Personnel Review, 45, 121-141.

Evans, S. (2015). Juggling on the line. Employee Relations, 37, 459-474.

Farndale, E., \& Kelliher, C. (2013). IMPLEMENTING PERFORMANCE APPRAISAL: EXPLORING THE EMPLOYEE EXPERIENCE. Human Resource Management, 52, 879-897.

Flinchbaugh, C., Li, P., Luth, M. T., \& Chadwick, C. (2016). Team-level high involvement work practices: Investigating the role of knowledge sharing and perspective taking. Human Resource Management Journal, 26, 134150.

Garcia-Chas, R., Neira-Fontela, E., \& Varela-Neira, C. (2016). High-performance work systems and job satisfaction: a multilevel model. Journal of Managerial Psychology, 31, 451-466. 
Gittell, J. H., Seidner, R., \& Wimbush, J. (2010). A relational model of how highperformance work systems work. Organization Science, 21, 490-506.

Harney, B., \& Jordan, C. (2008). Unlocking the black box: Line managers and HRM-Performance in a call centre context. International Journal of Productivity and Performance Management, 57, 275-296.

Heffernan, M., \& Dundon, T. (2016). Cross-level effects of high-performance work systems (HPWS) and employee well-being: the mediating effect of organisational justice. Human Resource Management Journal, 26, 211231.

Holden, L. (1996). HRM and employee involvement in Britain and Sweden: a comparative study. International Journal of Human Resource Management, 7, 59-81.

Holman, D., Frenkel, S., Sorensen, O., \& Wood, S. (2009). Work design variation and outcomes in call centers: Strategic choice and institutional explanations. Industrial and Labor Relations Review, 62, 510-532.

Hong, Y., Liao, H., Raub, S., \& Han, J. H. (2016). What it takes to get proactive: An integrative multilevel model of the antecedents of personal initiative. Journal of Applied Psychology, 101, 687-701.

Hopkins, B., Dawson, C., \& Veliziotis, M. (2016). Absence management of migrant agency workers in the food manufacturing sector. The International Journal of Human Resource Management, 27, 1082-1100.

Huang, L. C., Ahlstrom, D., Lee, A. Y. P., Chen, S. Y., \& Hsieh, M. J. (2016). High performance work systems, employee well-being, and job involvement: an empirical study. Personnel Review, 45, 296-314.

Innocenti, L., Peluso, A. M., \& Pilati, M. (2012). The interplay between HR practices and perceived behavioural integrity in determining positive employee outcomes. Journal of Change Management, 12, 399-415.

Innocenti, L., Profili, S., \& Sammarra, A. (2013). Age as moderator in the relationship between HR development practices and employees' positive attitudes. Personnel Review, 42, 724-744.

Jensen, J. M., Patel, P. C., \& Messersmith, J. G. (2013). High-performance work systems and job control consequences for anxiety, role overload, and turnover intentions. Journal of Management, 39, 1699-1724.

Jiang, K., Hu, J., Liu, S., \& Lepak, D. P. (In Press). Understanding Employees' Perceptions of Human Resource Practices: Effects of Demographic Dissimilarity to Managers and Coworkers. Human Resource Management.

Jiang, Y., Colakoglu, S., Lepak, D. P., Blasi, J. R., \& Kruse, D. L. (2015). Involvement work systems and operational effectiveness: Exploring the moderating effect of national power distance. Journal of International Business Studies, 46, 332-354.

Kehoe, R. R., \& Wright, P. M. (2013). The impact of high-performance human resource practices on employees' attitudes and behaviors. Journal of Management, 39, 366-391.

Khilji, S. E., \& Wang, X. (2006). 'Intended' and 'implemented' HRM: the missing linchpin in strategic human resource management research. The International Journal of Human Resource Management, 17, 1171-1189. 
Korff, J., Biemann, T., \& Voelpel, S. C. (2016). Human resource management systems and work attitudes: The mediating role of future time perspective. Journal of Organizational Behavior.

Koster, F., \& Wittek, R. (2016). Competition and constraint Economic globalization and human resource practices in 23 European countries. Employee Relations, 38, 286-303.

Kostopoulos, K. C., Bozionelos, N., \& Syrigos, E. (2015). Ambidexterity and Unit Performance: Intellectual Capital Antecedents and Cross-Level Moderating Effects of Human Resource Practices. Human Resource Management, 54, s111-s132.

Kroon, B., van de Voorde, K., \& van Veldhoven, M. (2009). Cross-level effects of high-performance work practices on burnout: Two counteracting mediating mechanisms compared. Personnel Review, 38, 509-525.

Kydd, C. T., \& Oppenheim, L. (1990). Using human resource management to enhance competitiveness: Lessons from four excellent companies. Human Resource Management, 29, 145.

Li, X., \& Frenkel, S. (2017). Where hukou status matters: analyzing the linkage between supervisor perceptions of HR practices and employee work engagement. The International Journal of Human Resource Management, 28(17), 2375-2402.

Liao, H., \& Chuang, A. (2004). A multilevel investigation of factors influencing employee service performance and customer outcomes. Academy of Management Journal, 47, 41-58.

Liao, H., Toya, K., Lepak, D. P., \& Hong, Y. (2009). Do They See Eye to Eye? Management and Employee Perspectives of High-Performance Work Systems and Influence Processes on Service Quality. Journal of Applied Psychology, 94, 371-391.

Mahmood, M. (2015). Strategy, structure, and HRM policy orientation: Employee recruitment and selection practices in multinational subsidiaries. Asia Pacific Journal of Human Resources, 53, 331-350.

Makhecha, U. P., Srinivasan, V., Prabhu, G. N., \& Mukherji, S. (2016). Multi-level gaps: a study of intended, actual and experienced human resource practices in a hypermarket chain in India. The International Journal of Human Resource Management, 1-39.

Messersmith, J. G., Patel, P. C., Lepak, D. P., \& Gould-Williams, J. S. (2011). Unlocking the black box: exploring the link between high-performance work systems and performance. Journal of Applied Psychology, 96, 1105.

Monks, K., Kelly, G., Conway, E., Flood, P., Truss, K., \& Hannon, E. (2013). Understanding how HR systems work: the role of HR philosophy and HR processes. Human Resource Management Journal, 23, 379-395.

Nishii, L. H., Lepak, D. P., \& Schneider, B. (2008). Employee attributions of the "why" of HR practices: Their effects on employee attitudes and behaviors, and customer satisfaction. Personnel psychology, 61, 503-545.

Ogbonnaya, C., \& Valizade, D. (2016). High performance work practices, employee outcomes and organizational performance: a 2-1-2 multilevel 
mediation analysis. The International Journal of Human Resource Management, 1-21.

Onyemah, V., Rouziès, D., \& Panagopoulos, N. G. (2010). How HRM control affects boundary-spanning employees' behavioural strategies and satisfaction: The moderating impact of cultural performance orientation. International Journal of Human Resource Management, 21, 1951-1975.

Oppenauer, V., \& Van De Voorde, K. (2016). Exploring the relationships between high involvement work system practices, work demands and emotional exhaustion: a multi-level study. The International Journal of Human Resource Management, 1-27.

Park, R. (2016). Autonomy and citizenship behavior: a moderated mediation model. Journal of Managerial Psychology, 31, 280-295.

Peretz, H., Levi, A., \& Fried, Y. (2015). Organizational diversity programs across cultures: effects on absenteeism, turnover, performance and innovation. International Journal of Human Resource Management, 26, 875-903.

Peters, P., Poutsma, E., Van Der Heijden, B. I. J. M., Bakker, A. B., \& Bruijn, T. D. (2014). Enjoying New Ways to Work: An HRM-Process Approach to Study Flow. Human Resource Management, 53, 271-290.

Piening, E. P., Baluch, A. M., \& Ridder, H. G. (2014). Mind the intendedimplemented gap: Understanding employees' perceptions of HRM. Human Resource Management, 53, 545-567.

Sanders, K., \& Yang, H. D. (2016). The HRM Process Approach: The Influence of Employees' Attribution to Explain the HRM-Performance Relationship. Human Resource Management, 55, 201-217.

Scheel, T., Rigotti, T., \& Mohr, G. (2014). Training and performance of a diverse workforce. Human Resource Management, 53, 749-772.

Seeck, H., \& Parzefall, M.-R. (2010). From HRM to psychological contracting-the case of Finnish mobile content producing companies. The International Journal of Human Resource Management, 21, 2677-2693.

Shen, J. (2016). Principles and Applications of Multilevel Modeling in Human Resource Management Research. Human Resource Management, 55, 951-965.

Shen, J., \& Benson, J. (2016). When CSR Is a Social Norm: How Socially Responsible Human Resource Management Affects Employee Work Behavior. Journal of Management, 42, 1723-1746.

Shen, J., Benson, J., \& Huang, B. (2014). High-Performance Work Systems and Teachers' Work Performance: The Mediating Role of Quality of Working Life. Human Resource Management, 53, 817-833.

Shen, J., Tang, N., \& D'Netto, B. (2014). A multilevel analysis of the effects of HR diversity management on employee knowledge sharing: the case of Chinese employees. International Journal of Human Resource Management, 25(12), 1720-1738. doi:10.1080/09585192.2013.859163

Shin, S. J., Jeong, I., \& Bae, J. (2016). Do high-involvement HRM practices matter for worker creativity? a cross-level approach. The International Journal of Human Resource Management, 1-26.

Snape, E., \& Redman, T. (2010). HRM Practices, Organizational Citizenship Behaviour, and Performance: A Multi-Level Analysis. Journal of Management Studies, 47, 1219-1247. 
Sonnenberg, M., Koene, B., \& Paauwe, J. (2011). Balancing HRM: The psychological contract of employees: A multi-level study. Personnel Review, 40, 664-683.

Sun, L.-Y., Aryee, S., \& Law, K. S. (2007). High-performance human resource practices, citizenship behavior, and organizational performance: A relational perspective. Academy of Management Journal, 50, 558-577.

Takeuchi, R., Chen, G., \& Lepak, D. P. (2009). Through The Looking Glass Of A Social System: Cross-Level Effects Of High-Performance Work Systems On Employees' Attitudes. Personnel psychology, 62, 1-29.

Tayeb, M. (1998). Transfer of HRM practices across cultures: an American company in Scotland. International Journal of Human Resource Management, 9, 332-358.

Uen, J.-f., Chien, M. S., \& Yen, Y.-F. (2009). The mediating effects of psychological contracts on the relationship between human resource systems and role behaviors: A multilevel analysis. Journal of Business and Psychology, 24, 215-223.

Van De Voorde, K., \& Beijer, S. (2015). The role of employee HR attributions in the relationship between high-performance work systems and employee outcomes. Human Resource Management Journal, 25, 62-78.

Van De Voorde, K., Van Veldhoven, M., \& Veld, M. (2016). Connecting empowerment-focused HRM and labour productivity to work engagement: the mediating role of job demands and resources. Human Resource Management Journal, 26, 192-210.

Vermeeren, B. (2014). Variability in HRM implementation among line managers and its effect on performance: a 2-1-2 mediational multilevel approach. International Journal of Human Resource Management, 25, 3039-3059.

Wei, Y.-C. (2015). Do employees high in general human capital tend to have higher turnover intention? The moderating role of high-performance HR practices and P-O fit. Personnel Review, 44, 739-756.

Wei, Y.-C., Han, T.-S., \& Hsu, I. C. (2010). High-performance HR practices and OCB: a cross-level investigation of a causal path. International Journal of Human Resource Management, 21, 1631-1648.

Wheeler, A. R., Halbesleben, J. R. B., \& Harris, K. J. (2012). How job-level HRM effectiveness influences employee intent to turnover and workarounds in hospitals. Journal of Business Research, 65, 547-554.

Whitener, E. M. (2001). Do "high commitment" human resource practices affect employee commitment? A cross-level analysis using hierarchical linear modeling. Journal of Management, 27, 515-535.

Wood, S., \& de Menezes, L. M. (2011). High involvement management, highperformance work systems and well-being. International Journal of Human Resource Management, 22, 1586-1610.

Wood, S., Van Veldhoven, M., Croon, M., \& De Menezes, L. M. (2012). Enriched job design, high involvement management and organizational performance: The mediating roles of job satisfaction and well-being. Human Relations, 65, 419-445.

Wu, P.-C., \& Chaturvedi, S. (2009). The Role of Procedural Justice and Power Distance in the Relationship Between High Performance Work Systems 
and Employee Attitudes: A Multilevel Perspective. Journal of Management, 35, 1228-1247.

Zatzick, C. D., \& Iverson, R. D. (2011). Putting employee involvement in context: a cross-level model examining job satisfaction and absenteeism in highinvolvement work systems. International Journal of Human Resource Management, 22, 3462-3476.

Zhu, C. J., Cooper, B. K., Fan, D., \& De Cieri, H. (2013). HR practices from the perspective of managers and employees in multinational enterprises in China: Alignment issues and implications. Journal of World Business, 48, 241-250.

Zoogah, D. B. (2016). Tribal diversity, human resources management practices, and firm performance. Canadian Journal of Administrative Sciences. 


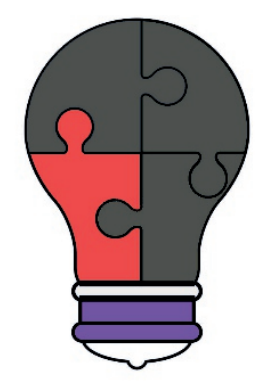

\section{CHAPTER 3}

\section{Exploring the Implications for the HRM function of Implementing Self-Managing Teams: Evidence from a Case Study in the Netherlands}

"Great things in business are never done by one person. They're done by a team of people."

(Steve Jobs) 


\section{Abstract}

Organizations increasingly implement self-managing teams (SMTs) to empower their employees. By drawing from the HRM process model and multilevel thinking, we explore how the HRM function transforms when organizations implement SMTs. Therefore, the aim of this study is to discover the most important changes to the HRM function in terms of actors and activities. To do so, we adopted an exploratory research and conducted a multilevel case study at a large healthcare organization in The Netherlands. Based on 70 interviews, documents, and observations, our findings show that SMTs transform the HRM function by changing the responsibilities of teams, HRM professionals and line managers in the implementation of HRM activities and alters the dynamics between intended, actual and perceived HRM. Our most important theoretical contribution is that these changes in the HRM function influence the entire HRM implementation process and provides all actors with new roles and activities.

\subsection{Introduction}

In the last few decades, we have seen a trend of increasing empowerment of employees. In an effort to increase innovativeness, adaptability, and involvement (Kirkman \& Rosen, 1999; Lawler, 1986), many organisations are adopting the concept of empowered teams (Maynard et al., 2012). In the HRM literature, there are many examples of HRM innovations that are used to promote employee empowerment: for example, job-crafting (Tims, Bakker, \& Derks, 2012; Wrzesniewski \& Dutton, 2001), idiosyncratic deal negotiations (Rousseau et al., 2006), and HRM shared services (Meijerink, Bondarouk, \& Maatman, 2013). The introduction of high-involvement HRM systems is focused on empowering employees as well, through involving, empowering, and supporting them to be more autonomous (Guthrie, 2001; Lawler, 1992).

In this study, we focus on one particular HRM innovation that is used to empower employees, namely self-managing teams (SMTs). Recently, we have witnessed a new wave of adoption of the self-management concept by implementing SMTs (Druskat \& Wheeler, 2004; Maynard et al., 2012). SMTs are defined as groups of interdependent individuals that can self-regulate their behaviour on relatively whole tasks (Goodman, Devadas, \& Griffith Hughson, 1988). They take collective responsibility for the outcomes of their work, monitor their own performance, and manage their work by changing strategy and activities (Hackman, 1987). The idea behind implementing self-management is that teams and employees become more effective when they feel empowered (Kirkman \& Rosen, 1999; Spreitzer, 1995). Many studies have presented findings on the effects of SMTs (Magpili \& Pazos, 2018). In fact, SMTs have been 
associated with enhanced productivity (Cohen \& Ledford Jr, 1994), higher effectiveness (Kirkman \& Rosen, 1999; Mathieu, Gilson, \& Ruddy, 2006), and better quality of working life (Cohen, Ledford Jr, \& Spreitzer, 1996). To understand how SMTs can be successful, many studies have examined antecedents of SMTs (Magpili \& Pazos, 2018; Seibert et al., 2011), but we lack an understanding of the implications that implementing SMTs bring to the HRM function itself.

To fill this gap, we can learn from the HRM implementation literature. Recent studies have suggested that the implementation of HRM is not a straightforward process (Van Mierlo et al., 2018) and stressed that multiple actors are involved (Bos-Nehles \& Bondarouk, 2015; Bos-Nehles \& Meijerink, 2018). We believe that the implementation of SMTs is dependent on various HRM actors as well, which we refer to as the HRM function - defined as "all managerial actions carried out at any level regarding the organisation of work and the entry, development and exit of people in the organisation so that their competencies are used at their best in order to achieve corporate objectives" (Valverde, 2001, p. 19). Although self-managing employees are supposed to implement HRM activities in their own teams, they are supported by line managers and HRM professionals in the organisation (Bondarouk et al., 2018). In our view, the SMT implementation is not only dependent on the HRM function, it also affects the HRM actors and their activities.

The implementation and execution of HRM practices are up to the SMTs themselves, forcing the role of HRM actors to change. SMTs execute HRMrelated tasks such as selection and termination of workers, cross-training, evaluating team members, setting working schedules, determining budgets, planning, and quality assessment (Barker, 1993; Stewart et al., 1999; Spreitzer, 2008). Nevertheless, SMTs do not take over all HRM-related functions (Spreitzer, 2008) and still need a form of leadership to increase their effectiveness (Mathieu et al., 2006; Rapp et al., 2016). We still know little about how the responsibilities and activities of HRM actors involved in implementing HRM change as a result.

HRM professionals need more knowledge about SMTs and a better understanding of the factors that are crucial for their development and implementation (Gibson \& Kirkman, 1999). Line managers need to learn to let go of some of their HRM responsibilities and guide employees to lead themselves (Manz \& Sims, 1987). Employees, on the other hand, need to get acquainted with the new HRM responsibilities and distribute HRM tasks among team members. Therefore, in this study, we have addressed the following research question: "What are the most important changes to the HRM function regarding its actors and activities when implementing SMTs?" Answering this research question is important for at least two reasons. First, it helps us to understand better how the 
HRM function engages in the implementation of SMTs in organisations. Second, this is theoretically important as self-management introduces employees as key HRM players, meaning that HRM outcomes are dependent on the collective of HRM actors, so we first need to understand the HRM function in organisations with SMTs before we can explain the outcomes of self-management.

To study the changes wrought in the HRM function as a consequence of implementing SMTs, we analysed how HRM activities, implemented by HRM professionals, line managers, and employees in teams, change during the implementation of SMTs. We explored this role transformation using the HRM process theory (Bowen \& Ostroff, 2004; Wright \& Nishii, 2013) and applied lessons from multilevel HRM research (Renkema, Meijerink, \& Bondarouk, 2017). We adopted an in-depth, case-study approach and examined the changes to the HRM actors and activities due to the implementation of SMTs at a large, longterm and elderly care provider in The Netherlands. In doing so, this paper makes important theoretical contributions. By applying principles of multilevel thinking to the HRM implementation process (Renkema et al., 2017), we contribute to the HRM process literature (Bowen \& Ostroff, 2004; Wright \& Nishii, 2013). We distinguish not only between intended-actual-perceived HRM (Makhecha et al., 2018; Wright \& Nishii, 2013), but also between HRM philosophies, policies, and practices as well as organisational actors at the organisation, unit, and employee levels in organisations. We show that changes in the HRM function influence the entire HRM implementation process and provide all actors with new roles and activities. Based on our findings, we propose a model of HRM implementation in the era of empowerment.

\subsection{Theoretical background}

\subsubsection{Self-managing teams}

One of the most influential definitions of SMTs was coined by Goodman et al. (1988), who stated that SMTs are "groups of interdependent individuals that can self-regulate their behaviour on relatively whole tasks". Many studies have built on this definition to examine the antecedents and effects of SMTs (e.g. Cohen \& Ledford Jr, 1994; Spreitzer, 1995). Recently, SMTs were defined as "groups of interdependent individuals who have the autonomy to self-regulate their behaviour on relatively whole tasks, they possess a variety of work skills, are responsible for decision making, monitoring and altering their performance, they fulfil traditional management tasks and meet company goals" (Bondarouk et al., 2018, p. 12).

The degree of SMTs' autonomy is an important issue in the SMT literature. Some argue that self-management implies no role for managers 
(Laloux, 2014), whereas others state that leaders remain essential (Morgeson, 2005). Hackman (1986) identified three behavioural indicators for the extent to which teams are self-managing: (1) the degree to which team members take collective responsibility for the outcomes of their work; (2) the degree to which a team monitors its performance; and (3) the degree to which the team manages its own performance, making changes in work strategies when circumstances change or feedback indicates that a new approach is needed (Wageman, 2001).

More specifically, the responsibilities of SMTs can be divided into two categories: (1) operational functions that are related to the primary work process, and (2) regulatory functions that are related to management tasks such as planning, monitoring, problem-solving, and improving performance (e.g. Amelsvoort \& Scholtes, 1994; Tjepkema, 2003). The shift towards SMTs implies that both functions are performed by teams, whereas in a traditional organisation, the regulatory functions were the responsibility of managers. In this paper, we focus on the regulatory functions that are related to HRM, such as recruitment and training. Given that SMTs are responsible for implementing these HRM activities in their teams, it can be expected that the roles of HRM actors will change. Nevertheless, to our knowledge, there have been almost no studies that provided empirical evidence about the HRM function in organisations with SMTs. It would be valuable to explore and better understand the HRM function in such a context. In the next section, we explain the HRM function in more detail.

\subsubsection{HRM function and the implementation of HRM}

Previous research introduced a variety of models that delineate the actors that jointly constitute the HRM function. Jackson, Schuler, and Werner (2009), for instance, drafted the so-called HR triad to explain that HRM professionals, line managers, and employees are the primary players in HRM processes. In an attempt to delineate who these HRM professionals are, Valverde et al. (2006) noted that the HRM function includes both the corporate HRM department and external HRM agencies that work alongside line and top managers in executing HRM activities. Throughout the years, HRM function typologies have expanded further to include HRM shared service centres that offer administrative and operational HRM services to employees from a centralized location (Boglind, Hällstén, \& Thilander, 2011; Maatman, Bondarouk, \& Looise, 2010) as well as HR business partners and centres of expertise that support line managers in implementing HRM (Ulrich, Younger, \& Brockbank, 2008). Although differing in the specific HRM actors included, what unites the current typologies is that they imply a three-legged HRM function that consists of HRM professionals, line managers on various hierarchical levels (e.g. first-line, middle, and top 
managers), and employees. With the advent of SMTs, it is time to add 'teams' as a key HRM actor, with SMTs taking over regulatory HRM responsibilities. Although contributing to the HRM function differently, all four actors are involved in the implementation or execution of HRM.

The implementation of HRM is understood here as a process in which HRM policies and/or practices evolve until they are used by all HRM actors on a regular basis (Bondarouk, Trullen, \& Valverde, 2016; Trullen, Bos-Nehles, \& Valverde, 2018). According to Bos-Nehles and Bondarouk (2017), the implementation of HRM is a multilevel and multi-actor process because HRM practices are present at various levels and are implemented by various HRM stakeholders. Usually, three HRM levels are distinguished, i.e. intended HRM practices at the design level, actual HRM practices at the implementation level, and perceived HRM practices at the experience level (Makhecha et al., 2018; Wright \& Nishii, 2013). The various HRM actors are involved in the HRM implementation at different levels. HRM professionals are usually responsible for designing intended HRM practices, line managers for implementing actual HRM practices, and employees for perceiving HRM practices (Guest \& Bos-Nehles, 2013). Since HRM implementation is a 'social process in which implementation depends on the social exchange relationships among HRM actors' (Bos-Nehles \& Meijerink, 2018, p. 2), it is advisable to consider the contribution of all HRM actors - including SMTs - in the HRM implementation process.

The HRM implementation literature has recently addressed a more dynamic view of the HRM implementation process (e.g. Van Mierlo et al., 2018), in which e.g. HRM professionals and line managers can become communicators as well as receivers of HRM practices, and HRM actors influence HRM practices because they behave within but also outside of the behavioural boundaries of HRM practices. Employees have been given a more active role in the HRM implementation process because they not only perceive HRM practices (BosNehles \& Meijerink, 2018; Piening, Baluch, \& Salge, 2013), but also co-create and co-produce them (collectively as a team) (Meijerink et al., 2016; Meijerink \& Bos-Nehles, 2017), and shape as well as influence them during their design and implementation (Budjanovcanin, 2018). Yet, apart from the studies mentioned in this section, there is a lack of research that focused on understanding HRM implementation in the era of empowerment, where employees become active part of the HRM function. By building on the insights of HRM implementation, we aim to understand in what way the three HRM actors - HRM professionals, line managers, employees - deal with changes in their tasks and responsibilities, interact, and influence HRM activities during the implementation of SMTs. 


\subsubsection{Multilevelity Cube}

To analyse the HRM function in organisations with SMTs, we make use of the multilevelity cube of HRM (Renkema et al., 2017). The cube consists of three dimensions - abstraction levels, internalization levels, and organisational levels - each describing one aspect of multilevel HRM. Based on multilevel thinking, one of the applications of the cube is to analyse how the HRM function is organised in firms by identifying the level of HRM activities. First, HRM activities can be distinguished based on the level of abstraction, referring to the HRM philosophies, policies, and practices (Schuler, 1992). HRM philosophies are statements about how the organisation sees its human resources and include guiding principles for the choice of HRM policies and practices (Arthur \& Boyles, 2007; Schuler, 1992). HRM policies describe specific objectives for managing human resources and attaining employee performance. HRM practices are specific instruments that are used to manage employees' abilities, motivation, and opportunities to perform (Jiang et al., 2012). For example, training and recruitment can be used to enhance employees' abilities, while performance management and rewards are more geared towards motivation (Lepak, Liao, Chung, \& Harden, 2006).

Second, HRM activities can be categorized using the level of internalization, referring to whether HRM activities are intended, introduced, or experienced (Wright \& Nishii, 2013). Intended HRM is defined as the rationally designed HRM practices during HRM strategy development to realize specific employee behaviours; introduced HRM refers to the actual realization of intended HRM practices; and experienced HRM is understood as employees' perceptions of these HRM practices (Wright \& Nishii, 2013).

Third, HRM activities can manifest at different organisational levels, referring to the organisation as a whole, to separate units or teams, or to individual employees (Ostroff \& Bowen, 2000). To distinguish between these HRM activities at different levels, it is important to identify the most suitable HRM actors to report on the HRM activities (Banks \& Kepes, 2015). In our study, the levels correspond with different HRM actors responsible for HRM activities: HRM department, line management, teams, and individual employees. The organisational level is represented by the HRM department, the unit level by line managers and teams, and the individual level by work floor employees. Therefore, in this study, organisational levels are embodied by the HRM actors, and the internalization and abstraction levels represent the HRM activities.

In the past, most studies assumed that line managers were responsible for the implementation of HRM activities (e.g. Bos-Nehles, Van Riemsdijk, \& Looise, 2013), or employees themselves were seen as proactive HRM implementation partners (Meijerink et al., 2016). However, in organisations with 
SMTs, teams are part of the decision-making and implementation of HRM. For that reason, SMTs are responsible for a great part of the HRM activities and coproduce the value of HRM. Based on the research of Morgeson (2005) and Wageman (2001), we expect that line managers lose their responsibility for HRM implementation but may still coach the HRM implementation process from the outside. The HRM department is expected to support the employees in this process (Bondarouk et al., 2018). Although some studies provided insights into the role of line-managers for SMTs, we are lacking empirical evidence that holistically shows in what ways the HRM function is organised to support SMTs and HRM implementation. What do these expected changes in responsibilities of HRM actors mean for the HRM function? Who becomes responsible for designing intended HRM practices when HRM professionals become supporters of SMTs? These are questions we hope to answer on the basis of a case study about the implementation of SMTs. The case presents a unique chance to study in what ways HRM changes when introducing SMTs.

\subsection{Methodology}

We used a qualitative research design with a single case study to explore the role of the HRM function in organisations with SMTs (Yin, 2014). This research design was chosen because it involves the use of one case organisation to expand the theory on HRM for SMTs based on empirical evidence (Eisenhardt, 1989). We conducted this case study within a large Dutch care organisation. This organisation was deliberately selected because it is well positioned to study SMTs and the role of the HRM function, given that it recently decided to introduce SMTs, enabling us to analyse the design and implementation processes. The case study organisation will hereafter be called "HealthServ" for reasons of anonymity.

\subsubsection{Data Collection}

The research at HealthServ was carried out between December 2016 and January 2018. Given the multilevel approach, we collected data from informants at all different hierarchical levels of the organisation. For triangulation purposes, we relied on multiple data sources, including interviews, documents, and observations. HealthServ allowed us to access the organisation's intranet and project groups, enabling us to collect strategic plans and documents, internal reports, minutes, presentations, communication, and policy documents. In addition, several company meetings were attended during the research project. In total, 70 semi-structured interviews were conducted at 10 different locations of 
HealthServ (see Table 3.1). All interviewees were assured of confidentiality and anonymity.

\begin{tabular}{lc}
\hline Informants & \#Interviews \\
Management team & 6 \\
First-line managers (FLMs) & 13 \\
HRM professionals & 9 \\
Team members SMTs & 42 \\
Total & 70 \\
\hline
\end{tabular}

Table 3.1. Overview of interviews at HealthServ

\subsubsection{Procedure and data sources}

Given the focus on the activities performed by HRM professionals, first-line managers (FLMs), and employees in teams, we collected data from all these groups of HRM actors. The data collection started with a pre-study phase in which we discussed SMTs in the case study organisation and gained formal approval. The first period of data collection consisted of studying official policy documents, strategic plans, and presentations to gain an understanding of the organisation and its vision, strategy, and approach to SMTs. Subsequently, we collected data through semi-structured interviews with all 6 members of the management team. These interviews were meant to clarify the vision of the organisation and its strategic choices regarding SMTs. Based on an analysis of these interviews and the literature review, protocols were developed for semi-structured interviews with FLMs (see Appendix B to Appendix D). The second phase of the data collection involved interviews with 13 FLMs - called 'coach-managers' at HealthServ - employees who were formerly responsible for managing one or several teams but recently switched to a coach function. These in-depth interviews focused on the design of SMTs, the role of the FLM and HRM department, and team processes. The third phase consisted of 42 interviews with employees working in SMTs. These interviews mainly focused on their experience of working in SMTs, the HRM activities they conducted, the support they need, and team processes. During this phase, other employees of the HRM department were also interviewed to explore the role of the HRM function in the transition towards SMTs.

Along with the data from interviews, notes from non-participant observations at the organisation were used to add additional insights into SMTs. To increase the trustworthiness and rigor of our research, we took several actions. First, we used triangulation methods as proposed by Patton (1990). For instance, we used interviews with employees with different functions. Also, several company meetings about SMTs were attended as an observer to gain a more profound understanding of SMTs and to triangulate the interview data. 
Second, documents and internal communications were analysed and informal discussions held with key stakeholders increase the validity and enhance the credibility of the research findings (Yin, 2014). Third, all interviews followed a semi-structured protocol for which questions were pre-determined based on both the literature and previous interviews. Interviewers also asked probing questions to gain a more profound understanding of the topics. The interview protocols were refined as we progressed from one phase to the other, and were extensively discussed by the team of researchers to align them with the organisational context and the literature.

\subsubsection{Data analysis}

All the raw data collected from the interviews were transcribed verbatim and imported together with all the documents and observation notes into the data analysis software (NVivo, v10). Because of our explorative qualitative research design, we used several coding strategies based on both inductive and deductive analysis. In our analysis, we focused on the role of HRM actors and corresponding HRM activities. We used the interviews with HRM professionals, FLMs, and employees to find out how HRM activities and responsibilities are distributed.

To examine the HRM function and SMTs, we used qualitative content analysis with three successive levels of coding (Strauss \& Corbin, 1998). In the first step, all raw data files were read, and notes and ideas were written down and discussed. We assessed the data for themes that were linked to introduction of SMTs and the HRM function. This resulted in core thematic concepts and categories based on SMTs at HealthServ and the existing literature. We coded all texts that were related to specific HRM domains, such as recruitment \& selection and training \& development. Next, we went deeper into the data and identified first-order codes, terms, and categories using open coding to identify and describe specific activities (Gioia, Corley, \& Hamilton, 2013). These codes came directly from the interview transcripts and words used by the informants (Miles \& Huberman, 1994; Strauss \& Corbin, 1998). Then the analysis progressed to theoretical coding, in which we theorize patterns in the data in relation to the literature - specifically the multilevelity cube as described in the theoretical background. Based on codes from the first phase, we analysed and grouped the HRM activities performed by the different HRM actors into philosophies, policy domains, and practices, and categorized them as intended, introduced, or perceived activities.

From the interviews and documents, we extracted the most frequently mentioned HRM activity-clusters for further analysis. Based on these clusters, we 
identified first-order descriptive inductive codes (Miles \& Huberman, 1994). These codes were grouped into second-order labels - which constitute the most important aspects of the HRM clusters. Subsequently, we identified the focal HRM actors in these activities and categorized the activities using two crosstables (see Appendix E), including HRM policy domains and practices, the identified activity areas and HRM actors and their activities. This led to the identification of the 6 most important HRM activity-clusters: recruitment \& selection, training \& development, performance management, HRM staffing \& formation, work design, and scheduling \& planning.

\subsection{Findings}

In this section, we describe the results and illustrate how SMTs change the HRM function. We also clarify how HRM activities are performed by different HRM actors.

\subsubsection{Case description and approach to SMTs}

HealthServ is a long-term and elderly care organisation located in the eastern part of The Netherlands, which employs around 2500 employees and is focused on the field of caring, living, and health. The most important activities of the organisation are providing home care, residential care, and care for disabled people. HealthServ has two main business units: 'Home Care' (i.e. care provided at people's homes) and 'Residential Care' (i.e. care provided in a care facility), including 60-80 teams and around a thousand volunteers. As part of its mission, HealthServ believes that people want to lead their own lives and remain independent, and thus focuses on client-centred care. This makes the clients themselves and their families responsible for being active in the caring process. It also instils self-management among its clients, who become the centre of the organisational model (Figure 3.1). This requires more client-focused working methods, empowering clients to make their own decisions. To facilitate this, the care professionals needed enough freedom to act upon the demands of their clients, which partly determined why HealthServ chose to introduce a team of employees around the client to provide that care. It developed support functions around the teams, including departments or functions with different specializations such as HRM and coaching.

Along these lines, HealthServ chose to empower those teams by giving them more responsibilities and authority, introducing SMTs. It developed a set of leading principles for the design of what they call 'professionally organised' teams: (1) small teams of set employees and clients, (2) shared responsibilities, (3) professionalism and craftsmanship of individual employees, (4) division of 
roles and tasks within the team, and (5) a coach-manager to provide support and adjust when necessary. Together with the employees, the team tasks, roles, goals and guidelines, composition, and support were designed.

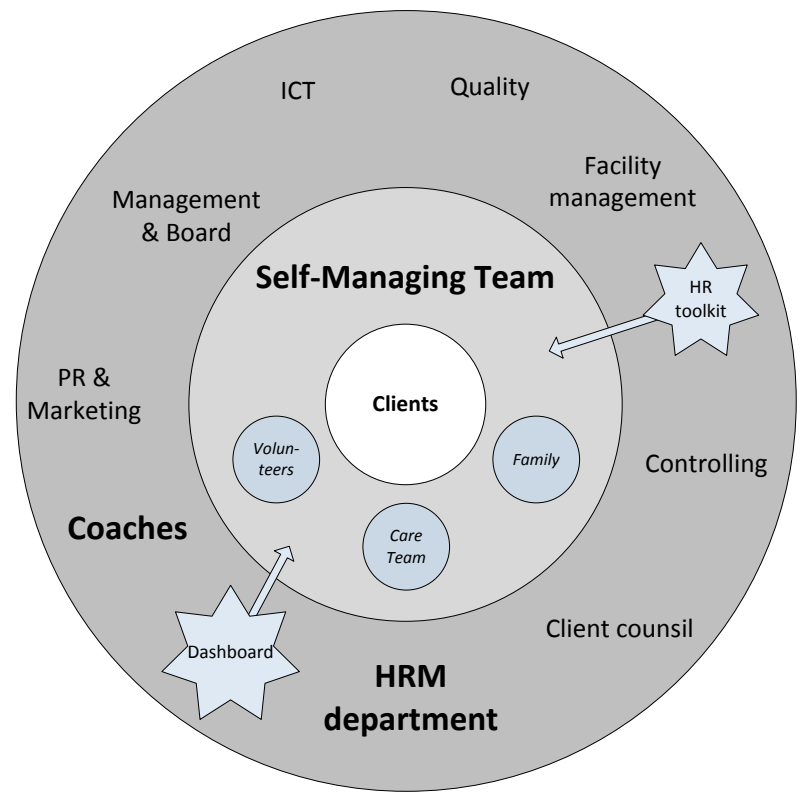

Figure 3.1. Organisational model of self-managing teams (SMTs)

\subsubsection{HRM activities in organizations with SMTs}

In this section, we describe the HRM activities along the lines of the multilevelity cube that was introduced earlier. First, the HRM philosophies, policies, and practices are described as representing HRM activities. Second, we describe the intended-actual-perceived HRM activities, delineating how HRM activities are planned and designed, how they exist and are used in the organisation, and how employees perceive them. Specifically, perceived HRM refers to employees' subjective perceptions and interpretations of the HRM philosophies, policies, and practices that are used in an organisation. Third, we focus on the role of HRM actors - the HRM professionals, line managers, and employees in teams - who are part of the implementation process of SMTs.

As discussed in the Methods section, part of the data analysis was based on identifying how HRM activities are performed at HealthServ. We uncovered important differences between the two main business units in terms of HRM activities. Therefore, we created two tables that display the division of HRM activities between the Management Team (MT), HRM department (HRM), FLMs, and SMTs in the two main business units of HealthServ (Appendix E). In the 
following sections, we elaborate on these findings in terms of the HRM actors and activities.

\subsubsection{HRM philosophies}

In terms of the HRM philosophy, the intention of HealthServ's management team was to empower teams to make their own decisions regarding both operational and regulatory functions of their work by introducing SMTs. In other words, HealthServ espoused a high-involvement HRM philosophy. The HRM philosophy reflected the strategic choices, as it was aligned with the mission, vision, and newly developed core values of the organisation. Furthermore, it emphasized that employees were seen as the backbone of the organisation, who should be trusted and supported to deliver high-quality care. Employees were viewed as valuable assets for the organisation, as illustrated by the investment in education programs for employees and teams. The management team was mostly responsible for developing the HRM philosophy. Its members agreed on the value of the employees and expressed that employees are capable of bearing more responsibility.

"It means that every team of employees should work as self-managing as possible, which will lead to increased quality of care and services and through which the employees can practice their profession best."

(Management 4).

The data show that the newly developed HRM philosophy was not implemented fully at HealthServ, as one of the business units (Home Care) already worked according to the HRM philosophy, while the other business unit (Residential Care) was still in the early phases of the implementation process. Therefore, the actual use of the HRM philosophy in the organisation was limited. This can be partly attributed to the lack of HRM actors taking charge of this process. The HRM philosophy was being communicated and implemented before being translated into a clear set of HRM policies and practices. In other words, there was no clear plan or guidelines for implementing the new HRM philosophy. HRM professionals did not have sufficient capacity to take on this responsibility, and FLMs were too busy with operational activities. Thus, SMTs and FLMs indicated that they needed support in performing HRM activities.

"Like I said, let them first describe what they expect from us, the role division. And I think that we need more time to organise these things; now, we have to do it during working hours, in between other tasks." (SMT36)

The case study also highlighted that there is a wide variety of employee perceptions of the newly implemented HRM philosophy. While many employees indicated that they appreciated the increased autonomy, several employees also 
expressed that they felt the additional responsibilities (such as recruitment) as an extra burden on top of their operational duties.

\begin{abstract}
"And my task is personnel and recruitment. But I am not very active with those things, because I don't think these are my tasks. I think HealthServ should organise these things first, because I have to do them alongside my own activities." (SMT9).
\end{abstract}

There were also two competing attributions as to why the organisation was switching to SMTs. On the one hand, employees believed that the intention was to enhance the quality of care, while others indicated that this transition was predominantly motivated by cost reductions.

"I think it is partly cost reduction from the management, because before we were managed, but now we have to do everything ourselves, within the same time and costs." (SMT4)

The interpretation of the HRM philosophy is partly dependent on the communication from the organisation. The data show that mixed messages were sent to SMTs by the organisation. On the one hand, HealthServ repeatedly communicated that the teams were self-managing, but on the other, it intervened with top-down actions and initiatives. This negatively influenced the employees' perceptions of HRM's underlying intentions:

"I think that many things are still decided by HealthServ. I think if you want us to make our own decisions, you have to support us. You should not still impose your ideas on us." (SMT23)

\title{
3.4.2.2 HRM policies
}

Regarding the HRM policies to realize the newly introduced HRM philosophy, managers agreed about the important role of HRM. A number of HRM policies were developed by management and HRM with the intention to empower and develop employees at HealthServ. These activities included the policy domains focused on enhancing employees' abilities (recruitment and training), motivation (performance management), and opportunities (job design/self-management, scheduling and staffing). Substantial investments were made in HRM activities. At the same time, the teams became responsible for the design and execution of many HRM practices themselves, such as recruitment \& selection, training, performance appraisal, scheduling, and staffing. As Figure 3.2 shows, the intention by the management and HRM was that these HRM activities would be performed by SMTs, with the support of the HRM department. This also meant that SMTs actually became responsible for intended HRM. Some SMTs developed their own specific objectives for performing HRM activities, for example by creating their own performance appraisal, task division, and 
scheduling policies. In terms of recruitment, some SMTs created a goal and guidelines to hire new colleagues that fit with the values of the team.

"We have our own guidelines. We ask them what they find important within the team. That is not determined 'from above', we as a team have certain issues we think are important." (SMT4)

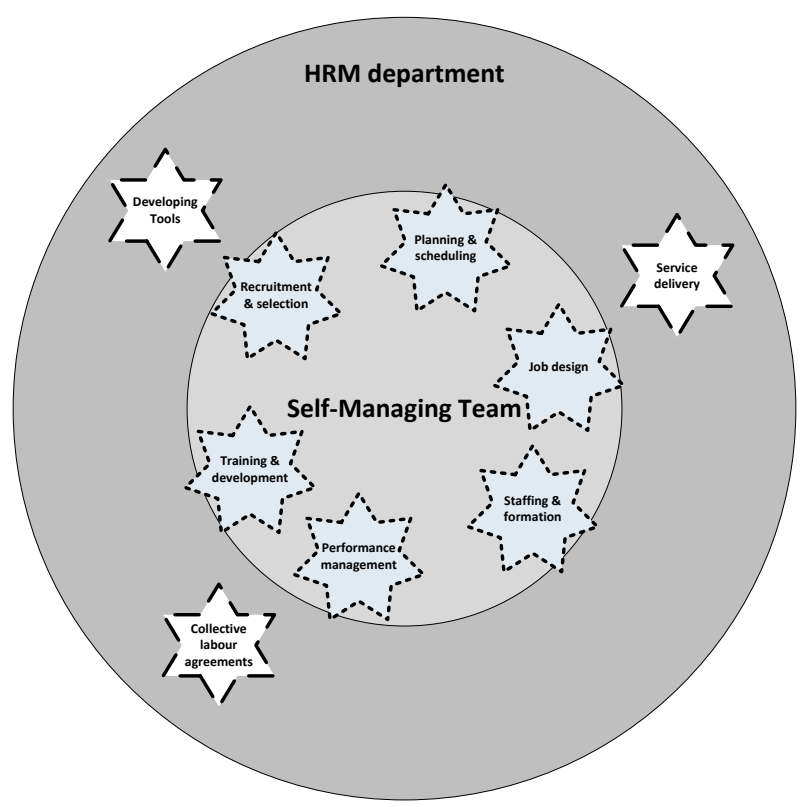

Figure 3.2. Overview of intended HRM policy-distribution

Concerning the targeted implementation and use of HRM policies, the data show that there were large differences between implementation in the two main business units and teams within those business units. HealthServ chose for phased implementation of HRM policies, and started by introducing SMTs. To support the implementation of the HRM philosophy, the HRM department developed and initiated several HRM projects simultaneously, some of which were only partially implemented. For example, the HRM department launched a tool to support SMTs to effectively organise team meetings for decision-making, but only a small number of teams made use of this instrument. FLMs were first turned into coach-managers and later on into coach-coordinators, reflecting the loss of their hierarchical position. At the same time, a large number of FLMs had to leave the organisation, and the remaining ones were made responsible for many teams. This made it more difficult to implement HRM policies in the SMTs. In many SMTs, the FLM still had to act as manager instead of coach, because 
SMTs did not adopt their HRM responsibilities. Moreover, FLMs were formerly responsible for carrying out most of the HRM functions and did not receive sufficient information and support to implement the new HRM philosophy and corresponding policies. As one FLM explained, they particularly lacked information about the boundary conditions and performance indicators for their teams:
"If you give them [the teams] boundary conditions, they are quite capable of acting, provided that you give them the right tools to manage themselves. And that is something we note is missing. Especially when you look at the financial information. Teams have to keep themselves in the black, but there is no dashboard for these teams available at the moment. How should they do that?" (FLM1)

The data show that in 'Residential Care', many of the most prominent HRM activities were still being executed by a combination of HRM professionals and FLMs, while in 'Home Care' the SMTs performed most of the HRM activities with the support of the HRM department. At a policy level, HRM professionals developed instruments to support SMTs to implement HRM activities, and SMTs developed their own policies and procedures to cope with these additional responsibilities. For example, HRM created a team development instrument, while SMTs developed their own recruitment policies, including the use of their own networks and design of flyers; and SMTs created their own app to coordinate scheduling issues. Therefore, many of the responsibilities of the HRM policy domains were actually shared between SMTs and the HRM department, as Figure 3.3 shows. With many of these HRM activities, the FLM plays a prominent role in the transformation process (Figure 3.3 - the darker activities), for example in helping to re-design jobs.

"What we are doing at the moment is looking at which task areas can be combined, to look at how we can cluster certain tasks. And then you can choose to develop them into team tasks." (FLM11) 


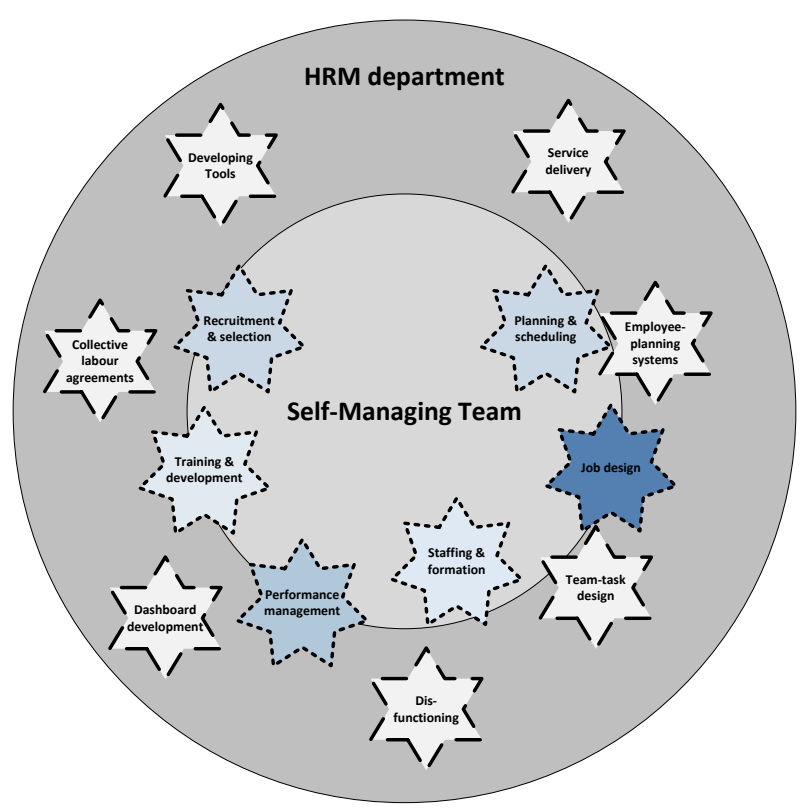

Figure 3.3. Overview of actual HRM policy-distribution

Regarding employees' perceptions about the HRM policies, employees received inconsistent messages about the implemented HRM policies, and these in turn were not always in line with the overarching HRM philosophy. The most pressing issues were that SMTs received additional responsibilities for HRM policies, but not sufficient time and resources to execute them, and they were reproached for not attaining the rigid performance goals. Several additional tasks were unclear to SMTs, for example because of the absence of clear task descriptions or boundary conditions. Employees also had difficulties with apparent contradictions between HRM policies. For example, SMTs did gain a lot of autonomy to make their own decisions and received additional responsibilities, but HealthServ decided to squeeze performance goals, which led to problems in implementing the additional HRM responsibilities.

"I think they are very much focused on production, this really is a production-driven organisation. Nurses have to be $80 \%$ production, but that is impossible, while you should focus on the question of the client."

(SMT6)

\subsubsection{HRM practices and processes}

With respect to HRM practices and processes, the intention of the management and HRM department was that SMTs would perform most of the HRM activities 
themselves. When looking at intended HRM practices, most of them involved ideas to provide SMTs with responsibilities and decision-making rights. Nevertheless, the findings show that in both 'Residential Care' and 'Home Care', the most important HRM practices were not fully performed by SMTs. At the same time, SMTs in both business units were more involved in HRM activities than before their implementation. In 'Residential Care', most of the FLMs were still focal actors in the implementation of HRM activities. The tasks and responsibilities were often unclear for SMTs, and management information and instruments were largely unavailable. In 'Home Care', almost all SMTs actively engaged in implementing and using HRM activities. For example, they were independently hiring new colleagues (recruitment \& selection) and adapting work structures and working hours in line with the demand for care (HRM staffing \& formation). Strikingly, we found several cases in which FLMs were ignored by SMTs when performing HRM activities, evidencing their independence.

"Recently, there was a vacancy in one of the teams, but I did not see one letter, not one candidate and took no decision. The team did this all independently." (FLM5)

Combined with the lack of clarity from the management team, this led to FLMs feeling less in charge and ambiguous about their role in the whole transformation process. The data show that FLMs predominantly helped organise underperforming teams, by creating structures and making important decisions, such as outplacement of employees or taking the lead in team meetings.

Employees' perceptions of HRM practices reveal a wide variety of different interpretations. We can derive from them that the HRM philosophy is not completely and successfully implemented. Employees were often unaware of the available HRM instruments and initiatives or indicated that these instruments were not available to them. One of the most frequently mentioned experiences of SMTs executing HRM practices was the lack of clarity about the exact HRM responsibilities and the lack of time to actually implement the HRM practices. Many interviewees also emphasized that authorization often lags behind organisational developments, leading to employees' negative interpretations:

"If there are unforeseen expenses, you need a signature of the coachmanager." (SMT33)

Nevertheless, the data reveal that many teams already perform many of the HRM activities that they were made responsible for, occasionally with the help of the FLM or HRM professional. Our data show that SMTs determined the need for hiring, developed a job profile (in collaboration with HRM), interviewed and selected candidates, monitored and assessed both individual and team performance, and developed and implemented their own long-term planning and 
working schedules. For example, regarding recruitment and selection, the intention of HealthServ was that SMTs would be independent in selecting their own colleagues, and supported by HRM. The management team and HRM determined rules for qualifications and team composition. The actual training practice was that HRM developed job profiles and contacted recruitment channels. HRM, FLMs, and SMTs were involved in selecting candidates and conducting interviews. HRM conducted employment conversations and handled the administrative actions. Employees perceived this practice in different ways: some appreciated having an influence in hiring new colleagues, while others saw it as a burden and a task for HRM. Hence, the results indicate that many of the HRM activities at the practice and process level are already devolved to the SMTs, who successfully engage in them.

Overall, we can conclude that the way in which HRM activities are designed, introduced, and implemented significantly changed as a result of implementing SMTs. The implementation and use of HRM activities were disrupted because of the shift in responsibilities of HRM actors. Formerly, HRM activities were designed by higher management and HRM professionals, aligning them both horizontally and vertically, and subsequently implemented and used by the HRM professionals and FLMs. When implementing SMTs, HRM activities are no longer designed exclusively by higher management, the SMTs also contribute. HRM activities are implemented in both a top-down and a bottom-up fashion. For instance, HRM activities such as appraisal tools were developed by HRM professionals, while SMTs developed their own recruitment and scheduling practices. SMTs work more on the HRM practices level, while HRM professionals react to bottom-up policy development and proactively design new policies and practices. These developments illustrate that the 'multilevelity cube' of HRM changes as a consequence of introducing SMTs. Most importantly, the prominence of HRM actors shifts towards employees; the intended-introducedexperienced process becomes a mixture of top-down and bottom-up implementation; and the responsibility for attaining horizontal and vertical alignment across philosophies, policies, and practices in the HRM system is distributed over several HRM actors (e.g. HRM professionals and SMTs).

\subsection{Implications for the HRM function: a multilevel perspective}

Our results have implications for the HRM function. We show how the HRM function changes given the introduction of employee empowerment and the active role of employees in HRM activities. The explorative case study allowed us to map the changes of the HRM function as a consequence of introducing 
SMTs (Figure 3.4). This is a process that develops through several cycles - as is represented by top-down and bottom-up arrows. The top half shows the traditional model of the HRM function, where intended practices are developed at the organisation level by management and HRM, implemented at the unit level by FLMs, and perceived by employees at the individual level. The bottom half illustrates the empowered model of the HRM function in SMT organisations, where HRM philosophies are co-designed by HRM professionals and SMTs, and HRM policies and practices are implemented and used by SMTs. The line between the individual and team level fades because individual employees become active participants in decision-making processes at the team level. Furthermore, intended HRM activities are found at both the organisation and team level, since SMTs develop and implement their own HRM activities. Lastly, there is a direct link between HRM departments and SMTs since the role of the FLM as a HRM actor is marginalized. 

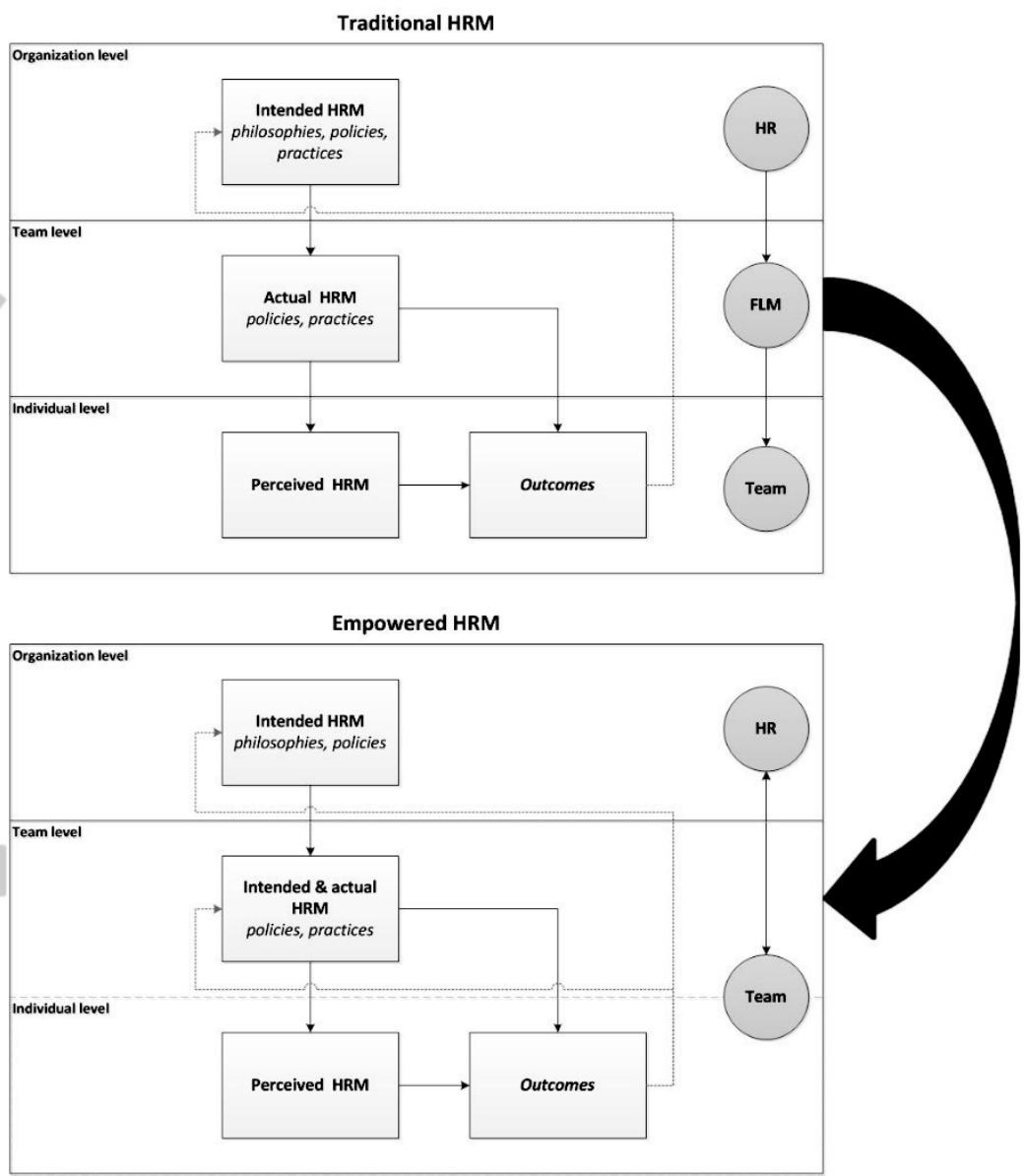

Figure 3.4. The cyclical relationship model between HRM function and SMTs 


\subsection{Discussion and conclusions}

This study empirically uncovered how the HRM function changes as a consequence of introducing SMTs, which redistributes HRM responsibilities over multiple HRM actors. We discussed how the transformed HRM function influences the HRM implementation process. In doing so, we developed an inductive model that specifies how the HRM function is changing under the influence of employee empowerment. Previous research in HRM has shown that employees have an active role in HRM implementation (Meijerink et al., 2016). We built on this research by analysing how HRM actors and activities change at multiple organisational levels. Our findings contribute to a more nuanced view on multilevel HRM (Renkema et al., 2017), a view that incorporates multiple organisational actors and highlights that employees are key HRM players. More specifically, we have shown how HRM actors and activities change when introducing SMTs: teams design and perform HRM activities themselves, FLMs coach and advise from the outside, and the HRM department becomes a service department that facilitates HRM being developed in a bottom-up fashion rather than in a traditional top-down manner. This means that SMTs are added as a key HRM actor, taking responsibility for HRM activities. For that reason, the HRM function represents an 'HRM quartet', consisting of HRM professionals, FLMs, teams, and individual employees. Although contributing to the HRM function differently, all four actors are involved in the implementation and execution of HRM. This highlights the importance of investigating the active role of selfmanaging employees in the HRM implementation process.

\subsubsection{Theoretical contributions}

This study makes important contributions to the HRM literature. First, in recent years, the HRM implementation literature has predominantly targeted the process model of HRM (Wright \& Nishii, 2013). Studies have focused either on the relationships between perceptions of HRM and its outcomes (e.g. Nishii et al., 2008) or on the link between intended, actual, and perceived HRM (Makhecha et al., 2018), thereby mainly focusing on the top-down implementation of HRM policies and practices. This study is one of the first to integrate organisational-, unit-, and individual-level processes to study how innovations in HRM change the HRM function and how this in turn affects HRM implementation. In this research, we suggest that more attention should be paid to the active role of multiple HRM actors in the process of developing, implementing, and experiencing HRM activities. Introducing SMTs demands an adapted version of the process model of HRM, in which the dynamics between intended, actual, and perceived HRM change due to the changing responsibilities of HRM actors. We point at a two- 
way street when analysing HRM and its effects on employee outcomes: HRM implementation works in both a top-down and a bottom-up fashion. Recent work on HRM implementation has argued that it is an iterative process of policy development and adaptation between HRM professionals, managers, and employees (Van Mierlo et al., 2018). We build on this assertion and provide empirical evidence that shows that HRM implementation does indeed work topdown as well as bottom-up and requires a change in the role of various HRM actors.

Second, our findings contribute to the research into the implementation gaps in the HRM literature (Makhecha et al., 2016), as the change in HRM function can explain why gaps exist between intended and perceived practices employees and teams themselves determine how the HRM practices are used and perceived. SMTs become HRM actors and thereby designers and implementers of HRM activities, who are able to ignore, adapt, or initiate HRM policies and practices in their own team context. As a consequence, a multiplicity of HRM activities can arise within organisations, leading to increased intendedactual-perceived gaps. An important factor that determines the plurality of activities is the extent to which intended HRM provides leeway for alteration. Intended HRM policies could theoretically strictly determine how SMTs should perform HRM activities. Paradoxically, this will lead to a decreased sense of empowerment in teams, as they are self-managing and should be able to make their own decisions about both primary and regulatory functions. We therefore propose a dual responsibility for intended HRM activities in which the HRM department and team members of SMTs take on the tasks related to this role. In SMTs, team members become active HRM actors, taking on responsibilities for intended, actual, and perceived HRM activities. By developing new HRM practices and processes, implementing intended ones, and perceiving the results of their own actions in implementing these practices, employees gain the most important and influential role in the HRM implementation process. In earlier research, there has often been a focus on intended, actual, and perceived HRM systems, where researchers examine discrepancies between HRM professional reports in the design of a bundle of HRM activities, line manager reports on whether they implement such systems, and finally, how employees perceive a collective of HRM activities. As a consequence, disconnections in intentions, actions, and perceptions of individual HRM activities (e.g. training or job design) are considered limited. Our results show, however, that there are significant differences for each individual HRM activity, with intention-action-perception gaps being non-existent for some HRM activities, while other HRM activities were highly disconnected across intended-actual-perceived levels. To better 
understand gaps across these internalization levels, future studies can best consider differences for individual HRM activities.

Third, our insights add to the HRM devolution literature (e.g. Guest, 1987; Purcell \& Hutchinson, 2007) as we have shown that the role of the FLM significantly decreases in terms of HRM responsibilities. When teams take on HRM responsibilities, the FLM loses influence and may eventually disappear as a manager. The decline of the influence of the FLM has important implications for the HRM implementation literature, as the FLM is often regarded as a principal actor in implementing HRM activities (Makhecha et al., 2018). Our findings show that the number of FLMs was already significantly lower, and their role on the work floor significantly reduced. We have seen that several HRM activities are not being implemented in the organisation, because responsibilities are not clearly distributed or tasks are unclear. FLMs no longer performed any HRM activities, but SMTs did not always adopt them. The introduction of SMTs meant that managers stopped the top-down development and implementation of HRM activities, while SMTs were not ready yet to take over this role. The idea behind the new HRM philosophy was that SMTs are responsible for designing and implementing HRM activities, to shift the implementation process from top-down to bottom-up. A similar process was observed by Van Mierlo, Bondarouk, and Loohuis (2018) in a case study in a Dutch service organisation, which adopted a bottom-up approach to change the hiring policy. In this study, the actions of actors from this organisation were explored in a context of a so-called non-envisioned routine creation. Without a clear plan or guidelines, several organisational actors (e.g. HRM professionals, managers, and FLMs) created their own new hiring routines (Van Mierlo et al., 2018). The FLMs in our case study experienced trouble with the ambiguous expectations regarding their role in the implementation process of the new HRM philosophy. Although they were supposed to facilitate teams becoming more independent, they also felt the need to make decisions for their teams. For example, they decided to keep certain HRM responsibilities from the teams in the first phases of the SMT implementation process in order to help them adopt to the new situation and figure out how to divide the new tasks among team members. They also actively participated in decision-making processes to support team members to take the best decisions. Thus, although the intended policy was to devolve HRM responsibilities to team members, FLMs decided to ignore the policy, sometimes together with their teams (or former teams), and modified the intended policies according to what they thought worked best in the given situation.

In summary, the case presented here shows that SMTs become key HRM actors, who are responsible for designing and carrying out HRM activities. As a result, HRM implementation involves both a top-down and bottom-up 
process, in which responsibilities for philosophies, policies, and practices shift and the differences between intended, actual, and perceived HRM activities are blurred.

\subsubsection{Practical implications}

This study has several implications for HRM professionals, managers, and employees. First, HRM professionals who decide to introduce SMTs should provide a clear idea about the redistribution of HRM responsibilities. SMTs and FLMs need to know what is expected of them in order to organise themselves. During the implementation process of SMTs, HRM professionals should actively support teams to take on their new HRM responsibilities. They also need to be open to bottom-up policy development, instigated by the SMTs themselves. Second, managers need to adjust their role during the implementation process towards self-management. At first, a more active role is required to hand over new HRM responsibilities to SMTs, while in later phases FLMs need to step back and trust that the teams can act independently. Correspondingly, FLMs should stay involved as coaches, rather than decision-makers. They should identify problems in SMTs and help them with issues that transcend individual teams. Third, employees should familiarize themselves with their new role as a HRM specialist. They should invest in HRM-specific knowledge in order to increase the effectiveness of HRM activities. SMTs should make use of the autonomy to organise themselves by developing and implementing HRM activities that are tailored to their specific context. They should also monitor and assess their HRM effectiveness to improve their performance.

\subsubsection{Limitations and suggestions for future research}

This study naturally has to deal with limitations. We address three of them and suggest opportunities to tackle them in future research. First, although we focused on shifts between intended, actual, and perceived HRM practices, our analysis was limited to the causes of these shifts that resulted from the change in responsibilities and activities of the various actors. We did not explore other reasons for multilevel implementation gaps between intended, implemented, and perceived HRM policies and practices. Although this study did not focus on identifying and explaining gaps between intended-actual-perceived HRM, some of our findings correspond to the factors found by Makhecha et al. (2018). Future research could examine whether these factors indeed influence the implementation of HRM in organisations with SMTs.

This research focused on the transformation of the HRM function due to the implementation of SMTs. Since the HRM function is not only affected by the 
implementation of SMTs but also actively shapes the implementation process, this research has neglected the double role the HRM function plays in SMT implementation: being influenced by the SMT implementation and actively influencing the implementation of SMTs. We call this our second limitation. This limitation offers another direction for future research by examining how the changes in the HRM function actually contribute to the implementation of SMTs. In the current study, we could not establish how HRM contributes to SMTs, but with future research in multiple organisations, we could learn to what extent and in what way the HRM function increases the implementation effectiveness of SMTs.

The third limitation is related to the prominent role of employees in the HRM implementation of SMTs. Although we knew from the SMT literature that employees gained HRM responsibilities in SMTs, this research paid more attention to them than to the other HRM actors. Since our aim was to explore the entire HRM function, we acknowledge that by regarding employees as just one of the HRM function actors, we missed the chance to identify what they need to effectively implement HRM. Future research could focus on the role of employees in HRM implementation effectiveness, similar to other research on the role of line managers in the implementation of HRM (e.g. Bos-Nehles et al., 2013; Op de Beeck et al., 2016). In what Bondarouk et al. (forthcoming) have called the two stages of devolution, HRM responsibilities were transferred to FLMs in the first stage (Nehles et al., 2006; Purcell \& Hutchinson, 2007), and researchers examined the factors that influenced the effective implementation by FLMs (BosNehles et al., 2013). As we are now experiencing a second wave of HRM devolution, there is a need to examine which factors influence their effective implementation. It would be valuable to investigate whether SMT employees need the same factors as FLMs to implement HRM practices effectively.

\subsection{References}

References can be found on page 209. 


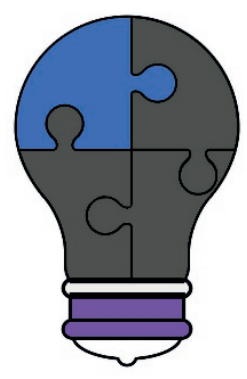

\section{CHAPTER 4}

\section{High-Involvement HRM and Innovative Work Behavior: the Mediating Role of Autonomy and Affective Commitment}

"When you innovate, you've got to be prepared for everyone telling you you're nuts"

(Larry Ellison) 


\begin{abstract}
Although current research shows that HRM can enhance employees' innovative work behaviour (IWB), the ways in which HRM leads to IWB have been less well explored. To increase our understanding of how HRM influences IWB, attention needs to be focused on the underlying mechanisms that link HRM practices with IWB. In this paper, the extent to which IWB can be stimulated by high-involvement HRM practices, and how these practices lead to IWB, are examined. Further, by drawing on social exchange theory and self-determination theory, we examine affective commitment and autonomy as mediators in this relationship. To test the model, a survey study was conducted with 567 respondents from four organizations in the Netherlands. The findings show that high-involvement HRM positively influences IWB and that commitment and autonomy fully mediate this relationship. As such, our results help to further unpack the 'black box' between HRM and innovation, and point towards the importance of increasing autonomy and commitment when organizations aim to increase employees' innovativeness.
\end{abstract}

\title{
4.1 Introduction
}

Innovation is widely accepted as crucial if organizations are to achieve long-term fiscal success (Anderson et al., 2014). One way to increase innovation performance is for organizations to encourage their employees to be innovative (Agarwal, 2014) since, ultimately, innovation depends on the generation and implementation of creative new ideas by employees (Mumford, 2000; Van de Ven, 1986). Therefore, it is important to understand the factors that stimulate innovative work behaviour (IWB) (Scott \& Bruce, 1994), which has been defined as "... the intentional creation, introduction, and application of new ideas within a work role, group, or organization, in order to benefit role performance, the group, or the organization" (Janssen, 2000, p. 288).

One of the ways in which organizations can stimulate IWB is by applying Human Resource Management (HRM) practices and systems that encourage employees to generate and implement new ideas (De Leede \& Looise, 2005; Laursen \& Foss, 2003; Shipton et al., 2005). Indeed, managing employees to increase innovative outputs through HRM has received increasing attention in recent years (Seeck \& Diehl, 2017; Shipton et al., 2016a). Initially, such studies focused predominantly on the organizational-level of analysis (e.g. Beugelsdijk, 2008; Shipton et al., 2006) but, nowadays, scholars increasingly also study the link between HRM and innovation at the individual level (Bos-Nehles, Renkema, et al., 2017).

Although researchers have established links from several HRM practices and systems to innovation and IWB, existing studies are criticized for lacking a 
theoretical underpinning, and overlooking variables that could act as mechanisms to link these concepts (Bos-Nehles, Renkema, et al., 2017; Lin, 2015; Seeck \& Diehl, 2017). As such, a better understanding of the underlying mechanisms that link HRM and IWB is needed. Even though theoretical arguments and assumptions are often made about this relationship, empirical evidence is lacking. As such, the relationship between HRM and IWB remains a so-called 'black box'. For these reasons, gaining a deeper understanding into the factors that link HRM and IWB is crucial to further advancing this field of research.

Currently, the relationship between HRM and IWB is often explained using Social Exchange Theory (Blau, 1964) and Signalling Theory (Bergh, Connelly, Ketchen, \& Shannon, 2014), The basic premise is that employees perceive HRM practices as signals from the organization (Bowen \& Ostroff, 2004) and, when these practices signal that IWBs are valued, rewarded and expected, employees will respond accordingly. That is, if employees feel that the organization is investing in them by offering valued HRM practices, they will reciprocate through innovative ideas that help the organization (e.g. Alfes, Truss, Soane, Rees, \& Gatenby, 2013). Existing studies provide some evidence that there are several HRM practices that influence employees' IWB, such as training and development, recruitment and selection, appraisals, information-sharing, participation and autonomy (Bos-Nehles, Renkema, et al., 2017). These practices are thought to lead to more highly motivated employees with more valuable human capital, and provide enhanced opportunities to perform innovative activities.

Now that we recognize that HRM practices are important in influencing IWB, and also why employees perceive HRM as a signal of the organization's investment in them, it is time to deepen our understanding of the relationship between HRM and IWB. Here, progress can be made in providing theory and empirical evidence on the precise impact of HRM on IWB and specifically on the causal mechanisms underlying this relationship. To this end, this study aims to examine mechanisms that underlie the HRM-IWB relationship. By adopting an employee-centred perspective (Wright \& Boswell, 2002), we focus on the effect that perceptions of HRM have on employees' IWBs (Bowen \& Ostroff, 2004; Nishii et al., 2008). We have made this choice because an increasing number of studies have shown that employee outcomes are often strongly related to employees' perception of HRM (Den Hartog et al., 2013; Kehoe \& Wright, 2013; Takeuchi et al., 2009).

Given that employees often perceive HRM practices and systems differently to how they were originally intended and also respond differently to them (Aryee et al., 2012; Liao et al., 2009; Nishii et al., 2008), we need to obtain a better understanding as to what perceptions lead employees to reciprocate the 
invested HRM practices by demonstrating IWB. Two main perspectives have been identified in the HRM literature to explain the influence of perceived HRM on employee outcomes: the job resources perspective and the job attitudes perspective (e.g. Boon \& Kalshoven, 2014; Paauwe \& Blok, 2015). The former is focused on job resources, such as abilities and autonomy, while the latter is focused on employees' attitudes, such as affective commitment and job satisfaction, to explain the influence of HRM on employee outcomes. Typically, one or other of these perspectives is applied when examining how perceived HRM is associated with employee performance (Jiang et al., 2013; Peccei et al., 2013). In line with recent research (Meijerink et al., 2017), we include both perspectives in aiming to gain a fuller understanding of how HRM affects IWB.

Several HRM scholars have already examined the HRM-innovation relationship and found that especially practices related to autonomy and commitment positively influence employees' IWB (Bos-Nehles, Renkema, et al., 2017; Seeck \& Diehl, 2017). Autonomy has been defined as "the degree to which the job provides substantial freedom, independence, and discretion to the individual in scheduling the work and in determining the procedures to be used in carrying it out" (Hackman \& Oldham, 1980, p. 162), while commitment refers to the emotional attachment and involvement of employees in the organization (Meyer \& Smith, 2000). It has been an HRM trend in recent decades to focus more on the commitment and involvement of human resources than to adopt control-oriented practices (Guest, 1997; Lawler, 1986). Here, high-involvement management creates empowered employees by providing information and decision-making authority. The literature shows that employees are more likely to demonstrate innovative behaviour when they feel ownership and concern for problems related to the workplace (Abstein \& Spieth, 2014; Axtell et al., 2000; Dorenbosch et al., 2005). In line with this important research trend, this study focuses on the influence of employees' perceptions of high-involvement HRM (HIHRM) on IWB.

Hence, the main aim of this study is to respond to calls to examine underlying mechanisms in the relationship between HRM and IWB. In doing so, we examine how autonomy and affective commitment mediate the effect of HIHRM on IWB. Our main contributions are threefold. First, the paper reveals the mechanism between HRM and employees' IWB by examining two mediators (autonomy and commitment). This is valuable because it reveals the characteristics in which organizations should invest. Second, we contribute to the HRM literature by examining and distinguishing the joint effect of resource-based and attitude-based variables as mediators in the relationship between perceived HRM and employee outcomes. Third, we investigate the relationship between HRM and IWB in a context where IWB is not overtly required and therefore seen 
as a discretionary or extra-role behaviour. Whereas most IWB research is focused on examining its antecedents in a setting where innovation is explicitly sought, we test our hypothesis in a sample of service workers whose work is steered by protocols where there is a lower requirement or expectation of innovative behaviour (Montag et al., 2012). This will help to further our understanding of how one can improve the innovativeness of 'ordinary' employees (Renkema et al., 2018).

The paper is structured as follows. We start by conceptualizing IWB and the relationships among employees' perceptions of high-involvement HRM, commitment, autonomy and IWB. This is followed by a description of the methodology used. After presenting our results, we close with a discussion of the theoretical and practical implications.

\subsection{Theoretical Background And Hypotheses}

\subsubsection{Innovative Work Behaviour}

In the late 1980s, Kanter (1988) and West and Farr (1989) developed the concept of the innovative behaviour of employees. Kanter (1988) saw this type of employee behaviour as consisting of four tasks: idea generation, coalition building, idea realization and transfer. Later, based on these ideas, researchers started to investigate what could stimulate employees to show individual innovative behaviour (Scott \& Bruce, 1994). A decade later, Janssen (2000) first introduced the concept of Innovative Work Behaviour (IWB), and defined it as “... the intentional creation, introduction, and application of new ideas within a work role, group, or organization, in order to benefit role performance, the group, or the organization" (p. 288). Furthermore, IWB can be seen as an extra-role behaviour since the work descriptions of employees do not usually include innovative tasks (Janssen, 2000; Katz \& Kahn, 1978). Therefore, IWB should be seen as a discretionary behaviour and, in general, employees will prioritize the behaviours that are needed to accomplish their primary work tasks (Veenendaal \& Bondarouk, 2015)

Many studies have conceptualized IWB as a multidimensional concept consisting of specific phases (e.g. De Jong \& Den Hartog, 2010; Janssen, 2004). In line with definitions of innovation, most researchers include both the creation and the implementation of such ideas (Dorenbosch et al., 2005). The idea generation phase involves searching for opportunities to improve current products and processes, and then producing solutions (De Jong \& Den Hartog, 2010). Once a new idea has been generated, the idea implementation phase consists of the promotion and realization of the idea (De Jong \& Den Hartog, 2010), achieved by championing and building networks (Janssen, 2004; Scott \& 
Bruce, 1994) and integrating the idea into organizational routines (De Jong \& Den Hartog, 2010; Kleysen \& Street, 2001).

\subsubsection{HRM, employee involvement and IWB}

More than a decade ago, HRM research has started to conceptualize the link between HRM systems and innovation (De Leede \& Looise, 2005; Laursen \& Foss, 2003). Since then, many HRM scholars have examined the HRM innovation relationship and found that multiple HRM systems and practices increase innovation (Seeck \& Diehl, 2017) and stimulate employees' IWBs (BosNehles, Renkema, et al., 2017). Especially the freedom and autonomy of employees seem to be important HRM practices facilitating IWB. This is consistent with the HRM trends of the to focus more on high commitment and high-involvement of human resources rather than control oriented practices (Lawler, 1986). High-involvement management creates empowered employees by providing information and decision-making authority. When employees are considered as a more important source for competitive advantage (Bae \& Lawler, 2000), firms focus more on employee-centered work design. Among other things, this means that information and decision-making are distributed throughout the organization (Guthrie, 2001). Because employees are responsible for organizational success, this approach uses HRM practices that develop and support a workforce that is relatively self-managing (Lawler, 1992). Highinvolvement practices have found to positively affect innovation in a recent literature review by Seeck and Diehl (2017). Therefore, this research focuses on high-involvement HRM practices.

Involvement policies and practices enable employees to be engaged in direct participation (Cotton, 1993). Employee participation is a mechanism through which employees can voice their creative ideas (Frese, Teng, \& Wijnen, 1999). High-involvement implies that organization make better use of employee capabilities for self-management, personal development and problem solving (Boxall \& Macky, 2009). Based on previous work (Arthur, 1994; Lawler, 1986), Guerrero and Barraud-Didier (2004) found that information sharing, skill development, compensation, and empowerment appear together as the most important practices for high-involvement management. Also Paré and Tremblay (2007) discuss five distinct high-involvement practices that may influence employees' work-related attitudes and performance behaviors: empowerment, competence development, information-sharing, recognition, and rewards. In line with this, we focus on four high-involvement HRM practices: teamwork, training and development, information sharing, and performance feedback. As compensation and rewards are mostly restricted by collective labor agreements 
(as we will show in our research setting), this research focuses on performance feedback instead. The selected practices represent the four high-involvement processes as proposed in earlier high-involvement models: power, information, rewards, and knowledge (Lawler, 1986; Vandenberg, Richardson, \& Eastman, 1999). Furthermore, these practices are expected to increase IWB because employees have more opportunities to conduct innovative ideas and feel more committed to the organization (Zhou, Hong, \& Liu, 2013).

The idea behind the positive relationship between these highinvolvement HRM practices and IWB is that when employees perceive that they can work closely together in teams, are offered sufficient training and development opportunities, feel that information is shared with them, and get adequate feedback on their work, they will give back innovative behaviors to the organization. Research shows that the effect of a bundle of HRM practices leads to higher levels of innovative behavior than the implementation of single HRM practices (Laursen \& Foss, 2003; Shipton et al., 2006; Zhou et al., 2013). In line with earlier research (Bae \& Lawler, 2000; Shin, Jeong, \& Bae, 2016; Sun, Aryee, \& Law, 2007), we use a bundles-approach instead of a systems-approach as we do not consider synergies between HRM practices (Guthrie, 2001). Together, high-involvement HRM practices increase the abilities, motivation, and opportunities of employees to develop new ideas and implement them in practice (Appelbaum et al., 2000; Jiang et al., 2012).

It is important that employees experience the presence of highinvolvement HRM practices and perceive it as a signal of investment in a longterm relationship (Kehoe \& Wright, 2013; Nishii et al., 2008), as several studies have shown that employee outcomes are more strongly associated with their perception of HRM practices than the actual HRM practices as implemented by the organization or its managers (Den Hartog et al., 2013; Liao et al., 2009). As a result, the response of employees is more likely to be influenced by perceptions of HRM compared to actual presence of HRM practices. When designed well, such a system of high-involvement HRM practices will signal to employees that their involvement is appreciated and supported (Bowen \& Ostroff, 2004). By drawing from social exchange theory (Blau, 1964), employees are assumed to reciprocate the HRM investment by showing valuable behaviors (Gouldner, 1960). Moreover, the inducement-contribution model suggests that organizations offer inducements to their employees to stay, while employees contribute to organizational performance by high levels of job performance (March and Simon, 1958). Hence, the investments of the employer in the employee, and the opportunities that the employee receives, are expected to be reciprocated by the employee by showing innovative behavior that is valuable for the organization. Earlier research shows that social exchange theory can help to explain the 
relationship between HRM and IWB (Alfes et al., 2013; Veenendaal \& Bondarouk, 2015).

In addition, high-involvement HRM is also likely to increase the motivation of employees to be innovative, because employees receive developmental feedback, recognition and rewards, and the autonomy to decide on their own work. Practices such as working in empowered teams, recognition, and rewards can be linked to the motivation of employees to be engaged in IWB. For example, the study by Liao et al. (2009) found that high performance work practices - which are closely related to high-involvement HRM - are positively related to psychological empowerment, a self-motivating mechanism. Self-determination theory can explain this relationship, as contextual factors that enhance perceptions of competence and autonomy, such as high-involvement HRM practices, lead to increased intrinsic motivation (Deci \& Ryan, 1985). In line with others (Shin et al., 2016), we argue that high-involvement HRM practices are associated with higher levels of IWB, because these practices can make employees feel motivated (Ryan \& Deci, 2000). Motivation increases IWB of employees because it enhances persistence, cognitive flexibility, and risk taking (Amabile et al., 1996; Shalley, Zhou, \& Oldham, 2004). For those reasons, we expect that employees' perceptions of high-involvement HRM are positively related to IWB.

\subsubsection{High-involvement HRM, autonomy and commitment}

As we have discussed above, several studies have found support for a relationship between employees' perceptions of HRM and IWB (Bos-Nehles \& Veenendaal, 2017; Veenendaal \& Bondarouk, 2015). Nevertheless, recent literature reviews on HRM and innovation have highlighted the fact that little is known about the causal mechanisms and theoretical foundations that connect HRM with IWB (Bos-Nehles, Renkema, et al., 2017; Seeck \& Diehl, 2017). That is, research to date has mainly studied the direct relationship between HRM and IWB rather than its underlying causal mechanisms. As such, the 'black box' that constitutes the HRM-innovation relationship remains unopened.

Two perspectives are mainly used in the HRM literature to explain how perceived HRM influences employee outcomes: through providing job resources (Boon \& Kalshoven, 2014; Peccei et al., 2013) and through increasing desired job attitudes such as affective commitment and job satisfaction (Jiang et al., 2013; Paauwe \& Blok, 2015). Typically, researchers have applied one of these standpoints to examine how perceived HRM is associated with employee outcomes (Jiang et al., 2013; Peccei et al., 2013). A recent meta-analysis of mediating mechanisms has shown that job attitudes and resources jointly provide 
a fuller understanding of how employees' perceptions of HRM are related to employee outcomes (Meijerink et al., 2017). Employee outcomes do not follow only from the availability of resources, but also from a situation in which job attitudes motivate employees to use those available resources (Hobfoll, 2001). Given that performance depends on the interplay between employees' abilities and motivation, and the opportunities to perform (Jiang et al., 2012), including both mediators in concert should offer a better explanation of HRM-employee outcome relationships (Meijerink et al., 2017). For those reasons, we include variables from both the job resource and the attitudes perspectives to gain a better understanding of how perceived HIHRM is related to employees' IWB.

In doing so, we have included autonomy as a job-resource-related mediator and affective commitment as a attitudinal-oriented mediator. Several studies had found that especially practices related to autonomy and commitment have a positive influence on IWB (Bos-Nehles, Renkema, et al., 2017; Seeck \& Diehl, 2017). We argue that the influence of employees' perceptions of HIHRM on IWB can be explained by employees' responses to those HRM practices. If HIHRM leads to enhanced feelings of autonomy and commitment, it will positively influence employees' IWB. Research supports this idea, with HIHRM having been found to affect intrinsic motivation, in part because employees perceive increased autonomy (Shin et al., 2016). HIHRM practices are also thought to be conducive to the autonomous feeling of employees (e.g. Liao et al., 2009). Consequently, we focus on autonomy and affective commitment when exploring the mediating link between employees' perceptions of HIHRM and IWB.

\subsubsection{HRM, autonomy and IWB}

Theoretically, autonomy, which is understood as the independence that employees have in doing their tasks (Abstein \& Spieth, 2014), has been seen as a crucial factor in motivating employees. Early job characteristics models, such as the one developed by Hackman and Oldham (1980), already attributed a positive role to autonomy in motivation. Self-determination theory posits that job autonomy, next to a feeling of competence and connectedness with others, is likely to increase employees' intrinsic motivation (Ryan \& Deci, 2000). Therefore, HRM practices that increase autonomy, feelings of competence and connectedness to others can enhance employees' intrinsic motivation. Here, HIHRM practices, because they are focused on increasing the autonomy of employees, are well-positioned to increase their intrinsic motivation, which in turn could lead to enhanced innovative behaviour (Shin et al., 2016). Indeed, HIHRM have been shown to increase autonomy because employees are treated more as strategic partners (Barney \& Wright, 1998) and because these practices 
encourage employees to perform their tasks in their own ways (Liao et al., 2009). Therefore, we expect employees' perceptions of HIHRM to be positively related to employees' autonomy, leading to our first hypothesis:

\section{Hypothesis 1: Employees' perceptions of high-involvement HRM positively affect their feeling of autonomy.}

When employees perceive that they have greater autonomy, they sense they have more freedom and motivation to take part in innovative activities. This increased job autonomy has been associated with employees' innovative behaviours (Ramamoorthy, Flood, Slattery, \& Sardessai, 2005). Many theories help to explain the effect of autonomy on IWB. First, social exchange theory (Blau, 1964) suggests that autonomy works as a motivational factor for IWB as employees who feel that their organization provides them with considerable freedom, also feel a need to reciprocate in terms of generating and implementing valuable ideas through IWB (Marane, 2012; Ramamoorthy et al., 2005). Second, in line with self-determination theory (Gagné \& Deci, 2005), autonomy spurs IWB through enhanced intrinsic motivation. That is, employees are more intrinsically motivated when they feel autonomous, and this, in turn, leads to more discretionary behaviours such as IWB (Ohly, Sonnentag, \& Pluntke, 2006). As such, motivation triggered by autonomy plays an important role in stimulating employees' IWB (De Spiegelaere, Van Gyes, \& Hootegem, 2012a; Sanders, Moorkamp, Torka, Groeneveld, \& Groeneveld, 2010). Third, the job-demands resources (JD-R) model by Bakker and Demerouti (2007) also highlights the importance of job autonomy for employee outcomes. Here, autonomy can be considered as a job resource that helps employees to develop and realize new ideas. A study by Martín, Salanova, and Peiró (2007) tested the JD-R model with individual innovation as an outcome variable and found that job resources such as autonomy have a significant positive effect on individual innovation.

Empirical evidence also supports the idea of a positive relationship between autonomy and innovative behaviours. Amabile (1988) showed that freedom was an important factor in so-called creative accidents. Further, autonomy has been found to be a requisite for creative performance (Shalley, 1991; Zhou, 1998), and to be positively related to the innovative behaviour of service employees (De Jong \& Kemp, 2003). Further, the related concept of job control has been shown to be an important factor for innovation by promoting personal initiatives (Frese \& Fay, 2001) and to be positively influence creativity and innovation (Ohly et al., 2006). On top of that, a review by Bos-Nehles, Renkema, et al. (2017) showed that autonomy was a significant antecedent of innovative behaviour in the majority of studies that investigated the relationship 
between HRM and innovative behaviour. Accordingly, we expect the autonomy of employees to be positively related to employees' IWB:

Hypothesis 2: Employees' feelings of autonomy positively affect their innovative work behaviour.

\subsubsection{HRM, affective commitment and IWB}

Organizational commitment is another important outcome of HIHRM. Employees who work in organizations with attractive organizational practices might well perceive their employer as supportive and, therefore, develop a stronger affective commitment, defined as the emotional attachment and involvement of employees in the organization (Meyer \& Smith, 2000). HIHRM can increase the affective commitment of employees by facilitating their participation in and connection to their employer, and is thus seen as an attractive organizational practice. Affective organizational commitment is seen as the psychological bond that employees have with the organization (Meyer \& Allen, 1997), and it encourages employees to pursue actions that benefit the organization (Gardner et al., 2011). Based on social exchange theory (Blau, 1964), one can expect that employees who work in organizations that invest in their employees by giving them opportunities to make their own decisions, will show greater commitment towards their organization. This idea is supported by several studies that have indeed found a positive relationship between HRM and organizational commitment at different organizational levels of analysis (Kehoe \& Wright, 2013; Takeuchi et al., 2009). This is reflected in our third hypothesis:

Hypothesis 3: Employees' perceptions of high-involvement HRM positively affect their affective commitment.

Employees highly committed towards their employer are expected to show greater innovative behaviour. Commitment is particularly important in employees showing discretionary behaviours, such as IWB, for at least two reasons. First, because committed employees are more likely to stay at their organization and therefore more likely to receive something in reciprocation for investing in innovative behaviours. Second, because these employees will themselves benefit more from valuable new ideas by remaining longer in the organization. As such, the explanation for the relationship between affective commitment and IWB is based on the likelihood that committed employees will stay longer at the organization and therefore benefit from their own innovative behaviour. Employees who are committed to their organization are also willing to make 
additional efforts in support of that organization (Wright \& Kehoe, 2008). Empirical evidence indeed supports the view that employees' affective commitment is positively associated with their IWB (Jafri, 2010; Taylor \& Greve, 2006). This can also be explained by the fact that employees with low affective commitment only display the minimum behaviours necessary to stay employed at the organization (Riketta, 2002). Several researchers have produced results that indicate that HRM practices can lead to more-committed employees, which in turn leads to knowledge sharing and creativity (Monks et al., 2013). Further evidence for a relationship between commitment and innovation was found by Chang et al. (2014), who showed that high-commitment HRM was positively related with employees' creativity. Thus, we hypothesise that affective commitment towards the organization enhances employees' IWB.

Hypothesis 4: Employees' affective commitment positively affects their innovative work behaviour.

\subsubsection{The mediating role of autonomy and commitment}

So far, we have argued that employees' perceptions of HIHRM are positively related with IWB through their effect on autonomy and commitment (see also Figure 4.1 which presents our conceptual model). This is in line with social exchange theory (Blau, 1964; Gouldner, 1960) in that HIHRM represents an organizational investment in employees and a signal of trust that employees are capable of making their own decisions regarding their work which, in turn, increases employees' commitment and autonomy in reciprocating these investments by generating and implementing ideas that help the organization. Extra-role or discretionary behaviours, such as innovative behaviours, can be particularly stimulated by HRM practices that aim to achieve commitment from employees (McClean \& Collins, 2011).

Hence, HIHRM will increase employees' IWB if it results in employees perceiving greater autonomy in their job and becoming more committed to the organization. When employees actually perceive the positive value of HIHRM practices, in the form of increased autonomy and commitment, they will put more effort into generating and implementing innovative ideas. As such, an HIHRM system results in positive employee effects and motivation, which in turn stimulates employees to become more engaged in IWB. Therefore, in our final hypothesis, we expect employees' perceptions of HIHRM to be indirectly related to IWB through the mediating effects of autonomy and commitment: 
Hypothesis 5: High-involvement HRM indirectly and positively affects employees' innovative work behaviour through autonomy and affective commitment.

\subsubsection{Research framework}

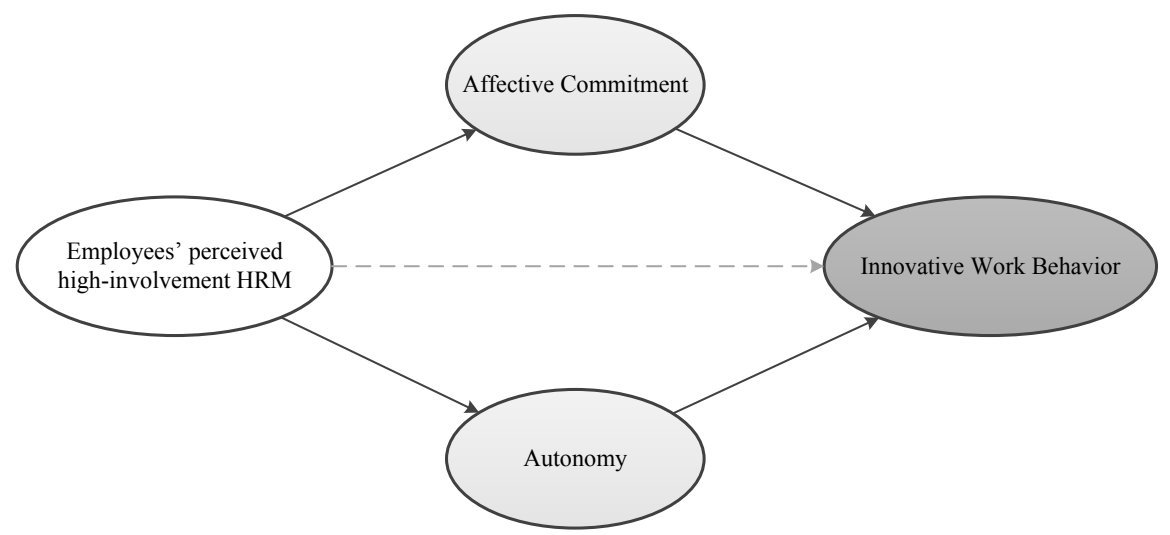

Figure 4.1. Conceptual model of HRM and IWB

\subsection{Methodology}

\subsubsection{Research design}

A cross-sectional survey-based research design was employed in four Dutch healthcare organizations to obtain data to test the hypotheses. This research design was chosen because the aim was to explore the mechanisms within an organizational context that explain the relationship between HRM and IWB. This research design is appropriate because it enables one to uncover relationships and associations between factors at a given time within a specific population (Van Zyl, 2013).

\subsubsection{Research Procedure}

Data for this study were collected between May 2016 and January 2018. A convenience sampling strategy, based on healthcare organizations that participated in programmes focused on employee involvement ${ }^{6}$, was used to identify organizations for this research. We aimed to obtain a sample with the

6 These programmes were agreed upon by both employer and employee organizations within the elderly care sector in the Netherlands. The core of the agreement entailed a shift in decision power over working times from employer to employee. Each local works council had to reach agreement with the local employer on the framework within which teams could decide their working hours. With such a framework in place, teams could decide on the working times themselves. 
maximum geographical scope by purposefully selecting organizations in different parts of the Netherlands. We also ensured variation in firm size by purposefully contacting organizations with different numbers of employees. We contacted the HR managers of each potential organization and introduced our research, after which, through several rounds of communication and discussion, agreements were reached on participating in the study. Eventually, four healthcare organizations from different regions of the Netherlands, and of different sizes, agreed to participate.

With the support of the HR managers of the four organizations, we obtained lists of employees who primarily worked in healthcare provision, administration or support departments. We further ensured that the lists of employees were a good representation of the entire workforce. Based on voluntary sampling, employees were invited to participate through an email that included a hyperlink to the online survey. In the accompanying message in the email, and on the survey platform, we gave a short description of the research goal and emphasized the anonymity of respondents. Further, it was stressed that participation was voluntary and that the data would not be distributed. In addition, the participating organizations placed an introductory message on their intranet websites to encourage responses. The online survey was open for about four weeks and two email reminders were sent to encourage employees to complete the survey. The online survey was eventually distributed to 1540 employees? Through this, data on their perceptions of HR practices, commitment, autonomy and IWB were collected from individual employees. These were combined with data on overall employee characteristics (i.e. gender, tenure etc.) that were collected from databases provided by the organizations. In total, 567 questionnaires were completed, an overall response rate of $37 \%$, ranging from 33 to $54 \%$ for the individual organizations. By adopting forced-entry methods in our online questionnaire we ensured there were no missing values in our dataset.

The participating organizations also imposed a strict limitation on the survey in terms of the number of items. For this reason, it was not possible to include complete scales that had previously been developed in peer-reviewed work to measure HRM practices. In developing our measures, we therefore aimed to cover the full width of the construct.

\footnotetext{
${ }^{7}$ In one of the participating organizations the survey was distributed through an online platform related to their intranet. This makes it impossible to calculate the exact sample. Overall, in this organization, 148 employees accessed the questionnaire, of which 80 completed the survey.
} 


\subsubsection{Participants}

Of the respondents who completed the questionnaire, 95\% were female, $95 \%$ were in permanent employment, with an average tenure of 12 years $(S D=8)$, and an average age of 45 (Table 4.1). These characteristics reflected those of the entire population of the participating organizations for which this information was available through documents provided by their managements. For example, female workers made up between $95 \%$ and $98 \%$ of the workforce in the individual organizations.

Table 4.1. Demographic and biographical characteristics

\begin{tabular}{|c|c|c|c|}
\hline Variable & Category & $\begin{array}{c}\text { Frequency } \\
(f)\end{array}$ & $\begin{array}{c}\text { Percentage } \\
(\%)\end{array}$ \\
\hline \multirow[t]{2}{*}{ Gender } & Male & 29 & 5.1 \\
\hline & Female & 538 & 94.9 \\
\hline \multirow[t]{2}{*}{ Contract type } & Permanent & 539 & 95.1 \\
\hline & Temporary & 28 & 4.9 \\
\hline \multirow[t]{6}{*}{ Age } & 18 to 20 years & 3 & 0.5 \\
\hline & 21 to 30 years & 84 & 14.8 \\
\hline & 31 to 40 years & 97 & 17.1 \\
\hline & 41 to 50 years & 157 & 27.7 \\
\hline & 51 to 60 years & 194 & 34.2 \\
\hline & 61 years and older & 31 & 5.5 \\
\hline \multirow[t]{5}{*}{ Marital Status } & Single & 75 & 13.2 \\
\hline & Living with a partner & 120 & 21.2 \\
\hline & $\begin{array}{l}\text { Living with a partner and } \\
\text { children }\end{array}$ & 265 & 46.7 \\
\hline & $\begin{array}{l}\text { Living with a partner where the } \\
\text { children have moved out }\end{array}$ & 79 & 13.9 \\
\hline & Single with children & 28 & 4.9 \\
\hline \multirow[t]{5}{*}{$\begin{array}{l}\text { Years of } \\
\text { employment }\end{array}$} & 0 to 5 years & 138 & 24.3 \\
\hline & 6 to 10 years & 152 & 26.8 \\
\hline & 11 to 15 years & 103 & 18.2 \\
\hline & 16 to 20 years & 79 & 13.9 \\
\hline & 21 years and longer & 94 & 16.6 \\
\hline
\end{tabular}

\subsubsection{Measures}

We predominantly relied on existing scales for the measurement of our variables (Appendix F). However, because the original scales were in English, we 
translated them to Dutch since the organizations were all located in the Netherlands. We used the translation-back-translation procedure as an accuracy check by using two researchers who were proficient in Dutch and English but not engaged in the project (Beaton, Bombardier, Guillemin, \& Ferraz, 2000). Furthermore, we asked a small sample of employees from one of the participating organizations to test the survey and indicate whether the items were clear. Minor changes were based on the feedback from this pilot group. Responses to all measures were based on a five-point Likert-scale ranging from 1 = "completely disagree" to 5 = "completely agree".

\subsubsection{High-Involvement Human Resource Management}

High-involvement HRM practices were measured in terms of four different HRM practices, using four different subscales that measured employees' perceptions of their presence. Autonomous teamwork was measured by four items adapted from Boon, Den Hartog, Boselie, and Paauwe (2011) (e.g. "I work in a selforganizing team"; $\alpha=.74)$. Training and development refers to the presence of training and development activities to increase employees' knowledge and skills, and was measured using three items from Gould-Williams and Mohamed (2010) and from Boselie et al. (2005) that were adapted to fit the context of the study (e.g. "I get sufficient opportunities to attend skills training to improve my current functioning"; $\alpha=.91)$. Information sharing was measured with five items adapted from Paré and Tremblay (2007) and from Boselie et al. (2001) (e.g. "I am regularly informed on the vision and mission of the company"; $\alpha=.88$ ). Performance feedback was measured with four items adapted from Chuang and Liao (2010) and from Zhou (2003) to match the context of the current study (e.g. "My supervisor never gives me developmental feedback" (reverse item); $\alpha=.82$ ).

\subsubsection{Autonomy}

Autonomy was assessed in terms of employees' feelings regarding the control they have over how they do their own work. Here, we adapted three items from Boon et al. (2011) to measure the extent to which employees experience opportunities to make their own decisions (e.g. "I have the opportunity to make my own decisions on how to do my tasks"). The Cronbach's alpha for this scale was 0.82 and the Composite Reliability (CR) 0.83 .

\subsubsection{Affective commitment}

To measure affective commitment, we used the affective commitment scales developed by Allen and Meyer (1990). The items in this scale measure the commitment that employees have towards their organization. Employees are 
asked to respond to eight statements (e.g. "I would be very happy to spend the rest of my career with this organization"). Cronbach's alpha for the scale measurement was $0.80, \mathrm{CR}=0.80$.

\subsubsection{Innovative Work Behaviour}

To measure the innovative work behaviour of employees, we measured the employees' perceptions of their own innovative behaviour at work (i.e. a selfreported measurement). The items used were drawn from De Jong and Den Hartog (2010) and reworded to fit the HRM context of our study. The ten-item questionnaire measured four components: idea exploration (2 items), generation ( 3 items), championing ( 2 items) and realization ( 3 items). An example item under the generation component is "I find new approaches to execute tasks in my work". The Cronbach's alpha for the ten-item scale was 0.91 and the CR 0.92.

\subsubsection{Control variables}

Tenure and gender have been identified as potentially having an effect on IWB (see for example Bos-Nehles \& Veenendaal, 2017; De Jong \& Den Hartog, 2010), and we therefore included these characteristics as control variables. Tenure was measured in number of years, gender was included as a dummy variable (male $=1)$.

\subsubsection{Data analysis}

The data was processed using SPSS v25 (IBM, 2018) and Mplus v8 (Muthén \& Muthén, 2010). First, descriptive statistics (means, standard deviations, skewness and kurtosis) were calculated to determine the distribution of the data. Second, Pearson and Spearman (for non-normally distributed variables) correlations were calculated to describe the dataset and to determine relationships among the variables. Third, the internal consistency of the instruments was estimated using Cronbach's Alpha (lower bound; > 0.70) and Composite reliability (upper bound; > 0.70) computations (Olckers and Van Zyl, 2016). Fourth, structural equation modelling (SEM), with robust maximumlikelihood estimator (MLM), was employed to first assess the fit of the competing measurement models, and then of the final structural model (Muthén \& Muthén, 2010). The measurement model evaluates the relationships between observed and latent variables, whereas the structural model addresses the associations between the latent variables (Hair, Black, Babin, \& Anderson, 2010). In total, we compared four measurement models and the resulting best-fit model became the basis for the structural model. The robust maximum-likelihood estimation (MLM) calculation is used to indicate non-normality, with the observed variables being 
classified as measured on a continuous scale (Muthén \& Muthén, 2010). For the structural model, we report on the resulting chi-square statistics and significance. Additionally, we follow the suggestions of Hair et al. (2010) and calculate the following fit indices: (a) two absolute fit indices: Root-Means-Square Error of Approximation (RMSEA) and Standardized Root Mean Residual (SRMR), and (b) two incremental fit indices: Comparative Fit Index (CFI) and the Tucker-Lewis Index (TLI). For an acceptable model, CFI and TLI values above 0.90 and SRMR and RMSEA values below 0.08 are frequently seen as appropriate (Wang and Wang, 2012). Finally, the indirect effects of autonomy and affective commitment on the relationship between HIHRM and IWB were tested using a path model with bootstrapping, as proposed by Preacher, Zyphur, and Zhang (2010). A biascorrected bootstrapping method with 20,000 iterations was used, and assessed at the $95 \%$ confidence interval limit.

Furthermore, prior to testing our hypotheses, we conducted a Harman's single-factor test for common method bias (Podsakoff, MacKenzie, Lee, \& Podsakoff, 2003). The results of a principal component analysis including all items showed that no single factor explained more than $23 \%$ of the variance. As a further check for systematic measurement error, we carried out a confirmatory factor analysis alongside an unmeasured latent factor analysis. Here, we tested a model that included all our variables against a model with a common latent factor (Podsakoff et al., 2003). This indicated that our model had a common variance of $6.8 \%$, well below the threshold of $25 \%$ recommended by (Williams, Cote, \& Buckley, 1989). Given these findings, we conclude that common method bias does not appear to be an issue.

\subsection{Results}

To evaluate the relationship linking HIHRM, autonomy, affective commitment and IWB, a four-phased approach was used. First, the descriptive statistics, correlations and internal consistencies of the measures are reported. Second, the competing, theory-driven, measurement models are evaluated to assess which model best fits the data. Third, the structural model including the effects of the focal variables is presented. Finally, indirect effects are assessed and presented.

\subsubsection{Descriptive statistics, reliabilities and correlations}

The means, standard deviations and correlations for the variables included in the study are presented in Table 4.2. Significant positive correlations were found for our hypothesized relationships. Further, tenure was found to be significantly correlated with perceptions of HIHRM and with affective commitment. 
Multicollinearity can be ruled out as the maximum correlation between independent variables (.56) is well below the acceptable threshold.

\subsubsection{Measurement models}

To establish the best measurement model, we compared various theoretical models using SEM in Mplus (Muthén \& Muthén, 2010). The hypothesized measurement models were tested to determine whether items loaded significantly onto the proposed constructs and whether the constructs are validly measured using these items. Observed variables were used as indicators of firstorder latent variables. It was not necessary to remove, correlate or parcel items to improve the fit and, further, error terms were uncorrelated. 
116 || Chapter 4

Table 4.2. Descriptive statistics, alpha coefficients, composite reliabilities and correlations

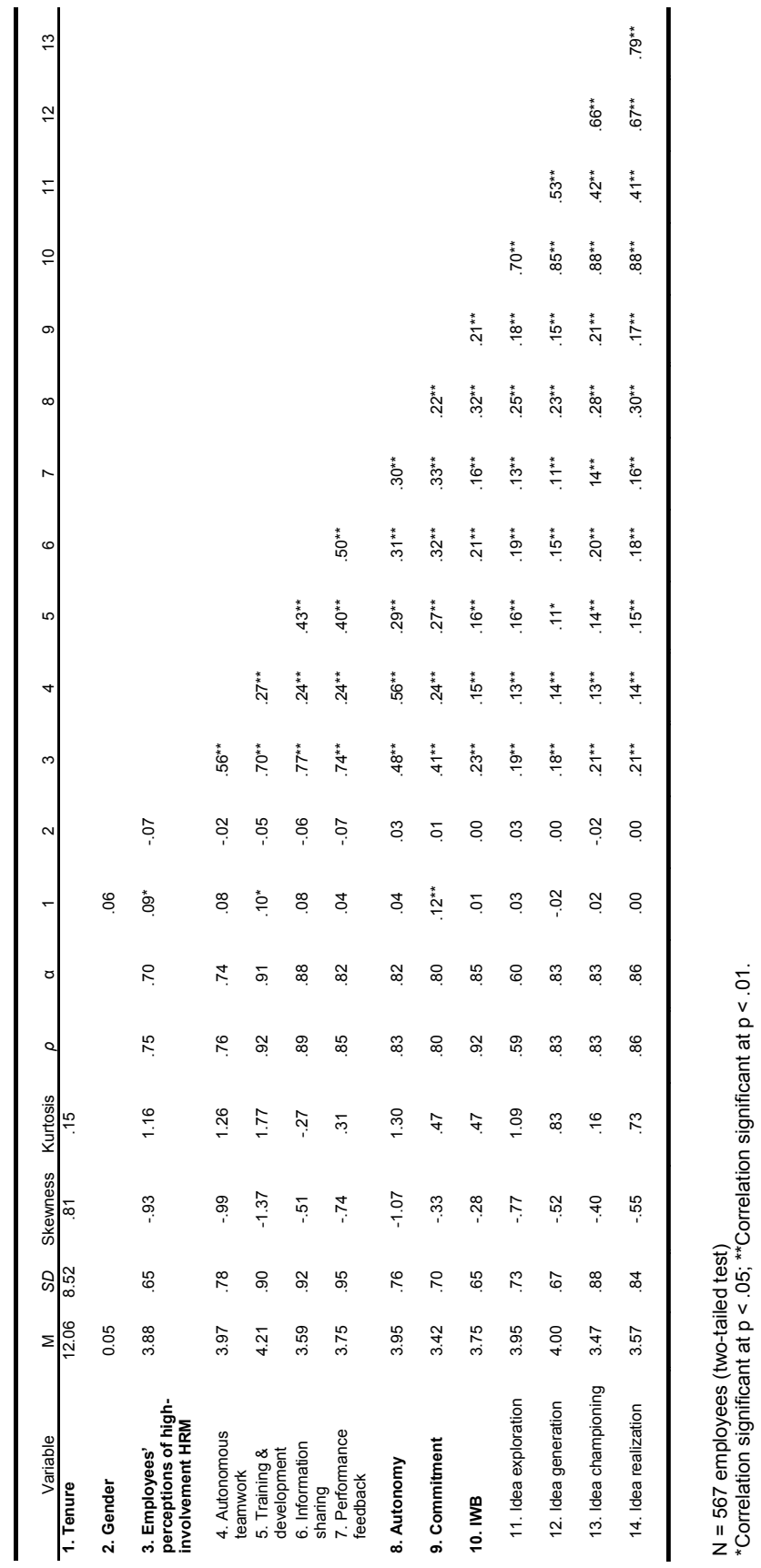


Four confirmatory factor analytical (CFA) models were calculated and compared to determine the best-fitting model. Table 4.3 provides a summary of the fit indices calculated for all four competing measurement models.

- Model 1: We first tested our hypothesized measurement model with four factors matching our four variables. HIHRM was found to be a secondorder four-factor construct with items loading on all four individual HRM practices. Further, autonomy included three items and affective commitment all eight items. Finally, IWB was modelled as a second-order four-factor variable with items loading onto idea exploration, generation, championing and realization. The four-factor model provided an adequate fit with $\mathrm{X}^{2 /}{ }_{(615)}=2.31 ; \mathrm{p}=.00 ; \mathrm{CFI}=.91 ; \mathrm{TLI}=.90 ; \mathrm{RMSEA}=$ $.05 ;$ SRMR $=.06$.

- Model 2: An alternative model, again with four factors for the four variables, was tested. A one-factor construct for HIHRM was fitted to the data in which all items were loaded directly onto HRM. As in Model 1, autonomy was made up of three items and affective commitment of all eight. Again, IWB was modelled as a second-order four-factor construct, with items loading onto idea exploration, generation, championing and realization. This time, the four-factor model provided a very poor fit: $X^{2} /(619)=5.05 ; p=.00 ; \mathrm{CFI}=.72 ; \mathrm{TLI}=.70 ; \mathrm{RMSEA}=.08 ; \mathrm{SRMR}=.08$.

- Model 3: This was another alternative model with four factors for our four variables. This time we used a four-factor model for HIHRM, with items loading onto the four individual HRM practices. Again, autonomy comprised three items and affective commitment all eight. This time, IWB was tested in a one-factor model in which all items were loaded directly onto the latent construct. This four-factor model was a worse fit than our first model: $X^{2} /(619)=2.59 ; p=.00 ; \mathrm{CFI}=.89 ; \mathrm{TLI}=.88 ; \mathrm{RMSEA}=.05$; SRMR $=.06$.

- Model 4: Our final option was a one-factor model with all items directly loading onto a single latent construct. This model resulted in a very poor fit: $X^{2}{ }_{(629)}=10.14 ; p=.00 ; \mathrm{CFI}=.36 ; \mathrm{TLI}=.32 ;$ RMSEA $=.13 ;$ SRMR $=$ .14 .

Table 4.3. Fit statistics for competing measurement models

\begin{tabular}{lllllllll}
\hline Model & $\mathrm{X}^{2}$ & $d f$ & $\mathrm{CFI}$ & $\mathrm{TLI}$ & $\mathrm{RMSEA}$ & SRMR & AIC & BIC \\
\hline Model 1 & 1422.48 & 615 & .91 & .90 & .05 & .06 & 50337.8 & 50880.4 \\
Model 2 & 3123.26 & 619 & .72 & .70 & .08 & .08 & 52366.5 & 52891.7 \\
Model 3 & 1605.19 & 619 & .89 & .88 & .05 & .06 & 50553.4 & 51078.6 \\
Model 4 & 6376.35 & 617 & .36 & .32 & .13 & .14 & 56252.2 & 56734.0 \\
\hline
\end{tabular}

$\chi^{2}=$ Chi-square; $d f=$ degrees of freedom; TLI= Tucker-Lewis Index; CFI= Comparative Fit Index; RMSEA= Root Mean Square Error of Approximation; SRMR= Standardised Root Mean Square Residual. 
As can be seen in Table 4.3, the original hypothesized model with four latent factors (Model 1), distinguishing a four-factor model for HIHRM, one-factor models for both autonomy and affective commitment and a four-factor model for IWB, best fitted the data in terms of all the proposed fit-indices. Consequently, Model 1 was used as an input for the structural modelling and further analyses.

\subsubsection{Structural model and hypotheses}

First, we tested our proposed structural model (Figure 4.1). As can be seen in Table 4.4, our hypothesized model had an acceptable fit: $X^{2}(686, N=567)=1519.10$; $\mathrm{p}=.00 ; \mathrm{CFI}=.91 ; \mathrm{TLI}=.90 ; \mathrm{RMSEA}=.05 ; \mathrm{SRMR}=.06$. We then added a direct path from employees' perceptions of HIHRM to IWB. This alternative model (Alternative Model 1) helps to assess whether autonomy and affective commitment fully or partly mediate the relationship between HIHRM and IWB $\left(X^{2}(688, N=567)=1518.88 ; p=.00 ; \mathrm{CFI}=.90 ; \mathrm{TLI}=.90 ; \mathrm{RMSEA}=.05 ; \mathrm{SRMR}=.06\right)$. Although the fit of the alternative model was adequate, it did not significantly improve the fit over the original model $(\Delta \mathrm{X} 2=.22 ; \Delta \mathrm{df}=1 ; \mathrm{p}=.57)$. Moreover, the added direct path from HIHRM to IWB was found to be insignificant $(\beta=.05, p=$ $.50)$. Therefore, the original proposed structural model was considered adequate for testing our hypotheses.

Table 4.4. Fit statistics for structural models

\begin{tabular}{llllllll}
\hline Model & $\mathbf{X}^{2}$ & $\boldsymbol{d} \boldsymbol{f}$ & $\Delta \mathbf{X}^{2}$ & $\mathbf{C F I}$ & TLI & RMSEA & SRMR \\
\hline Theoretical model & 1519.10 & 687 & & .91 & .90 & .05 & .06 \\
Alternative model $1^{\mathrm{a}}$ & 1518.88 & 686 & $.22^{\mathrm{b}}$ & .91 & .90 & .05 & .06 \\
\hline $\mathrm{N}=567$ employees \\
a Adds the direct path from employee perceptions of high-involvement HRM to IWB \\
${ }^{\mathrm{b}}$ Model fit compared with the theoretical model (Figure 4.1)
\end{tabular}

The first hypothesis claims that employees' perceptions of HIHRM positively affect their sense of autonomy. The SEM results in Figure 4.2 do indeed show that employees' perceptions of HIHRM are positively and significantly related to autonomy $(\beta=.56, p<.001)$. Therefore, we accept Hypothesis 1 . Hypothesis 2 suggests that employees' perceptions of HIHRM are positively related with their affective commitment. As can be seen in Figure 4.2, employees' perceptions of HIHRM are indeed also positively and significantly related with affective commitment $(\beta=.54, p<.001)$, leading to the acceptance of Hypothesis 2 . Hypothesis 3 states that autonomy is positively related with employees' IWB. Again as shown in Figure 4.2, the relationship between autonomy and IWB is indeed positive and significant $(\beta=.29, p<.001)$. Similarly, the positive relationship between affective commitment and IWB proposed in Hypothesis 4 
was shown to exist and be significant $(\beta=.17, p<.01)$. Finally, affective commitment and autonomy together predicted $14 \%$ of the variance in IWB, indicating sufficient support for Hypotheses 3 and 4. Therefore, hypotheses 3 and 4 can be accepted.

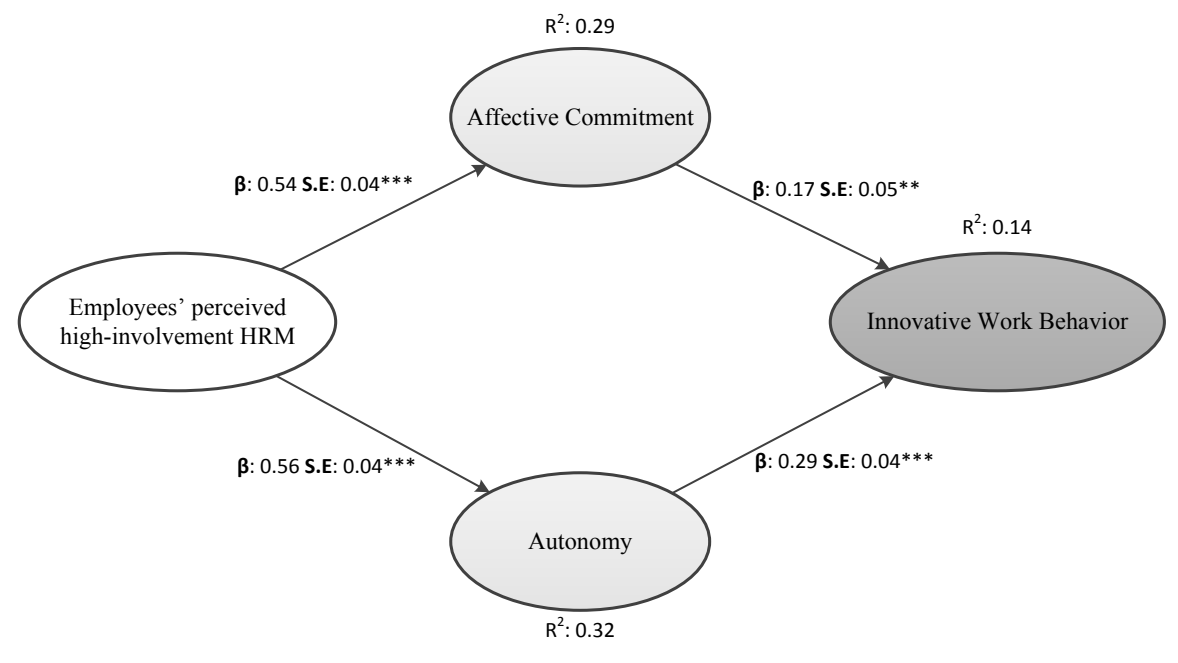

$N=567$ employees $\left({ }^{* *}\right.$ Significant at $p<.01 ;{ }^{* *}$ Significant at $\left.p<.001\right)$

Figure 4.2. Results of SEM: mediation effect of autonomy and affective commitment in the relationship between high-involvement HRM and IWB.

\subsubsection{Indirect effects}

Finally, Hypothesis 5 suggests that autonomy and affective commitment mediate the relationship between employees' perceptions of HIHRM and IWB. As can be seen in Figure 4.2, autonomy and affective commitment are positively and significantly affected by HIHRM and, in turn, they positively and significantly affect IWB. Further, having added these mediators, the direct relationship between HIHRM and IWB ceases to exist. We tested for these indirect effects using the bootstrap analysis option (with 20,000 iterations) in Mplus. We tested for the indirect effects, through both autonomy and affective commitment, of employees' perceptions of HIHRM on IWB. The results in Table 4.5 show that the combined indirect effect was significant (estimate $=.25, \mathrm{p}<.001$ ). Further, the individual indirect effects of autonomy (estimate $=.17, \mathrm{p}<.001$ ) and of affective commitment (estimate $=.09, \mathrm{p}<.01$ ) were also both significant. These results indicate that the positive effect of employees' HIHRM perceptions on IWB is fully mediated through autonomy and affective commitment. Therefore, we accept Hypothesis 5. 
Table 4.5. Indirect effects of autonomy and affective commitment on the relationship between high-involvement HRM and IWB

\begin{tabular}{lccc}
\hline Variable & Estimate & S.E & $\mathbf{9 5 \% ~ B C ~ C I ~}$ \\
\hline Indirect effect Autonomy & .17 & .04 & {$[0.10 ; 0.24]$} \\
Indirect effect Affective Commitment & .09 & .03 & {$[0.04 ; 0.15]$} \\
\hline
\end{tabular}

$\mathrm{SE}$, standard error; $\mathrm{BC} \mathrm{Cl}$, bias-corrected confidence interval

\subsubsection{Alternative models}

Several alternative models were tested to support the directions of the relationships as described above to reduce the chances of reversed causality that could be a consequence of our cross-sectional data. The first model that we tested includes IWB as mediator between HRM and autonomy and commitment (see Alternative Model 1 in Table 4.6). We tested this model because employees who are very innovative might as a result be awarded more autonomy and be more committed to the organization. However, the results show that this model has a significantly poorer fit compared to the original model $\left(X^{2}{ }_{(2)}=-142.36 ; p<\right.$ .001). The second alternative model that we tested included the mediation effect of high-involvement HRM in the relationship between autonomy and affective commitment as independent variables and IWB as outcome variable, as employees with positive attitudes and job-resources might be more positive about the presence of high-involvement HRM. Also this model shows a significantly poorer model fit $\left(X^{2}(2)=-16.84 ; p<.001\right)$. To conclude, the alternative models including different causal relationships between our focal variable do not provide better fit with the data and therefore we can be confident that our model was adequate for testing our hypotheses.

Table 4.6. Fit statistics for alternative models.

\begin{tabular}{lllllllll}
\hline Model & $\mathbf{X}^{2}$ & $\boldsymbol{d f}$ & $\mathbf{X}^{2} / \boldsymbol{d f}$ & $\Delta \mathbf{X}^{2}$ & CFI & TLI & RMSEA & SRMR \\
\hline Alternative Model 1 $^{\mathrm{a}}$ & 1661.5 & 685 & 2.43 & -142.4 & .89 & .88 & .05 & .09 \\
Alternative Model 2 $^{\mathrm{b}}$ & 1535.9 & 685 & 2.24 & -16.8 & .91 & .90 & .05 & .06 \\
\hline
\end{tabular}

$\mathrm{N}=567$ employees

athe mediation effect of IWB in the relationship between HIHRM and autonomy and affective commitment

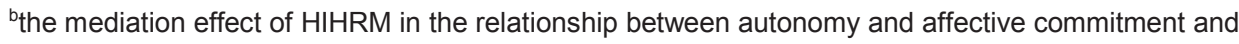
IWB.

Furthermore, we tested several alternative models based on the conceptualization of IWB. In our structural model we included IWB as a secondorder latent construct existing of four sub-dimensions (idea exploration, 
generation, championing, and realization). Because several measurement models of IWB had an adequate fit, we conducted several post-hoc tests to assess whether our results also hold when using different measures of IWB.

First, we assessed a structural model in which IWB is based on four distinct constructs (as in Table 4.7: Four factors (distinct)): idea exploration, generation, championing and realization. The results show that the relationships between high-involvement HRM and autonomy $(\beta=.56, p<.001)$ and affective commitment $(\beta=.54, p<.001)$ remain the same. Furthermore, autonomy was positively related with exploration $(\beta=.26, p<.001)$, generation $(\beta=.20, p<$ $.001)$, championing $(\beta=.28, p<.001)$, and realization $(\beta=.30, p<.001)$. In addition, affective commitment showed a positive and significant relationship with exploration $(\beta=.14, p<.05)$, generation $(\beta=.16, p<.01)$, championing $(\beta=.18$, $p<.001)$, and realization $(\beta=.13, p<.001)$. These results are in line with our initial structural model and findings.

Second, we assessed a structural model in which IWB is based on two distinct third-order constructs (as in Table 4.7: Four factors (third-order)a), one third-order construct including dimensions idea exploration and generation (called "invention") on the other dimension including idea championing and realization (called "application"). The results show that the relationships between high-involvement HRM and autonomy $(\beta=.56, p<.001)$ and affective commitment $(\beta=.54, p<.001)$ remain the same. Furthermore, autonomy was positively related to the invention $(\beta=.22, p<.001)$ and the application dimension $(\beta=.30, p<.001)$. Affective commitment was also positively related to both invention $(\beta=.16, p<.001)$ and application $(\beta=.16, p<.001)$. On this basis, we can conclude that our initial results hold.

Hence, based on these post-hoc analyses we can be confident that our results are not strongly influenced by the measurement model of IWB. All the same, the results of the post-hoc analyses show that there are differences regarding the effects of autonomy and affective commitment on the dimensions of IWB. For example, they suggest that autonomy is more important for the later stages of IWB. Nevertheless, the distinct dimensions of IWB were strongly correlated, which would cause multicollinearity problems when testing the hypotheses. For that reason, we tested the hypotheses with a single third-order IWB construct including the four sub-dimensions idea exploration, generation, championing and realization. 
Table 4.7. Fit statistics for alternative models of IWB.

\begin{tabular}{|c|c|c|c|c|c|c|c|}
\hline Model & $x^{2}$ & $d f$ & $x^{2} / d f$ & $\mathrm{CFI}$ & TLI & $\begin{array}{l}\text { RMSE } \\
\text { A }\end{array}$ & SRMR \\
\hline Four factors (distinct) & 1468.34 & 673 & 2.18 & .91 & .90 & .05 & .05 \\
\hline Four factors $\left(3^{\text {rd }} \text {-order }\right)^{a}$ & 1482.41 & 682 & 2.18 & .91 & .90 & .05 & .06 \\
\hline
\end{tabular}




\subsection{Discussion}

The aim of this study was to explore underlying mechanisms that could explain the relationship between HRM and innovative work behaviour. To do so, we examined the mediating role of autonomy and affective commitment in the relationship between high-involvement HRM and employees' IWB. In so doing, we also responded to multiple calls to shed light on the theoretical foundations and mediating mechanisms underlying the HRM-innovation relationship (BosNehles, Renkema, et al., 2017; Seeck \& Diehl, 2017). We were able to demonstrate that a combination of autonomy and affective commitment fully mediates the relationship between HIHRM and IWB. Below, we discuss the theoretical and practical implications of our research.

\subsubsection{Theoretical implications}

This research has several implications for HRM research. First, one of the most important implications from our findings is that attitudes and resources act as mediators between HRM and IWB. Here, we focused on employees' perceptions of HRM because perceptions are seen as a better indicator of employees' responses than actual HRM practices (Den Hartog et al., 2013; Liao et al., 2009). It is crucial that employees perceive the presence of HIHRM as such practices signal an investment in the employees and indicate that their involvement is both desired and appreciated (Kehoe \& Wright, 2013; Nishii \& Wright, 2008). Although several studies have found that employees' attitudes are more strongly affected by their perceptions of HRM than by the HRM practices as originally implemented by managers, none of the studies have explored the mechanisms through which HIHRM affects IWB. This study has filled this void by showing that autonomy and affective commitment fully mediate the relationship between employees' perceptions of HIHRM and IWB. This implies that employees' perceptions of HIHRM will only affect IWB if the employees actually feel they have greater freedom in their work and greater commitment to the organization. As such, our research shows that integrating the attitudes-perspective and the resourcesperspective provides a fuller explanation of how HRM relates to employee outcomes (Meijerink et al., 2017). As such, future HRM research should consider both employees' attitudinal responses and perceived resources when trying to explain how HRM relates to IWB.

Second, our results show that it is employees' perceptions of a bundle of HIHRM practices that have a positive effect on their IWB. We acknowledge that this finding is not completely new since earlier findings in the HRM-innovation literature have indicated that HRM practices are linked with innovative performance (Seeck \& Diehl, 2017). However, our study adds that it is HRM 
bundles, rather than single HRM practices, that affect IWB. Further, we contribute to the HIHRM stream by examining the factors through which employee involvement leads to behavioural outcomes such as innovative behaviour (Boxall \& Macky, 2009). Here, it is noteworthy that the effect of the HIHRM bundle is fully mediated by autonomy and affective commitment. We have provided evidence for the proposed indirect path, where HIHRM affects effectiveness by enhancing employees' attitudes (Lawler, 1986; Vandenberg et al., 1999). This full mediation thereby implies that HRM research should further study employees' abilities, motivations, and opportunities in order to explain the effect of HRM on IWB, as it is not the HRM system per se that directly triggers employees' IWB, but the attitudinal responses and resources that are generated by HRM systems.

Third, this study has implications for theoretical developments regarding mechanisms underlying the HRM-IWB relationship. Our findings are in line with arguments derived from social exchange theory (Blau, 1964) and reciprocity (Gouldner, 1960) in that employees seem to reciprocate investments in HIHRM practices with enhanced commitment towards the organization, which in turn leads to increases in generated and implemented innovative ideas. Previous research has argued that social exchange processes are important in explaining how HRM practices affect employee behaviours, but there has been scant attention to the potential role of affective commitment as a linking mechanism (Kehoe \& Wright, 2013), and therefore our findings offer an important contribution to this line of thinking. At the same time, by drawing on the job-demands resources model (Bakker \& Demerouti, 2007) and self-determination theory (Gagné \& Deci, 2005), we show that autonomy as a job-resource and motivating factor is even more significant than affective commitment in explaining the link between HRM and IWB. As such, our research adds to the HRM literature that a combination of these theories can further enhance our understanding of HRM and employee outcomes.

Finally, this research has empirically tested the effect of perceived HIHRM on IWB in a sample of 'regular' employees such as shop-floor service workers, professionals and middle managers (Kesting \& Ulhøi, 2010): individuals who are not explicitly required to be innovative (Montag et al., 2012). Through this, this study adds to the literature on employee-driven innovation (Høyrup, 2010) by showing that all organizational members can be creative and geared towards problem-solving provided there is a supportive HRM climate (Bos-Nehles \& Veenendaal, 2017; Kesting \& Ulhøi, 2010). Here we add to the research that has already shown that, even in a formalized context, employees can generate and implement ideas when they are facilitated by HRM (Renkema et al., 2018), by showing how HIHRM practices can be applied to encourage employees to be innovative. 


\subsubsection{Practical implications}

The results of this research have several implications for HR personnel, managers and employees. The results uncover three important steps that managers can take to increase innovative behaviours. First, managers should invest in involving employees. This can be achieved by adopting various HRM practices, such as investing in training and development, autonomous teamwork, information sharing and performance feedback. These practices signal to employees that their involvement is both desired and appreciated, and provide the autonomy that employees need to generate and implement new ideas.

Second, it is important that managers and HR professionals also invest in communicating such HIHRM practices because it is the perception of HRM practices that is linked to IWB. Perceptions can be influenced by communication, by stressing the idea and meaning of involvement, and not only explaining the functioning of the distinct HRM practices (Bowen \& Ostroff, 2004). As such, those implementing HRM practices play an important role in stimulating IWB because they have a strong influence on how employees interpret actual HRM policies and practices (Wright \& Nishii, 2013). Consequently, IWB can be enhanced by managers sharing information, increasing autonomous teamwork, investing in training and development, and focusing on continuous developmental feedback.

Finally, managers need to invest in boosting the commitment and autonomy of employees as our results show that it is these factors that lead to IWB. Involvement alone is not enough: it needs to be targeted towards commitment and autonomy. Committed employees may be more engaged in IWB because they expect to reap benefits from their innovations either through reciprocation by the organization, in terms of rewards or appreciation, or by improvements in their working conditions.

\subsubsection{Limitations and future research directions}

Our findings should be viewed in the light of the limitations of our research design. The first limitation is the use of self-reported data for IWB. Although this approach is quite common (Bos-Nehles \& Veenendaal, 2017; Veenendaal \& Bondarouk, 2015) and prior research has found strong links between self-reported and supervisor-reported IWBs (Axtell et al., 2000), future research could enhance confidence by better triangulating measurement of this concept, for example by comparing self-reporting measures with perceptions of supervisors (Janssen, 2000) and co-workers (De Jong, Parker, Wennekers, \& Wu, 2015). It would also be valuable to compare these somewhat subjective measures with more 
objective measures such as the number of ideas submitted to a suggestion scheme (Frese et al., 1999).

Another limitation is the use of cross-sectional data. All the measures were self-reported and collected at the same point in time. As a consequence, we cannot confidently draw conclusions about the causal directions of the proposed relationships. Also, given this approach, common method bias and reversed causality cannot be ruled out. However, we included a single factor test in our analysis and the results suggest that these issues are not a concern here. Further, we tested several models that reflected different relationships between our variables and all of these showed a poorer fit with the data than the hypothesized model. Therefore, we are confident that common method bias and reversed causality are unlikely to have distorted our findings. Nevertheless, future research could adopt a longitudinal design by separating the moments when the independent, mediating and dependent variables are measured.

Third, this research has been conducted in a specific context: the healthcare sector. Organizations in this sector are not usually involved in developing and introducing radically new products. Further, these organizations are publicly financed, and available budgets are relatively small. In the public sector, there is also a lack of competitive pressure compared to private firms (Bysted \& Jespersen, 2014), and innovations need to increase public value to be justified (Hartley, 2005). Furthermore, employees need to overcome many bureaucratic barriers to implement their ideas and to do so requires supportive leaders (Bos-Nehles, Bondarouk, \& Nijenhuis, 2017). Given all these constraints, care should be taken in extending the findings to other organizations, and especially to private firms.

A final limitation is that the findings are based on a single-level research design. Multilevel thinking has yet to be widely adopted in HRM research (Renkema et al., 2017) and future research could test whether innovative behaviour by individual employees actually leads to innovation at a higher organizational level, and the influence of HRM in this (Renkema et al., 2018; Shipton, Sparrow, et al., 2017). Research has shown that innovative behaviours can lead to innovation performance (Fu et al., 2015), but how innovation emerges at a higher organizational level remains unclear. 


\subsection{Conclusions}

In this research, we have examined the relationship between high-involvement HRM practices, autonomy, affective commitment and innovative work behaviour. The results provide important insights into the underlying mechanisms that explain how HRM is linked to IWB. The findings show that, if employees perceive HIHRM practices, they are more likely to feel they have autonomy in their work and be committed to the organization, which then boosts their IWB. In this way, this study has advanced understanding of the HRM-innovation relationship and added knowledge on the employee-level mechanisms that link HRM with employee outcomes to the HRM literature.

\subsection{References}

References can be found on page 209. 



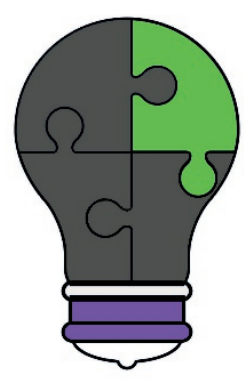

\section{CHAPTER 5}

\section{Routes for Employee-Driven Innovation: How HRM Supports Emergence of Innovation}

"Ideas are useless unless used"

(Theodore Levitt)

Authors are Renkema, M., Meijerink, J., \& Bondarouk, T. Currently, this paper is in preparation for submission to an international peer-reviewed journal. Earlier versions of this paper were presented at the 78th Annual Meeting of the Academy of Management, 10-14 August 2018, Chicago, IL (USA), at the 10th Biennial International Conference of the Dutch HRM Network, Nijmegen, The Netherlands, and at the British Academy of Management Conference 2017, Coventry, United Kingdom. 


\begin{abstract}
Although research has shown that HRM can contribute to innovation, both at the organizational level by stimulating innovation performance and at the individual level by stimulating innovative behavior, only limited attention has been given to the bottom-up emergence of innovation based on an individual's ideas. Furthermore, while scholars have accumulated knowledge about innovative behavior by employees in business contexts where innovation is nurtured, to fully understand "innovation by employees" we need to also address business contexts where innovation by employees is not overtly expected. For these reasons, the aim of this paper is to explore bottom-up innovation by studying socalled employee-driven innovation (EDI) in a formalized business context, and any associated HRM support mechanisms. To achieve this goal, we adopted an explorative research design, and conducted a single multilevel case study in a highly formalized company - a medical laboratory in the Netherlands. The data analysis was based on 40 interviews, documents, and observations. We found that a highly formalized business context does support innovation by employees, but that this has specific employee-driven innovation routes through which employees innovate in the organization. The data analysis enabled the distillation of emergence-enabling factors that are important for the development of EDI. Furthermore, the findings suggest that the content and process of EDI emergence should be studied using a multilevel perspective if one aims to map its routes and support mechanisms. Based on these findings, we offer recommendations on how EDI routes should be modelled and reflect on what this contributes to the HRM - innovation literature.
\end{abstract}

\title{
5.1 Introduction
}

Motivated by the evidence that innovation contributes to organizational success (Anderson et al., 2014), researchers have increasingly studied the contribution of HRM to innovation outcomes (Bos-Nehles, Renkema, et al., 2017; Seeck \& Diehl, 2017). HRM practices such as training, autonomy, teamwork, and rewards are considered to be instrumental in stimulating innovation through increasing organizational learning (Shipton et al., 2005), creating an innovative climate (Shipton et al., 2006), and enhancing innovative human capital (De Winne \& Sels, 2010). Recently, HRM scholars have started to acknowledge the multilevel nature of the HRM - innovation relationship (Shipton et al., 2016b). Indeed, researchers have already accumulated evidence that HRM practices positively relate to both the innovation performance of organizations (Beugelsdijk, 2008) and the innovative behavior of individual employees (Alfes et al., 2013; Dorenbosch et al., 2005; Veenendaal \& Bondarouk, 2015). 
Academic studies have gathered conceptual and empirical knowledge about the top-down effects of HRM on employees' innovative behavior. This has allowed scholars to turn their attention to the understudied bottom-up role of an individual's innovative behavior. This recent shift in scholarly focus has started to explore and examine the emergence of organizational-level innovation performance based on individuals' innovative behavior (Renkema et al., 2017; Shipton, Sparrow, et al., 2017). Studying the emergence of innovation through a bottom-up process is justified by observations that ideas generated by individual employees need to be shared and implemented within organizations for organizational-level innovation performance to occur (Gong et al., 2013). Although HRM researchers have studied both the idea generation and the idea implementation behaviors of employees, this does not yet explain how innovative ideas at the individual level develop into organizational-level innovation.

We build our arguments on research findings that show that the antecedents of different innovation dimensions reside on different levels of analysis (Axtell et al., 2006; Gong et al., 2013). For example, Axtell et al. (2000) showed that individual-level variables were more strongly related to idea generation, whereas group- and organizational-level variables were more related to the implementation of ideas. Another important organizational-level variable that affects innovation is structural formalization (Damanpour, 1991; Hirst, Van Knippenberg, Chen, \& Sacramento, 2011; Jansen, Van Den Bosch, \& Volberda, 2006), which refers to work processes such as pre-described rules, procedures, policy manuals, and job descriptions (Mintzberg, 1980). Innovation-management research shows that formalization can both enhance and inhibit the creation and implementation of innovative ideas (Aiken \& Hage, 1971; Jansen et al., 2006; Jung, Wu, \& Chow, 2008). We address these uncertainties and take this notion further by elaborating in this paper on how HRM activities support and/or inhibit the emergence of individual ideas and their route to boosting organization-level innovation performance. In so doing, we address the research gap resulting from HRM researchers mostly studying individual-level innovation while overlooking how these ideas are implemented at the organizational level, and the contribution of HRM to the emergence of innovation.

This study aims to explore the ways in which HRM contributes to the emergence of innovation in a formalized business context. In doing so, we introduce the concept of employee-driven innovation (EDI) to the HRM literature. EDI refers to the generation and implementation, across organizational levels, of new ideas, products, services, and/or processes originating from work-floor employees who are not overtly required to be active in these activities. We have chosen to study EDI in the healthcare sector, where one would expect enhancing EDI to be complicated by the high degree of formalization. In this context, the daily tasks of work-floor employees do not include innovative behavior (Montag 
et al., 2012) as they are expected to follow a large number of formalized routines to reduce errors (Kohn, Corrigan, \& Donaldson, 2000). However, given the rapidly changing environment, even mechanistic organizations face increasing demands to engage in innovative behavior (Ramamoorthy et al., 2005).

Our contribution to the literature is threefold. First, we add to the multilevel HRM and innovation research by examining the role of HRM in the bottom-up emergence of innovation. Following the idea that emergence has multiple aspects, we show that the role of HRM can be categorized by whether it influences the content or the process of emergence. Second, we adopt a process perspective on how innovative ideas are created, shared, and implemented, while also drawing on the vast body of knowledge about variance in employees' innovative behavior. Through this, we uncover different routes, their underlying phases, and the process steps that result in innovation. Further, we show which HRM practices play a role in those phases. Finally, we show how employees can contribute to innovation in a strictly formalized context. We describe how formalization can both support and restrain the emergence of innovation. In so doing, we develop a comprehensive, multilevel model of the emergence of innovation from employees who face the additional challenges of innovating in a formalized organizational context.

The paper continues as follows. We first conceptualize EDI in a formalized context, and the role of HRM in stimulating and facilitating EDI. Next, we present the results of a single, multilevel case study in a highly formalized company - a medical laboratory in the Netherlands, to identify the EDI process and the ways through which HRM encourages EDI. We finalize with a discussion on the theoretical and practical implications.

\subsection{Literature review}

\subsubsection{HRM, innovative work behavior \& EDI}

To date, the HRM scholarly field has conceptualized and empirically validated the relationship between HRM and innovation, with employees' innovative work behavior (IWB) seen as an important outcome of HRM practices. Here, IWB refers to the actions of individual employees focused on "[...] the intentional creation, introduction, and application of new ideas within a work role, group, or organization, in order to benefit role performance, the group, or the organization" (Janssen, 2000, p. 288). This definition reflects the idea that IWB consists of several dimensions and behavioral tasks. Scholars have shared a consensus in studying such IWB dimensions as idea generation, idea promotion, and idea realization (Scott \& Bruce, 1994). 
Studies of the "HRM - IWB link" have accumulated knowledge about single HRM practices that enhance IWB, the drawbacks of IWB, and the contribution of IWB to organizational outcomes. A recent literature review into the HRM - IWB link showed that practices such as training, rewards, job security, autonomy, task composition, job demands, and feedback all positively affect innovative work behavior (Bos-Nehles et al., 2017). Another review of studies addressing the HRM - innovation performance relationship found evidence for a positive relationship between HRM and innovation performance at the organizational level (Seeck \& Diehl, 2016). An important aspect for our study is the assumption made in these earlier works that the organization's capability to innovate is derived from the individual-level employees' capabilities and motivation, which is influenced by HRM (Jiménez-Jiménez \& Sanz-Valle, 2008). We take this a step forward and suggest building upon this assumption and examining the relationship between HRM and innovation from a multilevel perspective (Lin, 2015) since this is well-suited to the cross-level nature of both concepts (Seeck \& Diehl, 2016).

The multilevel approach will allow us to conceptualize the ways in which HRM contributes to the bottom-up process of innovation, i.e. turning IWBs into innovation outputs. For example, clarifying the link between employees' creativity and their firm's innovation performance can benefit from adopting a multilevel approach (Gong et al., 2013). Taken in isolation, the IWB concept is an individual behavioral construct that does not encompass how innovations are developed and implemented across organizational levels. From a behavioral perspective, one could expect greater innovative behavior to lead to more innovative outcomes, such as the development or improvement of products, services, and processes (Crossan \& Apaydin, 2010). The underlying assumption is that increasing employees' IWB leads to more ideas being generated and then implemented in the organization. Studies have broadly indicated that innovative behavior is positively related to organization-level innovation outcomes (Fu et al., 2015), and it is now time to address how the individual-level IWB constructs materialize as innovation performance. Innovative employees do not automatically succeed in getting their ideas implemented across the organization (De Spiegelaere, 2014). Hence, the question remains how to depict innovations as a bottom-up emergence, and how the behaviors of individual employees result in innovative output at the organizational level. To address this issue, we introduce employee-driven innovation (EDI) to the HRM literature, a concept that can connect IWB with innovative outcomes at two levels of analysis: the individual level and the organizational level. EDI is a relatively new concept that focuses on the development and outcomes of innovation rather than on employee behavior. 


\subsubsection{Employee-driven Innovation and HRM}

Following the definitions by Høyrup (2010) and Kesting and Ulhøi (2010), we view employee-driven innovation as:

The generation and implementation across organizational levels of new ideas, products, services, and/or processes that originate from one or more work-floor employees who are not overtly required to undertake such activities.

Our definition of EDI has two important implications for understanding how IWB emerges as organization-level innovation. First, EDI involves innovation activities in which frontline employees are at the core of the innovation process, rather than regular innovation channels such as R\&D departments (Høyrup, 2010). The definition highlights that EDIs are innovations that are not necessarily required from the employees. That is, employees who are not thought to be innovative come up with new ideas that are implemented. These innovations are conceptualized as emerging from 'regular' employees who do not have formal job tasks dedicated to innovation, such as shop-floor workers, service employees, and middle managers (Kesting \& Ulhøi, 2010). In practice, these employees are ideally positioned to provide innovative suggestions (Wihlman et al., 2014) since they face challenges during their work and understand market demands through their customer contacts (Skaggs \& Youndt, 2004). Second, Birkinshaw and Duke (2013) suggest that EDI has a potential to change the management approach from top-down to bottom-up because it is initiated and led by operational employees. This idea corresponds with the notion that one of the factors in the successful development and implementation of innovations is the active and constructive involvement of all stakeholders across all hierarchical levels of the organization (De Spiegelaere, Van Gyes, \& Hootegem, 2012b).

We recognize that how EDI is conceptualized is closely related to IWB. While innovation is the 'outcome' of the EDI process, employees' innovative behavior serves as the input to EDI. As such, EDI essentially combines both the individual innovative behaviors and the collective innovation outcomes. For this reason, we see EDI as a concept that can help understand how innovation unfolds across levels. Implicitly, EDI reveals employee behavior from a multilevel perspective: it is focused on the initial ideas generated by employees, and the involvement and participation of employees in the implementation of innovations at the organization. This bottom-up innovation process explains how the dynamics and interactions of the individual innovative behaviors, revealed over time, produce the collective phenomenon of innovation performance (Kozlowski \& Klein, 2000). As such, innovative behavior is a necessary but not sufficient 
condition for innovation outputs. Innovative outputs are only possible when employees share, interact, and coordinate their ideas across organizational levels. Hence, the emergence of EDI depends on individuals' innovative behaviors and the coordination and interaction of those behaviors. By integrating IWB and EDI into a process approach, we stress that all employees can be active in the EDI process to ensure that innovation outcomes materialize across organizational levels. In viewing EDI as a bottom-up process, we can start to uncover how HRM can shape and stimulate the process of innovation emergence. In the next section, we further elaborate on the emergence of innovation, and on how HRM can support these processes.

\subsubsection{Emergence of EDI through enabling processes}

We draw insights from multilevel theory building to describe EDI emergence (Kozlowski \& Klein, 2000). EDI can best be described as a process of emergence, a process whereby individual characteristics coalesce into a higher-level collective outcome (Kozlowski \& Klein, 2000). Characteristics such as affections, innovative and other behaviors, and cognitions are amplified through interaction and coordination to form a collective phenomenon (Allport, 1954; Katz \& Kahn, 1978). Task complexity and emergence-enabling states have been identified as elements that influence the emergence enabling process (Ployhart \& Moliterno, 2011). We treat innovation as such an emergent phenomenon because it has its foundations in the characteristics of individuals - innovations arise from an individual's ideas and interactions. Following Kozlowski and Klein (2000), we argue that EDI has emergent properties because it manifests itself as innovation - a collective phenomenon - when individuals interact and exchange ideas, knowledge, and/or attitudes. The principles underpinning multilevel theory show that there have to be underlying contextual and emergent mechanisms that drive the relationship between HRM and innovation (Ostroff \& Bowen, 2000). Emergence at a higher level is determined by multiple factors, while system interactions amplify and shape how emergence affects performance (Kozlowski \& Chao, 2012; Ployhart \& Moliterno, 2011).

Based on principles of multilevel theory, one can identify three features of EDI emergence: content, process, and structure (Fulmer \& Ostroff, 2016). The content of EDI emergence is the elemental content of individual operational employees' innovative ideas that are aggregated at a higher organizational level to result in innovation (Ostroff, Kinicki, \& Muhammad, 2013). The process of EDI emergence is related to the interaction and coordination among individual employees that is required to implement ideas and thereby shape higher-level outcomes such as innovation performance (Kozlowski \& Klein, 2000; Ployhart \& Moliterno, 2011). The EDI structures refer to higher-level contextual factors, such 
as HRM activities and formalization, that shape the process of EDI emergence. In this research, EDI captures the 'content', the 'process', and the 'structure' of emergence, as it entails both the innovative ideas and the process that leads to the implementation of the innovation across organizational levels, while also analyzing how the structure influences the content and process. Forming part of the 'structure' of emergence, organizational structure and practices have been identified as factors that potentially affect the emergence (Fulmer \& Ostroff, 2016). Driven by our research aim, to study how HRM affects innovation in a formalized context, we focus on HRM activities and formalization as structural features of EDI emergence.

\subsubsection{HRM activities as a structural factor}

HRM activities can affect both the content and the process of emergence, and thereby shape the EDI emergence process. HRM activities can both enhance the creation of innovative ideas (content) and stimulate their successful implementation (process). For example, HRM can shape features of the collective interactions of individuals - such as the concerted actions that are necessary to coordinate innovative activities (Li, Wang, van Jaarsveld, Lee, \& Ma, in press). However, different mechanisms might be involved regarding content and process. As an illustration, job complexity has been found to affect the implementation of ideas (i.e. process), but not to have an effect on the creativity of employees (i.e. content) (Ohly et al., 2006). Furthermore, an HRM practice such as training could have a greater effect on EDI content, whereas task composition and autonomy seem more likely to be related to the EDI process. Therefore, when analyzing EDI emergence from a multilevel perspective, it is important to analyze structural dimensions that enable emergence and to distinguish between HRM activities that affect the content and the process of emergence.

\subsubsection{A formalized work context as structural factor}

Formalization is a structural dimension that initially is not obviously associated with supporting the innovative behavior of employees. However, given that EDI involves ideas that arise from 'regular' employees, who often work in a formalized context, it is essential to reflect upon the rules and regulation of a workplace and these are embodied by formalization. The formalization of behavior is one of the design elements of an organizational structure, and refers to work processes that are prescribed through rules, procedures, policy manual, and job descriptions (Mintzberg, 1980). As such, formalization can be defined as the extent to which formal procedures, rules, and roles are used to regulate employee behavior (Pugh et al., 1963). Formalization is usually seen as limiting the 
discretionary power of employees, with power instead vested in formal systems and procedures. In relation to the link between formalization and innovation, we know that mechanistic organizational systems and the corresponding managerial control, which translate into high formalization and high centralization, inhibit innovativeness (Aiken \& Hage, 1971; Pierce \& Delbecq, 1977). In other words, a high degree of formalization suppresses the expression of individual differences and reduces creativity (Hirst et al., 2011).

In line with this, we can expect a formalized work environment to be an unfavorable context for EDI. However, this does not mean EDI is impossible. For example, Veenendaal and Bondarouk (2015) found that production workers could still be involved in innovative behavior. Typically, such blue-collar, manufacturing jobs are highly formalized and exist within machine bureaucracies (Mintzberg, 1980). Nevertheless, blue-collar employees in manufacturing organizations can make suggestions for improvements if they have autonomy, feel ownership, and can participate in decision-making (Axtell et al., 2000; Ramamoorthy et al., 2005). Vough, Bindl, and Parker (2017) show that, even in highly formalized jobs, individuals can be engaged in proactive work behaviors provided there is a clear routine that supports such behaviors. The apparently contradictory findings related to formalization poses the question as to how the formalized context affects EDI and which mechanisms explain the success of EDI. In line with the above, the effects of formalization could differ for the creation of innovative ideas (content) and for the successful implementation of those ideas (process).

\subsubsection{Initial research framework}

Based on the above discussion, we examine the emergence of innovation by studying how ideas coming from individuals are implemented within the organization, and how HRM and formalization contribute to this emergence process. We present the initial conceptual framework of this study in Figure 5.1. It delineates how the content, the process, and the structure of EDI emergence are connected. The assumption is that HRM, as a part of the EDI structure, can enhance the emergence of innovation by stimulating and facilitating both the content and the process of EDI. Building on the work on emergence-enabling processes (Ployhart \& Moliterno, 2011; Fulmer \& Ostroff, 2016), we use an emergence-based model of HRM and innovation by exploring how ideas stemming from individuals give rise to collective innovation, and how HRM can affect the emergence processes. First of all, HRM can increase the likelihood that employees come up with innovative ideas (i.e. the EDI content) by stimulating innovative work behavior (Bos-Nehles et al., 2017). Second, innovative work behavior has been shown to be positively associated with innovation outcomes (Fu et al., 2015). Finally, innovation can be stimulated by HRM through an 
emergence-enabling strategy (Li et al., in press; Wang \& Zatzick, 2015). Given that EDI refers to innovations that are developed by 'regular' employees who are not overtly expected to be innovative (Montag et al., 2012) and who, because of this, are often constrained by norms, rules, and procedures, we include formalization as a structural factor.

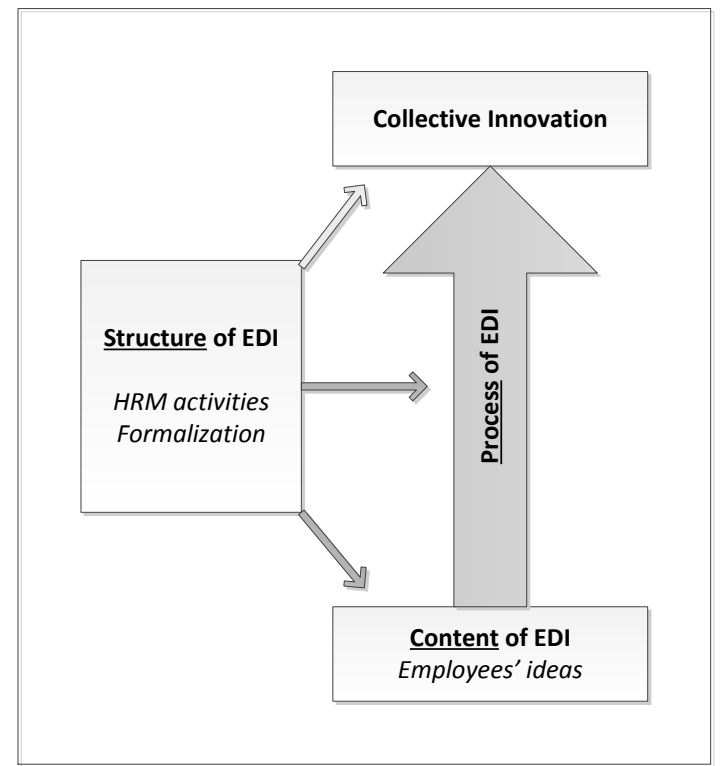

Figure 5.1. Initial conceptual framework: EDI emergence model

\subsection{Methodology}

To uncover how EDI emerges, and how HRM influences this process, an exploratory qualitative case study has been conducted at an organization that can be characterized as having a highly formalized context. We have opted for a case study because we are interested in exploring the emergence of EDI within an organizational context. Since this is not immediately apparent, an in-depth study of a single case will help uncover EDI process dynamics and stimulating factors (Elsbach \& Kramer, 2003). A lengthy interaction using inductive techniques will also be required (Lee, 1999). Qualitative research is further appropriate because we are focusing on developing theory using a process approach (Strauss \& Corbin, 1990). In addition, a case study is appropriate because our research is focused on elaborating HRM mechanisms, whereby we will contrast previous understanding with observed events to improve and extend, rather than test, existing theory (Lee, Mitchell, \& Sablynski, 1999).

We followed this approach by developing a research model of the HRM - EDI relationship based on the events observed in our case study, and through 
this refined and extended theory (Lee et al., 1999). The case study company is a Dutch medical laboratory, in this study labelled "MedLab". MedLab is a particularly appropriate organization in which to study EDI in a formalized context because it is highly formalized and has technological (e.g. new equipment) and market pressures (e.g. consolidation) that necessitate innovation to survive in its competitive markets.

\subsubsection{Data collection}

The case study was carried out between February 2016 and May 2017. For triangulation purposes, we relied on multiple data collection techniques, including document analysis, semi-structured interviews, and observations. Given our multilevel perspective, we interviewed and observed work-floor employees (i.e. analysts, phlebotomists, and specialists) who generated and implemented innovative ideas and then analyzed EDIs that are a result of these behaviors.

Data sources and procedure. The first research phase included desk research, document analysis, informal conversations, and observations. This allowed us to understand the organizational culture and traditions, to establish a common research language, and to get to know employees who were involved in the EDI processes. EDIs were operationalized as innovative initiatives that had involved work-floor employees. Potential EDIs were shortlisted based on documents and observations. In close collaboration with the HR manager, we then identified and selected employees involved in these innovation initiatives. We then conducted semi-structured interviews with these innovative employees. Consequently, we asked employees and managers about the EDI process and their role in it, and about the factors that stimulate and inhibit innovation. The secondary data used were in the form of written reports, strategic documents, research reports, and minutes of meetings.

Based on the preliminary observations from the first phase, we conducted interviews with top management, department managers, supervisors, and support staff to identify their role in EDI. We also conducted interviews with employees who were not necessarily innovative. We randomly selected employees from across the organizations for this purpose. The third phase of the research consisted of reflection and discussing the results. During this phase, results were discussed, reflected upon, and clarified with key informants to enhance the credibility and validity of our results (Yin, 2014).

The semi-structured interviews were conducted with employees to identify their role in EDI, their perceptions and behaviors regarding HRM practices, and factors that affect EDI. Sample questions from the interview protocol that we followed are: "How often do you look at opportunities to renew or improve products and/or processes?", "What do you do after you have 
developed an idea", and "What does the organization do to stimulate innovation?" (Appendix G). Each interview lasted approximately one hour and interviews were conducted in all the laboratories and within several units. Prior to each interview, interviewees were assured about confidentiality and anonymity. Interviews were audiotaped, fully transcribed, and verified by interviewees. The first author also made field notes to supplement the audiotapes. In total, 40 interviews were conducted at three different laboratory locations (see Table 5.1).

\begin{tabular}{lcc}
\hline Informants & \#Interviews & Length \\
Board of directors & 1 & $66 \mathrm{~min}$. \\
Clinical chemists & 2 & $103 \mathrm{~min}$. \\
Support staff & 7 & $425 \mathrm{~min}$. \\
Department managers & 6 & $335 \mathrm{~min}$. \\
Specialists & 4 & $247 \mathrm{~min}$. \\
Phlebotomists & 4 & $220 \mathrm{~min}$. \\
Analysts & 16 & $833 \mathrm{~min}$. \\
Total & $\mathbf{4 0}$ & $\mathbf{3 7}$ hours \\
\hline
\end{tabular}

Table 5.1. Overview of interviews at MedLab

\subsubsection{Data analysis}

The raw data were inserted in a data analysis software program (NViVo) and then analyzed using several steps and coding strategies. The qualitative analysis of the data consisted of three phases. First, each of the transcripts were read and re-read and, while reading through the 15-20 page documents, initial ideas on the main research concepts were written down. Core thematic concepts and critical incidents were identified, such as innovative initiatives. Subsequently, three successive levels of coding were applied to all the raw data: open and axial coding, selective coding, and theoretical coding (Strauss \& Corbin, 1998). Using the main research concepts developed in the first phase, we identified first-order codes using open coding - i.e. codes that came directly from the raw data - in order to make sense of the content and the processes of the concepts. For example, we coded the different activities undertaken by employees after generating a new idea (e.g. communicating and monitoring). During this open coding, we also identified groupings of codes - second-order codes. For example, where we had coded text about communicating ideas with colleagues and with managers as first-order open codes, we now grouped them together as 'idea communication'. The third level of coding was the construction of overall coding categories, integrating the inductively derived codes with the existing literature. This resulted in some categories that had already identified as themes within the literature, for example the EDI process, whereas others, such as 'EDIencouraging leadership behaviors', emerged as EDI-supporting mechanisms through the coding process. 
The second phase of data analysis consisted of identifying specific instances of EDIs. We assessed whether mentioned initiatives should be seen as EDIs by comparing them to the key elements of the EDI definition. They were assessed based on the following criteria: they had to include (1) the generation and/or implementation of a new idea, product/service, or process; (2) to originate from an employee for whom innovation was not a regular task; and (3) to be integrated within the organizational context. Next, the identified EDIs were individually analyzed and categorized, resulting in an inductively arrived at overview of different types and routes of EDI.

The third phase of data analysis consisted of developing a process overview of EDI. Based on the first two phases of analysis, a process approach was used to identify the general steps and phases of the EDI process. A number of second-order codes from the open coding process were used to develop the EDI process model. Although the stages of the model were all inductively deduced, some of them resembled dimensions of IWB and could therefore be equated with the existing literature. For example, we coded texts related to the application of initiatives and those about using ideas on the work floor as 'idea implementation', a dimension of IWB. Three key innovation 'routes' emerged from this analysis: (1) the organizational route, (2) the formalized-system route, and (3) the project-initiative route. Subsequently, stimulating and constraining factors that were associated with the EDI process and its various stages were inductively identified. For example, we linked phases of the EDI process with stimulating factors by analyzing comments where informants had mentioned what had helped them to further their ideas. We thus created a data structure consisting of the first, second, and aggregated categories to develop an inductive process model including the different stages of EDI emergence and the concepts that influence the development of EDI.

\subsection{Findings}

The case study highlights that HRM can positively contribute to EDI in a formalized environment. Despite the formalized context, we saw employees who were engaged in generating and implementing innovative ideas. First, we describe the organization where the case study took place and its approach to innovation. Following this, we provide an in-depth analysis of EDI at MedLab and outline the EDIs' contents (i.e. types) and processes (i.e. phases and routes). Finally, we describe support mechanisms and draw upon the findings to develop a phase model of EDI. 


\subsubsection{Case description and approach to innovation}

MedLab is a medical laboratory that performs diagnostics on blood samples and is responsible for reporting results to general practitioners, specialists and other customer organizations. The motto of MedLab is: "Faster, Better, Closer" (annual report, 2015), thereby emphasizing both quality and efficiency. The mission of the organization stresses the importance of service quality: "We are a service organization that offers medical diagnostics in its broadest sense. We support medical care around the patient by offering quality diagnostics at the right time and by this we promote the quality and expedience of healthcare" (website, 2017). In total, the organization has 445 employees, divided across three laboratories and around 80 locations for blood collection. MedLab, as an organization, has a large number of written norms, rules, and procedures. It has ISO 15189 accreditation, which defines norms about quality and competences in medical laboratories. It has implemented an extensive quality system in order to guarantee the quality of the healthcare it provides. The quality system has the goal of assessing and controlling the service quality as part of meeting the specific ISO norms.

In public documents, MedLab communicates that innovation is an important mission of the organization and part of its current approach. While we did not identify a documented long-term strategy, MedLab's vision clearly calls for innovation as an important part of the business. In its approach to innovation, MedLab aims to develop specific content-related priorities in which the organization wants to excel and innovate (strategic letter, 2016). Strategic documents also refer to this aim to innovate: "MedLab needs to distinguish itself more through quality, innovation, and entrepreneurship". However, it is also apparent that there is no clear operational plan on how to achieve this. Moreover, we found no mention of the importance of stimulating innovative behavior by employees. In fact, an external consultant advised MedLab to put more focus on innovation.

\subsubsection{Emergence of EDI - countless initiatives and unique approaches}

We identified over a hundred unique initiatives at MedLab. Most of the innovative ideas concerned innovations in processes, such as changes to procedures or improving communication between departments. The majority of the ideas were discussed among colleagues and supervisors and were implemented relatively easily. Of the many factors that constrained EDI, a lack of resources, priority, recognition, and organizational knowledge were the most consistently mentioned. In particular, given the procedures and quality assurances, the wider 
organizational implications that needed to be addressed were limiting EDI. Whereas there was an expectation from management that employees would develop their ideas, many employees saw limited possibilities to innovate. A bottom-up process through which innovation was fully initiated, developed, and implemented by work floor employees was an exception rather than the norm. Most of the developed initiatives involved an important role for (line-)managers in bottom-up innovation processes.

\subsubsection{The content of EDI emergence - different types of EDI}

In this section, we focus on the different types of EDI - referring to the elemental content of EDI emergence. The data revealed that there are clear differences in the underlying content of EDIs, and that this had an impact on the further development of emerging EDIs. Therefore, we provide a broad outline of the three main types of EDls identified at MedLab. The research revealed three main elemental content-types of innovations that were developed: these were ideas related to (1) primary work content (e.g. new test for vitamins), (2) work processes (e.g. changing blood sampling routing), and (3) organizational developments (e.g. education program for trainees). Table 5.2 illustrates the differences in these EDI routes using real examples of initiatives developed at MedLab. Our analysis has shown that the process of EDI emergence is dependent upon the elemental content of the EDI. Depending on the ideas that employees want to pursue, they use different routes. These EDI emergence processes and routes are now discussed.

\subsubsection{The process of EDI emergence - different phases and EDI routes}

In this section, we discuss the process of EDI emergence at MedLab. A clear process emerged that shows the phases through which EDI developed. First, we describe this generic bottom-up process of EDI based on the inductive analysis in terms of phases, activities, and actors involved. Second, we describe the different routes through which innovations emerge, and which are related to the process of EDI emergence.

Regarding the process, we inductively developed a phase-model outlining five phases through which EDIs develop: the onset, development, communication, finalization, and implementation of ideas. In all these phases, different employee behaviors played a role. In the first EDI phase - the onset phase - new ideas arise from the recognition of a problem or opportunity. In general, being very aware of the practicality of the work routines, employees were very good at recognizing challenges on the work floor. In the development phase, employees found solutions for the challenges and opportunities they encountered 
and generated ideas. The communication phase involved discussing the idea with direct colleagues and leaders, and receiving initial feedback. The finalization phase consisted of involving others in the idea, developing the idea further, testing/piloting, and convincing others. The final phase, the implementation phase, occurs once an idea has been established and decisions made that the idea is worth implementing, and the idea is then put into practice.

Route 1: Organizational route. The first EDI route reflects the organizational structure. Employees first shared their ideas with colleagues and direct supervisors, and then communicated them with the department heads. Often the manager took over the responsibility and communicated the idea further within the organization. Department managers adopted a leadership role and championed the initiatives with other departments, higher management, and/or customers. Often, the prevailing process no longer involved employees in the further development of the innovation. However, there were some exceptions in which employees were still active in the later phases of the EDI process.

The case study showed that supervisors needed to have knowledge about what to do with ideas generated on the work floor. Given the nature of the work and the formalized context, employees were not expressly required to be innovative and, therefore, official protocols for dealing with ideas were lacking. As a result, success in pursuing innovative ideas depended on the direct supervisors and their organizational knowledge. In our case study, direct supervisors indicated that they did know how to deal with EDIs, as highlighted in the following:

"I doubt whether it is described like that, but that is the way to go. Of course, you have to consult with colleagues. Actually, you know it - you know when a clinical chemist needs to make a decision or whether you can discuss it [the idea] with your department head, who in turn can discuss it with the clinical chemist" (Specialist 1).

The organizational route is predominantly used for EDIs related to the primary work content. That is, ideas directly related to blood collection and analysis such as ideas about how to better carry out blood analysis and improve the process steps for blood collection. This type of EDI requires specific knowledge and the approval by higher management - employees did not have the autonomy to themselves initiate innovations in this area:

"Well, they [employees] can make decisions about whether test results are analytically sound, that is verification. However, in the area of innovation, they cannot develop new diagnostics or whatever. That does not happen" (Clinical Chemist 1). 
Routes for Employee-Driven Innovation || 145

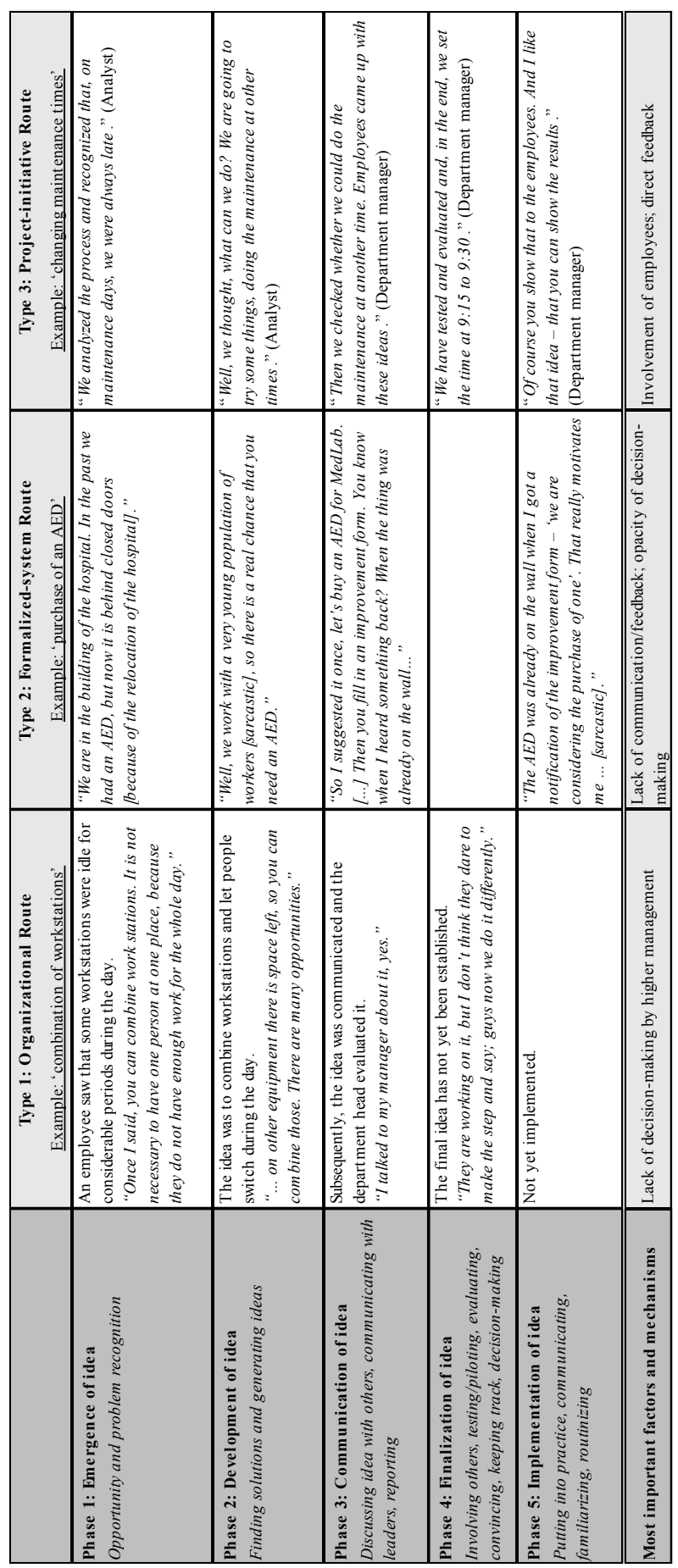

Table 5.2. Examples of different types of employee-driven innovation routes at MedLab. 
Moreover, most of the primary work content is formalized in protocols and cannot be changed without consulting many parties within the organization, requiring employees to share their ideas through the organizational hierarchy route. This is the case when it comes to new equipment, new tests, and also new software.

Further, we saw that EDIs that were concerned with work processes were also pursued through this route. In some cases, innovations in work processes could be implemented very quickly, particularly when the innovation did not affect other units in the organization and no coordination was necessary. Outside of the primary processes formalized in protocols, other ideas could be acted upon more easily. For example, it was relatively easy to create new workstations or take measures to improve customers' waiting times. That is, when innovative ideas did not relate directly to protocols they could be implemented more directly:

"And issues where there is no protocol involved. Those things can be arranged. And then the feedback is good." (Phlebotomist 3).

Route 2: Formalized-system route. All employees were encouraged to share problems and ideas through an online system in which official procedures and protocols were described. All inputs were assessed by the responsible department manager. Employees were able to keep track of their suggestions through the online system. In theory, employees were supposed to get an email about how the organization had dealt with the input. However, many of the respondents indicated their dissatisfaction with the system because it often took a long time before problems were resolved or ideas taken into consideration, and there was a lack of feedback to the employees. The quality department had the role of assessing whether any changes were appropriately enacted. Usually, other work-floor employees were given the responsibility for making small changes in the protocols based on inputs from employees.

The EDIs developed through this route were predominantly related to work processes, with employees often pointing out minor errors or ideas to improve work processes. Even ideas that were unrelated to the department manager's responsibilities were communicated through this route. For example, one employee mentioned that he used the formal system to communicate ideas about the ICT system. Further, the formalized system route was sometimes used to communicate ideas about or errors in the primary work content. Again, the department managers often played a crucial role in the development of an EDI, as they would formally need to assess the incident and also analyze whether further action was needed elsewhere in the organization. As such, the formalized incident system enhanced the influence of department managers on the EDI process and reduced the direct influence of work-floor employees. 
"They are supposed to assess those things for all incidents separately, if it is an issue only in their own department or within the whole organization" (Quality worker).

Route 3: Project-initiative route. Many employees claimed that there was much more room for their input in specifically arranged project teams. For example, MedLab had organized lean project teams to improve the logistics of their bloodsample collection. A number of employees had been asked to take part in the project, and non-participants were also encouraged to share ideas for improvement through project meetings and posters on the walls. As they were explicitly assigned the task of thinking creatively about existing processes and solutions, this EDI route offered more freedom for employees to develop and implement their ideas.

In principle, all types of EDI could be developed through this route, from work content and process to organization-level ideas. However, our data show that organizational developments were most likely to be developed through the project-initiative route. These ideas were not directly related to the primary work and processes of the organization. In general, ideas in this category were directed towards improving the quality of internal and external coordination and communication, finding new markets, or improving management processes. A typical example is the "Project Communication" project that was initiated by two employees from different departments to improve internal communication and coordination between departments. Within this project, several ideas were developed to fine-tune interdependent work processes. The HR manager championed the project and helped to prepare a project plan that was used to gain approval from the management team. Eventually, the two employees were put in charge of the project and recruited other colleagues to join. What is particularly striking in this example is that all management-level employees were explicitly excluded from participating in the project. Another example of this project-initiative route is the 'Market Opportunities' project, a strategic work team developed by one of the board members in which all employees of MedLab could participate to create and develop ideas to produce new value for the organization:

"From the start I was involved. I think around 20 to 25 ideas were proposed, particularly to generate more money. That was the goal, to generate more income by involving work-floor employees, since they have a clear picture of the processes and opportunities to generate more money. I think 25 ideas were developed, but none of them were accepted" (Analyst 1).

To summarize, we uncovered five different stages in the EDI process and we have here described the different types (content) and routes (process) through which EDIs emerge. By analyzing the distinct types and routes of the emergence process, we identified differences in the content and processes of EDIs. The case study also revealed that innovations emerged from employees' ideas through 
different routes within the organization, and that the route followed was contingent on the type and content of an employee's idea. Employees opted for one of the routes depending on the idea they wanted to pursue. Although our observations showed occasional overlap and mixing of routes and the elemental content, we hold to the three routes analytically distilled when modeling the EDI process.

\subsubsection{The structure of EDI emergence - enabling content and process}

Based on our analysis of the interdependency between the content and the processes of EDI, we now describe the mechanisms that support and constrain the emergence of EDI in a formalized context. We observed the influence of several HRM activities, particularly by increasing employees' opportunities to be involved in innovation (see Appendix $\mathrm{H}$ for an overview). Furthermore, what emerged from our data was the importance of the interplay between leadership and HRM activities. Therefore, in this section, we discuss both HRM activities and leadership as enablers of EDI.

\subsubsection{HRM activities as enabling factors}

Our data show that certain HRM practices are more relevant in some phases of EDI than in others. The in-depth analysis resulted in two main categories: practices that mainly affect the content of emergence, and practices that mainly affect the process of emergence. There are factors that increased the likelihood of new ideas being generated (top-down stimulation), and factors that increased the likelihood of employees' ideas being implemented (bottom-up championing). We categorized the HRM practices by where they appeared to have the most influence, and focused on the practices that were most evident and relevant for EDI emergence.

HRM policies that were related to the content of emergence were training, rewards, job design, recruitment, participation, information sharing, and performance management. When training opportunities were offered, this was perceived as a good vehicle for generating new ideas. In particular, training or collaboration with other organizations was valued for its influence on generating new ideas. The results show that rewards and recognition played a prominent role by acknowledging innovative initiatives. Recognition, for example through showing appreciation for employees' efforts, offering compliments, or providing a small non-monetary reward (e.g. vouchers or chocolate bars), was particularly beneficial in encouraging innovative employees to continue to develop ideas. The emergence of EDI was further enabled by appropriate job design. One of the practices that stimulated innovative content to emerge was offering extra tasks to 
employees. Especially with the many protocols in place, the regular work can become tedious for some employees. There was a group of employees who enjoyed more challenging work, and by allowing these employees to do extra tasks (such as quality assessments, scheduling, or website editing) or join projects, the organization benefited from the ideas they then generated. Further, one of the most important aspects was hampered by the specific situation at MedLab in that the organization had very low workforce mobility and flexibility, leading to virtually zero recruitment of new employees. However, for EDI to emerge, recruitment from outside seemed to be important as, through this, the organization gained novel insights and increased the likelihood of ideas being generated. The findings show that information sharing is another important enabler of EDI emergence. Here, EDI could be channeled and shaped by providing information about organizational developments: informing the workforce about strategy and future plans increased the likelihood that employees would develop ideas that were valuable for the organization, which in turn increased the potential of successful implementation across organizational levels. Significant levels of communication and information sharing enabled a common understanding regarding expectations and requirements for innovation to develop. Predominantly it appeared to be transparency that was key to successfully stimulating EDI emergence. Employees often lacked the management information that formed the basis of strategic decision-making, and we saw that this was important to get employees involved in the innovation process. Lastly, our data reveal that performance management, by facilitating employees to raise ideas, can stimulate EDI emergence. Almost all department managers used annual appraisals to raise the issue of employee development, and employees could bring forward their wishes to be involved in innovation projects or additional tasks.

HRM policies that were related to the process of EDI emergence were training, job design, selection, involvement, and feedback. Training helped to stimulate the implementation of new ideas across levels, for example when employees received training about how to involve the work floor in improvement projects. At MedLab, specialists were trained in the LEAN methodology and subsequently developed their own LEAN projects in which many innovative ideas of employees were generated and implemented. Our data analysis shows that especially the selection of staff for innovative projects proved to be an important factor in the process of EDI emergence. The success of innovation projects largely depended on the employees selected to participate. Department managers played a crucial role in this by selecting people based on their perceptions of their suitability and capacity. We also found that employees being involved and participating in decision-making or organization-wide project teams enabled the EDI process through which ideas are transformed into innovation 
because employees could more directly discuss, test, and apply their ideas. Lastly, our data reveals that feedback can stimulate the EDI emergence process. As managers were responsible for providing feedback, the implementation of related HRM practices depends on how they embody this role. Although the department managers at MedLab indicated that they aimed to give positive feedback on ideas, the employees often felt that feedback was either lacking or overly negative. Providing more extensive and more constructive feedback would have helped to further develop ideas. Feedback was especially important during the EDI development phases since it could help fine-tune employees' ideas and enhance the likelihood of approval by higher management.

Summarizing these findings, HRM practices facilitate the emergence of EDI by supporting both its content and process. In analyzing the influence of HRM, it is important to distinguish between the different sorts of practices within HRM policy domains. Some practices are more related to increasing the likelihood of new ideas arising, whereas others are more useful in facilitating the implementation process. However, in order to stimulate EDI, HRM practices should focus on both the content and the process of emergence. Although the identified practices were not always present at MedLab, a substantial number of EDIs could still be developed. Most employees indicated that they felt there was an openness to new ideas. However, getting their ideas implemented was often more challenging. The barriers could be eased to enable the further development of employees' ideas by using appropriate EDI routes and increasing the availability of HRM practices. Nevertheless, many initiatives require the involvement and support of managers to champion ideas further. As such, in our case study, EDI was often a co-production by work-floor employees and management.

\subsubsection{Leadership as enabling factor}

Strikingly, from an employee perspective, the HR department was not seen as playing a significant role in supporting the emergence of EDI. However, many HRM activities were in place that stimulated or constrained innovative behavior by employees and created a favorable environment for the implementation of ideas. Notably, department managers were responsible for the execution of many HRM activities. In terms of EDI, both managers and HR had a dual responsibility: they had to implement HRM activities and stimulate employees in a top-down fashion while, at the same time, supporting, facilitating, and championing ideas that arose in a bottom-up way from the work floor. We identified two main mechanisms through which EDIs were stimulated.

First, supervisors played a very important role in encouraging innovative behavior as they were the prime actors in stimulating, recognizing, appreciating, 
and rewarding employees who came up with innovative ideas. In a work design characterized by protocols and formalization, employees have very limited autonomy to pursue innovations by themselves. Therefore, they need to be activated, motivated, and actively invited by higher-ranked employees, who use their decision authority to involve employees in innovation. Especially the development and implementation of ideas was dependent on support from department managers. These managers were largely responsible for the implementation of HRM practices and were key agents in the bottom-up process. In turn, they needed to be facilitated and stimulated by HR to fulfil this role, for example by providing training and making innovation an integral component of feedback and performance management.

Second, the data show that leaders could integrate innovation in rewards and compensation and in performance management, for example by executing policies that rewarded innovative initiatives and making innovation part of the performance appraisal and feedback. The case study illustrated that MedLab integrated innovation in the annual appraisal talks, which helped the organization select appropriate employees for innovative projects. Furthermore, in departmental meetings, managers would always place discussing innovative ideas on the agenda.

\subsection{Towards a model of enabling EDI emergence}

We now continue the discussion of the results by focusing on how individual innovative behaviors are amplified by interactions (Kozlowski \& Klein, 2000), and result in the emergence of EDI. Based on the theoretical explanation by Ployhart and Moliterno (2011), we propose an emergence-based approach that models how employees' innovative ideas lead to organization-level innovation, and how HRM can act as an emergence enabler. In developing this model (see Figure 5.2), we started from the analysis of our data, but were also guided by the principles of multilevel theory. In this, emergence at a higher level is determined by multiple factors, and system interactions amplify and shape how emergence affects performance (Ployhart \& Moliterno, 2011; Kozlowski \& Chao, 2012). Two mechanisms to facilitate EDI emergence were distinguished in our research: structural enablers and leadership enablers. What was also apparent is that emergence consists of two components: the content and the process of emergence. 


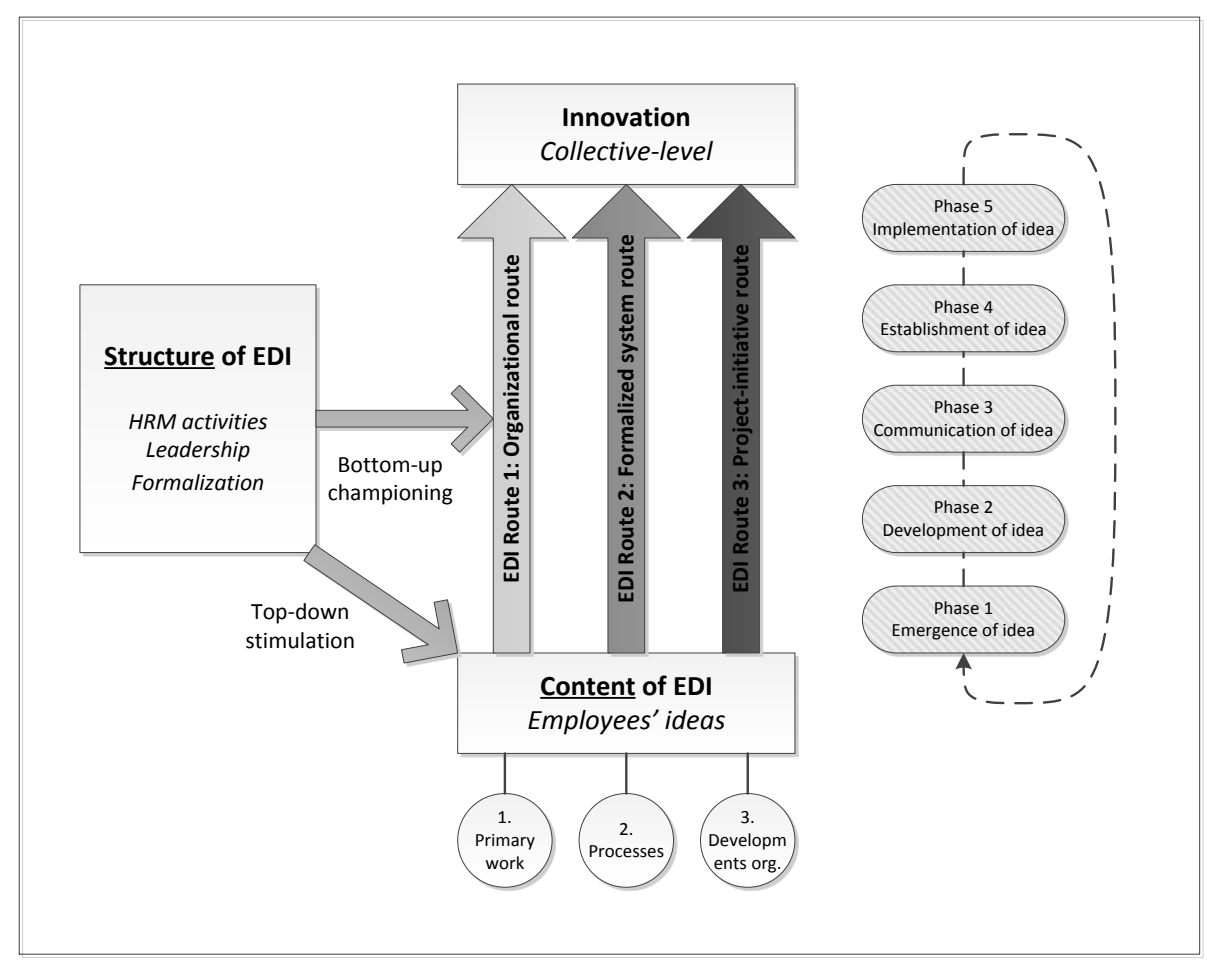

Figure 5.2. Inductive model of HRM and Employee-Driven Innovation emergence.

\subsubsection{Structural enablers of EDI emergence}

Structural enablers are mechanisms, related to the organizational structure and practices, that increase the likelihood of innovative ideas emerging and, in turn, developing into EDIs. Our results support previous assertions that organizational structure and HRM practices are important for the emergence process (Fulmer and Ostroff, 2016). In line with Guzzo and Noonan (1994), we have seen that practices can send strong signals to employees about which types of employees' innovative ideas are valued and expected in the organization. For example, the general staff meetings served as an important mechanism for information sharing by sending signals that ideas for efficiency improvements were highly valued.

The organizational structure also proved to be important for the emergence of EDI as the organization's formal structure affects employees' interaction possibilities (Kozlowski \& Chao, 2012). This is particularly true in a highly formalized context, such as in our case organization, as employees have only limited opportunities to interact with colleagues outside their own department. We have seen that practices such as project teams can reduce this 
constraint by offering additional channels for interaction. This supports the idea that enhancing communication and coordination is an important emergenceenabling process (e.g. Ployhart and Moliterno, 2011). Our results show that highinvolvement policies can help to stimulate interaction among and participation by employees. Practices such as teamwork, suggestion schemes, and flexible tasks were found to positively affect EDI, supporting the claimed positive effects of highinvolvement systems (Wood, Van Veldhoven, Croon, \& De Menezes, 2012). Through these practices, employees can share knowledge and ideas that would otherwise be restricted within departments.

The results also indicate that innovation might be hampered if employees are overtly commited to an organization. Although interaction and coordination form an important behavioral mechanism through which higher-level or collective outcomes can be achieved (Kozlowski and Klein, 2000; Ployhart \& Moliterno; 2011), valuable new ideas are less likely to arise when interaction is only possible with likeminded colleagues. In order to encourage meaningful interactions about innovation, organizations should facilitate workplace learning (Høyrup, 2010). Our analysis emphasizes that HRM practices related to the development of employees' knowledge, skills, and abilities are very important to promote learning and the acquisition of knowledge, for example through recruitment and selection and through training programs. Again, there is a double role for HRM. First, it is important to contribute to enabling cognitive emergence - to the ability to acquire, absorb, and transfer knowledge (Cohen \& Levinthal, 1990; Zahra \& George, 2002). Second, to facilitate the emergence of innovation, it is important to focus on how knowledge and skills can be replicated through practices such as knowledge-sharing systems (Wang \& Zatzick, 2015).

What is particularly important in a highly formalized context is that organizations offer channels through which ideas can be shared. Not only does this study support the idea that suggestion schemes are important to capture employees' creativity (Frese et al., 1999), we also offer new insights into how organizations can develop multiple channels through which employees can interact and communicate their ideas. Our results support the claim that employees who are not expressly expected to be innovative can still develop ideas (Montag et al., 2012; Shipton et al., 2017), making use of one of EDI routes to pursue many of their innovative ideas. HRM practices can be used to encourage employees to become involved, but there also have to be routes and channels through which employees can develop and implement their ideas. The presence of the former but absence of the latter sends mixed signals to employees: they could perceive that they are expected to innovate, but that their ideas are never implemented. Therefore, we propose a dual role of HRM in the emergence of EDI: combining top-down stimulation with bottom-up championing of innovative ideas. 


\subsubsection{Leadership enablers of EDI emergence}

By leadership enablers we refer to the behaviors of leaders that increase the likelihood that ideas arise and, more importantly, that generated ideas are pursued and implemented. As our results show, leadership is crucial for EDIs to emerge. Leaders act as filters for innovative ideas and then communicate ideas further within the organization. When acting as a filter, leaders send messages to their staff about what is expected and appreciated in the work context. Not only do leaders influence their subordinates by filtering and interpreting top-down messages, our study shows that leaders also have an important task in shaping subordinates' sensemaking by selecting innovative ideas for further promotion. Furthermore, leaders served as role models for innovation, and influence event cycles within their units by delegating innovative tasks to subordinates. Particularly striking in the case study organization was the emergence of collectiveness within organizational sub-units of departments. This can be partly attributed to the leadership behaviors of department managers and specialists in those units. Ideas were more easily developed and implemented when only one's own unit would be affected by the idea, whereas implementation was more constrained when multiple departments were involved. Some department leaders and specialists at MedLab, by always being open to innovation and delegating responsibilities, were successful in creating a climate for innovation. In addition, department managers influence the number of opportunities that employees have to discuss their ideas with colleagues and supervisors. Many informants commented that they had good working relationships with their managers and that there was no more than a low barrier to communicating or discussing new ideas with them. We also saw that department managers were important in EDI emergence through their role in selecting and further developing EDIs, and thereby influencing which ideas were further developed and which ideas were rejected. Furthermore, if ideas went beyond the scope of their employees, it was up to the department manager to consult with other departments and convince the management of the value of the initial idea. This supports the view that leaders are very important in the innovative behaviors of employees as they can both stimulate and constrain subordinates' innovative responses (Bos-Nehles, Bondarouk, \& Nijenhuis, 2017; De Jong \& Den Hartog, 2007).

\subsection{Contributions}

The goal of this research was to study how HRM, in a formalized context, can contribute to the bottom-up emergence of EDI. By considering the bottom-up process of EDI from a multilevel perspective, we have developed a model of EDI 
emergence that illustrates how ideas from individuals on the work floor can develop into collective innovations, and how HRM can contribute to this process. Theoretical insights from multilevel emergence theory combined with findings from HRM and innovation research provided information on the bottom-up process of EDI and its support mechanisms. The findings suggests that, despite being a seemingly unfavorable environment for innovation, in a context of high formalization, work-floor employees do develop EDIs provided innovation routes are made available for them, and that these EDIs can be stimulated by HRM practices. In this, the current research extends previous knowledge about HRM and innovation by picturing the bottom-up process of innovation and showing how different HRM practices can be usefully applied during this process. Specifically, the in-depth exploration of HRM practices for EDI emergence provide further insights into how organizations can ensure that ideas are transformed into successful innovations. In doing so, this research extends the work of Shipton et al. (2017) and of Lin and Sanders (2017), who proposed bottom-up models of HRM and innovation. Alongside this, this paper suggests that most work-floor initiatives address innovation and organizational change, thereby illustrating that employees who are not tasked with innovative activities nevertheless show a great deal of commitment to improving a wide variety of organizational aspects. Consequently, rather than focusing on a predetermined group of 'privileged' R\&D employees, organizations can benefit from harnessing the innovative potential of the whole workforce by ensuring enabling mechanisms are in place.

\subsubsection{Theoretical implications}

The findings both support and extend research on HRM and innovation. Our study contributes to the HRM and innovation literature, which increasingly acknowledges that is important to study multiple levels within the organization to explain how HRM affects innovation (e.g. Shipton et al., 2016; Bos-Nehles et al., 2017). Our contribution is the inductive model of bottom-up innovation emergence, arising from ideas proposed by work-floor employees whose job tasks do not require them to innovate. More specifically, we uncovered how innovative ideas are transformed into innovative outcomes at a higher organizational level. This nascent theory of EDI emergence extends the theorizing on HRM and innovation by suggesting a model that distinguishes between different forms of content, process, and structure, and thereby helps to understand more clearly how ideas develop upwards within an organization. By doing so, we contribute to solving one of the central problems in innovation - how employees' creative ideas can be better implemented and transformed into firmlevel innovation (Gong et al., 2013; Shipton et al., 2017). The results of our case study show that specific HRM practices are important in such a setting. For 
example, practices such as innovation channels and projects teams and the leadership of frontline managers are particularly important. Furthermore, by investigating the bottom-up emergence of innovation, we contribute to multilevel theory building (Kozlowski \& Klein, 2000) by presenting new insights into the inner workings of the emergence processes and enabling mechanisms of innovation (Ployhart \& Moliterno, 2011). Here, we believe this is one of the first papers to report an in-depth empirical study that uncovers this largely unknown territory for HRM and innovation scholars. Our study also supports previous claims that emergence-enabling mechanisms have a positive role in innovation ( $\mathrm{Li}$ et al., 2017; Wang \& Zatzick, 2015).

Finally, our results show that, as HRM researchers, we should distinguish between HRM practices that stimulate the content of emergence, and those the process of emergence, when studying emergent phenomena. As part of the 'structure' of emergence, HRM practices can affect both the content and the process of emergence and thereby shape the entire emergence process. HRM practices can both enhance the creation of innovative ideas (i.e. content) and stimulate their successful implementation (i.e. process). However, it is possible for HRM practices to increase the likelihood that ideas are generated, but without this leading to more implemented innovations within the organization. If there are no emergence-enabling HRM practices, the likelihood of ideas being successfully implemented is low. To stimulate the EDI emergence process, HRM scholars and practitioners need to focus attention on the bottom-up processes and uncover how individual attributes collectively contribute to higher-level outcomes through coordination and interaction. When emergence-enabling mechanisms are weak, any HRM initiatives to stimulate innovation are likely to be in vain and may even be counterproductive since employees become demotivated if they perceive their ideas are not being taken seriously.

\subsubsection{Practical implications}

Managers of organizations wishing to increase the innovativeness of their human resources need to address the challenges that employees face during the EDI process. Particularly, the existing protocols and norms may stifle innovative behavior and these should therefore be attended to. Reinforcing the existing protocols in formalized organizations will not stimulate employees to be engaged in EDI. Rather, changes need to be made that will increase the likelihood of innovative efforts. Possibilities include building an innovative climate, increasing employees' motivation to be innovative, and providing recognition and appreciation once EDIs have been accomplished. Further, various routes can be created through which employees' ideas can develop into EDIs. For example, by introducing project teams or suggestion schemes even organizations with many 
formal rules and regulations can still benefit from the innovative potential of their work force. HR managers can play a role in boosting employees' abilities, motivation, and opportunities to be engaged in EDI by implementing initiatives that invite employees to be innovative. More specifically, appraisal talks should emphasize the opportunities to do interesting tasks alongside regular work, regular workplace exchanges of employees should take place, and project groups could be developed that include employees from different departments. HR managers could also develop organization-wide initiatives such as innovation competitions, strategic work teams, or knowledge platforms to increase involvement and offer those employees who are looking for new challenges channels for their innovative ideas.

\subsubsection{Limitations and future research}

This study is not without its limitations and boundary conditions. First, the results are based on a case study in a single organization. Although this may limit generalizability, we believe that our findings can be generalized to theory (Stake, 1978). It should also be acknowledged that employees working in a medical laboratory might have unique characteristics that do not easily translate to other organizations. In laboratories providing health services it is plausible that innovation might be even more restricted by regulations than in other highly formalized organizations such as manufacturing companies. Second, there are limitations in the use of the process approach in this study. Most of the analyzed initiatives occurred in the past, and there may be important events missing from the data (Langley, 1999), for example due to misinterpretation or to the retrospective nature of the data. To reduce the risk of hindsight bias due to forgetting previous events, data triangulation was used. Furthermore, intermediate analyses and results were validated through discussions with key informants. Third, although we were focused exclusively on EDI, we might have included other related proactive employee behaviors such as innovative behavior or organizational citizenship behavior. These concepts are all closely related to each other and it is sometimes hard to isolate them in this type of research. Indeed, we acknowledge that parts of our EDI model resemble some of the dimensions of the IWB concept (e.g. De Jong \& Den Hartog, 2010). Nevertheless, the difference is more than a discursive one. First, EDI is focused on the innovation rather than on employees' behavior. Moreover, in our phase model, we combine EDI phases with employee behaviors. Phases such as idea onset and finalization of idea add new aspects to innovative behaviors and its subdimensions. Furthermore, we made a distinction between types of employees based on their work behaviors. Future research could try to establish links between these types of behaviors and employees' personal characteristics to 
inform organizations how to recruit the more innovative types of employees. Finally, the examples of employee-driven innovations we uncovered tended to be incremental in nature, rather than employee-driven technological or radical innovation initiatives. As such, one should be cautious in attempting to generalize our findings to contexts where more radical employee ideas are needed.

\subsection{References}

References can be found on page 209. 


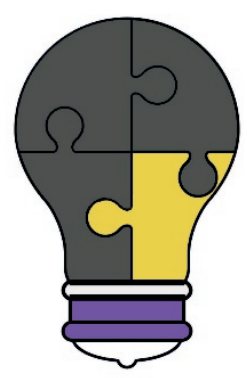

\title{
Advancing Multilevel Thinking and Methods in HRM Research
}

\author{
"You don't learn to walk by following rules. You \\ learn by doing, and by falling over."
}

(Sir Richard Branson) 


\section{Abstract}

Purpose - Despite the growing belief that multilevel research is necessary to advance HRM understanding, there remains a lack of multilevel thinking - the application of principles for multilevel theory building. The purpose of this paper is to propose a systematic approach for multilevel HRM research.

Design/methodology/approach - The paper proposes an agenda for multilevel HRM research by addressing three obstacles (concerning questions, theories and methods) that impede advancement in this field.

Findings - The paper provides an inclusive definition of multilevel HRM research that serves to advance its use, and maps out a multilevel HRM research landscape that captures the various aspects of this concept. The paper identifies unanswered multilevel questions within 16 research domains and develops a systematic approach to tackle these research questions by invoking three relevant theories and methodologies.

Research implications - Some of the identified research questions could not be answered due to limitations in mainstream multilevel theories and methodologies. In response, this paper proposes theories and methodologies that can address some of the multilevel HRM research questions identified in this paper.

Practical implications - The findings can help HRM academics working on cross-disciplinary and cross-level research problems with a clearly structured approach to what multilevel HRM research is and what steps should be taken in conducting such research.

Originality/value - The originality lies in the systematic approach that precisely describes multilevel HRM research, and addressing obstacles that inhibit rigorous and relevant multilevel HRM research by highlighting relevant research questions, theories and methodologies.

Keywords: Multilevel Research, Human Resource Management, Multilevel Theory Building, Levels of Analysis.

\subsection{Introduction}

Multilevel human resource management (HRM) research, the integration of constructs from different organizational levels, is rooted in the belief that organization-level HRM practices influence organizational performance through individual attitudes and behaviours (Ostroff \& Bowen, 2000; Paauwe, 2009; Schuler \& Jackson, 1987; Wright \& Boswell, 2002). This view implies that the strategic HRM research field is inherently multilevel and that core assumptions can be drawn from multilevel theory (Ostroff and Bowen, 2000; Kozlowski and Klein, 2000). Recent years have seen a growing number of multilevel HRM studies, with recent contributions providing two particular insights: into why actual 
and perceived HRM differ (e.g. Aryee et al., 2012; Liao et al., 2009); and how organization-level HRM practices affect individual-level outcomes including commitment and job performance (e.g. Ang et al., 2013; Bal et al., 2013).

Compared to other organizational research fields, such as strategy and entrepreneurship, HRM has been slow to adopt a multilevel perspective (Molloy et al., 2011). Further, the majority of multilevel HRM studies have examined topdown effects, and studies examining the lower-level emergence of phenomena (i.e. bottom-up effects) remain scarce. The few multilevel HRM studies that have examined bottom-up effects (Nishii et al., 2008; Aryee et al., 2012) have restricted their analysis to so-called composition models that assume that phenomena (e.g. the organizational climate) essentially remain unchanged as they emerge and move upward. As a result, HRM research has arguably missed the possibilities that compilation models offer in explaining how phenomena (such as human capital resources and collective performance of interdependent team members) differ between levels (Ployhart and Moliterno, 2011). A literature review highlighted that some of the core principles of multilevel theory, such as entrainment, bond strength and unit specification, have not yet found their way into HRM research (Renkema, Meijerink, \& Bondarouk, 2015). This is remarkable given that these principles could help identify the most relevant levels of analysis for selected HRM phenomena. As a late adopter of multilevel research, the HRM field still lacks multilevel thinking and this impedes further developments in this field. Currently three obstacles prevent multilevel HRM research from advancing:

1. The principles of multilevel theory building are not applied systematically in HRM research. Rather, the multilevel principles on how, where and when multilevel effects occur are applied arbitrarily, and this hampers our ability to build an integrated understanding of phenomena that unfold across organizational levels and explain how HRM is related to performance (Kozlowski and Klein, 2000).

2. In-depth insights and understanding of appropriate statistical and analytical methods for testing multilevel models are lacking (Shen, 2016). Popular multilevel-modelling software, such as HLM, and multilevel structural equation modelling (Hox, 2013) are primarily designed to test top-down models, and there is a lack of mastery of techniques for analysing bottom-up effects. This results in conceptual and statistical problems associated with multilevel analysis procedures such as a lack of appropriate sampling techniques for exploring multilevel effects (Preacher et al., 2010).

3. HRM research traditionally relies on theories that at best can explain bilevel relationships, and lacks theories that explain multilevel or bottomup relationships (Van Veldhoven, 2012). When bottom-up relationships are considered, composition-based theories that explain similarity dominate, rather than theories that explain emergence because of 
variability. HRM research needs to broaden its use of theories that could explain cross-level phenomena, and develop more-inclusive theories as it adopts multilevel research.

In addressing these three obstacles, we have three cascaded sub-goals: to provide new research directions based on multilevel HRM thinking; to suggest multilevel HRM theories; and to explore multilevel HRM methods and data analysis (see Figure 6.1). The first sub-goal leads to formulating unanswered multilevel HRM research questions based on the pillar of multilevel HRM thinking. Multilevel HRM thinking is defined as the application of principles of multilevel theory building (Renkema et al., 2015; Kozlowski and Klein, 2000). This lays the foundations for future multilevel HRM research questions because it shows where research gaps exist in the multilevel HRM literature. The second sub-goal, based on the pillar of multilevel theorizing, leads to identifying a set of theories to explain cross-level relationships in multilevel HRM research and to guide the operationalization of multilevel HRM relationships (the transformation from multilevel thinking to multilevel theorizing). The third sub-goal, based on the pillar of multilevel research, leads to an explanation of data analysis techniques and methodologies for answering research questions on multilevel effects in HRM.

Once achieved, these three sub-goals help overcome the three obstacles to multilevel thinking in HRM research described earlier by helping HRM researchers to conduct ground breaking, rigorous and relevant multilevel HRM research.

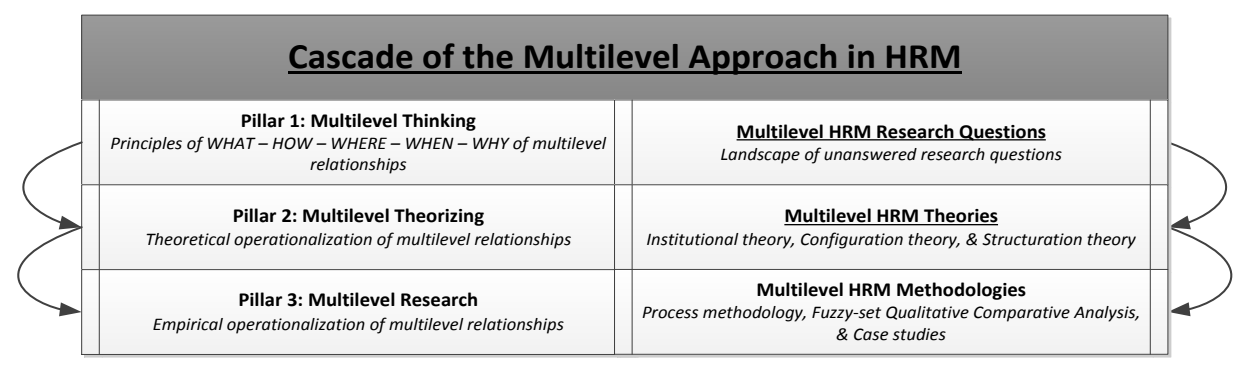

Figure 6.1. Cascading Multilevel Approach to HRM Research

\subsection{A multilevel HRM research landscape}

Multilevel research is a term that HRM researchers increasingly use to indicate studies that include variables that reside at more than one organizational level of analysis, typically to better account for the structural hierarchy in which organizational actors are embedded. A key tenet of such multilevel thinking is 
that organizational entities exist in nested arrangements (Hitt et al., 2007). Although many scholars share this fundamental understanding of what multilevel HRM research incorporates, and agree about the necessity to conduct it, we lack a definition of multilevel HRM research that captures the full breadth of a multilevel approach. There are five reasons why multilevel HRM research needs to be more precisely defined.

First, multilevel HRM research is about more than including variables at two different organizational levels of analysis. We need a definition that incorporates the need for multilevel HRM research to provide insights into managing people nested in organizational structures that enable and constrain their attitudes, behaviours and cognitions. Research therefore has to treat these employees, teams and organizations as embedded entities, each of which can be managed in many different ways and at different levels, and not as independent actors.

Second, we need a definition that emphasizes that the HRM construct is inherently multilevel because: (1) it consists of nested components such as philosophies, policies and practices which are hierarchically ordered (Schuler, 1992), (2) each of which can be manifested at different organizational levels (Ostroff and Bowen, 2000) and (3) each of which consists of intended, introduced and perceived activities which ideally are hierarchically ordered (Wright and Nishii, 2013); thereby stressing the interconnectedness of the various HRM systems components.

Third, we need a definition that leads to studies utilizing variables that exist at multiple organizational levels. The dominant approach to multilevel HRM (e.g. Kehoe and Wright, 2013; Bal et al., 2013) views HRM systems as being provided on the unit level and perceived by employees at the individual level (Jiang et al., 2013). Several HRM studies examining the relationship between actual and perceived HRM systems (e.g. Aryee et al., 2012; Den Hartog et al., 2013; Liao et al., 2009) have highlighted that HRM system components exist at multiple levels. HRM-performance relationships have been shown to exist at least at three organizational levels of analysis, classified as the individual, unit and organizational levels (Jiang et al., 2013), based on the view that organizationlevel HRM systems affect organizational performance by inducing organizational and psychological climates (Ostroff and Bowen, 2000). These climates reside at both the organizational and the individual levels, indicating that HRMperformance relationships are present at least at two levels of analysis. Additional levels have been included, such as the department or branch level (Liao et al., 2009) and more recently the team level (Chang et al., 2014).

Fourth, given that the application and effect of HRM practices are dependent on the external context of the organization (situational opportunities 
and constraints) (Paauwe, 2009; Paauwe \& Boselie, 2003), we need a definition that allows the context to be included in multilevel HRM research. It is widely acknowledged that organizations face institutional and competitive drivers, leading to different adoptions and adaptations of HR practices (Farndale \& Paauwe, 2007), thereby influencing multilevel HRM-performance relationships. There may be systematic contextual effects: the influence of HRM systems and climates may be more top-down in stable organizations, whereas they can have a stronger bottom-up influence in changing organizations (Ostroff and Bowen, 2000). In changing organizations, individuals can have a greater bottom-up impact on HRM systems, climate and normative contracts, and their influence on higher-level constructs may be more prominent, when the institutional environment is unstable (Bitektine and Haack, 2015). Hence, the extraorganizational level, incorporating aspects such as institutional and competitive factors, potentially influences HRM-performance relationships.

Fifth, the definition of multilevel HRM research needs to highlight the importance of time. Many organizational phenomena are influenced by temporal issues: multilevel relationships can change direction over time (Kozlowski and Klein, 2000); and there is a time lag between the adoption of HR practices and an improvement in organizational outcomes (Huselid \& Becker, 1996). However, time is frequently not included in multilevel models (House et al., 1995) despite temporal issues potentially influencing the strength and direction of cross-level relationships.

To address these five aspects, we offer the following broader definition of multilevel HRM research:

The study of time-dependent interconnections among various HRM system components and their relationships with contextual antecedents and outcomes at different organizational levels.

Together, multilevel HRM theories and research models need to conceptualize how constructs at different levels of analysis are linked, where these top-down and bottom-up processes originate and culminate, why they are linked, and how these linkages are influenced by time and context (Kozlowski and Klein, 2000).

Having more clearly defined what we mean by multilevel HRM research, we now construct a landscape of unanswered multilevel HRM research questions warranting scholarly investigation (see Figure 6.2) that addresses the first subgoal of the paper. 


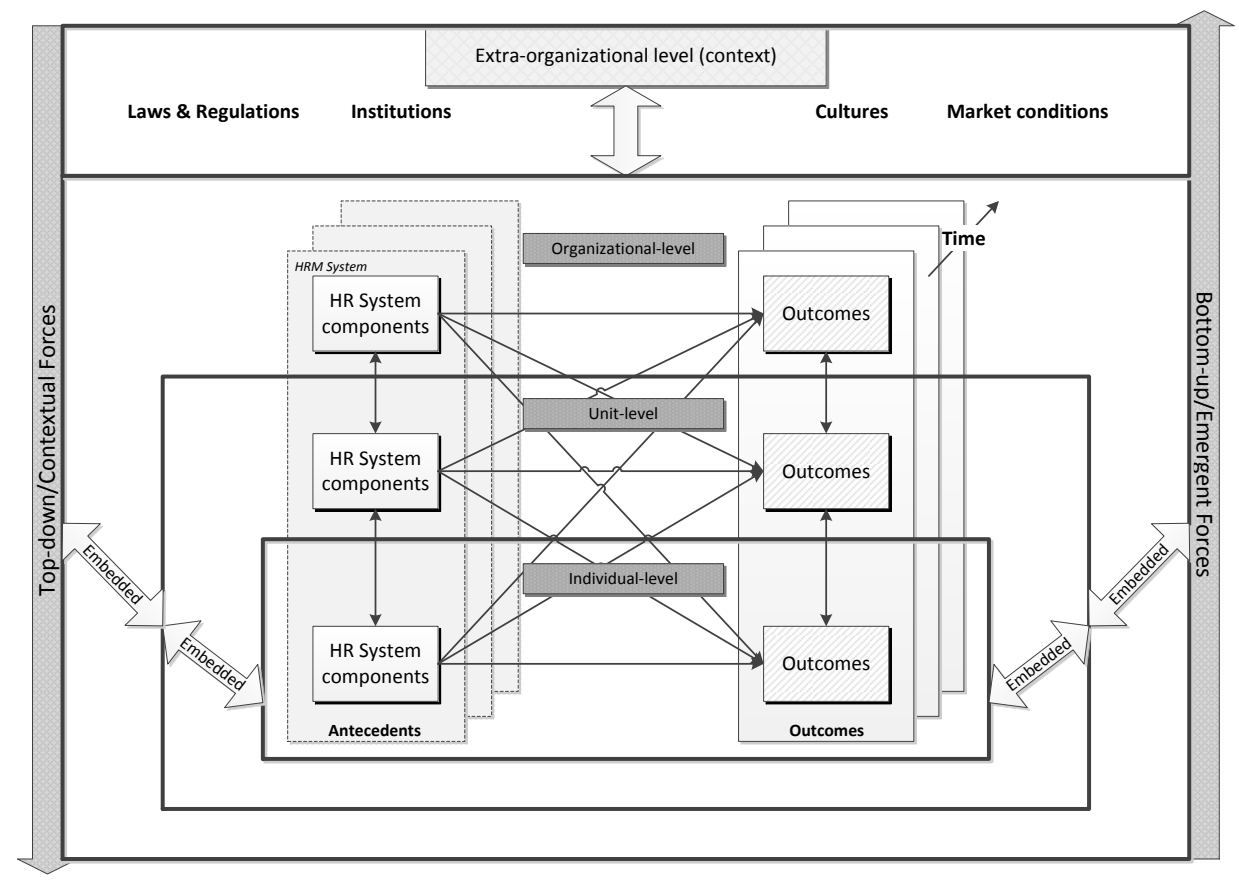

Figure 6.2. The Landscape of Unanswered Multilevel HRM Research Questions

Based on the above review, the landscape includes four levels of analysis, including an extra-organizational level of institutional or competitive factors that potentially influence HRM-performance relationships. We further emphasize the need to take account of the influence of the organization's external context on the direction of multilevel HRM relationships. Further, the landscape illustrates how outcomes are linked. HRM system components not only influence individual-level outcomes, but also higher-level outcomes through bottom-up relationships in which individual-level characteristics exert influence. These bottom-up relationships are often overlooked in HRM research, resulting in a failure to accumulate knowledge on how individuals contribute to the outcomes of organizational units. Finally, the landscape incorporates the important role of temporal issues by highlighting the development of multilevel relationships over time.

\subsubsection{Research Questions Overview}

There is a gap between the proposed landscape and current empirical work. To systematically address all the multilevel research issues and variables in the existing HRM literature to identify important research questions for the future, we 
integrate 16 research domains that capture the intersections between the four levels that describe HRM-outcomes relationships (see Table 6.1) in the proposed landscape. We analyse the antecedents and outcomes on three organizational levels plus the contextual environment level using relevant HRM constructs, providing sample research questions addressing the intersections.

\begin{tabular}{|c|c|c|c|c|}
\hline & $\begin{array}{l}\text { Extra- } \\
\text { organization- } \\
\text { level } \\
\text { outcomes }\end{array}$ & $\begin{array}{l}\text { Organization- } \\
\text { level } \\
\text { outcomes }\end{array}$ & $\begin{array}{l}\text { Unit-level } \\
\text { outcomes }\end{array}$ & $\begin{array}{l}\text { Individual- } \\
\text { level } \\
\text { outcomes }\end{array}$ \\
\hline $\begin{array}{l}\text { Extra- } \\
\text { organization- } \\
\text { level } \\
\text { antecedents }\end{array}$ & $\begin{array}{l}\text { To what } \\
\text { extent do } \\
\text { institutional } \\
\text { pressures } \\
\text { influence the } \\
\text { adoption of } \\
\text { HRM } \\
\text { practices } \\
\text { across } \\
\text { industries? }\end{array}$ & $\begin{array}{l}\text { How do } \\
\text { external } \\
\text { context } \\
\text { variables } \\
\text { influence the } \\
\text { adoption of } \\
\text { HRM } \\
\text { practices? }\end{array}$ & $\begin{array}{l}\text { In what ways } \\
\text { does culture } \\
\text { affect collective } \\
\text { sensemaking of } \\
\text { HRM practices? }\end{array}$ & $\begin{array}{l}\text { How do } \\
\text { market } \\
\text { conditions } \\
\text { influence } \\
\text { employees' } \\
\text { perceptions of } \\
\text { HRM? }\end{array}$ \\
\hline $\begin{array}{l}\text { Organization- } \\
\text { level } \\
\text { antecedents }\end{array}$ & $\begin{array}{l}\text { How can } \\
\text { organizational } \\
\text { HRM policies } \\
\text { influence } \\
\text { existing } \\
\text { institutions? }\end{array}$ & $\begin{array}{l}\text { To what extent } \\
\text { do HRM } \\
\text { policies and } \\
\text { practices } \\
\text { contribute to } \\
\text { organizational } \\
\text { performance? }\end{array}$ & $\begin{array}{l}\text { How do } \\
\text { organizational- } \\
\text { level HRM } \\
\text { activities } \\
\text { influence unit- } \\
\text { level HRM } \\
\text { practices and } \\
\text { outcomes? }\end{array}$ & $\begin{array}{l}\text { To what } \\
\text { extent do top } \\
\text { management } \\
\text { characteristics } \\
\text { affect } \\
\text { employees' } \\
\text { climate } \\
\text { perceptions? }\end{array}$ \\
\hline $\begin{array}{l}\text { Unit-level } \\
\text { antecedents }\end{array}$ & $\begin{array}{l}\text { To what } \\
\text { extent do } \\
\text { teams } \\
\text { contribute to } \\
\text { economic } \\
\text { growth? }\end{array}$ & $\begin{array}{l}\text { How do } \\
\text { organizational- } \\
\text { level HRM } \\
\text { outcomes } \\
\text { emerge } \\
\text { through the } \\
\text { integration of } \\
\text { various units? }\end{array}$ & $\begin{array}{l}\text { What is the } \\
\text { strength of the } \\
\text { relationship } \\
\text { between team } \\
\text { interdependence } \\
\text { and shared } \\
\text { perceptions of } \\
\text { the HRM } \\
\text { climate? }\end{array}$ & $\begin{array}{l}\text { How do team } \\
\text { leaders affect } \\
\text { the HRM } \\
\text { perceptions of } \\
\text { employees? }\end{array}$ \\
\hline $\begin{array}{l}\text { Individual- } \\
\text { level } \\
\text { antecedents }\end{array}$ & $\begin{array}{l}\text { How do } \\
\text { employees' } \\
\text { preferences } \\
\text { regarding } \\
\text { work design } \\
\text { affect labour } \\
\text { laws? }\end{array}$ & $\begin{array}{l}\text { How do } \\
\text { individual-level } \\
\text { constructs, } \\
\text { such as } \\
\text { attitudes and } \\
\text { behaviours, } \\
\text { contribute to } \\
\text { organizational- } \\
\text { level HRM } \\
\text { outcomes? }\end{array}$ & $\begin{array}{l}\text { How do } \\
\text { individual-level } \\
\text { attitudes and } \\
\text { behaviours } \\
\text { aggregate as a } \\
\text { collective unit- } \\
\text { level construct? }\end{array}$ & $\begin{array}{l}\text { To what } \\
\text { extent do } \\
\text { HRM } \\
\text { attributes } \\
\text { fluctuate over } \\
\text { time under the } \\
\text { influence of } \\
\text { adopting new } \\
\text { HRM } \\
\text { practices? }\end{array}$ \\
\hline
\end{tabular}

Table 6.1. Multilevel HRM Research Domains with Sample Research Questions 
The two central cells on the top row refer to research to examine the relationship between contextual factors and organization- and unit-level phenomena. These domains have received scant attention in multilevel HRM research, but the few examples available show that contextual factors (e.g. culture) affect the organization-level adoption of HRM practices (Peretz, Levi, \& Fried, 2015). There are several other questions about multilevel HRM that have not been answered. First, there are questions about the influence of institutional pressures on the adoption and effectiveness of HRM practices. Second, there are many unaddressed questions about the underlying reasons for the differences between actual (organization-level) HRM practices and (individual-level) perceptions of HRM practices. Third, bottom-up emergence of HRM phenomena received scant attention. Scholars often opt to conceptualize individual-level phenomena at the organizational-level by aggregating individual-level outcomes (e.g. Nishii et al., 2008), predominantly based on perceived similarities among employees in a single unit. Despite some advances, there is still a need to address bottom-up effects in more detail, in particular by using compilation models that analyse differences between individuals rather than similarities (Kozlowski and Klein, 2000). Fourth, time needs to feature more strongly in multilevel HRM research, especially when addressing the emergence of HRM phenomena (Kozlowski and Klein, 2000). Many questions remain open about how HRM-performance relationships change over time.

All these questions, in one way or the other, relate to the complex roles of context and time in multilevel HRM relationships. As Pettigrew (1987) observed nearly thirty years ago, a multilevel analysis requires taking account of both vertical (multiple levels of analysis) and horizontal (sequential interconnectedness) relationships, and the interconnections between them, over time. Given the influence of context and time, these aspects deserve greater attention in multilevel HRM research.

\subsection{Theories for multilevel HRM research}

The second pillar of this paper identifies theories that can be used to explain multilevel relationships in HRM research. We have identified three broad theories with potential value for multilevel HRM research: institutional theory, configuration theory and structuration theory.

\subsubsection{Institutional theory}

The unique contribution of institutional theory for multilevel research is its focus on explaining both the top-down influence of structures on behaviour and the 
bottom-up cross-level relationships and role of agents in the institutionalization processes. This makes it useful in examining multilevel HRM models that focus on how HRM influences employee behaviour and how employee behaviour leads to organizational changes. Institutional theory addresses the processes through which structures, such as schemes, rules, norms and routines, are developed into guidelines for social behaviour, and how these elements are created, diffused, adapted and abandoned over time (Scott, 2005). Further, agency is also important, with actors playing an important role in the institutionalization process (DiMaggio, 1988). Two examples show how institutional theory can aid multilevel theorizing.

First, Bitektine and Haack (2015) highlight how cross-level relationships can change direction under the influence of institutional processes. In a stable environment, the legitimacy process has a top-down influence that reinforces existing practices whereas, under conditions of institutional change, the legitimacy is weaker because of there are competing arguments (Bitektine and Haack, 2015). Second, Smets, Morris, and Greenwood (2012) revealed, from a multilevel study examining the bottom-up institutional change process, that employees' improvisations can generate institutional change. A crucial factor of their model is that practice-driven change is advanced within rather than across boundaries of the organization. They highlighted two enabling dynamics that affect the speed at which a practice-level improvisation will affect the field as a whole: organizational coordination and institutional distancing. As such, HR practices can be an important dynamic, for example by recruiting employees with no attachment to the existing organizational logics (Battilana \& Dorado, 2010).

In further theorizing on this bottom-up institutional change process in HRM, coordination theory could be used to uncover how organizational performance is linked to individual contributions and their interdependence (Van Veldhoven, 2012), and how HRM policies and practices influence individual efforts that lead to institutional change within organizations. These examples show that institutional theory opens several avenues for multilevel theorizing in HRM.

\subsubsection{Configuration theory}

Another theory that could help advance multilevel HRM research is configuration theory whose unique contribution lies in its ability to explain how combinations of embedded constructs lead to aggregated outcomes. Configuration theory can address several multilevel HRM research questions.

First, configurational thinking should be central to research into HRM systems since these are inherently multilevel with at least three hierarchically 
ordered components (Schuler, 1992). That is, HRM systems consist of philosophies, on how the organization regards its employees as sources of organizational success, that translate into policies, which are objectives for managing employees, that are ultimately operationalized as practices in the form of specific instruments used to implement HRM policies (Jiang et al., 2012). Configurational theory uses the concepts of equifinality and substitution to help explain how HRM practices aggregate into HRM policies (Jiang et al., 2012). Equifinality reflects the idea that different systems of multiple attributes can reach the same final state (Meyer, Tsui, \& Hinings, 1993). According to Jiang et al. (2012), different HRM practices can act as substitutes in realizing the same HRM policy where those practices have overlapping goals. Consequently, configuration theory has value when examining how HRM practices can be substitutes when aggregating to the HRM policy level.

Second, configuration theory discusses causal asymmetry, which can be helpful in understanding bottom-up effects in HRM-performance relationships. Kozlowski and Klein (2000) argue that bottom-up effects can be characterized by both content (i.e. raw elements that emerge at higher-levels of analysis) and process (i.e. interactions that enable elemental content to emerge). Bottom-up effects are likely to be causally asymmetric, i.e. "causes leading [to] the presence of the outcome can be different from those leading to the absence of the outcome" (Fiss, 2011, p. 394) . Causal asymmetry follows from the notion that causes can vary in their necessity and sufficiency for producing an outcome of interest. Individually, the content and process of an emerging construct, and thus the HRM practices that build them, are probably necessary, but not sufficient, for bottomup effects to occur. For example, HRM practices such as training and staffing are likely to affect the knowledge of individuals, but this will not emerge as organization-level human capital resources unless those individuals interact (Ployhart and Moliterno, 2011). Since interaction and knowledge-exchange depend on other HRM practices, multiple HRM practices are probably necessary and sufficient for bottom-up effects to occur. Thus, using configuration theory, multilevel HRM researchers could distinguish between content-enhancing and process-enhancing HRM practices and examine whether these are necessary and/or sufficient to explain bottom-up effects.

\subsubsection{Structuration Theory}

Structuration theory offers a unique contribution for multilevel HRM research by integrating the interaction between individuals and structures while including both time and space. Structuration theory, as proposed by Giddens (1984), focuses on the dynamic nature of social reality, seen as being both time and context 
dependent. Multilevel theory indeed argues that, to understand the multilevel nature of HRM-performance relationships, one has to understand their dependency on time and context. This requires understanding the contextual features of "locales through which actors move in their daily paths and the regionalization of locales stretching away across time-space" (Giddens 1984, p. 286).

This theory merges the ideas of a constructed society based on the micro-actions of individuals and the macro-social worlds of modern life, which is another element that can locate structuration theory in multilevel HRM research. The theory proposes viewing "objective" structures and subjective interpretations as a mutually interacting duality rather than as independent elements (Jones \& Karsten, 2008). Consequently, HRM systems and practices can be viewed as being created by human agents through actions that produce and reproduce the HRM systems. As such, the structuration process of HRM systems is understood as involving the reciprocal interaction between human agents and structural organizational features: human actions are enabled and constrained by rules and resources (i.e. structures) that are the result of previous actions. We argue that a structured HRM system implies an established system of domination within the HRM context that is legitimated by, and inscribed in, the framework of HR professionals, managers and non-managerial employees as part of their sensemaking processes. That is, HRM actors draw on existing culturally embedded HRM organizational properties of meaning, power and moral structures, and on existing HRM knowledge frames, to build assumptions about HRM systems (Prasad, 1997).

HRM researchers such as Björkman, Ehrnrooth, Mäkelä, Smale, and Sumelius (2014) have started to rediscover the value of structuration theory by applying it to conceptualize intersections between practitioners' views, practices and behaviour to understand the HRM-performance link. Meijerink (2014) conceptualized that employee-organization relationships are constructed and that day-to-day activities emerge from the recurrent actions of employees and managers.

In our view, structuration theory can add understanding to multilevel HRM research by conceptualizing the process through which HRM practices become nested within organizations; how HRM effects emerge; and the impact of the various organizational actors on HRM.

\subsection{Methods for multilevel HRM research}

The third pillar of this paper involves identifying research methods that can answer multilevel HRM research questions. We are not denigrating often-used 
methods for some aspects of multilevel HRM research such as Multilevel Structural Equation Modelling and Hierarchical Linear Modelling. Rather, our goal is to offer "new" research methods that can uncover new aspects of multilevel HRM. Here, we outline these methods and highlight their usefulness in multilevel HRM research. Specifically, we argue that multilevel HRM research could benefit from adopting process methodology, fuzzy-set qualitative comparative analysis and case studies, because all are well placed to uncover multilevel relationships and processes that until now have received scant attention from HRM researchers. We argue that all these approaches have not been fully applied, or could be applied differently, in multilevel HRM research.

\subsubsection{Process methodology}

The process methodology's unique contribution is its ability to reveal multilevel dynamics and developments over time. The process methodology is focused on organizational data that consist of information about events, activities and choices over time; what took place in organizations; and who did what and when (Langley, 1999). This method is appropriate for answering multilevel research questions because it analyses how organizational change unfolds, and what factors influence this change, rather than analysing determinants, success factors and causal relationships. A process explanation for questions concerning organizational change is appropriate because of the temporal order and the sequence of events (Van de Ven \& Huber, 1990). Given that process methodology is focused on how and why organizational change emerges, develops, grows or terminates over time (Langley, Smallman, Tsoukas, \& Van de Ven, 2013), it can be a valuable methodology in examining the role of HRM in the emergence of bottom-up organizational change or performance. Here, Smets et al. (2012) illustrated how a multilevel process study could be conducted into the bottom-up institutional change process using a chronology of key events. They contributed to institutional change theory by showing that improvisations by employees could generate institutional change.

More than a decade ago, Martin and Beaumont (2001) proposed a shift towards a process methodology in HRM. The process methodology addresses an important issue that was already receiving scholarly attention in the late 1990s: the choice between variance theory and process theory. Traditionally, variance theory has been the dominant approach in organizational research seeking to explain antecedents of strategic change (Langley, 1999). However, this approach fails to provide insights into the processes behind change, such as the key events and the patterns of change and the role of time. The process methodology is characterized by having various units and levels of analysis (emphasizing its 
multilevel nature), data at multiple points in time (a focus on events, activities etc.) and the integration of variables and process constructs (Langley, 1999).

As such, the process methodology enables the time-dependent integration of levels of analysis. It can highlight how HRM changes over time and how it influences employee characteristics that eventually lead to organizational change. As such, it is well placed to uncover multilevel relationships. Thus, process methodology, in combination with variance theory, can lead to better insights into HRM-performance relationships and their underlying mechanisms.

\subsubsection{Fuzzy-set Qualitative Comparative Analysis}

The fuzzy-set qualitative comparative analysis (fsQCA) methodology is particularly suited to examining bottom-up effects (Fiss, 2007; Ragin, 2000) because of its unique ability to examine bottom-up effects that are characterized by compilation processes. Klein and Kozlowski (2000) view compilation processes as equivalent to configurations of different lower-level properties (e.g. knowledge/skills of employees) that emerge as a higher-level property (e.g. human capital resource) that plays the same role as, but is not identical to, its lower-level properties (Ployhart and Moliterno, 2011). Since fsQCA helps in examining the inner workings of configurations (e.g. Fiss, 2011; Ragin, 2000), we argue that it is a useful methodology for multilevel research focused on compilation effects.

The core aspect of fsQCA in aiding multilevel researchers to study compilation effects is its case-based approach. That is, fsQCA classifies cases (e.g. employees nested in teams) into sets of cases that each represent a distinct value of the selected variable. As such, fsQCA uncovers whether cases that share the same value of the selected outcome variables (e.g. high team performance or low collective turnover) are also all members of certain sets representing the independent variables included in a study. By exploring the way set memberships intersect, fsQCA uncovers how variables combine in configurations that produce the outcome of interest.

By opening up the inner workings of configurations, fsQCA enables two types of multilevel research questions to be answered. First, by examining which sets of cases overlap in producing an outcome of interest, it helps identify variables that represent the content of a configuration, and thus are necessary/sufficient to produce the relevant outcome. Since higher-level phenomena emerge from various lower-level variables, fsQCA can empirically establish which lower-level variables of a set, once aggregated, represent higherlevel phenomena. Second, fsQCA helps to reveal whether configurational components substitute or synergize in creating a particular outcome. For 
example, it could show whether different types of individual competences substitute for each other in building team-level human capital resources (Ployhart and Moliterno, 2011). Further, fsQCA could show whether HRM practices synergize with employees' attitudes, cognitions or behaviour so that these employee characteristics emerge effectively on higher levels of analysis. Thus, overall, fSQCA could advance multilevel HRM research by empirically examining how lower-level properties combine to produce higher-level phenomena.

\subsubsection{Case Studies}

The unique contribution that case studies can make lies in their ability to uncover phenomena in their natural environment, including contextual processes, and expose how higher-order constructs emerge over time and space. We argue that if HRM scholars want to reveal multilevel HRM-performance relationships that are contextually bounded, they should further develop and refine rigorous casestudy techniques. A case study strategy will enable HRM scholars to address recent calls by Ostroff and Bowen (2016) to rethink conceptualizations and measurement approaches to HRM systems at a higher contextual level of analysis. Further, we believe that case studies do not exclude the application of statistical models but rather that their complementarity will help HRM research achieve the desired multilevel understanding.

We believe that the case study approach is essential to systematically apply multilevel HRM research principles. The primary goal is to explain an individual case embedded in a specific context (and thus, the mutual influence of "behaviours" in upper- and lower-level contexts). Research methods that can interpret context-dependency are essential if HRM scholars are to achieve a deep understanding of time-dependent, interconnected and context-bound developments in HRM system components. Relationships between variables usually begin to emerge from a within-site case analysis, leading to identifying or refining a theory. The first step, which is necessary in building a strong theory, is to refine the definition of a construct, and build evidence to measure it, thereby establishing the construct validity that emerges from the analysis process itself (rather than being defined a priori). The second step is to verify that the emerging relationships fit with the evidence in every case (cross-case analysis). In replication logic, cases that support a relationship enhance the confidence in its validity. Qualitative data are particularly useful in understanding why relationships hold, or do not. Moreover, qualitative data, once relationships are supported, deepen the understanding of the dynamics underlying the relationships. 
In itself, case study research can create a nested environment in which other research methods and techniques can be applied to answer more-specific research questions within a holistic inquiry.

\subsection{Conclusions}

The research questions, theories and methodologies proposed and outlined in this paper are appropriate for conducting multilevel HRM research in line with the suggested definition. Our aim has been to lay a foundation for multilevel HRM research that positions the field and provides impetus for new research directions. The inclusive definition and the resulting research landscape highlight the many aspects of multilevel theory that are yet to be addressed in the HRM literature. Describing crucial elements of multilevel HRM is a prelude to posing many questions that address the gaps. To integrate the issues, we have provided a cascade of a multilevel approach for HRM research. The resulting landscape of unanswered research questions highlights the neglect of several aspects such as the bottom-up emergence of employee outcomes and the part that time plays.

Consequently, we have argued that three theories - institutional theory, configuration theory and structuration theory - have unique potentials to address cross-level relationships and multiple aspects of our research landscape. Each in their own way points to uncultivated ground within multilevel HRM research. They all highlight how concepts embedded in nested arrangements are linked across levels of analysis. In particular, institutional theory and configuration theory enable top-down and bottom-up relationships to be examined simultaneously. Structuration theory addresses the time-space continuum of HRM systems and is able to address temporal issues in multilevel HRM research. However, we are not suggesting that these theories can answer all multilevel research questions, nor that they are limited to the above contributions.

Using these theories requires specific methodologies. We have proposed three methodologies that can make distinctive contributions to answering multilevel HRM research questions. The process methodology is particularly suited to addressing contextual and temporal issues given its focus on how, when and where multilevel relationships are manifested. Further, a process approach can be combined with both institutional theory, given its focus on the dynamics of change, and structuration theory, because the crucial events identified can provide information on the micro-actions of individuals across space and time in a macro-context. Second, fSQCA, given its focus on how constellations of lowerlevel processes are related to higher-level constructs, can answer questions about how and why cross-level constructs are connected, and can serve as a methodology for testing models from a configuration theory perspective, by 
classifying observations into configurations that lead to higher-level outcomes. Third, case studies can be used to determine whether HRM phenomena are multilevel, and if so the levels on which cross-level relationships should be studied, to provide a deeper understanding of the dynamics of cross-level relationships and the role of time in multilevel models, to identify observations that represent a configuration. Further, they can be combined with fsQCA to uncover how lower-level variables are organized in a configuration that produces the outcome of interest.

In conclusion, the proposed questions, theories and methodologies combine to divulge how and why constructs at different levels are linked, where top-down and bottom-up processes originate and manifest themselves, and the role of time, all areas seen as necessary by Kozlowski and Klein (2000). They enable the study of time-dependent interconnections between HRM system components and their relationship with contextual and outcome variables across organizational levels. Ultimately, the proposed cascading landscape of multilevel HRM should facilitate a more systematic approach to multilevel HRM research by enabling different routes for linking research questions to theories, and translating these into methodological choices.

\subsection{References}

References can be found on page 209. 



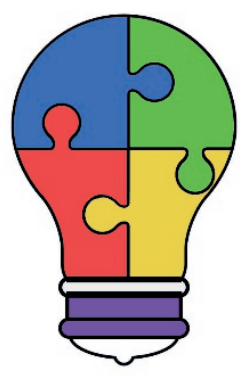

\section{CHAPTER 7}

\section{Discussion and conclusions}

"Shall I refuse my dinner because I do not fully understand the process of digestion?"

(Oliver Heaviside) 
The start of this dissertation was marked by two quotes from interviews. These quotes illustrated the benefits of involving employees in innovation processes to stimulate employee-driven innovation. Based on a combination of theoretical and practical reasons, I derived my main objective: to increase understanding of the multilevel relationship between HRM and innovation. In this dissertation, five studies are presented, two conceptual studies (Chapters 2 and 6) and three studies based on empirical findings (Chapter 3 to 5), which make their own contributions to the literature and understanding of the multilevel relationship between innovative HRM and employee-driven innovation. As such, these studies offer insights into how organizations can use innovative HRM to stimulate the innovativeness of their 'regular' employees.

In this final chapter of my dissertation, I provide an answer to the central research question: "In what ways does innovative HRM contribute to employeedriven innovation?" To answer this central question, I used a mixed method approach. First, a conceptual framework, involving multiple organizational levels, was established that outlined how innovative HRM might enhance innovation performance. Here, I also introduced the concept of employee-driven innovation to the HRM - innovation field. Second, we systematically reviewed the existing literature to see how the multilevel perspective had been applied and what we could learn from its principles. Third, we qualitatively explored how innovative HRM changes the HRM function. Fourth, we quantitatively assessed to what extent employees' perceptions of innovative HRM affect their innovative work behaviour and examined the underlying mechanisms of this relationship. Fifth, we explored employee-driven innovation in a formalized context and analysed how HRM can facilitate and support the emergence of innovation based on employees' ideas. Finally, we developed a research agenda for multilevel HRM thinking by proposing research questions, appropriate theories, methods and techniques.

In this chapter, I discuss the overall findings, their theoretical and practical implications and future research directions. First, the findings of the five studies are briefly presented (7.1). Then, I discuss the general theoretical contributions of this research (7.2). Subsequently, I address the limitations of this study (7.3) and provide suggestions for future research (7.4). I finish with the practical implications (7.5) and a general conclusion (7.6). 


\subsection{Main research findings}

\subsubsection{Chapter 2 - Advancing Multilevel Thinking in Human Resource Management Research}

The second chapter was focused on learning how HRM research has applied and could apply the multilevel perspective. In this chapter, I answered the question: "What can Human Resource Management research learn from the principles of multilevel theory building?" This question was addressed by developing a multidimensional framework of HRM research (the 'Multilevelity Cube'), and systematically reviewing the literature on the application of the principles of multilevel theory building (Kozlowski \& Klein, 2000). The Cube visualizes how to conceptualize multilevel HRM and provides a starting point for empirically studying multilevel HRM. The first important result of the study is a description of the evolution of multilevel research in the HRM field, resulting in the above mentioned conceptual framework. This model consists of three components that are each hierarchically ordered: abstraction levels, organizational levels and internalization levels. We argued that these three dimensions illustrate the various levels at which the HRM - outcome relationship can be studied and reflect the complexity of multilevel HRM research. A second finding is the way in which existing multilevel HRM studies have addressed the dimensions of multilevel HRM. The literature review highlighted that the internalization dimension is frequently connected to the organization-level dimension. Furthermore, we found that HRM philosophies are often overlooked and that HRM policies and practices are often examined at the unit level as 'introduced HRM' or at the individual level as 'experienced HRM'. The last finding is related to the application of principles of multilevel theory building in the HRM literature. We have assessed whether and how existing multilevel HRM research has used the principles of multilevel theory building. Based on evaluating how studies applied five sets of multilevel principles, we were able to propose future research directions in the form of guidelines. In particular, we saw that research had failed to adequately address how individual-level variables affect higher-level outcomes. Furthermore, we argued that more research is needed to understand where multilevel effects originate and emerge. Finally, we have shown that the time dimension is often absent, which led to our suggestion to study how multilevel effects change over time. Together, the three main findings led to our conclusion that HRM research could advance considerably by reaping the full benefits of multilevel thinking. We encourage researchers to integrate these multilevel principles to enhance our understanding of multilevel HRM and of the HRM - innovation relationship. 


\subsubsection{Chapter 3 - Exploring the Implications for the HRM Function of Implementing Self-Managing Teams}

The third chapter was focused on understanding how innovations in HRM change the HRM function. In this chapter, we examined how the HRM function changed as a consequence of implementing self-managing teams (SMTs) - which we view as an important HRM innovation aimed at empowering employees. Thus, my second research question was: "What are the most important changes to the HRM function regarding its actors and activities when implementing selfmanaging teams?" To answer this question, we conducted an in-depth single case study in a large healthcare organization. The 'Multilevelity Cube' served as a starting point for our empirical analysis of the HRM function. The first important finding here was that the HRM function is transformed in organizations that adopt SMTs: HRM responsibilities are redistributed over many HRM actors. In traditional organizations, HRM professionals predominantly design, first-line managers (FLMs) implement, and employees develop perceptions about HRM activities. However, in organizations with SMTs, HRM activities are designed and implemented both by HRM professionals and by SMTs. Thus, with the introduction of SMTs, a new key HRM actor is introduced. The findings show that SMTs carry out HRM activities that were previously performed by HRM professionals or FLMs. As a result, HRM implementation works in both top-down and bottom-up ways and requires a service-like role of the HRM department. Second, we discovered that implementing SMTs creates an inherent paradox for HRM actors. Introducing empowerment entails providing autonomy to employees and teams. However, the case study showed that HRM actors struggle with determining the degree of proactivity that is needed to facilitate the implementation of SMTs. We saw that HRM professionals and FLMs were uncertain about their own role, and that there was a lack of coordination over the implementation process. Finally, our findings show that the dynamics between intended, actual and perceived HRM changed. As SMTs become responsible for performing HRM activities, they also become involved in designing and implementing them and, therefore, intended and actual HRM no longer rely solely on HRM professionals, but also on SMTs. Based on these findings, we conclude that introducing SMTs in an existing organization changes the HRM function on the one hand, and that these changes to actors and activities in turn affect the implementation process of HRM. Furthermore, from this we could see that, in the multilevel HRM - innovation relationship, it is important to adopt an employeecentred approach since employees now actively design and shape their own HRM activities. 


\subsubsection{Chapter 4 - High-Involvement HRM and Innovative Work Behaviour (IWB)}

The fourth chapter aimed at increasing understanding of how HRM innovations lead to employees adopting innovative work behaviours. In this study, we considered affective commitment and experienced autonomy as mediators in the relationship between HRM and IWB. Hence, the third research question was formulated as: "To what extent do autonomy and affective commitment mediate the relationship between high-involvement HRM and IWB?" In answering this research question, we argued that adopting high-involvement practices is an important HRM innovation that stimulates employees' IWB. More specifically, we proposed that it is employees' perceptions of high-involvement HRM practices that positively influence their behaviours - by increasing their commitment to the organization and by enhancing the autonomy in their work. Hence, we hypothesized that high-involvement HRM leads to IWB through affective commitment and autonomy. To test this hypothesis, we collected data through a survey study involving 567 employees in the Netherlands. More specifically, we studied IWB in a sample of 'regular' work-floor employees. Our first finding was that a bundle of high-involvement HRM practices, as perceived by employees, stimulates their IWB. Employees' affective commitment and autonomy fully mediate this relationship. As such, we show that both attitudes and resources act as mediating mechanisms in the relationship between HRM perceptions and employee outcomes. Further, we showed that IWB is a latent construct consisting of four sub-dimensions. Our post-hoc analyses indicated that it is worthwhile further examining these sub-dimensions since we found different effect sizes, particularly of autonomy. These findings lead to the conclusion that if highinvolvement HRM practices are perceived as such by employees, they are likely to reciprocate this investment by showing more IWBs, mainly because they feel a greater sense of autonomy in their work and more committed to the organization. In this way, this study informed us about the underlying individuallevel mechanisms in the multilevel HRM - innovation relationship. We have thus shown how innovative HRM affects employees' attitudes and resources as proximal outcomes, which in turn lead to IWB as a more distal outcome. To understand the link between HRM and innovation, it is important to know the ways in which HRM activities affect innovative behaviours, and this study contributed to this by showing the impact of mediating mechanisms and distinguishing between proximal and distal outcomes. 


\subsubsection{Chapter 5 - Routes for Employee-Driven Innovation (EDI)}

The research for the fifth chapter was designed to acquire insights into the bottom-up relationship between employees' innovative behaviours and an organization's innovation outcomes. We explored a model that outlines how HRM can contribute to the bottom-up emergence of EDI in a formalized context. The associated fourth research question was: "How can HRM contribute to the bottom-up emergence of innovation in a formalized business context?" This research question was addressed by conducting an in-depth case study at a medical laboratory ('MedLab'). We adopted a process-like methodology to explore how innovations develop across organizational levels. We conceptualized the emergence of EDI as a route through which employees' innovative ideas develop into innovations. We distinguished between the elemental content (ideas), process (development) and structure (contextual factors) of EDI. Of particular significance is the idea that HRM activities, as contextual factors, can facilitate and enable the emergence process. Our first finding was that employees were actively engaged in EDI: that they did contribute to the generation and implementation of innovative ideas. We analysed over a hundred initiatives at MedLab, of which the majority could be seen as a collaborative effort between work-floor employees and managers. However, a bottom-up process whereby innovations were fully initiated and implemented by work-floor employees was rare Second, we analysed the elemental content of innovation emergence and found that employees' ideas can be categorized into three types: (1) primary work-content ideas, (2) work processes and (3) organizational developments. The results show that the EDI process is contingent upon the elemental content of EDI. We uncovered a pattern consisting of five phases through which EDIs are developed: onset, development, communication, establishment and implementation. We also found that employees used different paths to develop their ideas in the organization. We distinguished three EDI routes: (1) the organizational route, (2) the formalized system route, and (3) the project-initiative route. These routes constituted the process of EDI emergence. Finally, we revealed that HRM practices and leadership, as structural factors, can facilitate EDI emergence. Based on our framework, we found that HRM activities can influence both the content and the process of emergence. For this reason, we distinguish between top-down stimulation - HRM practices that affect the content of emergence by increasing the likelihood that employees generate new ideas - and bottom-up championing - HRM practices that increase the likelihood that ideas will be implemented. We concluded that, even in a formalized context, employees will develop EDIs provided routes are available to them, and that EDI emergence can be stimulated by HRM practices that are focused on the content and process of emergence. This study contributed to our understanding of the 
multilevel HRM - innovation relationship by exploring how work-floor ideas arise and develop through several stages, and by showing how HRM activities can contribute to this.

\subsubsection{Chapter 6 - Advancing Multilevel Thinking and Methods in HRM Research}

The sixth chapter focused on developing and advancing the multilevel perspective presented in the HRM literature. Thus, the fifth research question was: "What are the most valuable multilevel research directions, theories and methods for advancing multilevel thinking in HRM?" Here, we built on core assumptions and principles of multilevel theory (Kozlowski \& Klein, 2000) to advance multilevel thinking in HRM research. As an output, we have provided research questions, theories and methods that researchers can use to make further progress in this field. In addressing our question, we integrated and built on existing literature and our structured literature review presented in Chapter 2 to develop a conceptual model. Whereas Chapter 2 was predominantly focused on theoretical development, this chapter goes one step further and guides HRM researchers in choosing specific research questions, theories and methodologies to put our guidelines into practice. The first result was the formulation of a definition for multilevel HRM research: "The study of time-dependent interconnections among various HRM system components and their relationships with contextual antecedents and outcomes at different organizational levels". The second output of this study is an overview of important but unanswered multilevel HRM research questions. Based on the idea that both the intra-organizational and extra-organizational levels should be integrated, we developed multilevel research questions along a 4x4 framework consisting of organizational levels of analysis. The third outcome is a discussion of three theories that have the potential to increase our understanding of cross-level relationships in HRM research. We proposed using institutional theory, configuration theory and structuration theory to explain multilevel HRM relationships. We found that the unique contribution of institutional and structuration theories lie in their integration of both top-down and bottom-up processes. The main contribution of configuration theory is its ability to explain how combinations of embedded constructs lead to aggregated outcomes. Our fourth and final output is an overview of three methods for conducting multilevel research and answering multilevel HRM research questions. We proposed using process methodology, fuzzy-set qualitative comparative analysis (fsQCA) and case studies to uncover new aspects of multilevel HRM. In answering the overall research question of this dissertation, this study particularly informed us about how to approach the 
multilevel HRM - innovation relationship by bringing specific research questions, theories and methods to the fore that can be used to explore this link.

\subsection{Employee-driven innovation approaches in two organizations: cross-case analysis}

The two case studies in this dissertation, 'HealthServ' (Chapter 3) and 'MedLab' (Chapter 5), have provided in-depth insights into how innovative HRM can contribute to EDI. Although Chapter 3 was focused on the introduction of innovative HRM in terms of SMTs and Chapter 5 was focused on EDI processes, both cases were focused on innovation processes in which work-floor employees were involved. The two case studies can be seen as 'polar types' (Eisenhardt \& Graebner, 2007), with extreme cases being presented in order to observe patterns in the data. The differentiating criterion is the organization's approach to EDI, either primarily top-down or bottom-up. We have seen that HealthServ chose to implement SMTs as an HRM innovation to stimulate the adaptability and innovativeness of their employees (Chapter 3) whereas, at MedLab, the innovation process had more of a bottom-up orientation (Chapter 5). Nevertheless, both organizations were conducting innovation activities in which work-floor employees were important actors. Based on these two extreme types of EDI approach, we discuss the differences and similarities below (see also Table 7.1), which helps to identify patterns through which innovative HRM can contribute to EDI (Yin, 2014).

The individual sets of case-study data were re-analysed to compare the two case studies. This cross-case analysis allows one to identify and outline EDI patterns across cases and helps to explain the ways in which HRM can contribute to EDI. Initially, my analysis focused on creating an understanding of the innovation processes in each of the cases. Following this, the actions and activities of several HRM actors and work-floor employees in the innovation processes were analysed. These two rounds helped to depict the contribution of work-floor employees to the innovation process and to identify the roles of HRM actors and activities in this. 


\begin{tabular}{|c|c|c|}
\hline & 'HealthServ' (Ch. 3) & 'MedLab' (Ch. 5) \\
\hline $\begin{array}{l}\text { Approach to } \\
\text { innovation processes }\end{array}$ & $\begin{array}{l}\text { Primarily top-down } \\
\text { (management-driven) }\end{array}$ & $\begin{array}{l}\text { Primarily bottom-up } \\
\text { (employee-driven) }\end{array}$ \\
\hline Role of FLM & $\begin{array}{l}\text { First-line managers are } \\
\text { crucial, but their role is } \\
\text { diminishing }\end{array}$ & $\begin{array}{l}\text { First-line managers are } \\
\text { crucial }\end{array}$ \\
\hline $\begin{array}{l}\text { Role of HRM } \\
\text { department }\end{array}$ & As a service department & Policy development \\
\hline Innovation projects & Ad-hoc innovation & Innovation initiatives \\
\hline $\begin{array}{l}\text { Degree of } \\
\text { formalization }\end{array}$ & Protocols & Highly-formalized \\
\hline $\begin{array}{l}\text { Management } \\
\text { approach }\end{array}$ & Self-management & Hierarchical management \\
\hline Competitiveness & Moderate competition & Competitive market \\
\hline Innovation process & Unstructured & Unstructured \\
\hline $\begin{array}{l}\text { Organizational level } \\
\text { of innovation }\end{array}$ & $\begin{array}{l}\text { Predominantly employees' } \\
\text { own work practices }\end{array}$ & $\begin{array}{l}\text { Own work practices and } \\
\text { innovation at the organization } \\
\text { level }\end{array}$ \\
\hline Innovation routes & $\begin{array}{l}\text { Routes are not well- } \\
\text { developed }\end{array}$ & Several routes available \\
\hline $\begin{array}{l}\text { Ability-enhancing } \\
\text { practices }\end{array}$ & $\begin{array}{l}\text { Competences system; } \\
\text { training and education }\end{array}$ & $\begin{array}{l}\text { Selection of project workers; } \\
\text { training sessions; symposia } \\
\text { and company visits; } \\
\text { promotion from within }\end{array}$ \\
\hline $\begin{array}{l}\text { Motivation-enhancing } \\
\text { practices }\end{array}$ & $\begin{array}{l}\text { Peer feedback; job-based } \\
\text { pay; team bonuses; }\end{array}$ & $\begin{array}{l}\text { Performance appraisal; job- } \\
\text { based pay; incidental } \\
\text { individual bonuses; feedback }\end{array}$ \\
\hline $\begin{array}{l}\text { Opportunity- } \\
\text { enhancing practices }\end{array}$ & $\begin{array}{l}\text { Job autonomy; worktime } \\
\text { control; self-managing teams; } \\
\text { protocols }\end{array}$ & $\begin{array}{l}\text { Project teams; innovation } \\
\text { routes; general staff meetings } \\
\text { and information sharing; } \\
\text { participation system; } \\
\text { protocols }\end{array}$ \\
\hline Work processes & $\begin{array}{l}\text { Work processes are } \\
\text { independent - employees can } \\
\text { work in relative isolation }\end{array}$ & $\begin{array}{l}\text { Work processes are } \\
\text { interdependent and integrated } \\
\text { - employees need to take the } \\
\text { whole work process into } \\
\text { account }\end{array}$ \\
\hline
\end{tabular}

Table 7.1. Cross-case analysis 


\subsubsection{Approach to innovation}

The findings of the cross-case analysis show that the two organizations use different approaches to involving employees in EDI. HealthServ used a rather top-down approach in implementing SMTs in which SMTs were designed and introduced predominantly by the management, with employees involved in the implementation. HRM policies and practices, focused on increasing employees' responsibilities and innovativeness, were proactively designed by the HRM department and the management team: new roles were defined, task descriptions were created, project teams were started and communication was intensified. Initially, FLMs were tasked with implementing the HRM policies in their teams. Later, the involvement of FLMs in HRM activities became less influential with their span of control increasing while their job-function became more that of a coach. HRM professionals were mainly active in designing HRM policies with the intention of supporting the transformation towards an SMT approach. Beyond the implementation of SMTs, the role of the HRM department in EDI processes was limited.

MedLab adopted a more bottom-up approach in which employees developed their own ideas and were invited to contribute to innovation projects. In terms of innovation-focused HRM policies and practices, the HRM department's approach was more to respond to work-floor employees' activities than to purposefully develop policies that would stimulate EDI. FLMs were tasked with carrying out these HRM practices, with the support of the HRM department, and were the core actors in stimulating EDI. The role of the HRM department in the innovation process was rather small, although the HRM activities that the FLMs executed helped to stimulate EDI.

\subsubsection{EDI routes and role of the first-line manager}

EDI in the bottom-up approach developed through three routes that were used by work-floor employees, whereas with the top-down approach such innovation routes seemed less well developed. For example, employees at MedLab were active in several innovation projects on either a unit or the company level and were able to propose and develop their own innovative ideas within those projects. At HealthServ, there were few specific routes through which ideas could be developed. In part, this can be attributed to the fact that the role of the FLMs had become less prominent - with FLMs transforming into coaches and losing their hierarchical position. Nevertheless, in both cases, interviewees indicated that the FLMs had a crucial role in the further development of innovative ideas, particularly in terms of communicating and championing employees' ideas. 


\subsubsection{Organizational level of innovation}

HealthServ's employees were predominantly active in generating ideas for their own sphere of influence (team-level), whereas some of MedLab's employees also generated organization-level innovations. At the same time, HealthServ employees who were working in SMTs were freer to determine their own ways of working, which created sufficient space for workplace innovation, whereas MedLab's managers were still often involved in work-floor innovation processes. Nevertheless, several routes were available for MedLab employees to bypass the FLMs, for example by joining innovation projects, or by reporting ideas through the formal idea management system. Nevertheless, interviewees tended to agree with the statement that the majority of ideas were communicated within the work unit and through the organizational hierarchical route, which means that in both cases FLMs had a crucial role in the further development of ideas.

\subsubsection{A targeted HRM approach is required for innovative individuals}

Although we have seen that almost all employees generated ideas, in both cases, only a minority of employees were actively engaged in later stages of innovation processes. For that reason, HRM actors often used a targeted approach for innovative individuals, identifying those employees who showed an interest and motivation to perform extra tasks - thereby adopting a responsive approach. These employees were then offered support to further develop and implement their ideas. Furthermore, the HRM professionals expressed the view that they themselves have an important roles in recognizing valuable innovative ideas and transferring them to the organization level, in connecting different parts of the organization with each other and in enabling more units to benefit from innovative ideas.

\subsubsection{Work processes and forms of innovation: opportunities to innovate}

There seemed to be an important difference between the two cases in terms of work processes, and this affected the EDI processes. What primarily distinguished these two organizations was the independence of their work processes, which we operationalized as the task independence of employees. Employees' job tasks at MedLab were interdependent, whereas those at HealthServ were relatively independent. At MedLab, employees were part of a larger business process to which various employees contribute, from performing phlebotomies to reporting results of blood analyses. As such, innovating parts of the process could potentially change the entire business process. Given that the 
medical specialists were responsible for the quality of test results, they wanted a final say before any changes in the primary business processes. Strikingly, we found that several innovative ideas became becalmed on the top management level because of decision-making gridlock as a result of political infighting. At HealthServ, employees perform tasks that are relatively independent, which makes it easier for them to make changes. As a consequence, the opportunities to propose and implement innovative ideas in the daily work processes were greater at HealthServ than at MedLab.

\subsubsection{Abilities of work-floor employees}

Based on the data, we found differences between employees of the two organizations in terms of their abilities to innovate. As explained above, only a minority of employees were actively engaged in innovation at both organizations. Interviewees reported that knowledge levels differed between employees, meaning that some employees possessed more appropriate resources for generating and implementing ideas than others. These differences were acknowledged both by managers and by the employees themselves. Given that knowledge and learning are important foundations of innovation, HRM was shown to contribute to EDI by facilitating knowledge exchange. Notably, interviewees from both cases reported how external sources of knowledge and information exchange led to new ideas. For instance, several employees indicated that visiting other companies and attending training sessions led to new ideas. Knowledge was gained and refined through internal knowledge exchange with co-workers and in innovation projects. HRM was found to contribute to this in both organizations by offering training courses, by stimulating employees to go to symposia and on company visits, and by selecting qualified employees for innovation projects.

\subsubsection{Employees' motivation to be involved in EDI}

An important factor for EDI to take place is the motivation of employees to pursue their innovative ideas. Our analysis showed that in both cases there was a small core of employees who seemed to be highly motivated to be involved in innovation. Unlike most of their colleagues, who did not see the need or opportunities for improvements, these proactive employees were motivated to generate and realize their ideas. Receiving direct feedback from their FLMs was crucial, and a lack of this led to negativism among some employees and reduced the motivation to propose further ideas. In addition, employees indicated that, to maintain motivation, it is important that FLMs keep them updated about the progress of their innovative ideas. Both FLMs and employees emphasized the 
importance of managing expectations, taking all ideas seriously, and taking time to explain why some ideas cannot be pursued.

Interestingly, in both cases, employees did not receive monetary rewards for EDI, and a large majority of respondents indicated that rewards would not motivate them to develop ideas. More important was that employees' extra efforts should receive recognition and appreciation. Several employees stated that being involved in innovation projects was rewarding in itself. Alongside this, they were motivated by realizing improvements in their own job, in the work processes or for clients. Furthermore, employees seemed to be cautious about using rewards because it would be difficult to establish who deserves a bonus since it is often unclear exactly where an idea originated and difficult to identify everyone involved, and because it might attract employees who are only interested because of the bonus. Rather, employees valued the small non-monetary and team-based rewards as an expression of appreciation by the organization.

\subsection{Synthesis: three mechanisms underlying the HRM - EDI relationship}

In combination, the five chapters and the cross-case analysis help to formulate an answer to the main research question of this dissertation: "In what ways does innovative HRM contribute to employee-driven innovation?" In the introduction chapter, I developed a conceptual framework based on Coleman's (1990) model, with the goal to explore and advance knowledge about the relationship between HRM and innovation, in which I included two organizational levels and introduced the concept of employee-driven innovation (see Figure 1.1). The five studies of this dissertation have explored and examined various aspects of the overall research framework that links HRM to organization-level innovation through individual-level mechanisms. This resulted in a modified and extended version of the above-mentioned framework (Figure 7.1). 


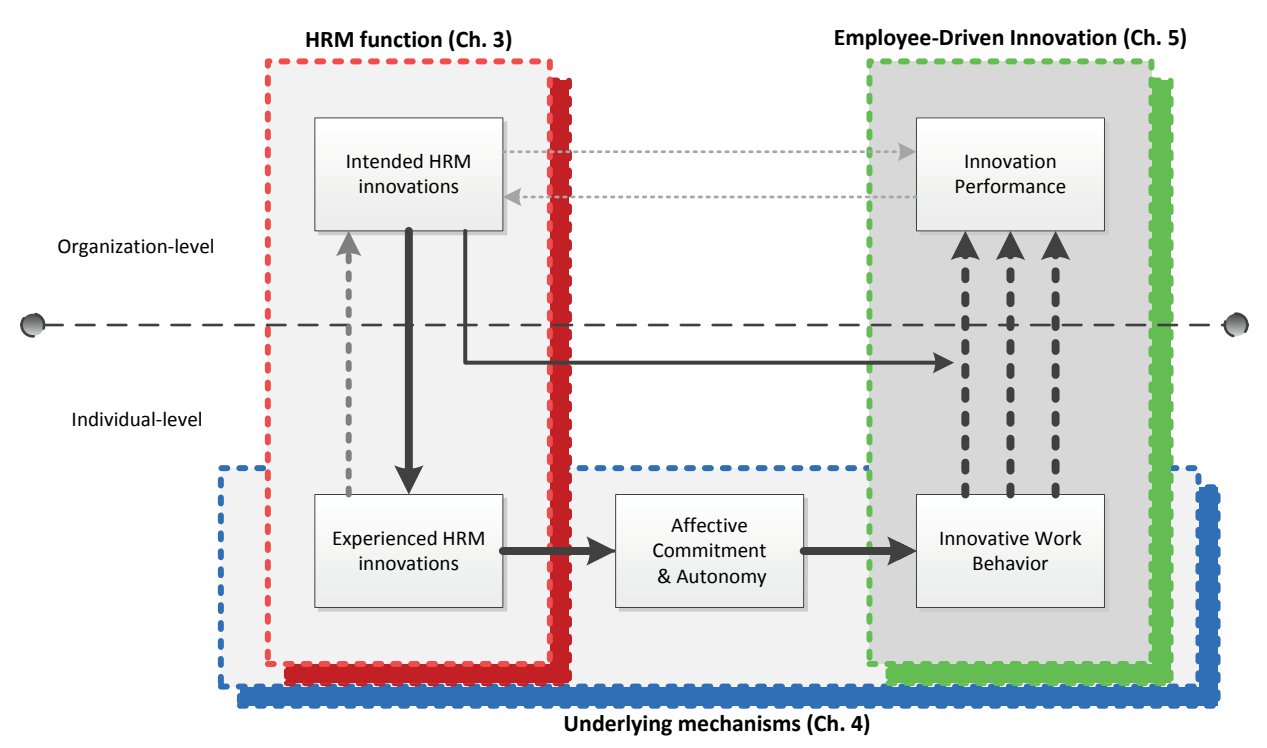

Figure 7.1. Adapted research framework: "Innovating HRM for Employee-Driven Innovation"

This framework remains largely based on the work of Coleman (1990), who studied the link between macro- and micro-level processes. The basic premise behind the so-called 'bathtub' model is that macro-concepts are connected to each other through micro-level processes. On this basis, in order to explain the link between macro-level HRM concepts and innovation, I looked at micro-level events and processes, thereby adopting a multilevel perspective. The model of Coleman (1990) is valuable for HRM - innovation research as it demonstrates the process through which, over time, intended HRM innovations lead to innovation performance through micro-level events. In this dissertation, I both explored the cross-level top-down and bottom-up processes as well as studying the murky waters at the bottom of the bathtub. By integrating the various findings, I offer an explanation of organization-level outcomes in terms of actions and activities of lower-level units (on the employee level). In discussing this explanation, Coleman states (1990, p. 3): "Since the system's behaviour is in fact resultant of the actions of its component parts, knowledge of how the actions of these parts combine to produce systematic behaviour can be expected to give greater predictability than statistical relations of surface characteristics of the system". In this dissertation, I explain innovation in organizations by analysing how its component parts (i.e. employees) are engaged in innovative activities, and explored the ways in which HRM contributes to this. HRM, as a macro-level factor, influences the perceptions of actors who, through their attitudes and 
resources, demonstrate innovative behaviours. Over time, these behaviours result in innovative ideas, some of which will result in collective innovations of the organization.

In answering the question as to in what ways HRM contributes to innovation, my findings suggest that there are at least three interdependent mechanisms through which innovative HRM affects innovation outcomes. First, organizations that introduce innovative HRM rely on the changes to the HRM function and the implementation process to influence employees' experienced HRM. Second, on the individual level, these employees' perceptions of HRM lead to employees' IWB through increased job resources (autonomy) and attitudes (commitment). Third, employees' innovative behaviours, through EDI emergence, result in ideas on the organizational level, consisting of content, process and structure. Innovative HRM contributes to this process by increasing the likelihood that employees generate ideas and by facilitating the bottom-up development of innovation.

Innovative HRM is designed at the organization level and implemented by several HRM actors across several organizational levels. Work-floor employees and other organizational members co-produce and implement HRM policies and practices, and develop perceptions about these HRM policies and practices. In this dissertation, I examined how a particular HRM innovation - selfmanaging teams - affects the HRM function, which in turn has implications for the HRM implementation process. We have shown in Chapter 3 that the implementation of innovative HRM should not be seen as a static top-down process. On the contrary, our study into the HRM function showed that introducing HRM innovations changes the activities of several HRM actors, making the HRM implementation process both a top-down and a bottom-up process. This is represented in Figure 7.1 by the feedback loop on the left side of the framework.

In addition to this, we examined the micro-level by focusing on employees' innovative work behaviour and studying how their perceptions of HRM affect this behaviour. We found that their perceptions of a bundle of highinvolvement HRM practices have significant effects on employees' innovative work behaviour. Employees who experienced the presence of teamwork, performance feedback, information sharing and training reported higher levels of IWB. Moreover, we investigated underlying mechanisms by analysing the role of employees' affective commitment and autonomy as mediating variables in the relationship between perceived HRM and IWB. The data confirmed our hypotheses - that both affective commitment and autonomy significantly influence IWB and are themselves affected by high-involvement HRM. Further, we have shown that they fully mediate the effect of high-involvement HRM on 
IWB. These findings indicate that the IWB of 'regular' employees is potentially influenced by how they perceive HRM practices. In line with social exchange theory, we argued that employees reciprocate the investment in HRM practices by becoming more committed to the organization, which in turn leads to a higher level of IWB. Furthermore, based on self-determination theory, we argued that high-involvement HRM enhances autonomy, which is used by employees as a resource to develop and implement ideas. In combination, these theories provide a fuller understanding of the HRM - IWB relationship.

Furthermore, Figure 7.1 shows how bottom-up innovation can occur through a process of employee-driven innovation. Employees' innovative ideas lead to innovation at a higher organizational level through various EDI routes, facilitated and supported by HRM practices that function as emergence-enabling factors. The three bottom-up arrows in the figure represent the different routes through which employees' ideas can develop. Our empirical data suggest that HRM can contribute to the bottom-up emergence of innovation through the topdown stimulation of employees' innovative ideas, represented by the top-down arrow from HRM, through employees' perceptions and reactions, to HRM policies and practices. Furthermore, HRM can contribute to the bottom-up emergence of innovation by championing bottom-up development of innovation directly, which is represented by the arrow from innovative HRM at the organizational level to the three bottom-up arrows. The latter arrows reflect HRM policies and practices that enable employees to further develop their ideas and realize their potential, whereas the former process reflects HRM increasing the likelihood that employees generate innovative ideas. Hence, employees' innovative work behaviour results in ideas that surface on the organization level through EDI emergence, consisting of content, process and structure.

Finally, the cross-case analysis showed that, although organizations adopt different approaches to EDI, several patterns can be identified. First, it is important that there are routes available for sharing and developing ideas. Further, FLMs have a very prominent role in stimulating, recognizing and championing employees' innovative ideas, whereas HRM professionals have more of a background role in developing policies and responding to employees' ideas. In essence, we have seen that all employees can have ideas for improvements, and therefore can be involved in EDI. Nevertheless, only a minority are willing and sufficiently motivated to pursue their ideas further and become engaged in the whole bottom-up process. What seems to be required is a targeted approach for this group of employees while, at the same time, leaving space for all employees to contribute.

Overall, this dissertation contributes to understanding the mechanisms underpinning the HRM - innovation relationship by theoretically and empirically 
exploring three important mechanisms (see Figure 7.1). Although one could observe a growing interest in the influence of HRM on innovation performance (Bos-Nehles, Renkema, et al., 2017; Seeck \& Diehl, 2017), there was still a need for a better understanding and fuller explanation of how and in what ways HRM contributes to innovation. We particularly responded to the need to study the role of HRM in stimulating individual employees' contributions to innovation. We have done so by applying the concept of EDI to the HRM - innovation field. In this way, we have been able to tackle some of the limitations of existing theoretical approaches that are used to connect innovative HRM with innovation performance. Introducing EDI helped to improve our knowledge about the role of employees in innovation processes, and is valuable in gaining a better understanding of how 'regular' employees can be stimulated to generate and implement ideas.

\subsection{Theoretical contributions}

I now discuss the implications of the research findings outlined in the previous section for three theoretical perspectives.

\subsubsection{Contributions to the multilevel HRM literature}

The primary theoretical contribution of this dissertation is in conceptualizing HRM using a multilevel theoretical perspective. First, my findings provide clear guidelines as to how multilevel thinking can be applied in HRM research. There have been repeated calls for more multilevel HRM research (Boselie et al., 2005; Paauwe, 2009), so that HRM research develops into a more fully-fledged multilevel field (Jiang et al., 2013). We showed that multilevel thinking has yet to become institutionalized in HRM research. In particular, we have shown that principles of multilevel theory building as described by Kozlowski and Klein (2000)have only been applied to a limited extent. Given that the HRM field has been slow to adopt the new multilevel paradigm (Peccei \& Van De Voorde, 2016), especially compared to other fields of organizational research (Molloy et al., 2011), we have attempted to bring the field forward by systematically reviewing the current state of affairs and offering guidelines that can advance multilevel HRM thinking. The findings imply that it is crucial for scholars to look beyond the cross-level top-down relationships if they are to achieve a fuller understanding of how HRM affects outcomes on different organizational levels. The case study findings in Chapter 3 showed the value of the conceptual multilevel HRM framework (Figure 2.1). The framework was helpful in analysing how HRM actors and activities change when introducing employee empowerment and involvement. Moreover, Chapter 3 provided empirical insights into the multilevel 
conceptualization of HRM, which helped in identifying the changes to the HRM function as a consequence of introducing SMTs. My research has shown that innovating HRM requires a fresh perspective on multilevel HRM and HRM implementation in organizations, namely a view that incorporates an active role for employees in implementing and carrying out HRM activities.

Second, through my research I have contributed to the ideas on how multilevel HRM research can be theorized and designed. HRM policies and practices not only contribute to employee and organizational performance outcomes through employees' perceptions and experiences of HRM, they also do so by directly influencing the bottom-up processes through which individuals contribute to higher-level outcomes. In this way, and in line with Coleman's (1990) bathtub model, there is an indirect pathway through which organization-level HRM policies affect employee and system-level (organizational) outcomes. Based on the findings reported in this dissertation, we can add a direct pathway through which HRM affects the bottom-up process by functioning as an emergence enabling factor (Ployhart \& Moliterno, 2011). Consequently, multilevel HRM research should include both direct and indirect effects to account for the top-down stimulation and bottom-up championing of employees. As such, in multilevel HRM research, it is important to distinguish between those HRM policies and practices that directly affect employee characteristics through their perceptions and experiences, and those that influence employees without necessarily being perceived by employees. Based on the findings in Chapter 5 , we know that HRM can influence both the content and the process of bottom-up emergence through changing employees' perceptions, but we also acknowledge that some HRM systems and practices do not have to be perceived or experienced to have an effect on employees and higher-level outcomes. For example, recruitment practices can enhance the human capital of organizations, leading to higher levels of innovation performance, without employees perceiving them as such.

Third, I have discussed HRM from a micro-perspective, focussing on assessing variance across individuals rather than across organizations (Wright \& Boswell, 2002). In this, I take into account the variability in HRM practices between employees as a result of differences in their perceptions and interpretations of these practices (Den Hartog et al., 2013; Liao et al., 2009; Nishii et al., 2008). In Chapter 4, we discussed the micro-HRM perspective to explain how HRM affects employees' behaviours - and specifically innovative behaviour. Our findings suggest that it is not only important to study employees' perceptions of HRM, but also how employees respond to these perceptions. We have shown that HRM perceptions lead to employee behaviours through their impact on employees' attitudes and perceived resources. 


\subsubsection{Contributions to the HRM - innovation literature}

The second major theoretical contribution of this dissertation is in its conceptualization of the HRM - innovation relationship from a multilevel theoretical perspective. The relationship between HRM and innovation performance is inherently multilevel (Kozlowski \& Klein, 2000; Ostroff \& Bowen, 2000). From an employee-centred perspective, HRM affects performance through its effects on an employee's attitudes and behaviours (Schuler \& Jackson, 1987; Wright \& Boswell, 2002), and therefore this relationship resides on multiple hierarchical levels of the organization. Despite this, the majority of studies have adopted a single-level approach when studying the HRM innovation relationship. One stream has focused on the organization level by examining the effect of HRM on the innovation performance of organizations (Beugelsdijk, 2008; Cabello-Medina et al., 2011; De Winne \& Sels, 2010; Shipton et al., 2006), while other streams have adopted an individual-level perspective in studying the effect of perceived HRM on IWB (Dorenbosch et al., 2005; Veenendaal \& Bondarouk, 2015). In this study we have built on and extended earlier multilevel frameworks outlining the HRM - innovation relationship (Veenendaal, 2015), mainly by empirically exploring the underlying mechanisms. Our multilevel framework and theoretical and empirical findings provide an enhanced understanding of how innovative HRM stimulates and enhances innovation performance. As such, we have demonstrated that it is important that HRM scholars integrate at least two levels of analysis when studying the HRM innovation performance relationship. This should include considering how intended innovative HRM policies and practices lead to employees' perceptions, to what extent these perceptions lead to innovative employee behaviours, how innovative behaviours contribute to innovation performance outcomes, and in what ways HRM can contribute to this bottom-up process. In considering the bottom-up process, several researchers have conceptualized multilevel models that display how employees can contribute to innovation (Lin \& Sanders, 2017; Shipton, Sparrow, et al., 2017). We have empirically extended this line of thinking by showing how employees generate and implement innovative ideas, and the ways in which HRM can contribute to this process. This suggests that scholars should consider the interaction between innovative behaviours and HRM when attempting to explain innovation performance. In this way, HRM can function as emergence-enabling mechanisms for employee-driven innovation ( $\mathrm{Li}$ et al., in press; Ployhart \& Moliterno, 2011; Wang \& Zatzick, 2015). The research framework that was created in Chapter 1 (Figure 1.1) depicts how individual-level processes, such as perceptions, attitudes and behaviours, explain how the 
innovative HRM policies that organizations introduce lead to innovation. The empirical findings of this dissertation, presented in Chapters 3 to 5 , provide support for this framework, and further extend it by revealing the mechanisms that influence employee perceptions, attitudes and innovative behaviours, leading to an adapted research framework (Figure 7.1). This framework could serve as a starting point for further research into the multilevel HRM - innovation relationship.

Second, our findings contribute to the current knowledge regarding employees' innovativeness in situations where this is not overtly expected or required (Montag et al., 2012; Shipton, Lin, et al., 2017). Several scholars have argued that 'regular' employees, who are not necessarily expected to be innovative, can still develop and implement innovative ideas (Høyrup, 2010; Kesting \& Ulhøi, 2010). My findings regarding employee-driven innovation supported these ideas and show that work-floor employees are indeed capable of contributing to innovation, both self-initiated and by active top-down stimulation. However, such employees often face high barriers, such as formalization. While there is a general assumption that formalization inhibits innovation (Aiken \& Hage, 1971; Hirst et al., 2011; Pierce \& Delbecq, 1977), we have shown that bottom-up innovation is still possible. In particular, the results of this dissertation show that certain innovation routes are important in enabling employees to share and develop their innovative ideas. Furthermore, the role of first-line managers is crucial for EDI to take place. FLMs can make a difference, not only as important actors in top-down HRM implementation (Bos-Nehles, 2010), but also in bottom-up innovation processes. Building on earlier research that showed the ability of FLMs to engage employees in innovative behaviour (Bos-Nehles, Bondarouk, \& Nijenhuis, 2017), this dissertation has holistically outlined the ways in which FLMs and HRM professionals, and the HRM activities they pursue, can together spur employee-driven innovation.

Third, the findings of this dissertation contribute to knowledge on the effect of employees' perceptions of HRM on their innovative behaviours. As can be seen in the research framework (Figure 7.1), the effect of HRM on innovation performance is understood from a process perspective. That is, we see employees' perceptions of HRM as an important mechanism through which intended HRM innovation affects the innovation performance of organizations. Following an HRM-as-a-process approach (Bowen \& Ostroff, 2004), this dissertation has integrated the ways in which employees perceive HRM, rather than focusing only on HRM as intended by management. This approach is based on the idea that intended HRM practices can be perceived differently by employees (Aryee et al., 2012; Den Hartog et al., 2013; Liao et al., 2009), for example by developing and adding positive or negative attributions to the 
intended HRM practices (Nishii et al., 2008). In this, we contribute to research that has focused on examining the HRM perceptions of employees. This is important because individual employees can develop distinctive perceptions of the very same set of HRM policies and practices, for example because of the fit between those practices and their own personal values (Guzzo \& Noonan, 1994). Employees can also develop different HRM perceptions because they actually receive different practices, for example through job crafting or i-deals (Rousseau et al., 2006; Wrzesniewski \& Dutton, 2001), because they make different attributions to HRM policies (Nishii et al., 2008), because HRM practices are not implemented as intended (Makhecha et al., 2018) or because HRM practices change during the implementation process (Van Mierlo, 2018). As a result, employees may respond differently than HRM professionals originally intended. Employees' responses could depend on how they assess the organization's HRM investments. Indeed, our results show that employees' perceptions of HRM do matter in terms of their innovative behaviours, with perceptions of highinvolvement HRM positively affecting IWB. Moreover, the findings in Chapter 4 highlight that employees do seem to reciprocate the invested HRM practices by enhanced commitment to the organization, which in turn positively influences their IWB. Further, the high-involvement HRM practices led to greater autonomy, which also increased employees' IWB. Together, these findings provide support for reciprocity as theorized in social exchange theory (Blau, 1964; Gouldner, 1960 ) in that employees seemed to reciprocate investments in HRM practices by generating and implementing innovative ideas. At the same time, the freedom and leeway that high-involvement HRM practices provide also stimulates innovative behaviours, thereby providing support for self-determination theory (Gagné \& Deci, 2005; Ryan \& Deci, 2000) and its value in HRM-IWB research. Combined, these findings support the idea that a fuller explanation of HRM performance relationships can be gained when researchers include both the attitude (commitment) and resource (autonomy) perspectives in seeking to explain the effect of HRM on employee outcomes (Meijerink et al., 2017). Overall, my results imply that HRM - innovation research would benefit from adopting an HRM process approach, and focusing on employee perceptions of HRM, in addition to considering manager intentions and implemented practices.

\subsubsection{Contributions to the multilevel HRM implementation literature}

The third main theoretical contribution of this dissertation is related to our findings on the ways in which introducing innovative HRM changes the HRM function, and thereby the multilevel and multi-actor HRM implementation process. We have shown that differences in HRM perceptions lead to different employee-level 
outcomes, and we have shown that employees actively shape HRM policies and practices, which could explain differences in HRM perceptions. In doing so, we contribute to the research that argues that HRM departments and work-floor employees co-produce and co-implement HRM activities (Meijerink et al., 2016; Meijerink \& Bos-Nehles, 2017) and shape as well as influence them during their development and implementation (Budjanovcanin, 2018). We have shown that HRM implementation is not only a top-down process, as often suggested in the existing literature (e.g. Makhecha et al., 2018; Wright \& Nishii, 2013), but a combination of top-down and bottom-up processes, thereby contributing to the nascent field of dynamic HRM implementation (Van Mierlo et al., 2018). HRM implementation is affected by the actions of several HRM actors, including line managers, HR specialists and employees (Farndale et al., 2010; Valverde et al., 2006). In our research, we substantiated these findings and showed that particularly the role of employees in SMTs is of growing importance in HRM implementation. This implies that, when studying the gaps between intended, actual and perceived HRM (Bondarouk et al., 2016; Bos-Nehles, Bondarouk, \& Labrenz, 2017; Khilji \& Wang, 2006; Makhecha et al., 2018; Piening et al., 2014a), the active role of work-floor employees in designing and co-implementing should be taken into account. Not only should the implementation of innovative HRM policies be seen as a process in which policies and practices evolve until they are used on a regular and consistent basis by different HRM actors (Bondarouk, Trullen, \& Valverde, 2016; Trullen, Bos-Nehles, \& Valverde, 2018), HRM implementation scholars should also take into account that teams of employees create and implement their own HRM activities. This has implications for the HRM implementation literature in that implementation should be seen as a combination of top-down and bottom-up processes. Hereby, we theoretically and empirically contribute to the idea that HRM implementation is an interplay between structure and action that continuously influences the process of implementation (Van Mierlo et al., 2018).

Second, the findings show that the HRM function changes as a consequence of implementing innovative HRM policies. Here, our results contribute to the literature on the HRM function. Most typologies of the HRM function adopt a three-legged function consisting of HRM professionals, line managers and employees (Jackson et al., 2009). Given the increasing use of selfmanaging teams (Maynard et al., 2012), we add the team as a further key HRM actor that takes over regulatory HRM responsibilities. The main implication is that, in a context of SMTs, the HRM function is represented by a so-called 'HRM quartet', consisting of HRM professionals, line managers, teams and individual employees. In our research, we have seen that all four actors contribute in different ways to the design, implementation and use of HRM. HRM research 
should take the changing roles of HRM actors into account when studying the effects of HRM policies and practices. For example, these changes have important implications when deciding who to select to report on HRM activities within organizations. Furthermore, the way in which the HRM function is organized may help to explain the gaps between intended and perceived HRM (Jiang et al., 2017; Makhecha et al., 2018) since differences can arise due to decentralizing HRM decision-making. This necessitates research into employees' HRM competences since these can contribute to HRM effectiveness. Here one could build on research that shows that employees' HRM competences stimulate HRM service value through their active co-production and consumption of HRM services (Meijerink et al., 2016). Our findings imply that members of SMTs require specific HRM competences in order to perform their HRM responsibilities. Therefore, I argue that researchers should take the HRM competences of employees into account when studying how HRM is implemented and how HRM effectiveness in organizations can be achieved. By studying the consequences of introducing SMTs for the HRM function, this dissertation has contributed to the knowledge on implementing new innovation-targeted HRM policies.

\subsection{Limitations}

Despite the theoretical contributions of this thesis, there are also several limitations, which in turn draw attention towards future research avenues. In this section, I address a number of limitations concerning the theoretical and methodological approaches I used in this dissertation.

\subsubsection{Theoretical limitations}

One theoretical limitation is related to the concept of EDI. Whereas our underlying premise is that all employees can contribute to innovation, and that work-floor employees are well-positioned to generate and implement innovative ideas (Kesting \& Ulhøi, 2010), we did not compare the concept of EDI with, for example, purely management-driven innovation or technology-driven innovation. Furthermore, one might criticize EDI for its relatedness to concepts such as highinvolvement innovation, continuous improvement (Tidd, Bessant, \& Pavitt, 1997) and workplace learning (Evans, Unwin, Hodkinson, \& Rainbird, 2007). Nevertheless, it has been argued that EDI is an important new concept because its focus is on innovative practices, to which any employee can contribute, that can lead to either incremental or radical innovation (Høyrup, 2010). There are indications that the conventional R\&D approach to innovation is a costly way to organize innovation, while practices to involve employees in innovation have been found to yield better business performance (Tidd, Bessant, \& Pavitt, 2005). 
Furthermore, in this chapter, I have compared the two case studies in terms of their approach to EDI and identified patterns based on differences and similarities. Future research should further compare different approaches to employee involvement in innovation processes and explore which HRM policies are needed to optimize their effectiveness.

We have also focused on EDI as a way to study the innovativeness of employees who are not overtly required to be innovative (Montag et al., 2012). A shortcoming here is that we did not include variables in our survey study to explicitly measure and integrate this into the HRM - IWB relationship. Nevertheless, we are confident that our sample consisted predominantly of employees who did not have innovation in their job task given the work tasks they were expected to carry out. All the respondents worked in organizations in the healthcare sector and were either providing care to people requiring assistance or performing laboratory tasks. Also in our investigations, we specifically inquired about the requirements to generate and implement ideas, which confirmed our idea that this was mostly not the case. Future research could explicitly examine the effect of innovation requirements, and study whether this leads to different HRM practices being needed to stimulate IWB.

Furthermore, the advent of employee empowerment in various sectors allows employees to make their own decisions regarding their work. This requires an important shift in the approach of HRM professionals in how human resources are managed. For instance, in a side project of this dissertation (Bondarouk et al., 2018), we applied the idea of governance mechanisms in the HRM function (Farndale et al., 2010) to study how HRM policies and practices can be aligned in organizations with self-managing teams. This showed that several governance mechanisms are used to achieve a fit between HRM practices. In combination with the findings of Chapter 3 of this dissertation, we can state that this also requires HRM scholars to adopt a different lens when studying the role of the HRM function and HRM implementation. Although we studied how the HRM function changes as a consequence of introducing SMTs, we did not examine how the changed HRM function can in turn improve the effectiveness of HRM. Given this limitation, we suggest that future research should examine how the HRM function can contribute to effectiveness in organizations with SMTs. It would be valuable to investigate whether employees need the same resources as firstline managers to implement HRM practices effectively. We would suggest that future researchers use the AMO framework (Appelbaum et al., 2000), which has proved valuable to researchers studying the factors affecting the HRM implementation effectiveness of line managers (Bos-Nehles et al., 2013), to examine what employees need in order to be able to implement HRM. 


\subsubsection{Methodological limitations}

A methodological limitation is linked to the quantitative analysis of the HRM innovation relationship. We did not test multilevel relationships statistically using quantitative analysis in this dissertation. In the research leading to Chapter 4, we did conduct a statistical analysis of the relationship between perceptions of highinvolvement HRM and IWB at the individual-level of analysis. Our initial intention was to also conduct a study in which we statistically tested cross-level relationships by including intended HRM as an antecedent and innovation performance as a unit-level outcome. In this way, we could have tested the relationship between innovative HRM and innovation performance. Although we have gathered data at the team-level, we do not have a sufficient number of teams, and respondents per team, to conduct a multilevel analysis (Hox, 1998; Maas \& Hox, 2005). Therefore, we are unable to statistically test our full research model. Nevertheless, we were able, based on the combination of case studies and statistical analysis, to expand theory and explain underlying mechanisms. Future research could investigate the relationship identified in our adapted research framework (Figure 7.1) more extensively to validate our findings and increase statistical generalizability by adopting a multilevel research approach using nested data from different organizational levels.

Among scholars in other streams within the philosophy of social sciences, critical realists would argue that usage of statistics do not provide meaningful causal explanations. Nevertheless, in Chapter 4 , despite being unable to directly observe a feeling of a need to reciprocate in employees, we were able to provide statistical evidence that high-involvement HRM leads to IWB based on the idea that employees feel the need to reciprocate the invested practices. We also hypothesized that autonomy would increase IWB based on the increase in selfdetermination (Gagné \& Deci, 2005; Ryan \& Deci, 2000) that would make employees more motivated to be engaged in innovative activities. Again, the underlying causal mechanism was not directly observed but statistically shown through our available dataset. For these reasons, we would argue that using statistical methods can help to further uncover causal mechanisms (McEvoy \& Richards, 2006).

A further methodological issue is the debatable generalizability of single case studies (as used in Chapter 3 and Chapter 5). Individual case studies are often criticized for the inability to generalize results. Our aim was different: in line with the critical realist perspective, we aimed only for analytical or theoretical generalizability. This means that we attempted to generalize to theory (Stake, 1978), rather than to other contexts. Further, all our empirical studies have been conducted in the healthcare sector, which might put additional limits on the generalizability of our findings to other industries. Nevertheless, by using our case 
studies to expand current theories, we provide findings that are useful for other organizations. There are many organizations that are introducing new HRM policies to improve their innovativeness, and these will find our insights useful. To further strengthen the analysis and conclusions from the individual research projects, I also conducted a cross-case analysis, reported in this discussion chapter, to uncover the different approaches to EDI and the underlying patterns regarding the role of HRM.

Finally, case study research inherently involves a degree of subjectivity and simplification. As transparently reported in the chapters of this dissertation, the data analysis involved several steps and integrated data from various sources (interviews, observations, documents and public information) to minimize the risk of subjectively and increase trustworthiness and rigor. Despite this, given the vast amount of data, important issues could have been overlooked or overemphasized. Future research could study these specific processes and mechanisms in a larger context to gain a more detailed picture and to identify alternative drivers of the particular mechanisms. This would also enable one to filter out distinctive processes that occurred only in our case study organizations. For example, it would be valuable to examine how different organizations approach the introduction of SMTs (Bondarouk et al., 2018).

\subsection{Suggestions for future research}

Based on the most important findings of this dissertation, we now suggest a number of further research directions. During our research, we developed several guidelines for applying lessons from multilevel theory to HRM research, and we have provided qualitative empirical evidence that multilevel theory helps to further our understanding of the relationship between HRM and innovation.

First, this dissertation includes one of the first empirical studies where the role of HRM is analysed in the process of bottom-up innovation. We explored the influence of HRM by distinguishing between content, process and structure in bottom-up emergence. There is a lack of theory and empirical evidence about the ways in which HRM policies and practices can contribute to the emergence of innovation. One suggestion for future research is to build on multilevel theory and study the extent to which, and in what ways, HRM can stimulate innovation by differentiating between the content, process and structure of emergence. Future research could test whether HRM policies and practices indeed have different effects on the content of EDI and on the process of innovation by also distinguishing between different types of innovative ideas, such as radical vs. incremental and/or process vs. product innovations. 
Second, the inductive model of HRM and EDI emergence, developed in Chapter 5, was based on explorative research carried out in order to refine and extend existing theory. More research is required to explore further the underlying causal mechanisms, and therefore we recommend qualitative and quantitative research that can provide additional insights into the bottom-up emergence process and analyse whether the factors we identified also play a role in other contexts. For example, a qualitative study could involve a comparative case study to further explore the different roles that HRM actors and activities play in bottomup innovation processes. Furthermore, a quantitative study could include the multilevel relationships proposed in Figure 7.1.

Third, we suggest exploring further the concept of EDI. We have already suggested comparing the concept to other approaches towards innovation, but it would also be valuable to study the skills and competences that employees need to (1) effectively design and use HRM activities, and (2) to be engaged in bottomup innovation. In this dissertation, we mainly focused on employees' ideas and HRM activities, and future research should also examine the abilities in which organizations should invest, and the HRM instruments to do this effectively, in order to stimulate their employees' innovative behaviours. Future research could also test and validate whether the EDI routes we identified, based on individuallevel innovative ideas, do indeed help to stimulate innovation emergence at the organization level.

Finally, we explored how a specific HRM innovation (i.e. self-managing teams) affects the HRM function. However, our study did not examine whether these changes in the HRM function, in turn, enable these HRM innovations to be more easily implemented. Based on our findings, we argued that SMTs have a significant impact on the way in which HRM policies are implemented. Future research could examine more precisely the impact that SMTs have on the HRM implementation process, and how the HRM function enables effective implementation. Furthermore, although the idea behind introducing SMTs is to enhance flexibility, resilience and innovativeness, we did not specifically test whether employees do become more innovative after introducing SMTs. In future research, scholars could go another step and test whether, once implemented, employees in SMTs show more innovative behaviours.

\subsection{Practical implications}

In this dissertation, I have outlined and emphasized the multilevel relationship between innovative HRM and employee-driven innovation. Based on a combination of theoretical and empirical studies, I now offer several recommendations that can help organizations to enhance their innovativeness. 
The results are not only relevant to HRM professionals and organizations, but can also inform first-line managers and employees. In this section, I describe practical implications for each of these groups.

\subsubsection{Implications for organizations and HRM managers}

First, organizations can enhance their innovativeness by acknowledging the innovative potential of their workforce and by actively involving employees in innovation processes. As we saw in our studies, work-floor employees will contribute to many initiatives when there are opportunities available for them, and when the organization takes their input into account. Managers and employees can create such opportunities by developing employee-driven innovation routes, i.e. structures through which employees can share and develop their ideas. The findings further inform organizations and HRM managers that, in order to stimulate innovation, they need to consider processes and mechanisms on at least the individual, team and organization levels. Organizations should be aware that gaps can arise between intended and perceived HRM policies, and between innovative ideas and innovation outcomes. Intended HRM policies might not be experienced as such by employees, and innovative ideas do not always lead to organization-level innovative outcomes.

Second, the results suggest that organizations can take active measures to increase EDI by developing HRM policies and practices that support innovation. Based on insights from several chapters, it has become clear that HRM practices to boost involvement were helpful in stimulating EDI. These practices can stimulate the abilities, motivation and opportunities employees have to contribute to EDI. For instance, organizations can actively support the inflow of external knowledge by organizing visits to other companies, symposia and training sessions, while also motivating employees by setting up a system for appreciating innovative employees, offering them opportunities to contribute by systematically integrating idea sharing and discussion sessions into regular meetings, and organizing off-the-job projects. Our results suggest that organizations could invest in high-involvement policies that increase employees' commitment and perceived autonomy since this will, in turn, lead to higher levels of innovative behaviour. Given that this link is partly based on reciprocation by employees, it is important that organizations clearly convey the message that these high-involvement practices are intended as an investment in their employees.

Third, EDI processes can be made more effective if organizations share information about innovation strategy and projects with their work-floor employees. The case study at MedLab showed that it was easier to implement 
innovative ideas if they were well aligned with current strategy and policy. Conversely, ideas that were more out-of-the-box and did not fit well with current policy often ground to a halt. For organizations, it is worthwhile to steer the content of employees' ideas by developing a clear strategy and communicating how employees can contribute to this strategy through their innovative ideas. For instance, at MedLab, it became clear that the organization was focused on cost reduction and, in its company communications, employees were encouraged to generate ideas that could achieve this. Some of these ideas were then supported by the HRM department. Initiatives that were linked to cost reduction were relatively easily implemented, whereas ideas that required additional investments needed to go through bureaucratic processes or died a silent death. HRM professionals and top managers could provide resources and share information about the organization's strategy with both employees and FLMs and, in turn, FLMs can then help employees to make sense of the strategy and act as gatekeepers for ideas.

Fourth, the innovative ideas of employees often run aground because of time constraints, a lack of priority or lack of acknowledgement. Organizations need not only to adopt policies and instruments that stimulate innovation, they also need to remove barriers to innovation. For example, our case study at MedLab showed that bureaucracy, rules and procedures limit the possibilities for employees to develop and implement ideas. Autonomy is one of the most important factors in delivering innovation: employees need to have the feeling that they can make decisions about their own work. Organizations can enhance employees' feeling of autonomy by giving them freedom to experiment. For example, our case studies showed that freeing up time for innovative projects, networking and personal development can help give employees the freedom to create ideas. HRM managers and FLMs can select work-floor employees to lead innovative projects and give them the resources to then carry this out autonomously.

Fifth, there is a need to differentiate between HRM policies for idea generation and for idea implementation. Distinct instruments can be deployed in these two phases. For instance, organizing training sessions can boost the likelihood that employees generate new ideas, but these sessions do not necessarily lead to those ideas being implemented. The findings at MedLab demonstrated several instances of instruments being used to generate ideas, while there was insufficient space to further develop and implement these ideas, leading to reduced motivation. Hence, it is important to align practices to stimulate innovative behaviour. 


\subsubsection{Implications for first-line managers}

Here, this dissertation demonstrated that FLMs have a crucial role in fostering EDI because they are closest to the EDI activities and can actively stimulate, recognize and champion employees' innovative ideas. The case studies showed examples in which FLMs orchestrated both top-down and bottom-up processes, illustrating the linchpin position that FLMs hold. Several instances showed that the support of the FLM makes the EDI process more successful and encourages employees to generate and implement ideas. FLMs can contribute to EDI by providing developmental feedback and showing their appreciation of employees with innovative ideas. Furthermore, FLMs can help by identifying potentially valuable ideas and communicating and championing them upwards in the organization.

Second, while we have seen that FLMs have an important role in the bottom-up process of innovation, we also saw that FLMs gradually lose influence over teams that become self-managing. In particular, at HealthServ, we found that managers become more like coaches, with an important function as a networker within organizations, but not necessarily holding hierarchical positions. Given this situation, FLMs and HRM professionals need to find new ways to deliver HRM practices for stimulating EDI to employees. As FLMs become less responsible for implementing and delivering HRM to employees, HRM professionals need to develop more direct ways to support employees with their HRM-related activities. HRM departments should develop policies to ensure that employees have the competences to perform HRM activities within their teams, and HRM professionals could also develop their own skills to successfully and efficiently support SMTs in performing these activities. At the same time, FLMs remain relevant for self-managing teams. FLMs should support teams to become self-managing by gradually handing over and explaining HRM tasks to the teams. FLMs should take a step back and change from a managing role to a coaching role. Employees need to make their own decisions and FLMs should ask SMTs what they need from the organization to perform. However, instead of complete laissez-faire, FLMs should keep connected with their SMTs to know where they can help and take decisions for teams when they are not performing well.

\subsubsection{Implications for work-floor employees}

Employees themselves have an active role in shaping innovation. First, we saw that employees in SMTs are responsible for decisions concerning several HRMrelated activities, such as recruitment, training, performance appraisal and scheduling. Our findings point to the importance of gaining specific HRM competences in order to increase the effectiveness of HRM activities in SMTs. 
Employees should use the opportunity to make their own decisions by implementing HRM activities that are appropriate for their team's specific context, while keeping in mind that HRM activities should be aligned both horizontally and vertically to increase their effectiveness. Second, we found that employees who perceive high levels of high-involvement HRM are more likely to be innovative, because they are more committed to the organization. Based on these findings, employees could proactively attempt to benefit from more high-involvement HRM practices, for example by going on training courses, actively monitoring information shared by their organization, working closely together in teams, and asking their supervisors for developmental feedback. Third, we found that innovative ideas mainly develop through three EDI routes. Employees should ensure that they know the ways through which they can further develop and implement their ideas. Finally, to be able to share and implement innovative ideas, it is also worthwhile taking part in organizational initiatives and work groups. 


\subsection{Conclusions}

This dissertation has explored the link between HRM and innovation from a multilevel perspective and studied its underlying mechanisms. Principles of multilevel theory building helped in gaining new insights into how the inherent multilevel concepts of HRM and innovation are connected. We adopted the concept of employee-driven innovation to study the ways in which HRM can stimulate 'regular' employees to generate and implement innovative ideas, and how HRM can support the bottom-up process of innovation by employees. First, we saw that introducing innovative HRM policies aiming to achieve high involvement, such as self-managing teams, forces changes upon the HRM function that, in turn, affects the HRM implementation process. Next, HRM involvement policies were found to be associated with work-floor employees' innovative behaviours through influencing their affective commitment and autonomy. Further, our results have shown that the innovative behaviours of work-floor employees contribute to innovation through specific for employeedriven innovation. HRM policies can support and facilitate this process by increasing the likelihood that employees generate ideas and then assisting in the process of getting them implemented. In other words, HRM can contribute to employee-driven innovation by both top-down stimulation and bottom-up championing - by focusing on the content and the process of innovation.

\section{References}

References can be found on page 209. 


\section{Bibliography}

Abstein, A., \& Spieth, P. (2014). Exploring HRM Meta-Features that Foster Employees' Innovative Work Behaviour in Times of Increasing Work-Life Conflict. Creativity and innovation management, 23(2), 211-225.

Agars, M. D., Kaufman, J. C., \& Locke, T. R. (2008). Social influence and creativity in organizations: A multilevel lens for theory, research, and practice. In M. D. Mumford, S. T. Hunter, \& K. E. Bedell-Avers (Eds.), Multi-level issues in creativity and innovation (Vol. 7, pp. 3-62): Emerald.

Agarwal, U. A. U. (2014). Linking justice, trust and innovative work behaviour to work engagement. Personnel Review, 43(1), 41-73.

Aiken, M., \& Hage, J. (1971). The organic organization and innovation. Sociology, 5(1), 63-82.

Alfes, K., Truss, C., Soane, E. C., Rees, C., \& Gatenby, M. (2013). The Relationship Between Line Manager Behavior, Perceived HRM Practices, and Individual Performance: Examining the Mediating Role of Engagement: Line Managers, HRM Practices, and Their Relationship with Engagement and Individual Performance. Human Resource Management, 52(6), 839-859. doi:10.1002/hrm.21512

Allen, N. J., \& Meyer, J. P. (1990). The measurement and antecedents of affective, continuance and normative commitment to the organization. Journal of occupational psychology, 63(1), 1-18.

Allport, F. H. (1954). The structuring of events: outline of a general theory with applications to psychology. Psychological Review, 61(5), 281-303.

Amabile, T. M. (1988). A model of creativity and innovation in organizations. Research in organizational behavior, 10(1), 123-167.

Amabile, T. M., Conti, R., Coon, H., Lazenby, J., \& Herron, M. (1996). Assessing the work environment for creativity. Academy of Management Journal, 39(5), 1154-1184.

Amelsvoort, P. J. L. M., \& Scholtes, G. (1994). Zelfsturende teams: ontwerpen, invoeren en begeleiden: ST-groep.

Ancona, D. G., \& Chong, C. L. (1996). Entrainment: Pace, cycle, and rhythm in organizational behavior. In L. L. Cummings \& B. M. Staw (Eds.), Research in organizational behavior (Vol. 18, pp. 251-284). Greenwich, CT: JAI Press.

Ancona, D. G., Goodman, P. S., Lawrence, B. S., \& Tushman, M. L. (2001). Time: A new research lens. Academy of Management Review, 26(4), 645-663.

Anderson, N., Potočnik, K., \& Zhou, J. (2014). Innovation and creativity in organizations a state-of-the-science review, prospective commentary, and guiding framework. Journal of Management, 40(5), 1297-1333.

Ang, S. H., Bartram, T., McNeil, N., Leggat, S. G., \& Stanton, P. (2013). The effects of high-performance work systems on hospital employees' work attitudes and intention to leave: a multi-level and occupational group analysis. The International Journal of Human Resource Management, 24(16), 3086-3114.

Appelbaum, E., Bailey, T., Berg, P., \& Kallenberg, A. (2000). Manufacturing advantage: Why high-performance work systems pay off. Ithaca, NY: Cornell University Press. 
Arthur, J. B. (1994). Effects of human resource systems on manufacturing performance and turnover. Academy of Management Journal, 37(3), 670-687.

Arthur, J. B., \& Boyles, T. (2007). Validating the human resource system structure: A levels-based strategic HRM approach. Human Resource Management Review, 17(1), 77-92.

Aryee, S., Walumbwa, F. O., Seidu, E. Y., \& Otaye, L. E. (2012). Impact of highperformance work systems on individual-and branch-level performance: test of a multilevel model of intermediate linkages. Journal of Applied Psychology, 97(2), 287-300.

Axtell, C. M., Holman, D., \& Wall, T. (2006). Promoting innovation: A change study. Journal of Occupational and organizational psychology, 79(3), 509-516.

Axtell, C. M., Holman, D. J., Unsworth, K. L., Wall, T. D., Waterson, P. E., \& Harrington, E. (2000). Shopfloor innovation: Facilitating the suggestion and implementation of ideas. Journal of Occupational and organizational psychology, 73(3), 265-285.

Bae, J., \& Lawler, J. J. (2000). Organizational and HRM strategies in Korea: Impact on firm performance in an emerging economy. Academy of Management Journal, 43(3), 502-517.

Baer, M. (2012). Putting creativity to work: The implementation of creative ideas in organizations. Academy of Management Journal, 55(5), 1102-1119.

Bakker, A. B., \& Bal, M. P. (2010). Weekly work engagement and performance: A study among starting teachers. Journal of Occupational and organizational psychology, 83(1), 189-206.

Bakker, A. B., \& Demerouti, E. (2007). The job demands-resources model: State of the art. Journal of Managerial Psychology, 22(3), 309-328.

Bal, P. M., Kooij, D. T. A. M., \& De Jong, S. B. (2013). How Do Developmental and Accommodative HRM Enhance Employee Engagement and Commitment? The Role of Psychological Contract and SOC Strategies. Journal of Management Studies, 50(4), 545-572. doi:10.1111/joms.12028

Banks, G. C., \& Kepes, S. (2015). The influence of internal HRM activity fit on the dynamics within the "black box". Human Resource Management Review, 25(4), 352-367.

Barney, J. B. (1991). Firm resources and sustained competitive advantage. Journal of Management, 17(1), 99-120.

Barney, J. B., \& Wright, P. M. (1998). On becoming a strategic partner: The role of human resources in gaining competitive advantage. Human Resource Management, 37, 31-46.

Battilana, J., \& Dorado, S. (2010). Building sustainable hybrid organizations: The case of commercial microfinance organizations. Academy of Management Journal, 53(6), 1419-1440.

Beaton, D. E., Bombardier, C., Guillemin, F., \& Ferraz, M. B. (2000). Guidelines for the process of cross-cultural adaptation of self-report measures. Spine, 25(24), 3186-3191. 
Becker, B., \& Gerhart, B. (1996). The impact of human resource management on organizational performance: Progress and prospects. Academy of Management Journal, 39(4), 779-801.

Bell, S. T. (2007). Deep-level composition variables as predictors of team performance: a meta-analysis. Journal of Applied Psychology, 92(3), 595-615.

Bergh, D. D., Connelly, B. L., Ketchen, D. J., \& Shannon, L. M. (2014). Signalling theory and equilibrium in strategic management research: An assessment and a research agenda. Journal of Management Studies, 51(8), 1334-1360.

Bessant, J. R. (2003). High-involvement innovation: Building and sustaining competitive advantage through continuous change: Wiley.

Beugelsdijk, S. (2008). Strategic human resource practices and product innovation. Organization Studies, 29(6), 821-847.

Bhaskar, R. (2009). Scientific realism and human emancipation: Routledge.

Bhaskar, R. (2013). A realist theory of science: Routledge.

Birkinshaw, J., \& Duke, L. (2013). Employee-Led Innovation. Business Strategy Review, 24(2), 46-51.

Bitektine, A., \& Haack, P. (2015). The "macro" and the "micro" of legitimacy: Toward a multilevel theory of the legitimacy process. Academy of Management Review, 40(1), 49-75.

Björkman, I., Ehrnrooth, M., Mäkelä, K., Smale, A., \& Sumelius, J. (2014). From HRM practices to the practice of HRM: Setting a research agenda. Journal of Organizational Effectiveness: People and Performance, 1(2), 122-140.

Blau, P. M. (1964). Exchange and power in social life. New York: Wiley.

Boglind, A., Hällstén, F., \& Thilander, P. (2011). HR transformation and shared services: Adoption and adaptation in Swedish organisations. Personnel Review, 40(5), 570-588.

Bondarouk, T., Bos-Nehles, A. C., \& Hesselink, X. (2016). Understanding the congruence of HRM frames in a healthcare organization. Baltic Journal of Management, 11(1), 2-20.

Bondarouk, T., Bos-Nehles, A. C., Renkema, M., Meijerink, J., \& De Leede, J. (2018). Organisational Roadmap Towards Teal Organisations (Vol. 19). Bingley (UK): Emerald Publishing.

Bondarouk, T., Looise, J. K., \& Lempsink, B. (2009). Framing the implementation of HRM innovation: HR professionals vs line managers in a construction company. Personnel Review, 38(5), 472-491.

Boon, C., Den Hartog, D. N., Boselie, P., \& Paauwe, J. (2011). The relationship between perceptions of HR practices and employee outcomes: examining the role of person-organisation and person-job fit. The International Journal of Human Resource Management, 22(01), 138-162.

Boon, C., \& Kalshoven, K. (2014). How High-Commitment HRM Relates to Engagement and Commitment: The Moderating Role of Task Proficiency. Human Resource Management, 53(3), 403-420. 
Bos-Nehles, A. C. (2010). The line makes the difference: Line managers as effective HR partners. Zutphen, The Netherlands: CPI Wöhrmann Print Service.

Bos-Nehles, A. C., \& Bondarouk, T. (2015). HRM Implementation Effectiveness in the International Arena: A Multi-Level and Multi-Actor Perspective. Paper presented at the 75th Academy of Management Annual Meeting 2015, Vancouver (BC), Canada.

Bos-Nehles, A. C., \& Bondarouk, T. (2017). HRM implementation in Europe-the need for a dialogue between $\mathrm{HR}$ and line management. European Journal of International Management, 11(5), 511-514.

Bos-Nehles, A. C., Bondarouk, T., \& Labrenz, S. (2017). HRM implementation in multinational companies: the dynamics of multifaceted scenarios. European Journal of International Management, 11(5), 515-536.

Bos-Nehles, A. C., Bondarouk, T. V., \& Nijenhuis, K. (2017). Innovative work behaviour in knowledge-intensive public sector organizations: the case of supervisors in the Netherlands fire services. The International Journal of Human Resource Management, 28(2), 379-398.

Bos-Nehles, A. C., \& Meijerink, J. G. (2018). HRM implementation by multiple HRM actors: a social exchange perspective. The International Journal of Human Resource Management, 1-25.

Bos-Nehles, A. C., Renkema, M., \& Janssen, M. (2017). HRM and Innovative Work Behaviour: A Systematic Literature Review. Personnel Review, 46(7), 1228-1253.

Bos-Nehles, A. C., Van Riemsdijk, M. J., \& Looise, J. K. (2013). Employee perceptions of line management performance: Applying the AMO theory to explain the effectiveness of line managers' HRM implementation. Human Resource Management, 52(6), 861-877.

Bos-Nehles, A. C., \& Veenendaal, A. A. R. (2017). Perceptions of HR practices and innovative work behavior: the moderating effect of an innovative climate. The International Journal of Human Resource Management, 123.

Boselie, P., Dietz, G., \& Boon, C. (2005). Commonalities and contradictions in HRM and performance research. Human Resource Management Journal, 15(3), 67-94.

Bowen, D. E., \& Ostroff, C. (2004). Understanding HRM-firm performance linkages: The role of the "strength" of the HRM system. Academy of Management Review, 29(2), 203-221.

Boxall, P., \& Macky, K. (2009). Research and theory on high-performance work systems: progressing the high-involvement stream. Human Resource Management Journal, 19(1), 3-23.

Budjanovcanin, A. (2018). Actions speak louder than words: how employees mind the implementation gap. The International Journal of Human Resource Management, 1-20.

Bysted, R., \& Jespersen, K. R. (2014). Exploring managerial mechanisms that influence innovative work behaviour: Comparing private and public employees. Public Management Review, 16(2), 217-241.

Cabello-Medina, C., López-Cabrales, Á., \& Valle-Cabrera, R. (2011). Leveraging the innovative performance of human capital through HRM and social 
capital in Spanish firms. The International Journal of Human Resource Management, 22(04), 807-828.

Cadwallader, S., Jarvis, C. B., Bitner, M. J., \& Ostrom, A. L. (2010). Frontline employee motivation to participate in service innovation implementation. Journal of the Academy of Marketing Science, 38(2), 219-239.

Call for Papers. (2014). The International Journal of Human Resource Management, 25(9), 1302-1305. doi:10.1080/09585192.2013.860299

Chang, E. (2005). Employees' overall perception of HRM effectiveness. Human Relations, 58(4), 523-544.

Chang, P. C., \& Chen, S. J. (2011). Crossing the level of employee's performance: HPWS, affective commitment, human capital, and employee job performance in professional service organizations. International Journal of Human Resource Management, 22(4), 883-901. doi:10.1080/09585192.2011.555130

Chang, S., Jia, L., Takeuchi, R., \& Cai, Y. (2014). Do high-commitment work systems affect creativity? A multilevel combinational approach to employee creativity. Journal of Applied Psychology, 99(4), 665-680.

Chesbrough, H. W. (2006). Open innovation: The new imperative for creating and profiting from technology: Harvard Business Press.

Chuang, C.-H., \& Liao, H. (2010). Strategic human resource management in service context: Taking care of business by taking care of employees and customers. Personnel psychology, 63(1), 153-196.

Coff, R., \& Kryscynski, D. (2011). Drilling for micro-foundations of human capitalbased competitive advantages. Journal of Management, 37(5), 14291443.

Cohen, S. G., \& Ledford Jr, G. E. (1994). The effectiveness of self-managing teams: A quasi-experiment. Human Relations, 47(1), 13-43.

Cohen, S. G., Ledford Jr, G. E., \& Spreitzer, G. M. (1996). A predictive model of self-managing work team effectiveness. Human Relations, 49(5), 643676.

Cohen, W. M., \& Levinthal, D. A. (1990). Absorptive capacity: a new perspective on learning and innovation. Administrative science quarterly, 35(1), 128152.

Coleman, J. S. (1990). Foundations of social theory. Cambridge MA (Belnkamp).

Collins, C. J., \& Smith, K. G. (2006). Knowledge exchange and combination: The role of human resource practices in the performance of high-technology firms. Academy of Management Journal, 49(3), 544-560.

Combs, J., Liu, Y., Hall, A., \& Ketchen, D. (2006). How much do highperformance work practices matter? A meta-analysis of their effects on organizational performance. Personnel psychology, 59(3), 501-528.

Cotton, J. L. (1993). Employee involvement: Methods for improving performance and work attitudes: Sage Publications, Inc.

Cropanzano, R. (2009). Writing nonempirical articles for Journal of Management: general thoughts and suggestions. Journal of Management, 35(6), 13041311. 
Crossan, M. M., \& Apaydin, M. (2010). A multi-dimensional framework of organizational innovation: A systematic review of the literature. Journal of Management Studies, 47(6), 1154-1191.

Damanpour, F. (1991). Organizational innovation: A meta-analysis of effects of determinants and moderators. Academy of Management Journal, 34(3), 555-590.

De Jong, J. P., \& Den Hartog, D. (2010). Measuring innovative work behaviour. Creativity and innovation management, 19(1), 23-36.

De Jong, J. P., \& Den Hartog, D. N. (2007). How leaders influence employees' innovative behaviour. European Journal of innovation management, 10(1), 41-64.

De Jong, J. P., \& Kemp, R. (2003). Determinants of co-workers' innovative behaviour: An investigation into knowledge intensive services. International Journal of Innovation Management, 7(02), 189-212.

De Jong, J. P., Parker, S. K., Wennekers, S., \& Wu, C. H. (2015). Entrepreneurial Behavior in Organizations: Does Job Design Matter? Entrepreneurship Theory and Practice, 39(4), 981-995.

De Leede, J., \& Looise, J. K. (2005). Innovation and HRM: towards an integrated framework. Creativity and innovation management, 14(2), 108-117.

De Spiegelaere, S. (2014). The Employment Relationship and Innovative Work Behaviour. Leuven: KU Leuven.

De Spiegelaere, S., Van Gyes, G., \& Hootegem, G. (2012a). Job design and innovative work behavior: one size does not fit all types of employees. Journal of Entrepreneurship, Management and Innovation (JEMI), 8(4), 5-20.

De Spiegelaere, S., Van Gyes, G., \& Hootegem, G. V. (2012b). Mainstreaming innovation in Europe-Findings on employee innovation and workplace learning from Belgium. Lifelong Learning in Europe (LLinE), 17(4).

De Winne, S., \& Sels, L. (2010). Interrelationships between human capital, HRM and innovation in Belgian start-ups aiming at an innovation strategy. The International Journal of Human Resource Management, 21(11), 18631883.

Deci, E. L., \& Ryan, R. M. (1985). Intrinsic motivation and self-determination in human behavior: Springer Science \& Business Media.

Den Hartog, D. N., Boon, C., Verburg, R. M., \& Croon, M. A. (2013). HRM, Communication, Satisfaction, and Perceived Performance A Cross-Level Test. Journal of Management, 39(6), 1637-1665.

DiMaggio, P. J. (1988). Interest and agency in institutional theory. In L. G. Zucker (Ed.), Institutional patterns and organizations: Culture and environment (Vol. 1, pp. 3-21). Cambridge (MA): Ballinger.

Dorenbosch, L., van Engen, M. L., \& Verhagen, M. (2005). On-the-job Innovation: The Impact of Job Design and Human Resource Management through Production Ownership. Creativity and innovation management, 14(2), 129-141.

Druskat, V. U., \& Wheeler, J. V. (2004). How to lead a self-managing team. MIT Sloan Management Review, 45(4), 65-71.

Eisenhardt, K. M. (1989). Building Theories from Case Study Research. The Academy of Management Review, 14(4), 532-550. doi:10.2307/258557 
Eisenhardt, K. M., \& Graebner, M. E. (2007). Theory building from cases: Opportunities and challenges. The Academy of Management Journal, 50(1), 25-32.

Elorza, U., Harris, C., Aritzeta, A., \& Balluerka, N. (2016). The effect of management and employee perspectives of high-performance work systems on employees' discretionary behaviour. Personnel Review, 45(1), 121-141. doi:10.1108/pr-07-2014-0167

Elsbach, K. D., \& Kramer, R. M. (2003). Assessing creativity in Hollywood pitch meetings: Evidence for a dual-process model of creativity judgments. Academy of Management Journal, 46(3), 283-301.

Engen, M. (2016). Frontline employees as participants in service innovation processes: innovation by weaving. Lillehammer: Lillehammer University College.

Evans, K., Unwin, L., Hodkinson, P., \& Rainbird, H. (2007). Improving workplace learning: Routledge.

Evans, K., \& Waite, E. (2010). Stimulating the innovation potential of 'routine'workers through workplace learning. Transfer: European Review of Labour and Research, 16(2), 243-258.

Falagas, M. E., Pitsouni, E. I., Malietzis, G. A., \& Pappas, G. (2008). Comparison of PubMed, Scopus, web of science, and Google scholar: strengths and weaknesses. The FASEB journal, 22(2), 338-342.

Farndale, E., \& Paauwe, J. (2007). Uncovering competitive and institutional drivers of HRM practices in multinational corporations. Human Resource Management Journal, 17(4), 355-375.

Farndale, E., Paauwe, J., \& Boselie, P. (2010). An exploratory study of governance in the intra-firm human resources supply chain. Human Resource Management, 49(5), 849-868.

Farr, J. L., \& Tran, V. (2008). Linking innovation and creativity with human resources strategies and practices: A matter of fit or flexibility? In M. D. Mumford, S. T. Hunter, \& K. E. Bedell-Avers (Eds.), Research in multilevel issues: Multi-level issues in creativity and innovation (Vol. 7, pp. 377-392): Emerald.

Felius, I. M., Bondarouk, T., \& Bos-Nehles, A. C. (2018). An AMO approach for the performance management of medical specialists, and the impact of medical specialists' professional unit culture(s). Paper presented at the Bi-Annual Seminar on Improving People Performance in Health Care, Utrecht, the Netherlands.

Fisher, C. D., \& To, M. L. (2012). Using experience sampling methodology in organizational behavior. Journal of Organizational Behavior, 33(7), 865877.

Fiss, P. C. (2007). A set-theoretic approach to organizational configurations. Academy of Management Review, 32(4), 1180-1198.

Fiss, P. C. (2011). Building better causal theories: A fuzzy set approach to typologies in organization research. Academy of Management Journal, 54(2), 393-420.

Fleetwood, S. (2005). Ontology in organization and management studies: A critical realist perspective. Organization, 12(2), 197-222. 
Frese, M., Teng, E., \& Wijnen, C. J. (1999). Helping to improve suggestion systems: Predictors of making suggestions in companies. Journal of Organizational Behavior, 20(7), 1139-1155.

Fu, N., Flood, P. C., Bosak, J., Morris, T., \& O'Regan, P. (2015). How do high performance work systems influence organizational innovation in professional service firms? Employee Relations, 37(2), 209-231.

Fuglsang, L. (2008). Innovation and the creative process: towards innovation with care: Edward Elgar Publishing.

Fuglsang, L., \& Sørensen, F. (2011). The balance between bricolage and innovation: Management dilemmas in sustainable public innovation. The service industries journal, 31(4), 581-595.

Fulmer, C. A., \& Ostroff, C. (2016). Convergence and emergence in organizations: An integrative framework and review. Journal of Organizational Behavior, 37, S122-S145. doi:10.1002/job.1987

Gagné, M., \& Deci, E. L. (2005). Self-determination theory and work motivation. Journal of Organizational Behavior, 26(4), 331-362.

Garcia, R., \& Calantone, R. (2002). A critical look at technological innovation typology and innovativeness terminology: a literature review. Journal of Product Innovation Management, 19(2), 110-132.

Gardner, T. M., Wright, P. M., \& Moynihan, L. M. (2011). The impact of motivation, empowerment, and skill-enhancing practices on aggregate voluntary turnover: The mediating effect of collective affective commitment. Personnel psychology, 64(2), 315-350.

Gibson, C. B., \& Kirkman, B. L. (1999). Our past, present, and future in teams: The role of human resource professionals in managing team performance. Evolving practices in human resource management: Responses to a changing world of work, 90-117.

Giddens, A. (1984). The constitution of society: Outline of the theory of structuration. United Kingdom, Cambridge: Polity Press.

Gioia, D. A., Corley, K. G., \& Hamilton, A. L. (2013). Seeking Qualitative Rigor in Inductive Research: Notes on the Gioia Methodology. Organizational Research Methods, 16(1), 15-31. doi:10.1177/1094428112452151

Gittell, J. H. (2000). Organizing work to support relational co-ordination. International Journal of Human Resource Management, 11(3), 517-539.

Gong, Y., Zhou, J., \& Chang, S. (2013). Core knowledge employee creativity and firm performance: The moderating role of riskiness orientation, firm size, and realized absorptive capacity. Personnel psychology, 66(2), 443-482.

Goodman, P. S., Devadas, R., \& Griffith Hughson, T. L. (1988). Groups and Productivity; Analyzing the Effectiveness of Self-Managing Teams. In J. P. Campbell \& R. J. Campbell (Eds.), PRODUCTIVITY IN ORGANIZATIONS. San Francisco: Jossey-Bass.

Gopalakrishnan, S., \& Damanpour, F. (1997). A review of innovation research in economics, sociology and technology management. Omega, 25(1), 1528.

Gould-Williams, J., \& Mohamed, R. (2010). A comparative study of the effects of 'best practice'HRM on worker outcomes in Malaysia and England local government. The International Journal of Human Resource Management, 21(5), 653-675. 
Gouldner, A. W. (1960). The norm of reciprocity: A preliminary statement. AMERICAN SOCIOLOGICAL REVIEW, 161-178.

Granovetter, M. (1985). Economic action and social structure: the problem of embeddedness. American journal of sociology, 91(3), 481-510.

Guerrero, S., \& Barraud-Didier, V. (2004). High-involvement practices and performance of French firms. The International Journal of Human Resource Management, 15(8), 1408-1423.

Guest, D. E. (1987). Human resource management and industrial relations. Journal of Management Studies, 24(5), 503-521.

Guest, D. E. (1997). Human resource management and performance: a review and research agenda. International Journal of Human Resource Management, 8(3), 263-276.

Guest, D. E., \& Bos-Nehles, A. C. (2013). Human resource management and performance: the role of effective implementation HRM and performance: Achievements and challenges. Chichester: Wiley-Blackwell.

Gupta, A. K., Tesluk, P. E., \& Taylor, M. S. (2007). Innovation at and across multiple levels of analysis. Organization Science, 18(6), 885-897.

Guthrie, J. P. (2001). High-involvement work practices, turnover, and productivity: Evidence from New Zealand. Academy of Management Journal, 44(1), 180-190.

Guzzo, R. A., \& Noonan, K. A. (1994). Human resource practices as communications and the psychological contract. Human Resource Management, 33(3), 447-462.

Hackman, J. R. (1986). The psychology of self-management in organizations: American Psychological Association.

Hackman, J. R. (1987). The design of work teams. Inj. w. lorsch (ed.), Handbook of organizational behavior (pp. 315-342): englewood cliffs, nj: prentice hall.

Hackman, J. R., \& Oldham, G. R. (1980). Work redesign.

Hair, J. F., Black, W. C., Babin, B. J., \& Anderson, R. E. (2010). Multivariate data analysis (Vol. 5). Upper Saddle River, NJ: Prentice Hall

Hartley, J. (2005). Innovation in governance and public services: Past and present. Public money and management, 25(1), 27-34.

Hesketh, A., \& Fleetwood, S. (2006). Beyond measuring the human resources management-organizational performance link: Applying critical realist meta-theory. Organization, 13(5), 677-699.

Hirst, G., Van Knippenberg, D., Chen, C.-h., \& Sacramento, C. A. (2011). How does bureaucracy impact individual creativity? A cross-level investigation of team contextual influences on goal orientation-creativity relationships. Academy of Management Journal, 54(3), 624-641.

Hitt, M. A., Beamish, P. W., Jackson, S. E., \& Mathieu, J. E. (2007). Building theoretical and empirical bridges across levels: Multilevel research in management. Academy of Management Journal, 50(6), 1385-1399.

Hobfoll, S. E. (2001). The influence of culture, community, and the nested-self in the stress process: advancing conservation of resources theory. Applied Psychology, 50(3), 337-421. 
Hong, Y., Liao, H., Raub, S., \& Han, J. H. (2016). What it takes to get proactive: An integrative multilevel model of the antecedents of personal initiative. Journal of Applied Psychology, 101(5), 687-701. doi:10.1037/apl0000064

House, R., Rousseau, D. M., \& Thomas-Hunt, M. (1995). The Meso Paradigm-a Framework for the Integration of Micro and Macro OrganizationalBehavior. Research In Organizational Behavior: An Annual Series Of Analytical Essays And Critical Reviews, 17, 71-114.

Hox, J. (1998). Multilevel Modeling: When and Why. In I. Balderjahn (Ed.), Classification, Data Analysis, and Data Highways. New York: Springer Verlag.

Hox, J. J. (2013). Multilevel regression and multilevel structural equation modeling. In T. D. Little (Ed.), The Oxford Handbook of Quantitative Methods in Psychology (Vol. 2, pp. 281-294).

Høyrup, S. (2010). Employee-driven innovation and workplace learning: basic concepts, approaches and themes. Transfer: European Review of Labour and Research, 16(2), 143-154.

Høyrup, S. (2012). Employee-driven innovation: a new phenomenon, concept and mode of innovation. In S. Høyrup, M. Bonnafous-Boucher, C. Hasse, M. Lotz, \& K. Møller (Eds.), Employee-driven innovation: A new approach (pp. 3-33). Basingstoke: Palgrave Macmillan.

Huselid, M. A., \& Becker, B. E. (1996). Methodological issues in cross-sectional and panel estimates of the human resource-firm performance link. Industrial Relations: A Journal of Economy and Society, 35(3), 400-422.

Ilies, R., Scott, B. A., \& Judge, T. A. (2006). The interactive effects of personal traits and experienced states on intraindividual patterns of citizenship behavior. Academy of Management Journal, 49(3), 561-575.

Jackson, S. E., Schuler, R. S., \& Werner, S. (2009). Managing Human Resources. Mason: South-Western Cengage Learning.

Jafri, M. H. (2010). Organizational commitment and employee's innovative behavior: A study in retail sector. Journal of Management Research, 10(1), 62.

Jansen, J. J., Van Den Bosch, F. A., \& Volberda, H. W. (2006). Exploratory innovation, exploitative innovation, and performance: Effects of organizational antecedents and environmental moderators. Management science, 52(11), 1661-1674.

Janssen, O. (2000). Job demands, perceptions of effort-reward fairness and innovative work behaviour. Journal of Occupational and organizational psychology, 73(3), 287-302.

Janssen, O. (2004). How fairness perceptions make innovative behavior more or less stressful. Journal of Organizational Behavior, 25(2), 201-215.

Jarzabkowski, P. (2004). Strategy as practice: recursiveness, adaptation, and practices-in-use. Organization Studies, 25(4), 529-560.

Jiang, K., Hu, J., Liu, S., \& Lepak, D. P. (2017). Understanding Employees' Perceptions of Human Resource Practices: Effects of Demographic Dissimilarity to Managers and Coworkers. Human Resource Management, 56(1), 69-91. 
Jiang, K., Lepak, D. P., Hu, J., \& Baer, J. C. (2012). How does human resource management influence organizational outcomes? A meta-analytic investigation of mediating mechanisms. Academy of Management Journal, 55(6), 1264-1294.

Jiang, K., Takeuchi, R., \& Lepak, D. P. (2013). Where do We Go From Here? New Perspectives on the Black Box in Strategic Human Resource Management Research. Journal of Management Studies, 50(8), 14481480. doi:10.1111/joms.12057

Jiménez-Jiménez, D., \& Sanz-Valle, R. (2008). Could HRM support organizational innovation? The International Journal of Human Resource Management, 19(7), 1208-1221.

Jones, M. R., \& Karsten, H. (2008). Giddens's Structuration Theory and Information Systems Research. MIS Quarterly, 32(1), 127-157.

Jung, D. D., Wu, A., \& Chow, C. W. (2008). Towards understanding the direct and indirect effects of CEOs' transformational leadership on firm innovation. The leadership quarterly, 19(5), 582-594.

Kanter, R. M. (1988). When a Thousand Flowers Bloom: Structural, Collective, and Social Conditions for Innovation in Organizations. In B. M. Staw \& L. L. Cummings (Eds.), Research in organizational behavior (Vol. 10, pp. 169-211). Greenwich, CT: JAI Press.

Katz, D., \& Kahn, R. L. (1978). The social psychology of organizations. New York: Wiley.

Kehoe, R. R., \& Wright, P. M. (2013). The impact of high-performance human resource practices on employees' attitudes and behaviors. Journal of Management, 39(2), 366-391.

Kepes, S., \& Delery, J. E. (2007). HRM systems and the problem of internal fit. In P. Boxall, J. Purcell, \& P. M. Wright (Eds.), The Oxford Handbook of Human Resource Management (pp. 385-405). New York: Oxford University Press.

Kesting, P., \& Ulhøi, J. P. (2010). Employee-driven innovation: extending the license to foster innovation. Management Decision, 48(1), 65-84.

Khilji, S. E., \& Wang, X. (2006). 'Intended' and 'implemented' HRM: the missing linchpin in strategic human resource management research. The International Journal of Human Resource Management, 17(7), 11711189.

Kirkman, B. L., \& Rosen, B. (1999). Beyond self-management: Antecedents and consequences of team empowerment. Academy of Management Journal, 42(1), 58-74.

Klein, K. J., \& Kozlowski, S. W. (2000). Multilevel theory, research, and methods in organizations: Foundations, extensions, and new directions. San Francisco (CA): Jossey-Bass.

Kleysen, R. F., \& Street, C. T. (2001). Toward a multi-dimensional measure of individual innovative behavior. Journal of intellectual Capital, 2(3), 284296.

Kohn, L. T., Corrigan, J. M., \& Donaldson, M. S. (2000). To err is human: building a safer health system (Vol. 6): National Academies Press. 
Korotka, M., \& Bos-Nehles, A. C. (2016). "Best" HRM-performance configurations?: A critical review and research agenda. Paper presented at the 76th Annual Meeting of the Academy of Management 2016, Anaheim, United States.

Kozlowski, S. W., \& Chao, G. T. (2012). The dynamics of emergence: Cognition and cohesion in work teams. Managerial and Decision Economics, 33(56), 335-354.

Kozlowski, S. W., \& Ilgen, D. R. (2006). Enhancing the effectiveness of work groups and teams. Psychological science in the public interest, 7(3), 77124.

Kozlowski, S. W., \& Klein, K. J. (2000). A multilevel approach to theory and research in organizations: Contextual, temporal, and emergent processes. In K. J. Klein \& S. W. Kozlowski (Eds.), Multilevel theory, research, and methods in organizations: Foundations, extensions, and new directions (pp. 3-90). San Francisco: Jossey-Bass.

Kreft, I. G. G. (1996). Are Multilevel Techniques Necessary? An Overview, Including Simulation Studies. Los Angeles: California State University.

Laloux, F. (2014). Reinventing organizations: A guide to creating organizations inspired by the next stage in human consciousness. Brussels: Nelson Parker.

Langley, A. (1999). Strategies for theorizing from process data. Academy of Management Review, 24(4), 691-710.

Langley, A., Smallman, C., Tsoukas, H., \& Van de Ven, A. H. (2013). Process studies of change in organization and management: unveiling temporality, activity, and flow. Academy of Management Journal, 56(1), 1-13.

Laureiro-Martínez, D., Brusoni, S., Canessa, N., \& Zollo, M. (2015). Understanding the exploration-exploitation dilemma: An MRI study of attention control and decision-making performance. Strategic Management Journal, 36(3), 319-338.

Laursen, K., \& Foss, N. J. (2003). New human resource management practices, complementarities and the impact on innovation performance. Cambridge Journal of economics, 27(2), 243-263.

Lawler, E. E. (1986). High-Involvement Management. Participative Strategies for Improving Organizational Performance: ERIC.

Lawler, E. E. (1992). The ultimate advantage: Creating the high-involvement organization: Jossey-Bass Inc Pub.

Lee, T. W. (1999). Using qualitative methods in organizational research: Sage.

Lee, T. W., Mitchell, T. R., \& Sablynski, C. J. (1999). Qualitative research in organizational and vocational psychology, 1979-1999. Journal of Vocational Behavior, 55(2), 161-187.

Lepak, D. P., Liao, H., Chung, Y., \& Harden, E. E. (2006). A conceptual review of human resource management systems in strategic human resource management research. Research in personnel and human resources management, 25(1), 217-271.

Lepak, D. P., \& Snell, S. A. (2002). Examining the human resource architecture: The relationships among human capital, employment, and human resource configurations. Journal of Management, 28(4), 517-543. 
Li, X., \& Frenkel, S. (2017). Where hukou status matters: analyzing the linkage between supervisor perceptions of HR practices and employee work engagement. The International Journal of Human Resource Management, 28(17), 2375-2402.

Li, Y., Wang, M., van Jaarsveld, D., Lee, G. K., \& Ma, D. (in press). From Employee-Experienced High-Involvement Work System to Innovation: An Emergence-Based Human Resource Management Framework. Academy of Management Journal.

Liao, H., \& Chuang, A. (2004). A multilevel investigation of factors influencing employee service performance and customer outcomes. Academy of Management Journal, 47(1), 41-58.

Liao, H., Toya, K., Lepak, D. P., \& Hong, Y. (2009). Do they see eye to eye? Management and employee perspectives of high-performance work systems and influence processes on service quality. Journal of Applied Psychology, 94(2), 371-391.

Lin, C.-H. V. (2015). HRM and innovation: Review, synthesis, and extension. Paper presented at the Academy of Management Proceedings.

Lin, C.-H. V., \& Sanders, K. (2017). HRM and innovation: a multi-level organisational learning perspective. Human Resource Management Journal, 27(2), 300-317.

Lopez-Cabrales, A., Pérez-Luño, A., \& Cabrera, R. V. (2009). Knowledge as a mediator between HRM practices and innovative activity. Human Resource Management, 48(4), 485-503.

Maas, C. J. M., \& Hox, J. (2005). Sufficient Sample Sizes for Multilevel Modeling. Methodology, 1(3), 86-92.

Maatman, M., Bondarouk, T., \& Looise, J. K. (2010). Conceptualising the capabilities and value creation of HRM shared service models. Human Resource Management Review, 20(4), 327-339.

Magpili, N. C., \& Pazos, P. (2018). Self-managing team performance: A systematic review of multilevel input factors. Small Group Research, 49(1), 3-33.

Makhecha, U. P., Srinivasan, V., Prabhu, G. N., \& Mukherji, S. (2018). Multi-level gaps: a study of intended, actual and experienced human resource practices in a hypermarket chain in India. The International Journal of Human Resource Management, 29(2), 360-398.

Marane, B. (2012). The mediating role of trust in organization on the influence of psychological empowerment on innovation behavior. European Journal of Social Sciences, 33(1), 39-51.

Martin, G., \& Beaumont, P. (2001). Transforming multinational enterprises: Towards a process model of strategic human resource management change. International Journal of Human Resource Management, 12(8), 1234-1250.

Martín, P., Salanova, M., \& Peiró, J. M. (2007). Job demands, job resources and individual innovation at work: Going beyond Karasek's model? Psicothema, 19(4), 621-626. 
Mathieu, J. E., Gilson, L. L., \& Ruddy, T. M. (2006). Empowerment and team effectiveness: an empirical test of an integrated model. Journal of Applied Psychology, 91(1), 97-108.

Mathieu, J. E., Tannenbaum, S. I., Donsbach, J. S., \& Alliger, G. M. (2014). A review and integration of team composition models moving toward a dynamic and temporal framework. Journal of Management, 40(1), 130160.

Maynard, M. T., Gilson, L. L., \& Mathieu, J. E. (2012). Empowerment-Fad or Fab? A Multilevel Review of the Past Two Decades of Research. Journal of Management, 38(4), 1231-1281. doi:10.1177/0149206312438773

McClean, E., \& Collins, C. J. (2011). High-commitment HR practices, employee effort, and firm performance: Investigating the effects of HR practices across employee groups within professional services firms. Human Resource Management, 50(3), 341-363.

McEvoy, P., \& Richards, D. (2006). A critical realist rationale for using a combination of quantitative and qualitative methods. Journal of research in nursing, 11(1), 66-78.

Meijerink, J. (2014). Practicing Social Innovation: Enactment of the EmployeeOrganization Relationship by Employees. In T. Bondarouk \& M. R. Olivas-Luján (Eds.), Human Resource Management, Social Innovation and Technology (Vol. 14, pp. 135-153): Emerald Group Publishing Limited.

Meijerink, J., Beijer, S., \& Bos-Nehles, A. C. (2017). How Do Employee Perceptions of HRM Relate to Performance? A Meta-Analysis of Mediating Mechanisms. Paper presented at the 77th Annual Meeting of the Academy of Management, Atlanta, GA (USA).

Meijerink, J., Bondarouk, T., \& Lepak, D. P. (2016). Employees as Active Consumers of HRM: Linking Employees' HRM Competences with Their Perceptions of HRM Service Value. Human Resource Management, 55(2), 219-240.

Meijerink, J., Bondarouk, T., \& Maatman, M. (2013). Exploring and comparing HR shared services in subsidiaries of multinational corporations and indigenous organisations in the Netherlands: A strategic response analysis. European journal of international management, 7(4), 469-492.

Meijerink, J., \& Bos-Nehles, A. C. (2017). Toward a Marketing Perspective on How 'Active Employees' Create Valuable Human Resource Management Outcomes: The Role of HRM Consumption and Psychological Ownership Theoretical Orientations and Practical Applications of Psychological Ownership (pp. 159-177). Cham: Springer.

Meyer, A. D., Tsui, A. S., \& Hinings, C. R. (1993). Configurational approaches to organizational analysis. Academy of Management Journal, 36(6), 11751195.

Meyer, J. P., \& Allen, N. J. (1997). Commitment in the workplace: Theory, research, and application: Sage.

Meyer, J. P., \& Smith, C. A. (2000). HRM practices and organizational commitment: Test of a mediation model. Canadian Journal of Administrative Sciences/Revue canadienne des sciences de l'administration, 17(4), 319-331. 
Miles, M. B., \& Huberman, A. M. (1994). Qualitative data analysis: An expanded sourcebook: sage.

Milliman, J., Von Glinow, M. A., \& Nathan, M. (1991). Organizational life cycles and strategic international human resource management in multinational companies: Implications for congruence theory. Academy of Management Review, 16(2), 318-339.

Minbaeva, D. B. (2013). Strategic HRM in building micro-foundations of organizational knowledge-based performance. Human Resource Management Review, 23(4), 378-390.

Mintzberg, H. (1980). Structure in 5's: A Synthesis of the Research on Organization Design. Management science, 26(3), 322-341.

Molloy, J. C., Ployhart, R. E., \& Wright, P. M. (2011). The Myth of "the" MicroMacro Divide: Bridging System-Level and Disciplinary Divides. Journal of Management, 37(2), 581-609. doi:10.1177/0149206310365000

Monks, K., Kelly, G., Conway, E., Flood, P., Truss, K., \& Hannon, E. (2013). Understanding how HR systems work: the role of HR philosophy and HR processes. Human Resource Management Journal, 23(4), 379-395.

Montag, T., Maertz, C. P., \& Baer, M. (2012). A critical analysis of the workplace creativity criterion space. Journal of Management, 38(4), 1362-1386.

Morgeson, F. P. (2005). The external leadership of self-managing teams: intervening in the context of novel and disruptive events. Journal of Applied Psychology, 90(3), 497-508.

Mumford, M. D. (2000). Managing creative people: Strategies and tactics for innovation. Human Resource Management Review, 10(3), 313-351.

Muthén, L. K., \& Muthén, B. O. (2010). Mplus: Statistical analysis with latent variables: User's guide: Muthén \& Muthén Los Angeles.

Nehles, A. C., van Riemsdijk, M., Kok, I., \& Looise, J. K. (2006). Implementing human resource management successfully: a first-line management challenge. Management revue, 17(3), 256-273.

Nishii, L. H., Lepak, D. P., \& Schneider, B. (2008). Employee attributions of the "why" of HR practices: Their effects on employee attitudes and behaviors, and customer satisfaction. Personnel psychology, 61(3), 503-545.

Nishii, L. H., \& Wright, P. M. (2007). Variability within organizations: Implications for strategic human resource management.

Nishii, L. H., \& Wright, P. M. (2008). Variability within organizations: Implications for strategic human resource management. In D. B. Smith (Ed.), The people make the place: Dynamic linkages between individuals and organizations (pp. 225-248). Mahwah, NJ: Lawrence Erlbaum Associates.

Nyberg, A. J., Moliterno, T. P., Hale, D., \& Lepak, D. P. (2014). Resource-Based Perspectives on Unit-Level Human Capital: A Review and Integration. Journal of Management, 40(1), 316-346. doi:10.1177/0149206312458703

Oeij, P., Rus, D., \& Pot, F. D. (2017). Workplace Innovation: Theory, Research and Practice: Springer. 
Ohly, S., Sonnentag, S., \& Pluntke, F. (2006). Routinization, work characteristics and their relationships with creative and proactive behaviors. Journal of Organizational Behavior, 27(3), 257-279.

Orlikowski, W. J., \& Yates, J. (2002). It's about time: Temporal structuring in organizations. Organization Science, 13(6), 684-700.

Ostroff, C., \& Bowen, D. E. (2000). Moving HR to a higher level: HR practices and organizational effectiveness. In K. J. Klein \& S. W. Kozlowski (Eds.), Multilevel theory, research, and methods in organizations: Foundations, extensions, and new directions (pp. 211-266). San Francisco: JosseyBass.

Ostroff, C., \& Bowen, D. E. (2016). Is there Strength in HR system Strength? Academy of Management Review, 41(2), 196-214.

Ostroff, C., Kinicki, A. J., \& Muhammad, R. S. (2013). Organizational culture and climate. In I. B. Weiner, N. W. Schmitt, \& S. Highhouse (Eds.), Handbook of Psychology, Vol 12: Industrial and Organizational Psychology (Vol. 12, pp. 643-676). Hoboken, NJ: John Wiley \& Sons.

Paauwe, J. (2009). HRM and performance: achievements, methodological issues and prospects. Journal of Management Studies, 46(1), 129-142.

Paauwe, J., \& Blok, T. (2014). Unraveling the different black boxes: in search for theories explaining the black boxes between HRM and performance. Paper presented at the 9th International Workshop on Human Resource Management, Seville, Spain.

Paauwe, J., \& Blok, T. (2015). Unraveling the different blackboxes: In search of theories explaining the blackboxes between hrm. In R. Valle-Cabrera \& A. López-Cabrales (Eds.), New Clues for Analysing the HRM Black Box (pp. 5). Newcastle: Cambridge Scholars Publishing.

Paauwe, J., \& Boselie, P. (2003). Challenging 'strategic HRM'and the relevance of the institutional setting. Human Resource Management Journal, 13(3), 56-70.

Paré, G., \& Tremblay, M. (2007). The influence of high-involvement human resources practices, procedural justice, organizational commitment, and citizenship behaviors on information technology professionals' turnover intentions. Group \& Organization Management, 32(3), 326-357.

Patton, M. Q. (1990). Qualitative evaluation and research methods: SAGE Publications, inc.

Peccei, R., van de Voorde, F., \& Van Veldhoven, M. (2013). HRM, well-being and performance: A theoretical and empirical review. Chichester: Wiley.

Peccei, R., \& Van De Voorde, K. (2016). The application of the multilevel paradigm in human resource management-outcomes research: Taking stock and going forward. Journal of Management, 0149206316673720.

Peretz, H., Levi, A., \& Fried, Y. (2015). Organizational diversity programs across cultures: effects on absenteeism, turnover, performance and innovation. International Journal of Human Resource Management, 26(6), 875-903. doi:10.1080/09585192.2014.991344

Pettigrew, A. M. (1987). Context and action in the transformation of the firm. Journal of Management Studies, 24(6), 649-670.

Piening, E. P., Baluch, A. M., \& Ridder, H.-G. (2014a). MIND THE INTENDEDIMPLEMENTED GAP: UNDERSTANDING EMPLOYEES' 
PERCEPTIONS OF HRM. Human Resource Management, 53(4), 545567. doi:10.1002/hrm.21605

Piening, E. P., Baluch, A. M., \& Ridder, H. G. (2014b). Mind the intendedimplemented gap: Understanding employees' perceptions of HRM. Human Resource Management, 53(4), 545-567. doi:10.1002/hrm.21605

Piening, E. P., Baluch, A. M., \& Salge, T. O. (2013). The relationship between employees' perceptions of human resource systems and organizational performance: Examining mediating mechanisms and temporal dynamics. Journal of Applied Psychology, 98(6), 926-947.

Pierce, J. L., \& Delbecq, A. L. (1977). Organization structure, individual attitudes and innovation. Academy of Management Review, 2(1), 27-37.

Ployhart, R. E., \& Moliterno, T. P. (2011). Emergence of the human capital resource: A multilevel model. Academy of Management Review, 36(1), 127-150.

Podsakoff, P. M., MacKenzie, S. B., Lee, J.-Y., \& Podsakoff, N. P. (2003). Common method biases in behavioral research: a critical review of the literature and recommended remedies. Journal of Applied Psychology, 88(5), 879.

Pot, F. (2011). Workplace innovation for better jobs and performance. International Journal of Productivity and Performance Management, 60(4), 404-415.

Prasad, P. (1997). Systems of meaning: ethnography as a methodology for the study of information technologies Information systems and qualitative research (pp. 101-118): Springer.

Preacher, K. J., Zyphur, M. J., \& Zhang, Z. (2010). A general multilevel SEM framework for assessing multilevel mediation. Psychological methods, 15(3), 209.

Pugh, D. S., Hickson, D. J., Hinings, C. R., Macdonald, K. M., Turner, C., \& Lupton, T. (1963). A conceptual scheme for organizational analysis. Administrative science quarterly, 8(3), 289-315.

Purcell, J., \& Hutchinson, S. (2007). Front-line managers as agents in the HRMperformance causal chain: theory, analysis and evidence. Human Resource Management Journal, 17(1), 3-20.

Ragin, C. C. (2000). Fuzzy-set social science. Chicago: University of Chicago Press.

Ramamoorthy, N., Flood, P., Slattery, T., \& Sardessai, R. (2005). Determinants of innovative work behaviour: Development and test of an integrated model. Creativity and innovation management, 14(2), 142-150.

Renkema, M., Meijerink, J., \& Bondarouk, T. (2016). Advancing multilevel thinking and methods in HRM research. Journal of Organizational Effectiveness: People and Performance, 3(2), 204-218.

Renkema, M., Meijerink, J., \& Bondarouk, T. (2017). Advancing multilevel thinking in human resource management research: Applications and guidelines. Human Resource Management Review, 27(3), 397-415. doi:http://dx.doi.org/10.1016/j.hrmr.2017.03.001 
Renkema, M., Meijerink, J., \& Bondarouk, T. (2018). Routes of Employee-Driven Innovation: How HRM Supports Emergence. Paper presented at the 78th Annual Meeting of the Academy of Management, Chicago, IL (USA).

Renkema, M., Meijerink, J., \& Bondarouk, T. V. (2015). Multilevel Theory Building in HRM Research: Critical Reflection and Guidelines. Paper presented at the 9th Biennial International Conference of the Dutch HRM Network, Utrecht, The Netherlands.

Rentsch, J. R. (1990). Climate and culture: Interaction and qualitative differences in organizational meanings. Journal of Applied Psychology, 75(6), 668.

Reynolds Fisher, S. L. (2000). A multilevel theory of organizational performance (Unpublished doctoral dissertation). Oklahoma State University. Stillwater, OK.

Riketta, M. (2002). Attitudinal organizational commitment and job performance: a meta-analysis. Journal of Organizational Behavior, 23(3), 257-266.

Rothaermel, F. T., \& Hess, A. M. (2007). Building dynamic capabilities: Innovation driven by individual-, firm-, and network-level effects. Organization Science, 18(6), 898-921.

Rousseau, D. M. (1985). Issues of level in organizational research: Multi-level and cross-level perspectives. Research in organizational behavior, 7(1), 1-37.

Rousseau, D. M., Ho, V. T., \& Greenberg, J. (2006). I-deals: Idiosyncratic terms in employment relationships. Academy of management review, 31(4), 977-994.

Ryan, R. M., \& Deci, E. L. (2000). Self-determination theory and the facilitation of intrinsic motivation, social development, and well-being. American psychologist, 55(1), 68.

Salancik, G. R., \& Pfeffer, J. (1978). A social information processing approach to job attitudes and task design. Administrative science quarterly, 23(2), 224-253.

Sanders, K., Moorkamp, M., Torka, N., Groeneveld, S., \& Groeneveld, C. (2010). How to support innovative behaviour? The role of LMX and satisfaction with HR practices. Technology and Investment, 2010.

Sayer, A. (2000). Realism and social science: Sage.

Schneider, B. (1990). The climate for service: An application of the climate construct. Organizational climate and culture, 1, 383-412.

Schneider, B., Goldstein, H. W., \& Smith, D. B. (1995). The ASA framework: An update. Personnel psychology, 48(4), 747-773.

Schuler, R. S. (1992). Strategic Human Resource Management: Linking the People with the Strategic Needs of the Business. Organizational Dynamics, 21(1), 18-32.

Schuler, R. S., \& Jackson, S. E. (1987). Linking competitive strategies with human resource management practices. The Academy of Management Executive (1987-1989), 1(3), 207-219.

Schumpeter, J. A. (1934). The theory of economic development: An inquiry into profits, capital, credit, interest, and the business cycle (Vol. 55): Transaction publishers. 
Scott, S. G., \& Bruce, R. A. (1994). Determinants of innovative behavior: A path model of individual innovation in the workplace. Academy of Management Journal, 37(3), 580-607.

Scott, W. R. (2005). Institutional theory: Contributing to a theoretical research program. In K. G. Smith \& M. A. Hitt (Eds.), Great minds in management: The process of theory development (pp. 460-485). Oxford: Oxford University Press.

Seeck, H., \& Diehl, M.-R. (2017). A literature review on HRM and innovation taking stock and future directions. The International Journal of Human Resource Management, 28(6), 913-944. doi:10.1080/09585192.2016.1143862

Seibert, S. E., Wang, G., \& Courtright, S. H. (2011). Antecedents and consequences of psychological and team empowerment in organizations: a meta-analytic review. Journal of Applied Psychology, 96(5), 981-1003.

Shalley, C. E., \& Gilson, L. L. (2004). What leaders need to know: A review of social and contextual factors that can foster or hinder creativity. The leadership quarterly, 15(1), 33-53.

Shalley, C. E., Zhou, J., \& Oldham, G. R. (2004). The effects of personal and contextual characteristics on creativity: Where should we go from here? Journal of Management, 30(6), 933-958.

Shen, J. (2016). Principles and Applications of Multilevel Modeling in Human Resource Management Research. Human Resource Management, 55(6), 951-965. doi:10.1002/hrm.21666

Shin, S. J., Jeong, I., \& Bae, J. (2016). Do high-involvement HRM practices matter for worker creativity? a cross-level approach. The International Journal of Human Resource Management, 1-26. doi:10.1080/09585192.2015.1137612

Shipton, H., Budhwar, P., Sparrow, P., \& Brown, A. (2016a). Human resource management, innovation and performance. Basingstoke: Palgrave Macmillan.

Shipton, H., Budhwar, P., Sparrow, P., \& Brown, A. (2016b). Human Resource Management, Innovation and Performance: Looking across Levels. In $\mathrm{H}$. Shipton, P. Budhwar, P. Sparrow, \& A. Brown (Eds.), Human Resource Management, Innovation and Performance (pp. 1-12). London: Palgrave Macmillan UK.

Shipton, H., Fay, D., West, M., Patterson, M., \& Birdi, K. (2005). Managing people to promote innovation. Creativity and innovation management, 14(2), 118-128.

Shipton, H., Lin, V., Sanders, K., \& Yang, H. (2017). 'We are not creative here!'Creativity and innovation for non-creatives through HRM. In P. Sparrow \& C. L. Cooper (Eds.), A Research Agenda for Human Resource Management (pp. 184). Cheltenham (UK): Edward Elgar Publishing Limited.

Shipton, H., Sparrow, P., Budhwar, P., \& Brown, A. (2017). HRM and innovation: looking across levels. Human Resource Management Journal, 27(2), 246-263. 
Shipton, H., West, M. A., Dawson, J., Birdi, K., \& Patterson, M. (2006). HRM as a predictor of innovation. Human Resource Management Journal, 16(1), 3-27.

Short, J. (2009). The art of writing a review. Journal of Management, 35(6), 13121317.

Simon, H. A. (1973). The organization of complex systems. In H. H. Pattee (Ed.), Hierarchy theory (pp. 1-27). New York: Braziller.

Skaggs, B. C., \& Youndt, M. (2004). Strategic positioning, human capital, and performance in service organizations: a customer interaction approach. Strategic Management Journal, 25(1), 85-99.

Smets, M., Morris, T., \& Greenwood, R. (2012). From practice to field: A multilevel model of practice-driven institutional change. Academy of Management Journal, 55(4), 877-904.

Snijders, T., \& Bosker, R. (1999). Multilevel analysis: An introduction to basic and applied multilevel analysis: London: Sage.

Sørensen, F., Sundbo, J., \& Mattsson, J. (2013). Organisational conditions for service encounter-based innovation. Research Policy, 42(8), 1446-1456.

Spreitzer, G. M. (1995). Psychological empowerment in the workplace: Dimensions, measurement, and validation. Academy of Management Journal, 38(5), 1442-1465.

Stake, R. E. (1978). The case study method in social inquiry. Educational researcher, 7(2), 5-8.

Stewart, G. L., Fulmer, I. S., \& Barrick, M. R. (2005). An exploration of member roles as a multilevel linking mechanism for individual traits and team outcomes. Personnel psychology, 58(2), 343-365.

Strauss, A., \& Corbin, J. (1990). Basics of qualitative research (Vol. 15): Newbury Park, CA: Sage.

Strauss, A., \& Corbin, J. (1998). Basics of qualitative research: Techniques and procedures for developing grounded theory: Sage Publications, Inc.

Sun, L.-Y., Aryee, S., \& Law, K. S. (2007). High-performance human resource practices, citizenship behavior, and organizational performance: A relational perspective. Academy of Management Journal, 50(3), 558577.

Sundbo, J. (2003). Innovation and strategic reflexivity: an evolutionary approach applied to services The international handbook on innovation (pp. 97114): Elsevier.

Takeuchi, R., Chen, G., \& Lepak, D. P. (2009). Through The Looking Glass Of A Social System: Cross-Level Effects Of High-Performance Work Systems On Employees' Attitudes. Personnel psychology, 62(1), 1-29.

Taylor, A., \& Greve, H. R. (2006). Superman or the fantastic four? Knowledge combination and experience in innovative teams. Academy of Management Journal, 49(4), 723-740.

Ten Brummelhuis, L. L., Bakker, A. B., Hetland, J., \& Keulemans, L. (2012). Do new ways of working foster work engagement? Psicothema, 24(1), 113120.

Tidd, J., Bessant, J., \& Pavitt, K. (1997). Managing innovation: Integrating technological, organizational and market change: Wiley, Chichester. 
Tidd, J., Bessant, J., \& Pavitt, K. (2005). Managing innovation integrating technological, market and organizational change: John Wiley and Sons Ltd.

Tims, M., Bakker, A. B., \& Derks, D. (2012). Development and validation of the job crafting scale. Journal of vocational behavior, 80(1), 173-186.

Tjepkema, S. (2003). The learning infrastructure of self-managing work teams. Enschede: Universiteit Twente.

Ulrich, D., Younger, J., \& Brockbank, W. (2008). The twenty-first-century HR organization. Human resource management, 47(4), 829-850.

Unsworth, K. L., \& Clegg, C. W. (2010). Why do employees undertake creative action? Journal of Occupational and organizational psychology, 83(1), 77-99.

Upton, M. G., \& Egan, T. M. (2010). Three approaches to multilevel theory building. Human Resource Development Review, 9(4), 333-356.

Valverde, M., Ryan, G., \& Soler, C. (2006). Distributing HRM responsibilities: a classification of organisations. Personnel Review, 35(6), 618-636.

Van de Ven, A. H. (1986). Central problems in the management of innovation. Management science, 32(5), 590-607.

Van de Ven, A. H., \& Huber, G. P. (1990). Longitudinal field research methods for studying processes of organizational change. Organization Science, 1(3), 213-219.

Van de Ven, A. H., Polley, D. E., Garud, R., \& Venkataraman, S. (2008). The innovation journey. Oxford: Oxford University Press.

Van Mierlo, J. (2018). The Dynamic Nature of HRM Implementation: Uncovering HRM-as-a-process. Enschede: University of Twente.

Van Mierlo, J., \& Bondarouk, T. (2018). The Process of Implementing HRM Practices: a Case Study in the Dutch Federal Government. Paper presented at the Academy of Management Conference, Chicago, USA.

Van Mierlo, J., Bondarouk, T., \& Sanders, K. (2018). The dynamic nature of HRM implementation: a structuration perspective. The International Journal of Human Resource Management, xx(xx), 1-30.

Van Veldhoven, M. J. P. M. (2012). Over knipogen, badkuipen en kampeertenten: arbeidsgedrag als fundament van strategisch HRM: Tilburg University.

Vandenberg, R. J., Richardson, H. A., \& Eastman, L. J. (1999). The impact of high involvement work processes on organizational effectiveness: A second-order latent variable approach. Group \& Organization Management, 24(3), 300-339.

Veenendaal, A. A. R. (2015). Enhancing innovation at work through human resource management. Enschede: University of Twente.

Veenendaal, A. A. R., \& Bondarouk, T. V. (2015). Perceptions of HRM and their effect on dimensions of innovative work behaviour: Evidence from a manufacturing firm. Management revue, 26(2), 138-160.

Veenendaal, A. A. R., Van Velzen, M., \& Looise, J. K. (2014). Affecting innovation through HRM: The role of creative capital. European Journal of International Management, 8(5), 472-487.

Von Hippel, E. (1986). Lead users: a source of novel product concepts. Management science, 32(7), 791-805. 
Vough, H. C., Bindl, U. K., \& Parker, S. K. (2017). Proactivity routines: The role of social processes in how employees self-initiate change. Human Relations, 70(10), 1191 - 1216.

Wageman, R. (2001). How leaders foster self-managing team effectiveness: Design choices versus hands-on coaching. Organization Science, 12(5), 559-577.

Wang, T. T., \& Zatzick, C. (2015). The Effect of Human Capital Renewal on Organizational Innovation over Time. Paper presented at the Academy of Management Annual Meeting, Vancouver.

West, M. A., \& Farr, J. L. (1989). Innovation at work: Psychological perspectives. Social Behaviour.

Whitener, E. M. (2001). Do "high commitment" human resource practices affect employee commitment? A cross-level analysis using hierarchical linear modeling. Journal of Management, 27(5), 515-535.

Wihlman, T., Hoppe, M., Wihlman, U., \& Sandmark, H. (2014). Employee-driven innovation in welfare services. Nordic journal of working life studies, 4(2), 159.

Williams, L. J., Cote, J. A., \& Buckley, M. R. (1989). Lack of method variance in self-reported affect and perceptions at work: Reality or artifact? Journal of Applied Psychology, 74(3), 462.

Wood, S., Van Veldhoven, M., Croon, M., \& De Menezes, L. M. (2012). Enriched job design, high involvement management and organizational performance: The mediating roles of job satisfaction and well-being. Human Relations, 65(4), 419-445.

Wright, P. M., \& Boswell, W. R. (2002). Desegregating HRM: A review and synthesis of micro and macro human resource management research. Journal of Management, 28(3), 247-276.

Wright, P. M., \& Kehoe, R. R. (2008). Human resource practices and organizational commitment: A deeper examination. Asia Pacific Journal of Human Resources, 46(1), 6-20.

Wright, P. M., \& McMahan, G. C. (1992). Theoretical perspectives for strategic human resource management. Journal of Management, 18(2), 295-320.

Wright, P. M., \& Nishii, L. H. (2007). Strategic HRM and organizational behavior: Integrating multiple levels of analysis. CAHRS Working Paper Series, 468.

Wright, P. M., \& Nishii, L. H. (2013). Strategic HRM and organizational behavior: Integrating multiple levels of analysis. In J. Paauwe, D. E. Guest, \& P. M. Wright (Eds.), HRM \& Performance: Achievements \& Challenges (pp. 97110). Chichester: Wiley.

Wrzesniewski, A., \& Dutton, J. E. (2001). Crafting a job: Revisioning employees as active crafters of their work. Academy of Management Review, 26(2), 179-201.

Wu, P.-C., \& Chaturvedi, S. (2009). The Role of Procedural Justice and Power Distance in the Relationship Between High Performance Work Systems and Employee Attitudes: A Multilevel Perspective. Journal of Management, 35(5), 1228-1247. doi:10.1177/0149206308331097

Yin, R. K. (2014). Case study research: Design and methods. Thousand Oaks: Sage publications. 
Yuan, F., \& Woodman, R. W. (2010). Innovative behavior in the workplace: The role of performance and image outcome expectations. Academy of Management Journal, 53(2), 323-342.

Zahra, S. A., \& George, G. (2002). Absorptive capacity: A review, reconceptualization, and extension. Academy of Management Review, 27(2), 185-203.

Zhou, J. (2003). When the presence of creative coworkers is related to creativity: role of supervisor close monitoring, developmental feedback, and creative personality. Journal of Applied Psychology, 88(3), 413.

Zhou, Y., Hong, Y., \& Liu, J. (2013). Internal commitment or external collaboration? The impact of human resource management systems on firm innovation and performance. Human Resource Management, 52(2), 263-288. 



\section{Appendices}

Appendix A. Systematic Literature Review process (Ch. 2)

Appendix B. Interview protocol HealthServ management (Ch. 3)

Appendix C. Interview protocol HealthServ HRM and FLMs (Ch. 3)

Appendix D. Interview protocol HealthServ teams (Ch. 3)

Appendix E. HRM activities in HealthServ (Ch. 3)

Appendix F. Measurement scales for HRM - IWB relationship (Ch. 4)

Appendix G. General interview protocol MedLab (Ch. 5)

Appendix $\mathrm{H}$. Overview of HR policies and practices for EDI at MedLab (Ch.

5) 
Appendix A. Systematic Literature Review process (Ch. 2)

During Round 1, we searched for articles that explicitly conducted multilevel HRM research in terms of relationships that crossed hierarchical (e.g. employee, unit, or organizational) levels. Therefore, we used the following search terms and keywords combined with Boolean Operators: "HRM" OR "Human Resource Management" AND "multilevel" OR "multi-level" OR "cross-level". This search yielded over 400 articles, reduced to 309 after duplicates were removed. We excluded a further 119 studies since they were not peer-reviewed, in English and/or empirical in nature, reducing the remaining total to 190 studies. We then considered the title of each of the remaining studies to assess whether they studied HRM systems, philosophies, policies, and/or practices (including recruitment, selection, training, development, performance management, compensation, benefits, job design, and/or involvement). A total of 86 did not fit this criterion and were therefore removed. Next, the abstracts and full texts of the remaining 104 studies were read to assess whether they were multilevel in nature along at least one of our three multilevelity cube dimensions, leading to 43 studies being excluded. We conducted back-and-forward reference checks on the remaining 61 articles in Google Scholar, and also looked at calls for papers for a special issue ${ }^{8}$ to check if there were important articles we had missed. This yielded 12 additional articles. As such, we had a list of 73 studies that explicitly conducted multilevel HRM research.

During Round 2, we searched for articles that had studied at least two HRM internalization levels. Therefore, we used the following search terms and keywords: "intended HRM" OR "actual HRM" OR "perceived HRM" OR "experienced HRM" OR "HRM implementation" OR "HRM internalization" OR "HR* perceptions". This search yielded 112 articles from the two databases, of which 20 were excluded because they were not peer-reviewed, written in English and/or empirical. The remaining 92 articles were reduced to 76 as 16 did not study HRM. After reading the abstracts and full texts of the remaining studies, 55 studies were excluded since they studied only one internationalization dimension (often employees' perceptions of HRM). As such, we retained a final sample of 21 studies that studied two or more HRM internationalization levels.

During the final round, we searched for articles that studied at least two HRM abstraction levels. Therefore, we used the following search terms and keywords: "HRM philosophies" OR "HRM policies" OR "HRM practices" OR "HR philosophies" OR "HR policies" OR "HR practices" OR "HRM systems" OR "HR

\footnotetext{
${ }^{8}$ A special issue of The International Journal of Human Resource Management ("Call for Papers," 2014).
} 
syst" ${ }^{*}$. This search yielded 125 articles from the two databases, of which 25 were excluded as they were not peer-reviewed, written in English and/or empirical. The remaining 100 articles were reduced to 92 after 8 were removed as they did not study human resource management. After reading the abstracts and full texts of the remaining studies, we excluded 88 studies because they used the terms 'policies' and 'practices' interchangeably, rather than systematically differentiating between the two. As such, we had a final sample of 4 studies that explicitly studied two or more HRM abstraction levels.

Some of the studies that had met our selection criteria could have focused on multiple multilevelity dimensions (e.g., studying both introduced HRM policies at the unit-level and experienced HRM practices at the employee-level). Indeed, 10 studies had been identified in more than one round and, after the duplicate entries were removed, our final sample consisted of $88 \mathrm{HRM}$ studies that were multilevel in nature along at least one of our three multilevelity cube dimensions. These 88 studies were analyzed by two researchers in terms of the organizational, internalization, and abstraction levels studied, and how each of the multilevel principles were applied. 
Appendix B. Interview protocol HealthServ management (Ch. 3)

The questions of the interview protocol were originally in Dutch.

\section{Introduction}

- Introduction to research, consent, and anonymity

- Personal introduction

\section{Self-managing teams}

- Meaning of self-managing teams

- Reasons and motivation

- Philosophy behind self-managing teams

- Enactment of self-managing teams

- Expected outcomes

\section{Implementation}

- Factors for success

- Support for teams

- Role of HRM department

\section{HRM policies and practices}

- Tasks and roles in self-managing teams

- Responsibilities and authority of teams

- Performing HRM activities

- Role of first-line manager

- Challenges for self-managing teams

\section{Outcomes}

- Desired outcomes

- Contribution to innovation

- Expectations for organisation, teams, employees

- Unexpected and undesired outcomes 
Appendix C. Interview protocol HealthServ HRM and FLMs (Ch. 3)

The questions of the interview protocol were originally in Dutch.

\section{Introduction}

- Introduction to research, consent, and anonymity

- Personal introduction

\section{Self-managing teams}

- Meaning of self-managing teams

- Reasons and motivation

- Philosophy behind self-managing teams

- Leadership style (FLMs)

- Characteristics of successful leaders

- Contribution to innovation

- Role of FLMs in innovation

- Role of HRM department (HRM)

- Relationship between HRM and FLMs (HRM)

\section{Implementation}

- Enactment of self-managing teams

- Factors for success

- Support for teams and first-line managers

- Role of first-line manager

- Role of HRM department

\section{HRM policies and practices}

- Tasks and roles in self-managing teams

- Responsibilities and authority of teams

- $\quad$ Role of HRM professionals (HRM)

- Instruments by HRM professionals (HRM)

- Performing HRM activities

- Challenges for self-managing teams

\section{Outcomes}

- Desired outcomes

- Expectations for organisation, teams, employees

- Clarity about goals

- Successful and unsuccessful teams (FLMs)

- Innovative teams (FLMs) 
Appendix D. Interview protocol HealthServ teams (Ch. 3)

The questions of the interview protocol were originally in Dutch.

\section{Introduction}

- Introduction to research, consent, and anonymity

- Personal introduction

\section{Self-managing teams}

- Meaning of self-managing teams

- Reasons and motivation

- Experiences of working in SMTs

- Transition towards SMTs

\section{Roles of actors}

- Role of the FLM

- Characteristics of successful leaders

- Own role within the team

\section{HRM Activities}

- Team-tasks and role-division

- Responsibilities for HRM activities (e.g. recruitment, training, appraisal, planning, job design, compensation, ethical issues).

\section{Support}

- Support from HRM department and FLM

- Expectations and experiences

- Areas of support

\section{Success factors}

- Success factors for SMTs

- Areas for improvement - what would you change? 


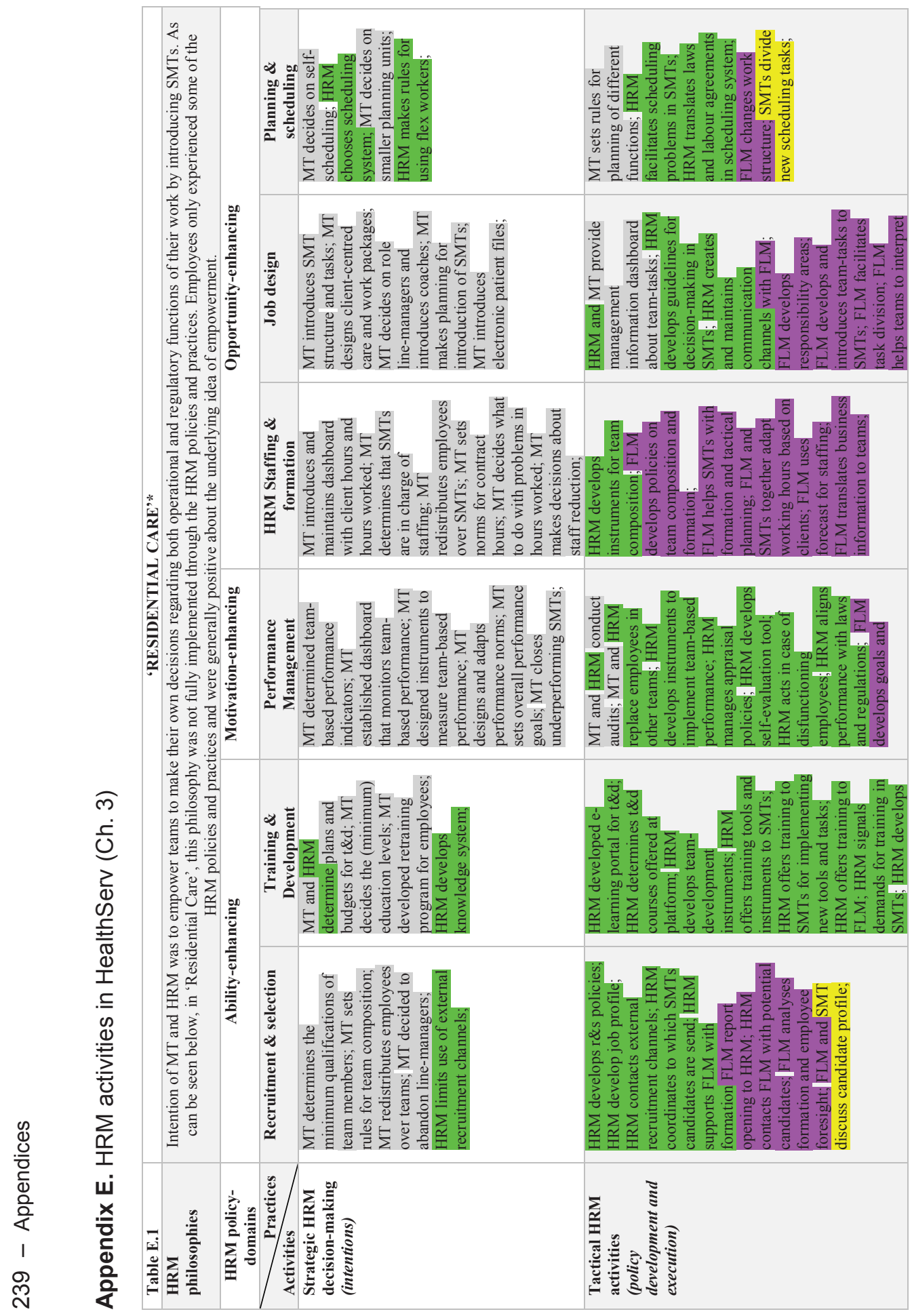




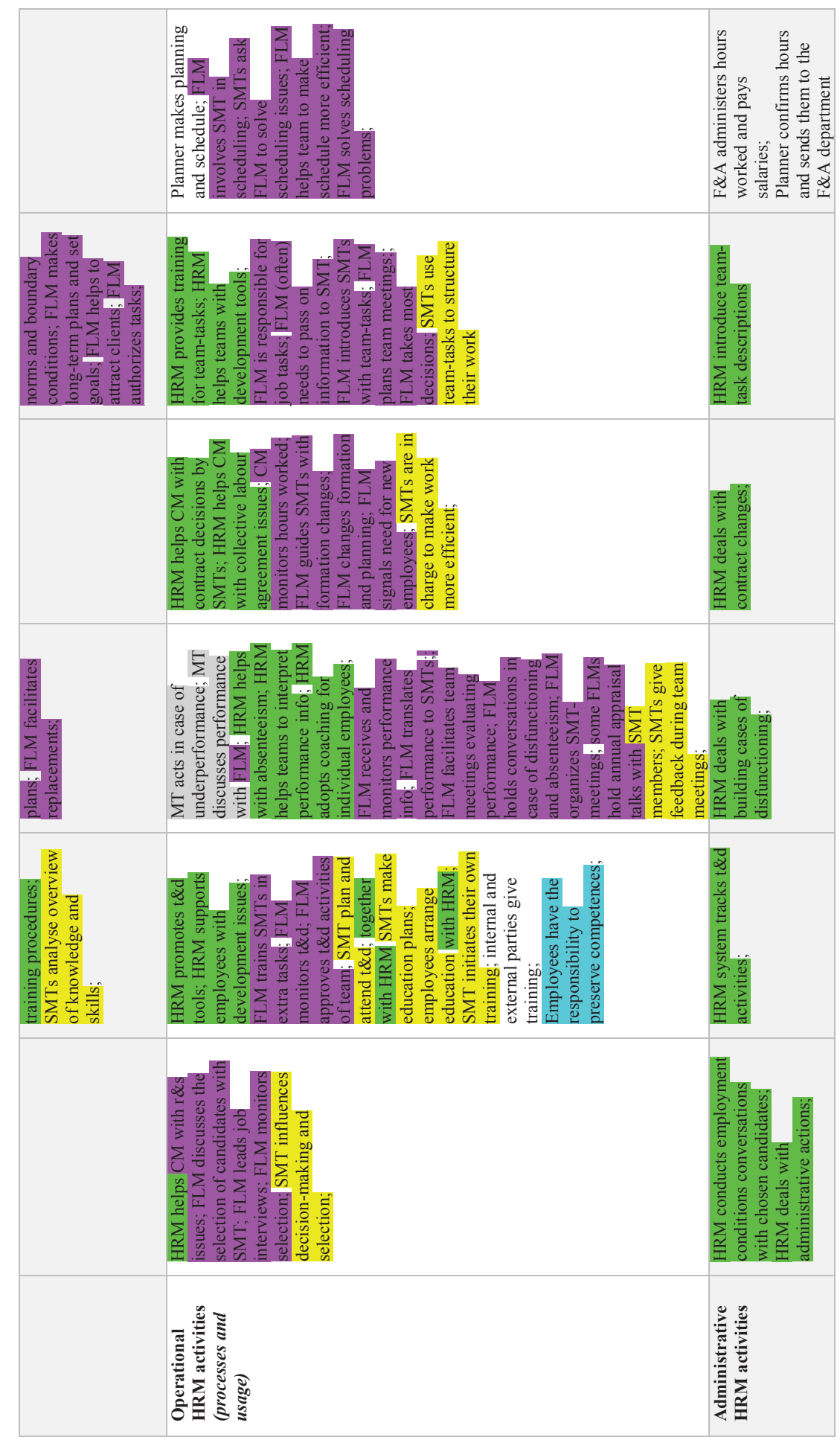


$\bar{j}$
$=$
$=$
0
.0
$\frac{0}{0}$
$\overline{0}$
$\frac{0}{2}$
$\frac{0}{\alpha}$

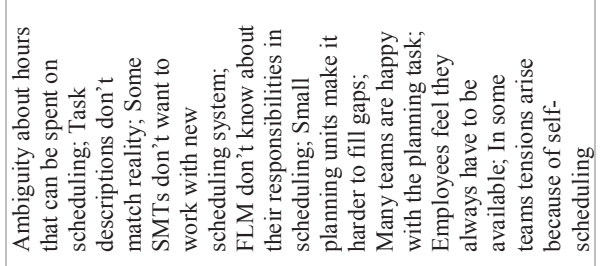

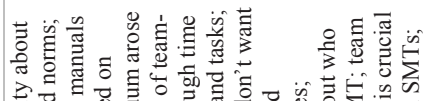

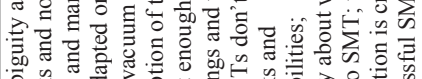
可

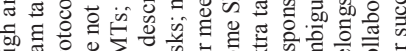

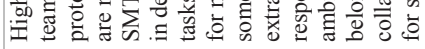
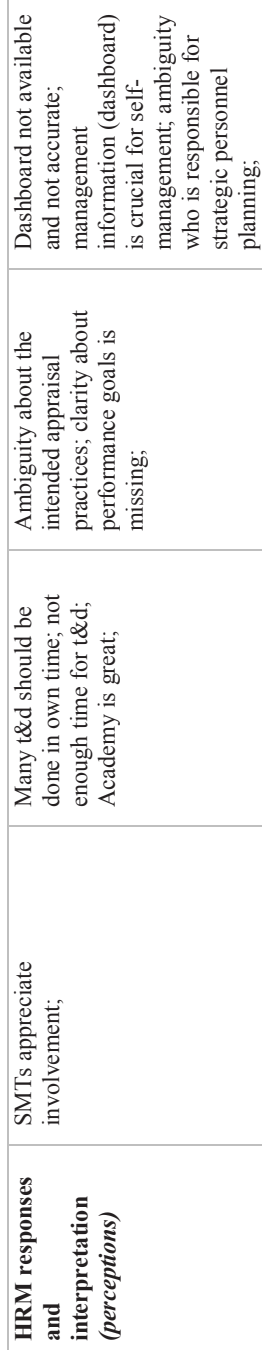


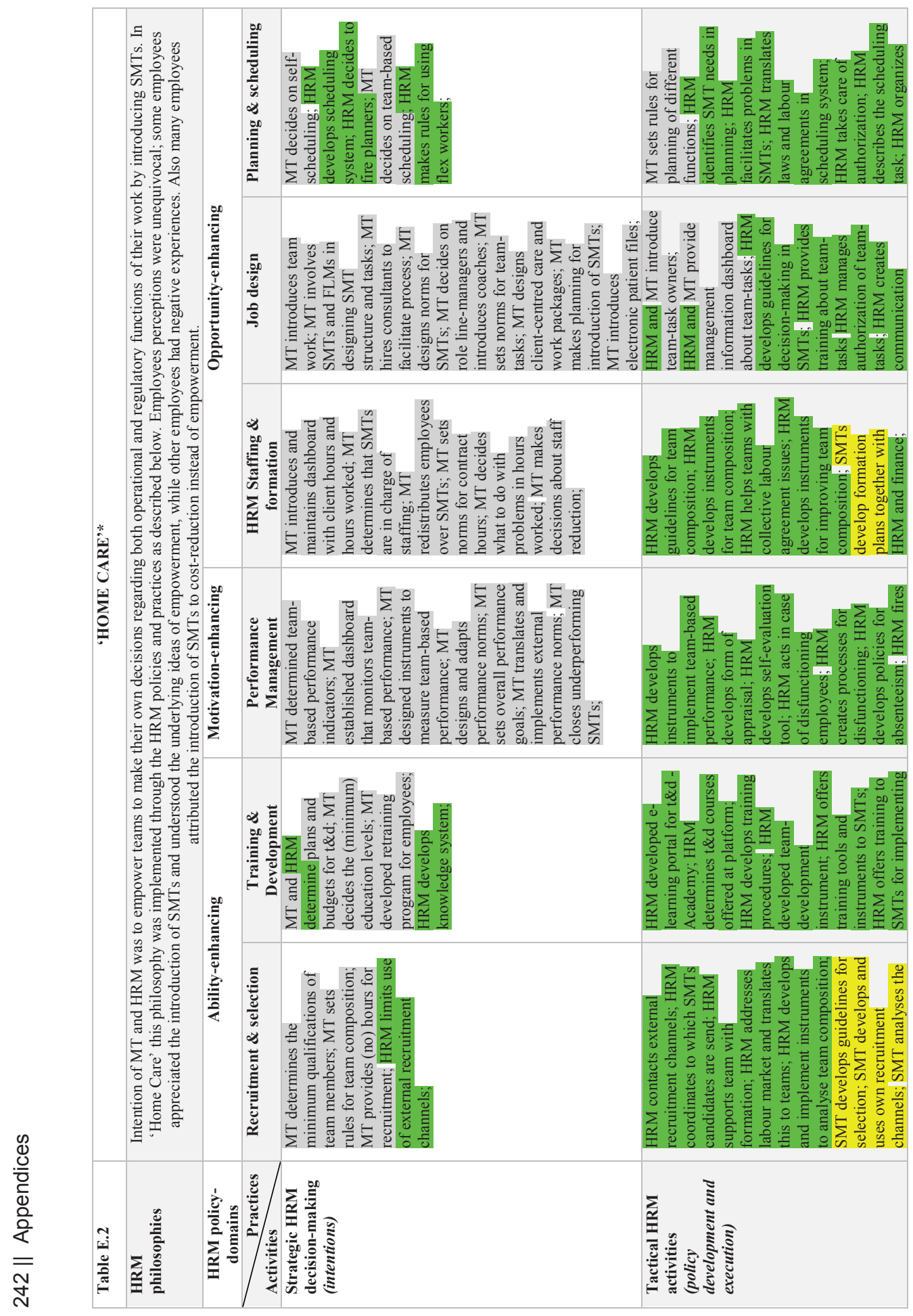




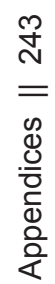
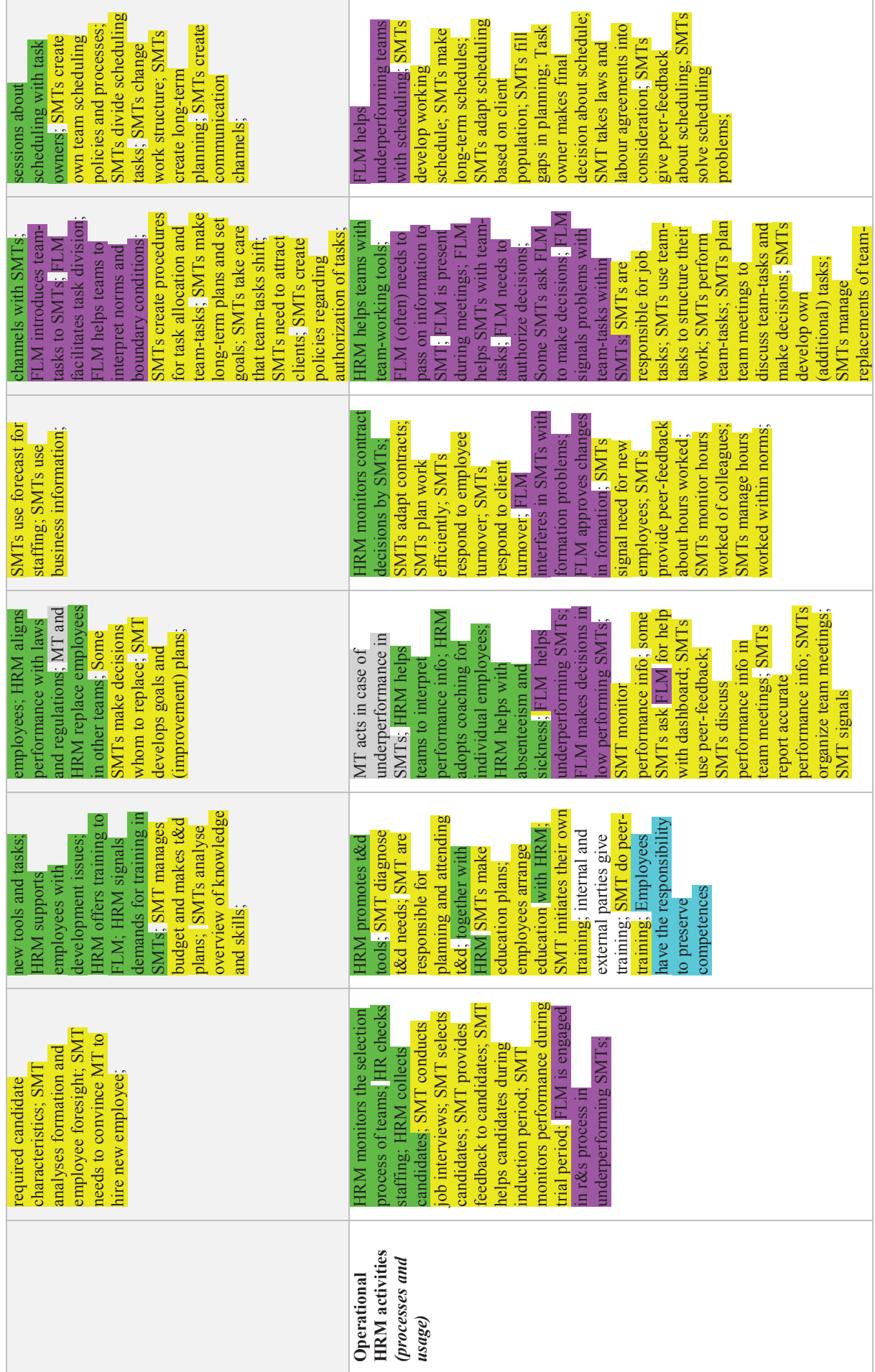


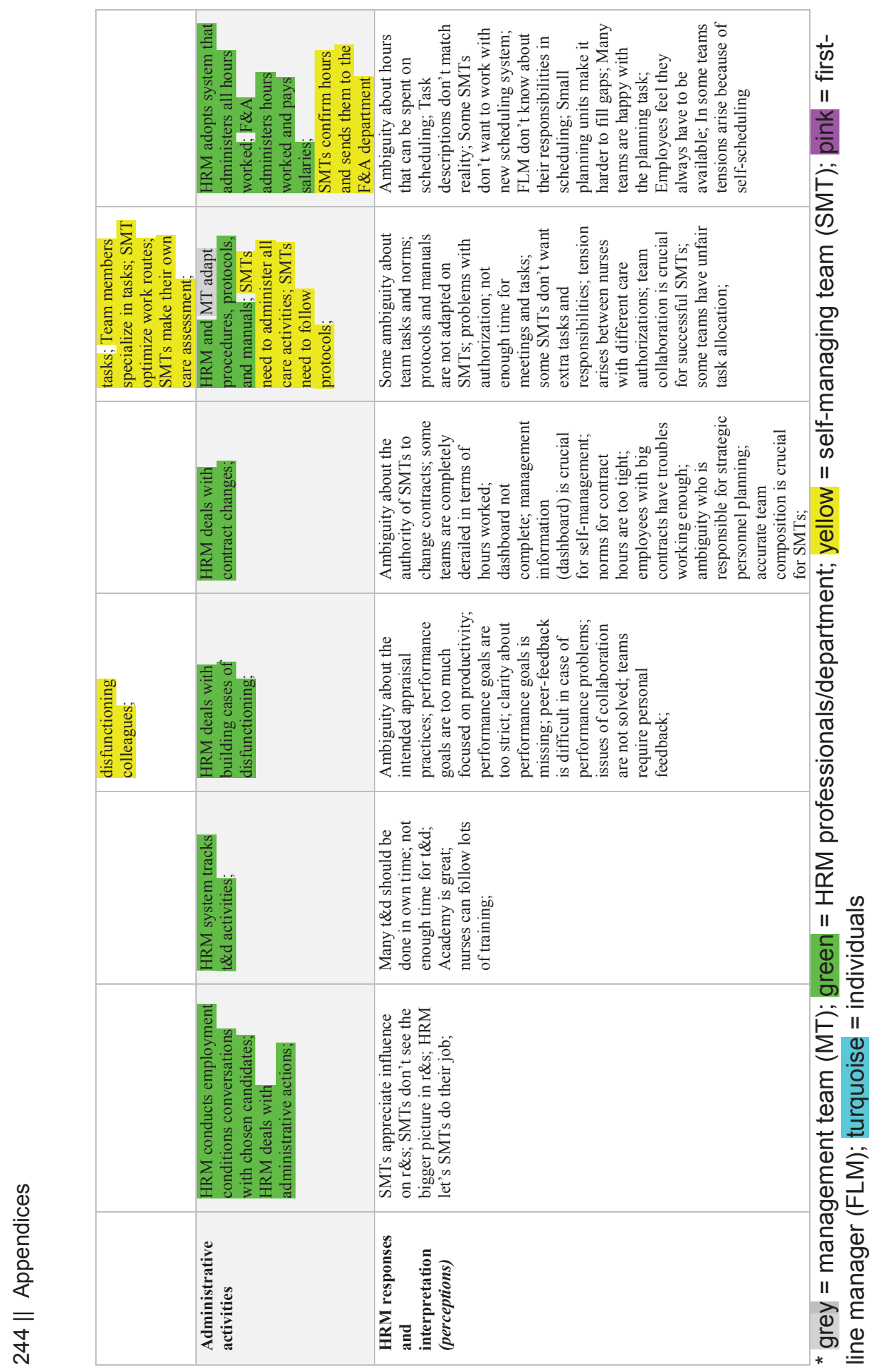


Appendix F. Measurement scales for HRM - IWB relationship (Ch. 4)

\section{Autonomous teamwork}

- I work in a self-organizing team.

- I work closely together with the colleagues in my team.

- I work in a team that makes decisions independently.

- I work in a team where we are responsible for our own performance.

\section{Training and development}

- I get enough opportunities to attend skills training (training, education, information) for improvement of my current functioning.

- I am well prepared for my work because of the training I got (training, education, information).

- I am provided with the training and development (training, education, information) to I need to perform well at work.

\section{Information sharing}

- I am regularly informed on the vision and mission of [/name organization].

- I am regularly informed about future projects of [/name organization].

- I am regularly informed about the (financial) performance of [/name organization].

- I am regularly informed about the level of client satisfaction.

- I am regularly informed about new technologies, products and services of [/name organization].

\section{Performance feedback}

- I am provided with appraisals that give feedback for personal development.

- Feedback is given to me to help me to learn and improve myself.

- My supervisor never gives me developmental feedback (R).

- My supervisor provides me with useful information how to improve my job performance.

\section{Perceived autonomy}

- I have the opportunity to participate in decision-making processes in my unit.

- I have the opportunity to make my own decisions how to do my tasks.

- I have the opportunity to do my work in my own ways.

\section{Affective commitment}

- I would be very happy to spend the rest of my career with this organization

- I enjoy discussing my organization with people outside it

- I really feel as if this organization's problems are my own

- I think that I could easily become as attached to another organization as I am to this one $(\mathrm{R})$

- I do not feel like 'part of the family' at my organization (R)

- I do not feel 'emotionally attached' to this organization (R) 
- This organization has a great deal of personal meaning for me

- I do not feel a strong sense of belonging to my organization $(R)$

\section{Innovative work behavior}

- I pay attention to issues that are not part of my daily work

- I regularly wonder how things in my work can be improved

- I search out for new working methods, techniques, or instruments

- I generate original solutions for problems at my work

- I find new approaches to execute tasks at my work

- I make important organizational members enthusiastic for innovative ideas at work

- I attempt to convince people to support an innovative idea

- I systematically introduce innovative ideas into work practices

- I contribute to the implementation of new ideas and ways of working in my organization

- I put effort in the development of new things and ways of working 


\section{Appendix G. General interview protocol MedLab (Ch. 5)}

The questions of the interview protocol were originally in Dutch.

\section{Introduction}

- Personal introduction and introduction to research, consent, and anonymity

- $\quad$ How would you describe your leadership style? (FLMs)

\section{Innovation}

- What is the role of innovation within MedLab? What is the involvement of work-floor employees in innovation processes?

- How often do you look at possibilities to renew or improve product and/or processes?

- What is generally the reason behind proposing innovative ideas?

- $\quad$ Can you describe examples of innovative ideas you were involved in?

- How did the idea emerge? What do you do after you have developed an idea?

$\circ \quad$ What were the most important factors that influenced the progress of the initiative?

- What are the most important factors that stimulate and constrain innovation?

- Can you describe initiatives that are undertaken in the organisation?

- What are personal factors that are needed for innovation?

- What is the role of the FLM in stimulating innovation? How do you support ideas from employees? What do you do when an employee proposes an idea? (FLMs)

\section{Institutional factors}

- How would you describe the climate for innovation at MedLab?

- What are the expectations regarding innovation? Is innovation important?

- What is the influence of standardised work processes?

\section{Organisational factors}

- How would you describe the communication within MedLab regarding innovation?

- How would you characterise the strategy of the organisation? (costs vs. quality)

- What does the organisation do to stimulate innovation? (instruments to stimulate innovativeness)

- $\quad$ To what degree does the organisation facilitate or support initiatives?

- How would you describe your relationship with your supervisor and colleagues?

- How would you describe your relationship with other supervisors and your employees? (FLMs)

- How does MedLab ensure that employees have the right [abilities; motivation; opportunities]?

- To what extent do the following practices help to generate and implement innovative ideas? (training, recruitment/selection, appraisal, performance management, feedback, rewards, communication, teamwork, autonomy, participation)

- What is your role as FLM in [HRM activities described above]? (FLMs)

\section{External factors}

- How does the organisational context affect MedLab? (crises, laws and regulation, market pressures, technologies)

- Can you describe the changes in the organisation? (structure, rules, expectations)

\section{Closing}

- How would you evaluate the current initiatives for innovation? What are strong and weak points? What can improve? Do you know other employees with innovative ideas? 


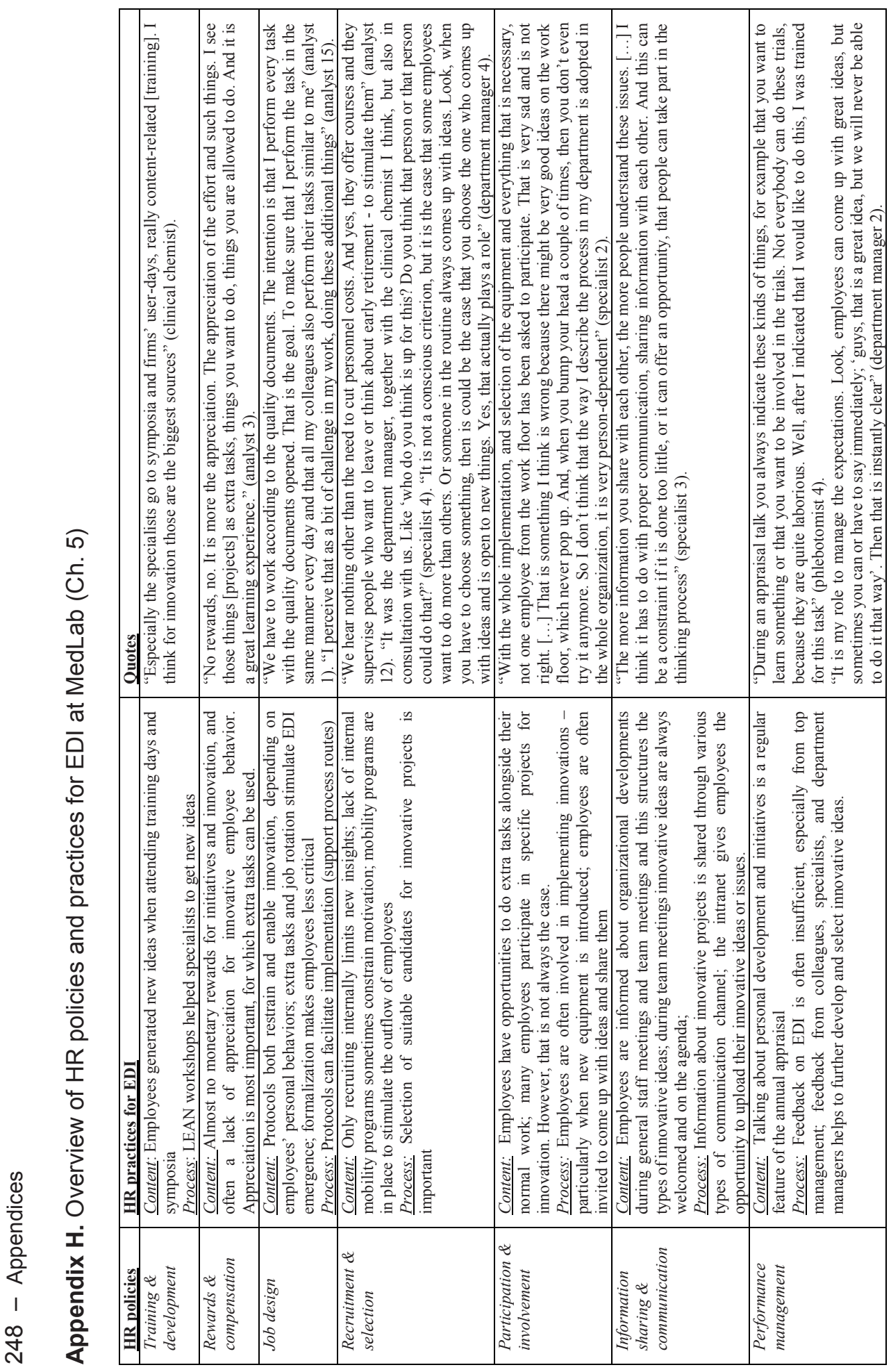


Appendices || 249 



\section{Summary}

This dissertation is focused on the contribution of work-floor employees to innovation processes, and the role of HRM as a stimulating and enabling factor. An increasing number of studies have shown that HRM positively influences innovation. Nevertheless, how work-floor employees can contribute to innovation, and how HRM can stimulate and facilitate this, remains unknown. In this dissertation, I focus on developing and uncovering the multilevel relationship between HRM and employee-driven innovation. Thereby the main research question is: "In what ways does innovative HRM contribute to employee-driven innovation?" To answer this question, this dissertation includes five studies (two conceptual and three empirical).

In the first study, we aim to understand how multilevel theory can improve HRM research. We describe the history of multilevel thinking in HRM research and develop the 'Multilevelity Cube' of HRM - a model that integrates three dimensions of multilevel HRM research. By drawing on the principles of multilevel theory building, this study examines how current multilevel HRM research has applied multilevel thinking. Through a systematic review of the literature, this study uncovers unexplored areas in multilevel HRM research and offers guidelines to further integrate multilevel thinking in the HRM literature. Based on these findings, we conclude that the field of HRM can benefit from a better application of multilevel thinking.

In the second study, we investigate how an HRM innovation focused on employee empowerment change the HRM function and consequently affect the process of HRM implementation. We apply the 'Multilevelity Cube' to study how the HRM actors and activities change as a consequence of introducing selfmanaging teams. The findings show that HRM responsibilities are redistributed, which means that work-floor employees play an active role in designing and shaping HRM activities. We also highlight that HRM implementation changes into a combination of top-down and bottom-up processes. Based on these results, we develop an interactive model that shows how multilevel implementation dynamics change in the era of employee empowerment.

In the third study, we examine how high-involvement HRM affects employees' innovative work behaviours. More specifically, we explore how HRM leads to innovation by studying mediating mechanisms at the individual-level of analysis. We analysed survey data from 567 work-floor employees in the healthcare sector and found that high-involvement HRM practices positively affect innovative work behaviour because they influence employees' feeling of autonomy and their commitment to the organisation. In doing so, we show that a combination of attitudes and resources can explain the relationship between 
HRM and innovation. We conclude that in a setting where employees are not overtly expected to be innovative, involving them through HRM can help to enhance innovation performance.

In the fourth study, we explore how work-floor employees contribute to the emergence of innovation in a formalised context. In applying principles of multilevel theory building and adopting a process perspective, we study how innovations are developed within organisations based on innovative ideas of work-floor employees. We use the concept of employee-driven innovation to integrate innovative behaviours and innovation outcomes. The findings demonstrate three different routes through which innovative ideas are developed by employees. Furthermore, we distinguish between content (type of idea) and process (routes) of employee-driven innovation. We show that HRM can contribute to the emergence of innovation by top-down stimulation and bottomup championing. Based on these findings, we conclude that work-floor employees are a powerful source of innovation when organisations have the right facilitative structure in place.

In the fifth study, we provide avenues for further development of the multilevel perspective in HRM. Whereas in study one we focused on reviewing current applications, in study five we offer specific guidance on how to start doing multilevel HRM research. First, we do so by offering an integrative definition of multilevel HRM research, based on the principles of multilevel theory building. Second, we provide future research questions that are relevant for scholars interested in this area. Third, we discuss three theories that, in our view, can help to further improve the theoretical basis of cross-level relationships. Finally, we provide a short description of three methods that can help scholars to study the multilevel phenomena of interest.

In integration, these five studies help to increase our understanding of how scholars can study the multilevel relationship between HRM and innovation and how organisations can use HRM activities to stimulate employee-driven innovation. By adopting a multilevel perspective, the results show how implementing innovative HRM changes the HRM function, in what ways HRM leads to innovative behaviours, and by what means HRM can contribute to bottom-up innovation processes. Thereby, this work contributes to both theory and practice of the HRM-innovation relationship. Based on the insights from the five studies, an integrative theoretical model of the relationship between HRM and employee-driven innovation is presented. Finally, we provide guidelines and avenues for future research on multilevel HRM thinking, which can help to further study the influence of HRM in stimulating innovation and the importance of workfloor employees in the innovation process. 


\section{Samenvatting}

Dit proefschrift richt zich op de bijdrage van werkvloer medewerkers aan innovatie processen en de rol van HRM als stimulerende en faciliterende factor. Een toenemend aantal studies laat zien dat HRM een positieve bijdrage kan leveren aan innovatie. Desalniettemin, op welke manier medewerkers van de werkvloer kunnen bijdragen aan innovatie en hoe HRM dit kan faciliteren en ondersteunen was tot op heden grotendeels onbekend. In dit proefschrift richt ik me daarom op het ontwikkelen en blootleggen van de relatie tussen HRM en medewerker-gedreven innovatie op meerdere organisatieniveaus (multilevel). Daarbij beantwoord ik de volgende hoofdvraag: "Op welke manieren levert HRM een bijdrage aan medewerker-gedreven innovatie?" Dit proefschrift bestaat uit 5 verschillende studies om tot een antwoord op deze vraag te komen, waarvan twee conceptuele studies en 3 empirische studies.

In de eerste studie richten we ons op het beter begrijpen op welke manier multilevel theorie het HRM onderzoek kan verbeteren. We beschrijven eerst een korte historie van het multilevel denken in HRM onderzoek en ontwikkelen vervolgens de zogenaamde 'Multilevelity Cube', een kubus model die drie dimensies van multilevel HRM onderzoek integreert. Door voort te borduren op de principes van het bouwen van multilevel theorieën onderzoeken we in deze studie hoe het huidige HRM onderzoek het multilevel gedachtegoed heeft toegepast. Door gebruik te maken van een systematische literatuurstudie hebben we ontdekt dat er een veelvoud van gebieden binnen multilevel onderzoek onontgonnen is. Op basis daarvan bieden we richtlijnen aan die kunnen helpen om de lessen van het multilevel denken beter te integreren binnen de HRM literatuur. Op basis van deze bevindingen concluderen we dat HRM onderzoekers kunnen profiteren van een betere toepassing van het multilevel denken zoals we dat in deze studie beschrijven.

In de tweede studie onderzoeken we hoe een HRM innovatie, die zich focust op het vergroten van medewerker empowerment, de HRM functie verandert en welke invloed dit vervolgens heeft op het proces van HRM implementatie. We gebruiken de 'Multilevelity Cube' om te bestuderen hoe de HRM actoren en activiteiten veranderen wanneer zelfsturende teams worden geïntroduceerd. De bevindingen laten zien dat HRM verantwoordelijkheden herverdeeld worden en dat werkvloer medewerkers een actieve rol krijgen bij het ontwerpen en vormgeven van HRM activiteiten. We benadrukken daarnaast dat het HRM implementatie proces verandert naar een combinatie tussen top-down en bottom-up processen. Gebaseerd op deze resultaten ontwikkelen we een interactief model dat schetst hoe multilevel implementatie dynamieken veranderen in het tijdperk van medewerker empowerment. 
In de derde studie focussen we ons hoe HRM op basis van hoge betrokkenheid van medewerkers effect heeft op het innovatief werkgedrag van medewerkers. We bekijken met name hoe HRM tot innovatie leidt door mediërende mechanismen op het individuele niveau te bestuderen. We analyseerden data van 567 werkvloer medewerkers in de gezondheidzorg. De bevindingen lieten zien dat HRM op basis van hoge betrokkenheid een positief effect heeft op innovatief werkgedrag omdat dit het gevoel van autonomie en de betrokkenheid bij de organisatie positief beïnvloedt. Door deze resultaten laten we zien dat een combinatie van medewerkers' houding en de aangeboden middelen de relatie tussen HRM en innovatie kunnen verklaren. We concluderen dat in een context waar het van medewerkers niet noodzakelijkerwijs wordt verwacht om innovatief te zijn HRM kan helpen om innovatie prestaties te verbeteren.

In de vierde studie verkennen we op welke manier medewerkers van de werkvloer een bijdrage leveren aan de ontwikkeling van innovatie in een geformaliseerde context. Door de principes van het bouwen van multilevel theorieën toe te passen en het gebruik te maken van een proces perspectief bestuderen we hoe innovaties op basis van ideeën van medewerkers worden ontwikkeld binnen een organisatie. We gebruiken het medewerker-gedreven innovatie concept om innovatief werkgedrag en innovatieprestaties te integreren. De bevindingen tonen drie verschillende routes waardoor innovatieve ideeën ontwikkeld worden door medewerkers. Daarnaast maken we het onderscheid tussen de inhoud van een innovatief idee (idee types) en het proces van medewerker-gedreven innovaties (verschillende routes). Daarbij laten we zien dat HRM kan bijdragen aan de ontwikkeling van innovatie door top-down stimulatie en door bottom-up championing. Gebaseerd op deze bevindingen concluderen we dat werkvloer-medewerkers een krachtige bron zijn van innovatie wanneer organisaties de juiste faciliterende structuren hebben.

In de vijfde studie beschrijven we mogelijkheden voor verdere ontwikkelingen van het multilevel perspectief binnen HRM onderzoek. Waar we ons in de eerste studie richten op het evalueren van de huidige toepassing van het multilevel perspectief, focussen we ons in studie vijf op specifiek advies hoe onderzoekers dit in de praktijk kunnen brengen. Ten eerste doen we dit door een integrale definitie van HRM voor te stellen, welke gebaseerd is op de multilevel principes. Ten tweede beschrijven we onderzoeksvragen voor toekomstig onderzoek op dit gebied. Ten derde bediscussiëren we drie theorieën die naar ons idee kunnen helpen om de theoretische basis van niveau-overschrijdende verbanden te verbeteren. En als laatste geven we een korte beschrijving van drie onderzoeksmethodes die onderzoekers kunnen gebruiken bij het bestuderen multilevel HRM fenomenen. 
Alles tezamen helpen deze vijf studies om ons begrip te vergroten hoe HRM onderzoekers de multilevel relatie tussen HRM en innovatie kunnen onderzoeken en hoe organisaties HRM activiteiten kunnen gebruiken om medewerker-gedreven innovatie te stimuleren. Door een multilevel perspectief te gebruiken geven de resultaten inzicht in hoe het implementeren van HRM innovaties de HRM functie veranderen, op welke manier HRM leidt tot innovatief werkgedrag van medewerkers, en op welke wijze HRM kan bijdragen aan bottom-up innovatie processen. Daardoor draagt dit proefschrift bij aan de theoretische en praktische inzichten op het gebied van HRM en innovatie. Gebaseerd op de vijf studies uit dit proefschrift presenteren we een geïntegreerd theoretisch model die het verband tussen HRM en medewerker-gedreven innovatie schetst. Tenslotte beschrijven we richtlijnen en richtingen voor vervolgonderzoek over het multilevel gedachtegoed binnen HRM, wat naar ons inzicht kan helpen om in de toekomst de invloed van HRM op medewerkergedreven innovatie processen te bestuderen. 



\section{Overview of publications}

\section{Academic publications and conference presentations $\underline{2018}$}

Renkema, M., Meijerink, J., \& Bondarouk, T. (2018). Routes of Employee-Driven Innovation: How HRM Supports Emergence. Presented at the 78th Annual Meeting of the Academy of Management, 10-14 August 2018, Chicago (IL), United States.

Renkema, M., Bos-Nehles, A.C., \& Meijerink, J. (2018). Exploring the Implications of the Implementation of Self-Managing Teams for the HRM function: Evidence from a Case Study in The Netherlands. Presented at the XI International Workshop on HRM, 25-26 October 2018, Seville, Spain.

Bondarouk, T., Bos-Nehles, A.C., Renkema, M., Meijerink, J., \& De Leede, J. (2018). Organisational Roadmap Towards Teal Organisations. Bingley (UK):

Emerald Publishing.

\section{$\underline{2017}$}

Bos-Nehles, A. C., Renkema, M., \& Janssen, M. (2017). HRM and innovative work behaviour: a systematic literature review. Personnel review, 46(7), 12281253.

Renkema, M., Meijerink, J. G., \& Bondarouk, T. (2017). Employee-Driven Innovation in a Formalized Business Context: The role of HRM. Paper presented at 10th Biennial International Conference of the Dutch HRM Network, 8-10 November 2017, Nijmegen, the Netherlands.

Renkema, M. \& Bondarouk, T. (2017). Swimming Against The Tide: A Case Study about Stimulating Employee-Driven Innovation In A Formalized Business Context Through HRM. Paper presented at the British Academy of Management Conference 2017, Coventry, United Kingdom.

Renkema, M., Meijerink, J. G., \& Bondarouk, T. (2017). Advancing multilevel thinking in human resource management research: applications and guidelines. Human resource management review, 27(3), 397-415. DOI:

http://dx.doi.org/10.1016/j.hrmr.2017.03.001 


\section{6}

Renkema, M., \& Meijerink, J. G. (2016). Advancing Multilevel Thinking in Human Resource Management Research: Applications and Guidelines. Presented at the 76th Annual Meeting of the Academy of Management, 5-9 August 2016, Anaheim (CA), United States.

Bos-Nehles, A. C., Renkema, M., Bondarouk, T., \& Janssen, M. (2016). The influence of HRM practices on innovative work behaviour: a systematic literature review. Paper presented at 16th Annual Conference of the European Academy of Management, EURAM 2016, Paris, France.

Renkema, M., Meijerink, J., \& Bondarouk, T. (2016). Advancing Multilevel Thinking and methods in HRM research. Journal of Organizational Effectiveness: People and Performance, 3(2), 204-218. DOI: https://doi.org/10.1108/JOEPP-03$\underline{2016-0027}$

\section{$\underline{2015}$}

Renkema, M., Meijerink, J. G., \& Bondarouk, T. (2015). Multilevel Theory Building in HRM Research: Critical Reflection and Guidelines. Paper presented at 9th International Conference of the Dutch HRM Network, 12-13 November 2015, Utrecht, the Netherlands.

\section{$\underline{2014}$}

Renkema, M., \& van den Broek, T. A. (2014). Promoting Practices: How Activists Employ Online Tactics to Promote Energy Efficiency. Presented at the 74th Annual Meeting of the Academy of Management, 1-5 August 2016, Philadelphia (PA), United States.

\section{Professional publications, media exposure, workshops \& lectures $\underline{2018}$}

Renkema, M. (2018). Nederlandse bedrijven laten innovatiekracht werkvloer onbenut. Management Site. Accessible on

https://www.managementsite.nl/nederlandse-bedrijven-laten-innovatiekrachtwerkvloer-onbenut

Renkema, M. (2018). Holacratie: 'Pas op met de hype'. CHRO.

Renkema, M., Bondarouk, T., \& Meijerink (2018). Ook zelfsturende teams hebben soms sturing van buiten nodig, interview in Tubantia, accessible on 
https://www.tubantia.nl/enschede/livio-gaat-werken-met-zelfstandigeteams a37f53bal

Renkema, M., Bondarouk, T. (2018). Zelfsturende teams in de zorg. HR \& Business Magazine.

Bos-Nehles, A.C., Renkema, M., Bondarouk, T. (2018), Is it possible to manage without managers? People Management.

'Werken in teams en de gevolgen voor performance'. Presentation for HR MeetUp Twente, May 29 2018, Enschede.

Renkema, M., Bondarouk, T., \& Bos-Nehles, A. (2018). Transformation to selfmanaging teams: lessons learned. Strategic HR Review, 17(2), 81-84.

\section{$\underline{2017}$}

Renkema, M. (2017). Medewerker-gedreven innovatie. BestuurdersMagazine, $5(1)$

"Innovatie door medewerkers". Presentation for DUO Platform: Innovation, Groningen, The Netherlands.

\section{$\underline{2016}$}

Professional Development Workshop entitled "Advancing Multilevel Thinking and Methods in HRM Research" (with Jeroen Meijerink, PhD.). $78^{\text {th }}$ Annual Meeting of the Academy of Management, 5-9 August, 2016, Anaheim (CA), USA.

Meijerink, J. G., van den Heuvel, S., Korotka, M., Bos-Nehles, A. C., Renkema, M., Bondarouk, T., Van Mierlo, J., De Leede, J., Herawati, S., Looise, J.C., Ruël, H., \& Wognum, I. (2016). HRM, technologie en innovatie: terug naar de toekomst. HR\&Business magazine, (7), 28-31

"Innovative HRM for Employee-Driven Innovation". Research presentation at the HRM Seminar Series, Nottingham Trent University, Nottingham.

\section{$\underline{2015}$}

Renkema, M. (2015). Medewerker-gedreven innovaties in de zorg. BestuurdersMagazine, 3(2). 



\section{About the author}

Maarten Renkema (1990) was born and raised in Nijverdal, located in the region of Twente, The Netherlands. He started his study Business Administration at the University of Twente in 2008 and obtained his Bachelor of Science degree in 2011. During his study, Maarten completed an internship at the marketing and finance department of his favourite football club Heracles Almelo, which he combined with a thesis on supporter loyalty and willingness-to-pay. Between 2011 and 2014, he was enrolled in a double degree program at the University of Twente and the Technical University Berlin, which resulted in a Master of Science degree in Business Administration and a Master of Science degree in Innovation Management \& Entrepreneurship. In 2013, Maarten was an intern at research institute TNO (The Netherlands Organisation for Applied Scientific Research). During his internship, he conducted his Master thesis research on the use of online tactics by social movement organisations to promote institutional innovation, which was accepted for presentation at the Academy of Management Annual Meeting 2014.

In September 2014, Maarten started his PhD project at the University of Twente in the department Human Resource Management. His project was co-financed by NWO - Netherlands Organisation for Scientific Research. The research was aimed at examining the relationship between HRM and innovation. Maarten focused his research on the link between HRM and employee-driven innovation, approached from a multilevel perspective.

Maarten published his research in several scientific journals (Human Resource Management Review, Journal of Organizational Effectiveness: People and Performance, and Personnel Review). Furthermore, he co-authored the book Organisational Roadmap towards Teal Organisations - which was partly based on one of his $\mathrm{PhD}$ projects. He also presented his research at international conferences, including the Academy of Management Annual Meeting (2016 and 2018), the International Conference of the Dutch HRM Network (2015 and 2017), the British Academy of Management Conference (2017) and the International Workshop on HRM (2018). He also co-organised a professional development workshop with Dr. Jeroen Meijerink on multilevel HRM (2016).

In addition, his research was published in professional journals and websites, such as Management Site, CHRO, Strategic HR Review, HR \& Business Magazine, People Management, and BestuurdersMagazine, and covered in 
newspaper Tubantia. Maarten has also gave workshops on innovation and selfmanaging teams for professional audiences.

Next to his PhD project, Maarten serves as board member of pHResh, a network of and for doctoral students in the fields of HRM and organisational behaviour, and in this role he helped to organise doctoral consortia at the EAWOP Conference (2017) and the Dutch HRM Network Conference (2017). Maarten also serves as honorary treasurer on the board of the UTKring Futsal association.

Maarten taught the Master course HRM \& Innovation for several years and has supervised several student theses in International Business Administration (Bachelor) and Business Administration (Master). He currently works as postdoctoral researcher at the University of Twente, Human Resource Management group. 



Innovating HRM for Employee-Driven Innovation

Organizations introduce new Human Resource Management activities to boost innovativeness. Although an increasing number of studies has shown that HRM can contribute to innovation, little research has been done that uncovers in what ways HRM makes employees more innovative and how employees can contribute to innovation processes across organizational levels. Therefore, this thesis adopts a multilevel perspective to study the underlying mechanisms of the HRM - innovation relationship and examines the role of multiple (HRM) actors in these processes.
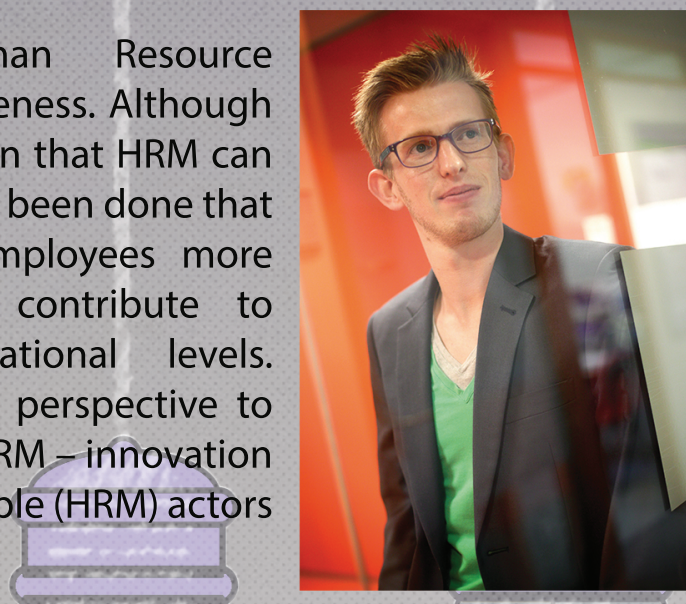

This thesis demonstrates that employee-driven innovation can be stimulated by HRM, and that this process should be characterised by its multilevel nature. By adopting a multilevel perspective, our current understanding of how organizations can stimulate employee-driven innovation is improved. In particular, three different mechanisms are examined that help to understand the multilevel nature of the HRM - innovation relationship. First, innovative HRM that is introduced to increase the involvement and autonomy of employees changes the HRM function and consequently the implementation process. Second, employees perceptions of HRM lead to more innovative behaviour of employees through increasing their autonomy and commitment. Third, HRM contributes to the bottom-up development of innovation by influencing both the types of ideas generated and the processes that lead to idea implementation. These findings inform organizations and their various HRM actors how they can improve innovativeness of their work-floor employees.

Maarten Renkema is currently working as a researcher at the University of Twente HRM group. His research focuses on novel HRM and its link with innovation. A main part of his research has been conducted in the healthcare sector. His research has been published in HRM Review, Personnel Review, and Journal of Organizational Effectiveness: People and Performance. He also co-authored a book about self-managing teams: Organisational Roadmap towards TEAL Organisations. 